\title{
Preclinical Development of Gene Therapy
}

Citation for published version (APA):

Giamouridis, D. (2019). Preclinical Development of Gene Therapy: The Effects of Urocortin 2 and Urocortin 3 Gene Transfer in Murine Models of Heart Failure and Diabetes. [Doctoral Thesis, Maastricht University]. Maastricht University. https://doi.org/10.26481/dis.20190605dg

Document status and date:

Published: 01/01/2019

DOI:

$10.26481 /$ dis.20190605dg

Document Version:

Publisher's PDF, also known as Version of record

\section{Please check the document version of this publication:}

- A submitted manuscript is the version of the article upon submission and before peer-review. There can be important differences between the submitted version and the official published version of record.

People interested in the research are advised to contact the author for the final version of the publication, or visit the DOI to the publisher's website.

- The final author version and the galley proof are versions of the publication after peer review.

- The final published version features the final layout of the paper including the volume, issue and page numbers.

Link to publication

\footnotetext{
General rights rights.

- You may freely distribute the URL identifying the publication in the public portal. please follow below link for the End User Agreement:

www.umlib.nl/taverne-license

Take down policy

If you believe that this document breaches copyright please contact us at:

repository@maastrichtuniversity.nl

providing details and we will investigate your claim.
}

Copyright and moral rights for the publications made accessible in the public portal are retained by the authors and/or other copyright owners and it is a condition of accessing publications that users recognise and abide by the legal requirements associated with these

- Users may download and print one copy of any publication from the public portal for the purpose of private study or research.

- You may not further distribute the material or use it for any profit-making activity or commercial gain

If the publication is distributed under the terms of Article $25 \mathrm{fa}$ of the Dutch Copyright Act, indicated by the "Taverne" license above, 


\section{PRECLINICAL DEVELOPMENT OF GENE THERAPY}

The Effects of Urocortin 2 and Urocortin 3 Gene Transfer in Murine Models of Heart Failure and Diabetes 
ISBN: 978-94-6323-668-3

Cover illustration: Jules, Pinterest

Cover design: Dimosthenis Giamouridis

Layout: Dimosthenis Giamouridis

Printed and published by: Gildeprint, Enschede

\section{(C) Dimosthenis Giamouridis, Maastricht 2019}

All rights reserved. No part of this thesis may be reproduced, stored in a retrieval system of any nature, or transmitted in any form or by any means, electronic, mechanical, photocopying, recording or otherwise without prior written permission of the author. 


\title{
PRECLINICAL DEVELOPMENT OF GENE THERAPY
}

\section{The Effects of Urocortin 2 and Urocortin 3 Gene Transfer in Murine Models of Heart Failure and Diabetes}

\section{DISSERTATION}

\author{
To obtain the degree of Doctor at the Maastricht University, \\ on the authority of the Rector Magnificus, \\ Prof. dr. Rianne M. Letschert \\ in accordance with the decision of the Board of Deans, \\ to be defended in public \\ on Wednesday 5 June 2019, at 12:00 hours
}

by

Dimosthenis Giamouridis

Born in Drama, 15 August 1987 


\section{Supervisors}

Prof. dr. Erik A. L. Biessen, Maastricht University

Prof. dr. H. Kirk Hammond, University of California San Diego, USA

\section{Co-supervisor}

Dr. W.M. Blankesteijn, Maastricht University

\section{Assessment committee}

Prof. dr. F. Prinzen (Chairman), Maastricht University

Prof. dr. A. Baker, University of Edinburgh, UK

Prof. dr. D. Duncker, Erasmus MC Rotterdam

Prof. dr. S.R.B. Heymans, Maastricht University

Prof. dr. C.G. Schalkwijk, Maastricht University 
...to the memory of my beloved grandfather and uncle

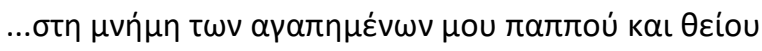




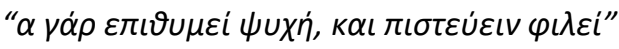

(by Demosthenes, $4^{\text {th }}$ century B.C.; loosely translated: "What a man desires, he also imagines to be true.") 


\section{Contents}

Chapter 1

Chapter 2

Chapter 3

Chapter 4

Chapter 5

Chapter 6

Appendices
General introduction

Effects of Urocortin 2 vs Urocortin 3 Gene Transfer on Left Ventricular Function and Glucose Disposal

Urocortin 3 Gene Transfer Increases Function of the Failing Murine Heart

One-time Injection of AAV8 Encoding Urocortin 2 Provides Long Term Resolution of Insulin Resistance

Urocortin 2 Gene Transfer Increases Diastolic Function in Aged Mice

Summary \& General Discussion

Valorization Addendum

Acknowledgements

159

Curriculum Vitae

List of publications and Presented Work 

Chapter $\perp$

General Introduction 


\section{HEART FAILURE}

Heart failure (HF) is the condition in which the heart is incapable of supplying tissues with oxygen and nutrients through blood circulation (1).

\section{Relevance}

Heart failure is the most common cause of death worldwide, and is more prevalent in highincome populations. According to the World Health Organization, ischemic heart disease, which is the insufficient supply of oxygen and nutrients to the heart, accounts for 18 million deaths each year, representing roughly a third of all deaths (2).

In the US there are about 5.1 million people with clinical signs and symptoms of heart failure and this number is increasing dramatically with 900,000 new cases diagnosed each year. It is estimated that there will be a total of 9 million -almost double than current numberAmericans diagnosed with heart failure by 2030 (3). Besides the huge societal problem this heart failure population increase will cause, by 2030 it is expected to raise the costs related to the disease from $\$ 30$ billion, nowadays, to almost $\$ 70$ billion (3).

\section{Classification of Heart Failure}

For many years, the pathophysiology of heart failure was considered to be an impaired state of systolic heart function and a subsequent state of low cardiac output. However, on 1937 there was the first report of distinct differences among heart failure patients that could be categorized into two groups; those with deficient ventricular ejection and those with inadequate ventricular filling (4). Only in the last decades, patients with preserved systolic function but impeded ventricular filling are considered as a separate heart failure category and this is a raising clinical issue (5). Diastolic dysfunction, or heart failure with preserved ejection fraction (HFpEF) as it is known among cardiologists, is the state in which heart muscle presents normal ejection fraction but abnormal relaxation and ventricular filling, usually due to hypertrophy or increased stiffness of the myocardium $(6,7)$. Systolic hear failure is commonly described as that pathophysiological state of the heart in which it is incapable of pumping adequate volume of blood to supply tissues with necessary nutrients and oxygen (1). In the recent years, not only annual mortality rates of HFpEF increased and are comparable with the mortality rates of systolic heart failure, but also there are no improvements in outcome due to poor efficacy of the current treatments (8-11).

\section{Heart Failure with Reduced Ejection Fraction}

Heart failure with reduced ejection fraction (HFrEF), also known as systolic heart failure, is characterized by substantial changes in the shape of the left ventricle (LV), which is dilated, as increased LV end-diastolic and end-systolic volumes indicate, and subsequently has lower ejection fraction (EF). EF is the ratio of the difference between end-diastolic and endsystolic volume (which defines LV stroke volume) to end-diastolic volume. In other words, stroke volume is the absolute amount of blood that is pumped out of the LV after a 
complete contraction cycle, and EF is the percentage of the LV blood volume that was pumped out. In the infarcted areas there is usually increased cell death due to stenosis or obstruction of upstream arteries which leads to lack of oxygen and nutrients vital for cell survival and function. As a result of that, LV myocardial wall is getting thinner and more malleable and LV chamber shape changes from its normal ellipsoidal to a more spherical one. These characteristic deformations of LV chamber change the position and structure of crucial for the heart function elements such as papillary muscles, chordate, and mitral valve leaflets. Abnormalities of the last can lead to mitral regurgitation, a condition that mitral valve is "leaky" and can further increase LV volumes and aggravate remodeling. Additionally, the increase in LV volumes leads to increases of wall stress which is inversely proportional to ejection fraction. In some cases, when LV wall is extremely thin, a phenomenon called dyskinesia, which is the asynchronous movement of thinner wall areas while contraction, is present. Another physiological abnormality that is present in patients with systolic heart failure is the reduction of filtration through the capillaries. Based on Starling's capillary law an increase on pulmonary capillary wedge pressure with a normal or reduced stroke volume, would decrease the rate of nutrients and oxygen exchange. Changes occur also in the architecture of the extracellular matrix, with collagen fibrils being disrupted, disorganized and thinner than normal (12). Fibrosis and myocardial collagen volume are increased in HFrEF, and procollagen elevated levels indicate an abnormal collagen metabolism (13).

Ventricular remodeling and progression of systolic heart failure is adversely affected by neurohormonal activation $(14,15)$. Circulating catecholamines, such as epinephrine and norepinephrine, are increased. Central sympathetic activity leads to increased norepinephrine release at adrenergic nerve terminals innervating myocardium. Additionally, activation of the renin-angiotensin-aldosterone (RAA) system leads to increased plasma levels of renin, angiotensin, and aldosterone. Subsequent activation of angiotensin receptor subtype 1 leads to vasoconstriction and smooth and cardiac muscle hypertrophy. Increased aldosterone levels promote collagen synthesis and fibrosis. Proinflammatory, mitogenic and pro-thrombotic effects are also induced by the elevated levels of vasopressins, endothelins and cytokines resulting in further vasoconstriction and increased vascular resistance. However, organism's attempt to maintain homeostasis and counterbalance these negative-impact neurohormonal changes, leads to elevation of natriuretic peptides, such as brain natriuretic peptide (BNP) and atrial natriuretic factor (ANF), nitric oxide, prostacyclins, and endothelium-derived relaxing factor. The vasodilatory, natriuretic, antimitogenic, and antithrombotic effects of these molecules can attenuate ventricular remodeling, unless there is an excessive activation of adrenergic and RAA systems.

As mentioned before, a main morphologic heart alteration in systolic heart failure is the increase in both right and left end-diastolic volumes which directly affect the hemodynamic characteristics of the heart. Pulmonary arterial pressure is increased inhibiting a normal right ventricular emptying, causing an elevation of pulmonary venous pressure and a subsequent increase in pulmonary vascular resistance and right ventricular afterload (the resistance that ventricle has to overcome to circulate blood). Stroke volume of the right 
ventricle is decreased and since it contributes to the left ventricular preload (the pressure built by the total amount of blood in the ventricle at the end of diastole), synergies with the decreased contractility and further reduces left ventricular stroke volume and cardiac output. In addition, mechanical dyssynchrony, usually observed in patients with left bundle branch block, is the phenomenon when lateral wall contracts and relaxes earlier than intraventricular septum and adversely affects hemodynamic parameters.

\section{Heart Failure with Preserved Ejection Fraction}

Heart failure with preserved ejection fraction (HFpEF), also known as diastolic dysfunction, is the state of the heart in which systolic function is normal, while, in diastole, left ventricular filling is impeded $(6,7)$. Main reason for this, and one of the basic pathophysiological characteristics of $\mathrm{HFpEF}$, is the increased myocardial fibrosis or hypertrophy, more common in the elderly and in patients with hypertension and diabetes. Elevated levels of collagen and stiffening of titin in myocardium lead to increased left ventricular stiffness and subsequently to prolonged isovolumetric LV relaxation and slower LV filling (16-21). End-systolic and end-diastolic volumes are both decreased since ventricular wall thickness is substantially increased, which is also reflected in the increased myocardial mass in patients with diastolic heart failure. Reduced LV cavity dimensions and thicker LV wall lead to a reduced LV wall stress, thus normal ejection fractions are seen in HFpEF patients, although their stroke volume is reduced. However, increased wall stiffness is related to hemodynamic decline, indicated by reduction of cardiac output, and $\mathrm{HF}$ symptom worsening (22). In cell level these deformations caused by increased cardiac myocyte thickness but not length, coupled with an increase in thickness of collagen bundles around the cardiac myocytes while collagen volumes remain the same (12).

Increased activation of RAA system and elevated plasma levels of catecholamines are increased in HFpEF similar to HFrEF (23). Other neurohormonal changes that occur in diastolic dysfunction include activation of vasodilatory, antimitogenic, and natriuretic peptides, such as BNP. Although there are similarities vis-à-vis neurohormonal changes between systolic and diastolic heart failure, there are substantial differences in the ventricular remodeling. Dilation of LV chamber and increase of end-diastolic and endsystolic volumes are the main characteristics of systolic HF, while in diastolic HF, LV cavity remains unchanged or reduced and LV wall becomes stiffer and hypertrophied.

Increased wall stiffness results in decreased LV compliance of the heart, which determines the ease of heart chamber's expansion while is filled with a volume of blood. Since compliance is decreased, LV filling is restricted resulting in lower stroke volume and cardiac output. Besides the increases in left ventricular and atrial pressures, pressures of pulmonary circulation, such as pulmonary vein and artery pressures, are also increased and are associated with right ventricular failure. For these reasons, despite the normal ejection fraction HFpEF patients present, they have signs and symptoms of systemic venous hypertension, like peripheral edema, and pulmonary, hepatic, and splachnic circulatory congestion. 


\section{Diagnosis of Heart Failure}

Distinctive symptoms of heart failure such as dyspnea, edema, and malaise are commonly seen in both systolic and diastolic heart failure. Usual symptoms and signs of HFpEF patients are shortness of breath, paroxysmal atrial fibrillation, and rapidly developing dyspnea induced by tachycardia, which are mainly results of increased wall stiffness and increased atrial and ventricular pressures. Although similar symptoms are noticed in HFrEF patients, they are mainly related to general malaise and poor organ perfusion. There are almost equal incidences of hospitalizations for patients diagnosed with reduced or preserved ejection fraction heart failure $(11,24)$.

Neurohormonal and other peptide levels are being used as quantitative biomarkers for heart failure prognosis and diagnosis (25-28). Plasma BNP levels are lower in HFpEF than in HFrEF patients, even though at a given level of BNP prognosis of HF is inefficient for both types (27). Biomarkers relevant to myocardial stress such as BNP, N-terminal proBNP (NTproBNP) and also biomarkers relevant to myocardial injury such as high sensitive troponin $\mathrm{T}$ (hsTnT) are significantly associated with high $\operatorname{HFrEF}$ risk $(25,26,28,29)$. However, biomarkers relevant to extracellular matrix remodeling such as Galectin-3 and growth differentiation factor 15 (GDF15), as well as cystatin C and urinary albumin excretion are significantly associated with the risk for $\operatorname{HFpEF}(25,26,28,29)$.

In order to distinguish between the different heart failure types and also evaluate the severity of the disease, assessment of LV remodeling is essential. Transthoracic echocardiography and cardiac magnetic resonance imaging (MRI) are the two main noninvasive means of measuring all the structural abnormalities. Ventricular dilation and/or eccentric cardiac hypertrophy are the main structural changes seen in HFrEF, while concentric cardiac hypertrophy without ventricular dilation characterizes HFpEF phenotype. Two major diastolic function indices measured by echocardiography are the ratio of early to late mitral inflow peak velocity (E/A ratio) which is affected by the hemodynamic load, and the ratio of early mitral inflow peak velocity to early diastolic mitral annular velocity ( $E / E^{\prime}$ ratio) which is independent of the hemodynamic status (30).

\section{Current Heart Failure Treatments}

Over the last decades there was a huge improvement in clinical heart failure management with optimized utilization of old and new drugs, to improve patient's symptoms and life. Although, survival rates are improved, worsening of the symptoms is directly related to deaths (31). Fundamental changes in lifestyle and diet, such as increased activity and reduced salt consumption, are the first line of HF management. Conventional treatments of $\mathrm{HF}$ are mainly focused on the improvement of symptoms and signs, without often affecting the pathophysiologic pathways contributing in the development and progression of the disease.

As mentioned above, renin-angiotensin-aldosterone system, which has been studied for over a century, is hyper-activated in HFrEF to maintain hemodynamic homeostasis (32-35). The upregulation of this system for long periods can result in deleterious effects such as 
myocardial hypertrophy and fibrosis, as well as sodium conservation and fluid retention (35, 36). Angiotensin converting enzyme (ACE) is playing a major role in RAA system regulation, by converting Angiotensin I to the active vasoconstrictor hormone Angiotensin II. Therefore, ACE inhibition thought and proved in clinical testing to be efficacious as HFrEF treatment $(37,38)$.

In the case that ACE inhibitors cannot be tolerated by a HFrEF patient, angiotensin II receptor blockers (ARB) can be used instead. Clinical trials showed that blocking the activation of angiotensin II receptor can improve morbidity and mortality as well as reduce HF hospitalizations of patients with systolic heart failure $(39,40)$.

Fluid overload, loss of magnesium and potassium, and myocardial fibrosis are characteristic symptoms of HFrEF patients caused by elevated aldosterone levels. Thus, inhibition of aldosterone receptor using antagonists has been shown to be beneficial in clinical setting $(41,42)$.

A more recent clinical trial assessed the effects of angiotensin and neprilysin combined inhibition. Neprilysin is a neutral endopeptidase involved in the degradation of natural vasoactive peptides, such as natriuretic peptides, bradykinin, and adrenomedullin. Its inhibition leads to increased levels of those peptides and subsequent reduction of the deleterious neurohormonal overactivation effects. Angiotensin-neprilysin combined agent inhibition positively affected HF hospitalization rate, improved HF patient's quality of life, as well as reduced mortality in a clinical trial with more than $10,000 \mathrm{HFrEF}$ patients (43).

Another major category of drugs used to manage systolic HF is the beta-blockers. As it was already described, prolonged sympathetic activation, mainly due to increased norepinephrine and dopamine levels, can cause devastating effects on cardiac structure and function. About three decades ago, it was not clear whether blockage of $\beta$-adrenergic receptor stimulation would be of any benefit for HF patients. At the end of 70's the first report of beneficial survival effects of a beta-blocker was published (44), and since then there are several studies which confirmed that beta-blockers usage as HF treatment improves morbidity and mortality (45-48).

Impaired chronotropy and water and salt retention are two other aspects of systolic heart failure which accept pharmacological intervention to benefit heart failure patients. Increased resting heart rate is associated with higher morbidity and mortality (49), therefore the use of ivabradine, an If channel inhibitor, can reduce the heart rate and prevent worsening of HF (50). Furthermore, HF patients have increased risk of sudden death and ventricular arrhythmias, and an effective solution for this is the surgical installation of an implantable defibrillator (51-53). Diuretics are commonly used to manage volume overload in HFrEF patients with symptoms of edema.

All the treatment options referred above have be tested and showed efficacy in HFrEF. Although, all of those are authorized optimal HFrEF treatments, none of them succeeded to improve symptoms or survival among HFpEF patients (7). Besides some minor improvements in hospitalization, the vast majority of the clinical trials in HFpEF patients using approved optimal therapies for HFrEF, failed to demonstrate any beneficial effects 
(54-57). The increased prevalence of the disease, the disappointing outcome and the lack of effective HFpEF treatments, make the development of new therapeutic solutions for heart failure necessary.

\section{Risk Factors for Heart Failure}

There are substantial differences in heart failure risk factors among geographical areas, ethnological origins, genders, and life styles. The more precise the identification of those risk factors among different population subgroups, the better the regional prevention and treatment strategies will be. Ischemic and congenital heart disease, hypertension, pulse pressure (PP), cardiomyopathy, cardiopulmonary disease, as well as valve diseases and rheumatic fever are risk factors that either alone or in combination with other factors may lead to heart failure development (58). Some of them are more prominent in different populations than others. For example, ischemic heart disease (IHD) is a risk factor for heart failure in $>50 \%$ of patients from the Western societies, but $<10 \%$ in sub-Saharan Africa patients. Similarly, hypertension is a heart failure risk factor in $13 \%$ of Asia Pacific highincome population, compared to $33.5 \%$ and $35 \%$ in Eastern and Central Europe and subSaharan Africa populations (58).

Other important risk factors for incident HF are age, smoking, diabetes, body-mass index (BMI), atrial fibrillation and black race (59). In a recent review, that reported the follow-up of the SCREEN-HF cohort (60), risk factors are categorized based on their association to a specific subtype of the disease. They reported that age, IHD, PP, NT-proBNP, waist circumference, obstructive sleep apnea, and pacemaker were common risk factors for both reduced and preserved ejection fraction heart failure. Key finding was also the strong association they found between increased BMI and pathogenesis of HFpEF (61). It is well know that increased BMI results in the development of type 2 diabetes and hypertension (62). Furthermore, increased blood glucose, a common characteristic of diabetes, can cause microvascular complications, such as neuropathy, retinopathy, and diabetic nephropathy, as well as macrovascular abnormalities, like coronary artery disease, peripheral arterial disease, and stroke, that will subsequently lead to the development of heart failure $(63,64)$. The close relation of diabetes and heart failure is also supported by the fact that over $50 \%$ of T2DM patients die due to coronary artery disease (65).

\section{DIABETES MELLITUS}

Diabetes mellitus (DM) is a chronic disease characterized by increased concentrations of glucose in the blood and caused by deficient pancreatic insulin production or ineffectiveness of insulin. 


\section{Relevance}

The International Diabetes Federation estimated in 2017 that $9 \%$ of adults aged $20-79$ years, a total of 425 million people worldwide, had diabetes. By 2045, this number is projected to rise up to 629 million (66). In 2012, diabetes was the eighth leading cause of death, with 1.5 million deaths directly caused by the disease and another 2.2 million deaths due to hyperglycemia-induced cardiovascular diseases, chronic nephropathies, and tuberculosis. The $43 \%$ of these deaths occur before the age of 70 (67). Low- and middle-income countries are the ones with the higher risk rates and the most increasing prevalence of diabetes, contributing to the astonishing increase in the global prevalence of diabetes from $4.7 \%$ in 1980 to $8.5 \%$ in 2014 (67). The direct annual cost of diabetes worldwide has been estimated to be more than $\$ 827$ billion $(68,69)$. Another study has estimated that in less than two decades, from 2011 to 2030, the direct and indirect costs of diabetes will result in global GDP losses of total \$1.7 trillion (70). Besides the economic burden, diabetes is also negatively affecting patients and their families' lives in a socioeconomic level. Diabetes can lead to amputation or even premature loss of life, contributing in the family income loss and also creating negative emotions and depressed psychology in patients and their close associates.

\section{Types and Pathophysiology of Diabetes}

The term "diabetes" (from the verb " $\delta\left\llcorner\alpha \beta \alpha i v \omega\right.$ " $=$ traverse) was used in the $2^{\text {nd }}$ century AD from the Greek doctor Aretaeus of Cappadocia (71). This term was used to describe the traverse of water from the moment one consumes it, until its secretion as urine. The word "diabetes" could be seen as a combined description of two main characteristics of diabetes; polydipsia and polyuria. Diabetes can be categorized based on clinical phenotype, the natural history of the disease, pathophysiological characteristics, disease consequences, and optimal treatment. Therefore we have classified diabetes as type I DM, type II DM, gestational diabetes, monogenic diabetes and other specific forms $(72,73)$.

Type I DM can be exclusively defined due to the characteristic existence of diabetesassociated autoantibodies (DAA) and the necessity of insulin treatment. Childhood onset and clinical insulin dependence with presence of DAA, high-disease-risk human leucocyte antigen (HLA) genotypes and very low C-peptide levels, a proxy of insulin levels secretion, would identify type I DM (72). However none of those factors are specific for type I DM, since the DAA detection method sensitivity detects $1 \%$ of the general non-diabetic population positive for DAA; age and C-peptide levels are continuous variables; HLA genotypes have good sensitivity but not the ideal specificity as markers; and initiation of insulin therapy depends on physician's decision (74). T-lemphocyte function related genetic polymorphisms are associated with $\operatorname{T1DM}(72,75)$.

Type II DM is a chronic disease with complex etiology that cannot be described by a single or a few features. The only defining feature of T2DM is the lack of DAA. As the other major diabetes subtype, T1DM, T2DM is a polygenic disease. Genetic polymorphisms associated to T2DM relate to beta cell function, and specifically a TCF7L2 polymorphism, which plays a role in insulin secretion, has a strong genetic relation with $\operatorname{T2DM}(76,77)$. In contrast to the 
vast reduction in insulin production that is seen in T1DM, patients with T2DM have almost normal or slightly decreased production of insulin, but they are not as sensitive to it. Thus, the metabolic syndrome, a surrogate for insulin insensitivity, has a prevalence of about $89 \%$ in T2DM compared to 32\% prevalence in T1DM (78).

There are a few other categories of diabetes and some of them are difficult to distinguish. For example there are cases with clinical T2DM, but with some immunogenic characteristics of T1DM; this is considered a different diabetes category, called latent autoimmune diabetes in adults (LADA), or slowly progressive insulin-dependent diabetes (SPIDDM), or type 1.5 diabetes $(76,79,80)$. Another type of diabetes, called maturity onset diabetes of the young (MODY), is more commonly diagnosed in children even though it has clinical features of the adult-onset diabetes. Noteworthy, there are at least 13 genes implicated in MODY, also known as monogenic diabetes, and different clinical characteristics are representative of the genetic types of $\operatorname{MODY}(76,81)$. Another type of $D M$, that is defined as any carbohydrate intolerance first diagnosed during pregnancy and is usually due to insulin-blocking hormones produced during pregnancy, called gestational diabetes mellitus (GDM) (82). Complications of GDM can affect both the mother and the fetus. Maternal adverse outcome is mainly long term associated to T2DM progression and onset of metabolic syndrome $(83,84)$, but can also be short term as hypertension preeclampsia, and increased risk of cesarean section $(85,86)$. Fetal risks can be short term as intrauterine fetal death (IUFD) $(87,88)$, aberrant fetal growth mainly macrosomia with its effect on delivery (87), and metabolic hematologic changes (88). Long term complications for the fetus are mainly early onset metabolic syndrome and adverse neurological and cognitive outcomes $(89,90)$.

\section{Current Treatments of Diabetes}

Besides insulin, which is the most closely related to diabetes agent that can be used as treatment, there are other substances such as sulfonylureas, metformin, and gliptins that can be used to control glucose levels. Although diabetes is directly associated with insulin production and sensitivity, insulin administration is not the optimal treatment for every type of diabetes $(76,81)$. Furthermore, drugs that are efficacious for a type of diabetes might not have similar benefits as treatment for another type. A great example for this comes from a study focused on MODY management. A clinical trial testing the effects of metformin and sulfonylureas in patients with T2DM and hepatic nuclear factor $1 \alpha$ (HNF1A) MODY, one of the most common forms of MODY, showed that HNF1A MODY patients had a 5-fold better response to sulfonylurea gliclazide than to metformin and an almost 4-fold greater response to gliclazide than T2DM patients (81). Interestingly, there is research supporting medication-gene interactions for glycemic control such as metformin and SLC22A1, SLC22A2, and SLC47A1 loci, as well as sulfonylureas and CYP2C9 and TCF7L2 loci (91). Although the current medications are quite effective in most of the cases, they still require daily dosing which can be inconvenient for the patients but also dangerous in cases of patient's memory loss. Therefore, a therapy aiming to a constant blood glucose level regulation would be the ideal therapeutic solution for diabetics. 


\section{UROCORTINS AND THEIR RECEPTORS}

\section{Historical Background}

In 1948 it was demonstrated that secretion of adenohypophyseal hormones can be triggered by hormones released from the median eminence of hypothalamus (92). A few years later, in 1955, one group in Montreal and an independent group in Houston, both provided evidence that a factor derived from hypothalamus could stimulate adrenocorticotropin (ACTH) secretion in intact rat pituitary $(93,94)$. This was the first discovered hypothalamic-releasing factor and it was named corticotropin releasing factor or hormone (CRF/CRH) after its ability to elicit ACTH secretion. After several other hypothalamic releasing factor peptides' structures were found, Vale et al determined the structure of ovine CRF, two and a half decades after its initial discovery (95). In the middle of 90's, a novel peptide with structural and biological homogeneity to urotensin and CRF was characterized and named urocortin (Ucn) by Vaughan et al (96). This peptide was later named Ucn1 because it was the first of the three urocortins to be discovered until today (Fig. 1). The discovery of the other two additional Ucns, Ucn2 (or stresscopin-related peptide) and Ucn3 (or stresscopin), was published simultaneously by Vale's lab at Salk Research Institute and Hsueh's lab at Stanford University in 2001 (97-99).

\section{Urocortins}

Human urocortins 1-3 are encoded by genes located in chromosomes 2 (2p23-p21), 3 (3p21.3), and 10 (10p15.1), respectively, and have the same basic gene structure consisting of two exons with the second one forming the coding region $(100,101)$. In translation process these genes produce precursor pre-pro-peptides $(122,112$, and 161 residues for Ucn1-3, respectively), which are going through proteolytic cleavage of their $\mathrm{N}$-terminal signals to finally produce mature C-terminally amidated peptides. Cleavage of the pre-signal is responsible for the secretion of the NT-pro-peptide, which after further cleavage of its pro-signal will reach its mature form. Mature Ucn1 has been isolated, sequenced, and found to be 40 amino acids long, whereas the length of the mature forms of Ucn2 and 3 is still uncertain and thought to be between 38 and 43 amino acids long (101-103). Ucn1 amino acid sequence is highly conserved across species and is more similar to CRF ( $45 \%$ homology) than to Ucn 2 and Ucn3 (43\% and 20\% homology, respectively) which are $40 \%$ homologous to each other.

Ucns can be detected in the CNS as well as in the periphery, and their expression patterns differ according tissues that are expressed. Highest expression of Ucn 1 in the brain can be seen in the Edinger-Westphal nucleus and lateral superior olive, but peptide is also expressed in other areas as hypothalamus, hippocampus, basal ganglia, medial septum, paraventricular nucleus, lateral superior olive cerebellum, substantia nigra pars compacta and ventral tegmental area $(104,105)$. In the periphery Ucn1 expression has also been detected in the heart, lung, spleen, kidney, thymus, skeletal muscle, skin, adrenal gland, placenta, immune system and digestive system (106). Ucn2 is distributed similarly to Ucn1 
in the CNS, with detectable amounts of expression in paraventricular and arcuate nuclei of hypothalamus, as well as locus coeruleus of the brainstem $(97,102)$. Peripheral tissues that show high Ucn2 expression include adrenal, heart, stomach, skin, placenta, ovaries, intestines, skeletal muscle, uterine smooth muscle, and peripheral blood vessels $(106,107)$, while lower levels have been detected in kidney $(99,101)$. Medial amygdala and hypothalamus are the main CNS regions that Ucn3 is expressed $(98,108-110)$. In the rest of the body, expression of Ucn3 is present in the adrenal, kidney, pancreas, gastrointestinal tract, skeletal muscle, skin, and heart $(98,111)$. Ucn3 expression in the kidney and specifically in the distal tubules of the renal cortex implies its involvement in tubular reabsorption and renal circulation (111), while Ucn3 expression in $\beta$ pancreatic cells has been shown to affect insulin production and release $(112,113)$. Endogenous expression of Ucns has been found in all 4 chambers of the heart, with noteworthy strong expression in the left ventricle $(99,107,111,114-117)$. It has been shown that Ucn1 and Ucn2 are expressed in both myocytes and non-myocytes (fibroblasts) $(107,114)$, and that Ucn1 is also expressed in the coronary vasculature $(118,119)$.

In normal healthy humans of both genders $(120,121)$ circulating levels of Ucn1 (120-125) and Ucn2 $(126,127)$ found to be similar varying from 20 to $100 \mathrm{pg} / \mathrm{mL}$. In a few studies higher levels of Ucn3, around $200 \mathrm{pg} / \mathrm{mL}$, were reported $(111,128)$, although published data also show similar circulating levels of all Ucns in healthy women (129).

\section{CRF Receptors}

In mammals, the two mediators of the CRF family peptides are the two subtypes of CRF receptors, CRF-R1 and CRF-R2. They have characteristic seven transmembrane helical domains and are coupled to trimeric G-proteins. Both receptors belong to the class B1 subfamily of the G-protein coupled receptors (GPCRs). CRF-R1 and CRF-R2, in humans, encoded by genes located on chromosomes 17 (17q12-q22) and 7 (7p21-p15) respectively, and through alternative splicing different isoforms can be created (isoforms a-h for CRF-R1 and isoforms $\alpha, \beta, \gamma$ for CRF-R2) $(130,131)$. Both receptors are expressed in mammalian brain with high levels of CRF-R1 found in cerebral cortex, cerebellum, amygdala, hippocampus, and olfactory bulb (132). CRF-R2 mRNA highest expression was found in the lateral septal nucleus, bed nucleus of stria terminalis, ventromedial hypothalamus (VMH) nucleus, olfactory bulb, and mesencephalic raphe nuclei (132). Expression of CRF-R1 has been found in a wide range of human peripheral tissues such as adrenal, adipose tissue, skin, spleen, heart, testis, ovary, endometrium, myometrium, placenta, and in some immune system's cell types $(114,117,132-141)$. In humans, skin, skeletal, smooth, and cardiac muscle have the highest mRNA expression levels of CRF-R2 levels $(142,143)$. All four chambers of the heart express CRF-R2 (predominantly isoform $\alpha$ in humans) (114), which is mainly localized in myocytes (116) and in intramyocardial blood vessels (115). Expression of CRF-R2 can be detected in smooth muscle and endothelial cells, as well as the medial layer of both arterial and venous vessels $(115,144,145)$.

The distinct distribution of CRF-R1 and CRF-R2 in the central nervous system (CNS) and periphery, suggests they are involved in different physiological functions. Studies in mice showed that CRF-R1 knockout affiliated with decreased anxiety-like behavior and had 
impaired stress response $(146,147)$, whereas mice with mutated CRF-R2 displayed increased anxiety-like behavior, accelerated hypothalamus-pituitary-adrenal (HPA) axis response, and impaired cardiovascular function (148-150). The two receptors are about $70 \%$ homologous and transmembrane and cytoplasmic domains are conserved among all isoforms $(101,151-153)$. Despite their amino acid similarities, CRF-Rs have different pharmacological characteristics, mainly due to their extracellular $\mathrm{N}$-terminus region which is less than $50 \%$ homologous and is responsible for agonist binding. CRF-R1 exhibits high ligand selectivity for CRF and Ucn1, but not for Ucn2 and Ucn3 which have higher affinity and almost exclusively bind CRF-R2 (Fig. 1) (106).

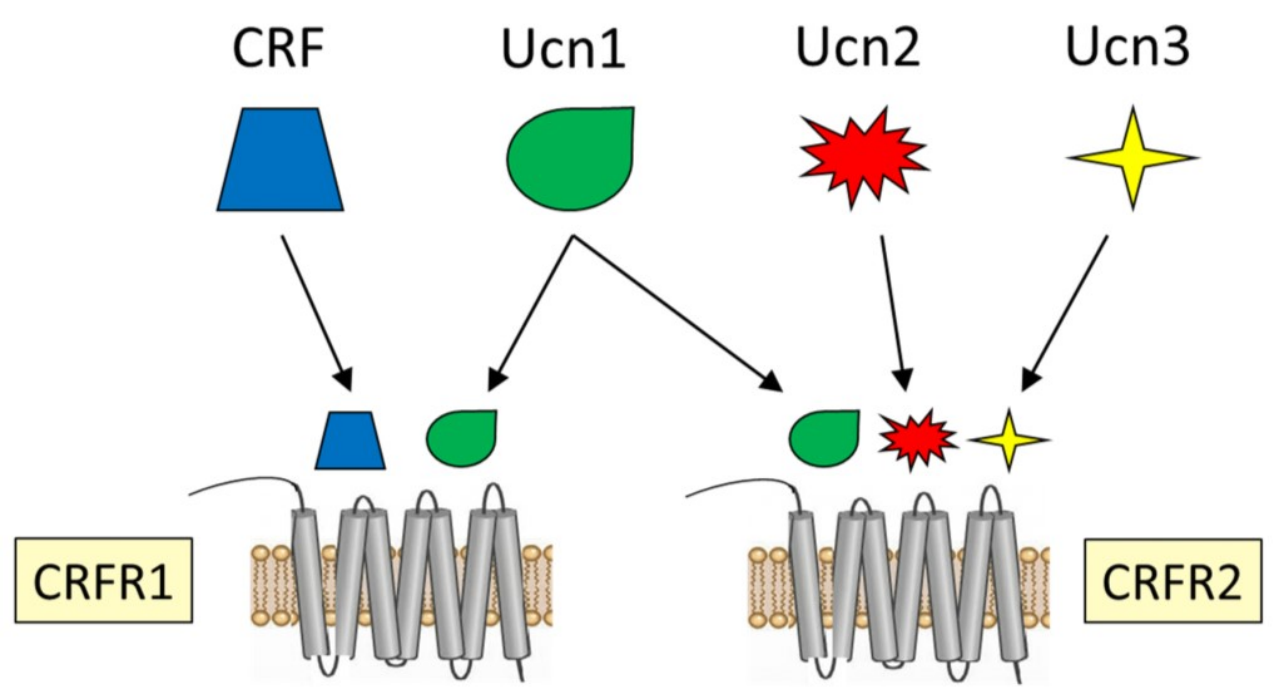

Figure 1. Schematic representation of CRF family peptides and their affinity to CRF receptors 1 and 2.

\section{Vasodilatory Effects}

As expected, due to their prominent expression in different cells within the heart and vasculature, corticotropin releasing factor receptor-2 (CRF-R2) and urocortins play a major role in the cardiovascular function via activation of G-protein coupled signaling pathways (102). It has been shown that an important effect of Ucns, mediated mainly through the CRF-R2 $(115,154)$, is reduction of systemic vascular resistance and blood pressure (155, 156). Absence of CRF-R2 in genetically modified mice can cause hypertension and also diminishes the presence of any Ucns' hemodynamic effects (150). Additionally, a protective compensatory function of the Ucn system has been suggested based on findings of preclinical heart failure studies showing that pharmacological blockade of CRF-R2 results in greater increase of systemic vascular resistance and arterial pressure in HF animals compared to wild type ones $(154,157)$. CRF-R2 antagonism, as well as adenylyl cyclase, protein kinase $A(P K A)$, and p38 mitogen-activated protein (MAP) kinase inhibition attenuated the effects of Ucns in rat aorta (158). Ucns signal transduction leading to pulmonary arteries relaxation is mediated, as reported, by protein kinase C (PKC) and stimulation of $\mathrm{Na}^{+}-\mathrm{Ca}^{2+}$ exchangers $(159,160)$. Two other possible molecular mechanisms 
contributing in Ucns' vasodilatory actions involve regulation of $\mathrm{Ca}^{2+}$-independent phospholipase A2 (iPLA2) and stimulation of CAMP/PKA-dependent signal transduction cascade $(161,162)$. Blood pressure and vascular tone are also affected by Ucns through the regulation of vasoactive neurohumoral systems, such as angiotensin II (AngII) and endothelin-1 (ET-1) (163). In ovine HF model administration of Ucns reduced Angll and ET1 concentration in a greater extend that in normal sheep $(157,164-166)$. Experimentation with spontaneously hypertensive rats (SHRs) showed that long-term administration of Ucn1 reduces Angll activity and circulating angiotensin-converting enzyme (ACE) resulting in elevation of serum and aortic NO levels and subsequent fall in systolic blood pressure (167). Besides the attenuation of ET-1 vasoconstriction effects that Ucns are capable of, blockade of the CRF-R2 leads to elevation of plasma ET-1 levels (157-163, 167-174). Also, secretion of natriuretic peptides with vasodilatory effects can also be triggered by Ucns (116).

\section{Endothelial Effects}

The endothelium may contribute also in the vasoactive effects of Ucns since it demonstrates high CRF-R2 expression. Research on the effects of Ucns on different vessels has revealed mechanisms and molecules involved in the vasodilatory actions which include nitric oxide (NO), prostaglandins, barium-sensitive and calcium-activated potassium channels, as well as production of cAMP with subsequent synthesis and release of sarcoplasmic $\mathrm{Ca}^{2+}$ and NO $(119,168-172)$. Besides its role in vasodilation, endothelium through many of its actions, such as regulation of vascular permeability and remodeling, vascularization, vasoprotection and thrombogenesis, orchestrates cardiovascular homeostasis. Based on the majority of reports, Ucns have anti-trophic, anti-proliferative effects on cultured endothelial cells (ECs), a theory that is supported by the fact that CRF-R2 deficient mice develop hyper-vascularization (175). Endothelial cell cycle reduction, reduced production of vascular endothelial growth factor (VEGF), and release of a transforming growth factor (TGF)- $\beta$ superfamily glycoprotein, activing-A, may serve as mechanisms through which Ucns and CRF-R2 affect endothelial cell proliferation $(175,176)$. There are controversial findings vis-à-vis the inflammatory effects of Ucns and their receptors. Findings in human umbilical vein endothelial cells (HUVECS) supporting pro-inflammatory actions of Ucns report activation of nuclear factor kappaB ( $\mathrm{nf}-\mathrm{kB}$ ) and increases in the expression levels of prostaglandin E2 (PGE2), intracellular adhesion molecule-1 (ICAM1), cyclooxygenase 2 and cytosolic phospholipases A2 (177). In contrast, anti-inflammatory actions of Ucns are suggested by other studies in HUVECs which demonstrate inhibition of Angll-induced reactive oxygen species (ROS) (178). Furthermore, suppression of LPS-induced TNF- $\alpha$ release from macrophages and induction of their apoptosis can serve as more evidences towards the anti-inflammatory effects of Ucns $(179,180)$. It is noteworthy that Ucn2 has pro-inflammatory and Ucn3 anti-inflammatory effects in the CRF-R2-mediated regulation of TNF- $\alpha$ and IL-10 expression and secretion in human trophoblast explants $(181,182)$. Additionally, blockade of CRF-R1 exacerbates, but blockade of CRF-R2 diminishes LPSinduced increased hydraulic permeability in rat mesenteric venules (183). Even though there is an overall favor to an endothelial-protective role of Ucns, there are contradictory findings suggesting a differential regulation of endothelial functions depending on the type 
of receptor being activated, systemic vs local activation, pathophysiological settings, and possibly species.

\section{Cardiac Effects}

Ucns actions in the heart vary from increasing contractility and relaxation, to altering the heart rate and affecting apoptosis as well as cardiac hypertrophy. Ucn expression is increased in $\mathrm{HF}$ and its decline is associated with disease progression due to diminished cardioprotective and anti-inflammatory effects (120). The inotropic and lusitropic mechanisms of Ucns are mediated through the AMP-activated protein kinase (AMPK) pathway and increases in phosphorylation of $\mathrm{PKA}, \mathrm{Ca}^{2+} /$ calmodulin-dependent protein kinase II (CamKII), and phospholamban (PLN) as studies in isolated cardiac myocytes have shown (184-186). Furthermore, exchange protein activated by CAMP (EPAC), PKC, MAP kinase, and increased intracellular NO are other mechanistic pathways via which Ucn2 inotropes heart function $(187,188)$. Additionally, sarco/endoplasmic reticulum $\mathrm{Ca}^{2+}$ ATPase (SERCA2a) were increased in LVs of mice with elevated plasma Ucn2 levels due to Ucn2 gene transfer $(189,190)$. As expected, all these changes in $\mathrm{Ca}^{2+}$ handling proteins lead to increased intracellular and sarcoplasmic reticulum (SR) $\mathrm{Ca}^{2+}$ and also in faster reabsorption of $\mathrm{Ca}^{2+}$ back to the SR, as it was found in isolated cardiac myocyte experiments $(189,190)$.

The phenotype of those molecular changes mediated by Ucns is present in isolated heart $(169,187)$ and intact animal studies $(164-166,189-191)$ in which increased cardiac output, contractility, and relaxation as well as reduced vascular resistance and cardiac filling pressure are associated with Ucns. Research on murine HF models showed that Ucn2 treatment results in decreased systemic vascular resistance and aortic impedance, increased cardiac output, reduced LV mass index, myofibrillar disarray, cardiac fibrosis and inflammation, and also improved intracellular calcium cycling, LV contractility and relaxation $(156,192)$. Ucn2 gene transfer increased contractility and relaxation for up to 7 months in normal and failing mouse hearts, through improved $\mathrm{Ca}^{2+}$ handling and increases in functional proteins, like myosin light chain kinase $(189,190)$. In rat models of hypertension and pulmonary hypertension with subsequent right ventricular failure, Ucn1 and Ucn2 administration increased cardiac function and mitigated ventricular and blood pressure increases, resulting in attenuation of hypertension-induced vascular remodeling and LV hypertrophy $(155,167,193-195)$. In an ovine animal model of heart failure administration of Ucns resulted in a range of beneficial dose-dependent cardiovascular and renal effects (164-166). Improved hemodynamics are related to normalization of elevated vasoconstrictor neurohormones levels such as renin, Angll, aldosterone, ET-1, and arginine vasopressin. High levels of CRF-R2 and Ucns in the kidneys, especially in the proximal and distal tubules of the renal cortex, are likely associated with the renal effects in the setting of heart failure including enhanced renal filtration, diuresis, and natriuresis $(111,196)$. Further experiments in sheep with HF, tested the combination of Ucns with current human $\mathrm{HF}$ treatments, as ACE inhibitors, $\beta$-adrenergic receptor blockers, diuretics, and mineralocorticoid receptor antagonists. Those studies showed synergistic augmentation of the beneficial cardiovascular effects of each agent alone, as well as restriction of the adverse effects of the current treatments used to manage human $\operatorname{HF}(163,197-199)$. 
Elevated heart rate is another effect of Ucns which is mediated through the CRF-R2 (164$166,191)$ and, as the inotropic and lusitropic effects described above, is not affected by autonomic nervous system (200). However, studies in rats revealed that use of atropine and propanolol to block autonomic nervous system can reduce Ucn1 and Ucn2 induced tachycardia (201). It has been shown in larger animal studies that administration of Ucns, at doses low enough without any vasodilatory effects up to doses that increase heart rate, suppresses the cardiac sympathetic nerve activity (202-205).

Induction of pathways involving MAPK, phosphorinositol-3-kinase (PI3K), and PKC by the Ucns, not only enhances cardiac function but also demonstrate cardioprotective effects $(102,112,153)$. Two other proteins increased by Ucns resulting in their cardioprotective properties are cardiotrophin-1 (CT-1) (206) and heat shock protein 90 (207). In vitro experiments simulating hypoxia in cardiac myocytes and ischemia/reperfusion (I/R) experiments in isolated rat hearts revealed that Ucns increase cell survival (208-211). In the same experimental setting was found that secretion of Ucns occurs prior to the development of irreversible myocardial damage and is inversely proportional to injury size (209). Furthermore, the cardioprotective actions of Ucns in cardiac myocytes occur independent on whether Ucns are given many hours before the ischemia, immediately prior to it or at the time of re-oxygenation $(212,213)$. Isolated perfused heart I/R studies support the cardioprotective abilities of Ucns shown in cardiac myocyte experiments, since administration of Ucns after $\mathrm{I} / \mathrm{R}$ was associated with reduced infarct size and infarct size/risk ratio $(208,214,215)$.

Contradictory findings between cell and intact animal studies show that Ucns can either promote or reduce cardiac hypertrophy. In cardiac myocytes studies Ucns induced expression of $\beta$-myosin heavy chain $(\beta-M H C)$, atrial natriuretic factor (ANF) and B-type natriuretic peptide (BNP), and also increased cell size and protein synthesis (206, 216-218). Proteins involved in the cardioprotective actions of Ucns, as PKA, PI3K, and CT-1, are also mediators in these pro-hypertrophic effects of Ucns (206, 216, 218, 219). Contrarily, in studies with hypertensive rats and mice with heart failure, Ucn2 treatment reduced heart weight to body weight (HW/BW) ratio, LV wall thickness, and expression of $\beta-\mathrm{MHC}$ and collagen-1 $(155,190,220)$. Administration of Ucn-1 had similar anti-hypertrophic effects in rats with streptozotocin-induced diabetic cardiomyopathy, reducing LV mass index and the levels of fibrosis and inflammation markers (221).

\section{Metabolic Effects}

CRF and urocortins play significant role in regulation of neurohormonal responses to stress, changes in energy homeostasis, as well as in lipid and glucose metabolism $(222,223)$. Additionally, CRF-R2 is also involved in metabolic regulation, as it was shown in CRF-R2 knockout mice studies. Animals lacking this receptor resist high-fat diet induced obesity and insulin resistance, potentially due to increased sympathetic activity which increases thermogenesis in brown adipose tissue resulting in a higher metabolic rate $(224,225)$. Besides these central metabolic actions that Ucns promote, their presence at high levels in peripheral metabolic tissues, including skeletal muscle, implying that they also have local peripheral metabolic effects $(226,227)$. Studies have shown that CRF can stimulate 
thermogenesis in skeletal muscle via substrate cycling between de novo lipogenesis and lipid oxidation, requiring both PI3K and AMPK signaling (228). Regulation of thermogenesis in peripheral tissues, especially skeletal muscle, by the CRF family peptides underlies their importance for protection against excessive intramyocellular lipid storage, and subsequently against lipotoxicity-induced insulin resistance. However, deletion of Ucn2 increased whole-body insulin sensitivity in mice, due to CRF-R2-mediated activation of protein kinase $B(A K T)$ and extracellular signal regulated kinase (ERK) $1 / 2$ signaling in skeletal muscle (226). Deletion of Ucn3, also protected mice from glucose intolerance (113), even though pancreatic Ucn3 enhances insulin production by beta cells (227). In another study global knockout of Ucn3 increased food intake and reduced insulin sensitivity without affecting energy expenditure (229). Overexpression of Ucn3 in the rostral perifornical area of the brain resulted in elevated energy consumption and a reduction in insulin sensitivity (230), while injection of Ucn3 into the VMH reduced food intake and increased blood glucose and insulin levels (231). Transgenic mice overexpressing Ucn3 showed elevated Ucn3 expression in skeletal muscle associated with reduced plasma glucose, improved glucose tolerance, enhanced glucose disposal into muscle and elevated muscle insulin-like growth factor 1 (IGF1), while promoting muscle hypertrophy (232). Furthermore, experiments in rat skeletal muscle revealed that Ucn3 activates AMPK and AKT pathways and increases glucose disposal (233). Summarizing the metabolic effects of Ucns, we can clearly state their potency to regulate glucose homeostasis, however there are various findings on underlying mechanisms and key tissues of action that impede the clarification of their predominant effects.

\section{Urocortins in Human Healthy and Failing Heart}

The role of Ucns in healthy and failing human hearts was attempted to be explained by a few studies in which the levels of Ucn1, Ucn2 and amino-terminal pro-Ucn2 (NT-proUcn2) were determined $(120,123,234,235)$. Those studies showed that Ucn1 levels are increased in patients with severe HF $(120,123,234)$. A barely minimum number of publications are reporting an 8-fold increase in Ucn2 levels (235), and a slight but highly significant increase in NT-proUcn2 levels (236) in human HF. Gene expression analysis using RT-PCR revealed that CRF-R1, CRF, and Ucn3 expression were increased in failing hearts while CRF-R2 expression was decreased (237).

All three Ucns have been tested in infusion studies in healthy volunteers $(122,126,238$, 239). Ucn1 infusion was associated with increased plasma levels of corticotropin, cortisol, and ANF, and reduced levels of ghrelin, a hormone related to appetite increase. The dose used in the study had no hemodynamic or renal effects (122). On the other hand, infusion of Ucn 2 and $U \mathrm{cn} 3$ in healthy males resulted in potent and prolonged vasodilation (238). In separate studies, Ucn2 infusion in healthy humans increased cardiac output (126).

The efficacy of Ucns infusion in heart failure patients has also been tested (239-243). Although, Ucn1 infusion resulted in increased plasma Ucn1, corticotropin, and cortisol, there were no effects in heart and renal function (240). On the other hand, infusion of Ucn2 in patients with congestive heart failure promoted vasodilation, increased cardiac output and ejection fraction, and reduced peripheral vascular resistance, cardiac work, and LV size 
$(239,241,243)$. No neurohormonal and renal effects were seen after Ucn2 infusion. The effects of stresscopin (Ucn3 analog) infusion in human subjects with heart failure were also investigated $(239,242)$. Significant increases in cardiac output, cardiac index, and EF, as well as reductions in systemic vascular resistance were affiliated with Ucn3 intravenous (IV) infusion. No adverse effects were noticed on heart rate, systolic blood pressure, or pulmonary capillary wedge pressure $(239,242)$.

The pre-clinical and clinical findings on the effects of Ucns in heart function and metabolism, underline the potential of those peptides to be used as heart failure or diabetes treatments. However, their short half-life (a few minutes), requires continuous IV infusion for chronic therapy (244). To overcome the subsequent problems of constant IV infusions we proposed gene transfer of Ucns, with vision the development of gene therapy for heart failure or diabetes.

\section{GENE THERAPY APPROACH}

In the mid-1960s scientific community started a discussion towards more applied use of genetic knowledge, which was only intended to be used for genetic defect detection. Work from Dr. Dulbecco's laboratory with tumorigenic papovavirus SV40 and polyoma revealed that these viruses act by transferring foreign genetic material into their host cells. Foreign genes were then integrated into the host genome and expressed by the cellular mechanisms as new cellular genetic functions (245). In 1972 Theodore Friedman and Richard Roblin were the first to talk about treating a genetic disease using gene therapy (246). Martin Cline was the first to apply gene therapy technique in human patients with $\beta$ thalassemia in 1980, after testing the in vitro transformation of bone marrow cells which he then injected in intact animals (247). However, this attempt was criticized and Drs Cline and Salser of UCLA got penalized for not complying with the NIH and FDA clinical trial standards for the use of recombinant genetic material (248). In 1990 work from Drs Anderson, Blaese, and Culver on adenosine deaminase (ADA) deficiency, which causes severe combined immunodeficiency (SCID), resulted in the initiation of the first official gene therapy clinical trial (249). In this trial T-cells from the patients were extracted, correction of the defected ADA gene was performed using retroviral gene transfer, and last the genecorrected T-cells were re-infused into the patient. In the next decade some clinical trial failures and a serious incident of a young ornithine transcardamylase deficiency, an X-linked genetic liver disease, that died due the gene therapy treatment that he received (250), diminished the interest on gene therapy treatment development. However, from the early 2000s there are a lot of successful and promising studies using gene transfer approach to develop treatments for a variety of diseases, some of which were tried in clinical trials and are currently approved commercialized therapies $(251,252)$.

Attempts were also done towards development of gene therapy for HF. The first step was accomplished in 1990 when $\beta$-galactosidase gene was expressed in myocardium after direct 
DNA injection (253). Adenylyl cyclase 6 (AC6) is an enzyme that catalyzes the conversion of ATP to cyclic adenosine monophosphate (cAMP), a signaling molecule that modulates excitation-contraction coupling resulting in inotropy after $\beta$-adrenergic receptor stimulation by catecholamines (254). Using an adenoviral vector AC6 was overexpressed in murine and porcine hearts leading to improved heart function, reversed pathological LV remodeling, and prolonged life in mice with genetic cardiomyopathy, without excessive CAMP generation (255-257). Recently, the efficacy and safety of an intracoronary delivery of an adenoviral vector encoding AC6 was tested in a double-blinded, placebo-controlled, phase 2 clinical study with symptomatic HF patients (258). SERCA2a is a transmembrane protein that pumps cytosolic $\mathrm{Ca}^{2+}$ into the sarcoplasmic reticulum and plays a key role in cardiac myocyte $\mathrm{Ca}^{2+}$ handling. Therefore, gene transfer of such protein was thought to have the potential to treat HF. Although the idea worked successfully in isolated human cardiac myocytes (259), rodent (260), and porcine (261) HF models, unfortunately, when tried to be translated to the clinics (Calcium Up-Regulation by Percutaneous Administration of Gene Therapy in Cardiac Disease, CUPID), it failed (262-264). Another important protein that modulates $\mathrm{Ca}^{2+}$ cycling and mitochondrial function via interactions with ryanodine receptor, SERCA2a, and mitochondrial F1-ATPase, is the S100A1. This protein has been shown to have inotropic, antihypertrophic, and antiarrhythmic effects in HF, and it was also downregulated in human and various animal models of HF (265-267). The potency of S100A1 gene transfer to improve heart function was tested and proved by rescuing cardiac contractility in large animal model of HF (267). Additionally, an adeno-associated viral vector (type 6) encoding S100A1 (AAV6.S100A1) is proved to be safe in a preclinical model (268) and the initiation of clinical trials will possibly happen in the near future. Preclinical studies on HF are testing gene transfer of vascular endothelial growth factor B (VEGF-B), which has strong antiapoptotic/cytoprotective effects through its receptor VEGFR-1 (269, 270). The results from rat and dog models of HF are promising, showing that AAV.VEGF-B gene transfer has beneficial effects for the heart such as delayed onset of cardiac decompensation, and attenuation of the development of functional, histological, and molecular alterations, including apoptosis (271-273). Lastly, clinical studies were also conducted to test the gene transfer of stromal cell-derived factor 1 (SDF-1), which induces cardiac repair, affects cardiomyocyte survival, ventricular remodeling, and in cases of stem cell therapy it affects stem cell homing $(274,275)$. This approach was slightly different from the ones described previously since the transgene was delivered by direct naked plasmid DNA injection, avoiding the use of a viral vector. Although, phase I was successful enough to initiate phase II clinical trials, the therapy failed to meet its goals, but thoughts of another trial on a specific subgroup of HF patients are ongoing $(276,277)$.

\section{RESEARCH GOALS}

Based on pre-clinical and clinical studies testing the effects of Ucns in heart function, one can see the great potential of those peptides, especially Ucn2 and Ucn3, to be used as heart failure treatment. Additionally, their association and involvement in lipid metabolism and 
glucose homeostasis pathways supports their potency to be used as antidiabetic treatments. Ucns' short half-life (a few minutes) though, dictates the necessity of continuous IV infusion in order to yield the beneficial cardiovascular effects. Consequently, there are more problems caused due to the constant infusions requirement such as often hospitalizations, increased risk of infections, increased healthcare costs, and reduced patient's quality of life. To overcome this impediment, it is proposed gene transfer of Ucns. In few words, adeno-associated virus (type 8, AAV8) carrying a plasmid with a transcription cassette including one of Ucns' genes will be created and injected intravenously. Specifically, in the current studies two AAV8 vectors, one that encodes Ucn2 and the other Ucn3 under a chicken beta actin (CBA) promoter were constructed and used in animal studies. Since Ucn2 and stresscopin (Ucn3 homologue) were shown to improve cardiac function in IV infusion studies, the main goal of our studies was to assess the cardiovascular and metabolic effects of Ucn2 and Ucn3 gene transfer in normal mice, as well as evaluate the efficacy of those transgenes in murine heart failure models. Additionally, the existence of two peptides, Ucn2 and Ucn3, which bind with similar affinity to CRFR2 raises the question whether or not gene transfer of these peptides will result in similar physiologic changes. Therefore, another goal of these studies was to identify similarities and differences on the effects of Ucn2 and Ucn3 gene transfer. The ultimate aim of this translational research project is to investigate the potential of Ucn2 and Ucn3 gene transfer as new therapeutic approaches for human heart failure and diabetes management.

\section{THESIS OUTLINE}

An overview of the main topics that this thesis is dealing with is given in the introductory Chapter 1. Heart failure and diabetes, their relevance and pathophysiology, as well as their current treatments are firstly described to set the ground of the research goals. Urocortins' and their receptors' effects on cardiovascular activity and metabolism are mentioned to rationalize the use of Ucn2 and Ucn3 in these studies. Last, the specific aims of this thesis are stated.

Initially the cardiac and metabolic effects of Ucn2 and Ucn3 gene transfer were tested. In Chapter 2 assessment of heart function, vasodilatory effects, and glucose clearance 8-10 weeks after Ucn2 and Ucn3 gene transfer in normal mice are presented and compared. $\mathrm{Ca}^{2+}$ transient measurements, immunoblotting analysis and gene expression data are used to speculate on the molecular pathways these peptides are working through.

Next step, as presented in Chapter 3, was the evaluation of Ucn3 gene transfer effects in a murine model of HF. Mice underwent cryoinjury to induce HF and once HF was verified by echocardiography, mice were split in two groups and treated with AAV8.Ucn3 or saline. Left ventricular function and dimensions were recorded and analyzed to investigate the Ucn3 gene transfer effects on heart function. $\mathrm{Ca}^{2+}$ transients and $\mathrm{Ca}^{2+}$ handling proteins were also 
quantified and used to suggest potential mechanistic pathways resulting in the observed effects.

In Chapter 4, the effects of Ucn2 gene transfer on glucose metabolism in type-2 diabetes mouse models were studied. Diet- and genetically-induced diabetic mice were injected, after confirmation of hyperglycemia, with AAV8.Ucn2 or saline. Insulin sensitivity and glucose intolerance were thoroughly examined to evaluate the physiological actions of Ucn2 gene transfer on glucose homeostasis. Additionally, molecular and biochemical experiments yielded informative results regarding the glucose-related key proteomic changes caused by Ucn2 transgene.

Cardiac effects of Ucn2 gene transfer in 2-year-old mice with diastolic dysfunction, or HF with preserved ejection fraction (HFpEF), are presented in Chapter 5. Aged mice received AAV8.Ucn2 or saline and also compared to a young group of mice from the same strain. Assessment of diastolic dysfunction was done via echocardiography and LV in situ hemodynamic measurements, and those techniques were also used for the evaluation of transgene effects in cardiac function. Furthermore, the duration of gene transfer's effect was examined. Young mice were injected with saline or a vector encoding Ucn2 and studied 18 months later. It was also attempted to identify the important protein changes contributing to the effects observed.

Lastly, in Chapter 6 a brief summary and the conclusions of this scientific work are presented. Findings from all chapters are broadly discussed and speculation on the involvement of specific molecular mechanisms in the transgenes' effects is done. 


\section{REFERENCES}

1. Mann DL, Zipes DP, Libby P, Bonow RO, Braunwald E. Braunwald's heart disease : a textbook of cardiovascular medicine. Tenth edition. ed. volumes $p$.

2. WHO. World Health Organization website2018; Available from: http://www.who.int/cardiovascular diseases/en/.

3. Mozaffarian D, Benjamin EJ, Go AS, Arnett DK, Blaha MJ, Cushman M, et al. Heart Disease and Stroke Statistics-2016 Update: A Report From the American Heart Association. Circulation. 2016;133(4):e38-360. Epub 2015/12/18.

4. $\quad$ AM F. Heart failure. Philadelphia: Lea \& Febiger. 1937.

5. Borlaug BA, Paulus WJ. Heart failure with preserved ejection fraction: pathophysiology, diagnosis, and treatment. European heart journal. 2011;32(6):670-9. Epub 2010/12/09.

6. Ouzounian M, Lee DS, Liu PP. Diastolic heart failure: mechanisms and controversies. Nature clinical practice Cardiovascular medicine. 2008;5(7):375-86. Epub 2008/06/11.

7. Maeder MT, Kaye DM. Heart failure with normal left ventricular ejection fraction. Journal of the American College of Cardiology. 2009;53(11):905-18. Epub 2009/03/14.

8. Setaro JF, Soufer R, Remetz MS, Perlmutter RA, Zaret BL. Long-term outcome in patients with congestive heart failure and intact systolic left ventricular performance. The American journal of cardiology. 1992;69(14):1212-6. Epub 1992/05/01.

9. Judge KW, Pawitan Y, Caldwell J, Gersh BJ, Kennedy JW. Congestive heart failure symptoms in patients with preserved left ventricular systolic function: analysis of the CASS registry. Journal of the American College of Cardiology. 1991;18(2):377-82. Epub 1991/08/01.

10. Brogan WC, 3rd, Hillis LD, Flores ED, Lange RA. The natural history of isolated left ventricular diastolic dysfunction. The American journal of medicine. 1992;92(6):627-30. Epub 1992/06/01.

11. Owan TE, Hodge DO, Herges RM, Jacobsen SJ, Roger VL, Redfield MM. Trends in prevalence and outcome of heart failure with preserved ejection fraction. The New England journal of medicine. 2006;355(3):251-9. Epub 2006/07/21.

12. Aurigemma GP, Zile MR, Gaasch WH. Contractile behavior of the left ventricle in diastolic heart failure: with emphasis on regional systolic function. Circulation. 2006;113(2):296-304. Epub 2006/01/19.

13. Rossi A, Cicoira M, Golia G, Zanolla L, Franceschini L, Marino P, et al. Amino-terminal propeptide of type III procollagen is associated with restrictive mitral filling pattern in patients with dilated cardiomyopathy: a possible link between diastolic dysfunction and prognosis. Heart. 2004;90(6):650-4. Epub 2004/05/18.

14. Aurigemma GP, Gaasch WH. Clinical practice. Diastolic heart failure. The New England journal of medicine. 2004;351(11):1097-105. Epub 2004/09/10.

15. Chatterjee K, Massie B. Systolic and diastolic heart failure: differences and similarities. Journal of cardiac failure. 2007;13(7):569-76. Epub 2007/09/11.

16. Hamdani N, Paulus WJ. Myocardial titin and collagen in cardiac diastolic dysfunction: partners in crime. Circulation. 2013;128(1):5-8.

17. Sanderson JE, Gibson DG, Brown DJ, Goodwin JF. Left ventricular filling in hypertrophic cardiomyopathy. An angiographic study. British heart journal. 1977;39(6):661-70. Epub 1977/06/01.

18. Hess OM, Grimm J, Krayenbuehl HP. Diastolic simple elastic and viscoelastic properties of the left ventricle in man. Circulation. 1979;59(6):1178-87. Epub 1979/06/01. 
19. Hanrath P, Mathey DG, Siegert R, Bleifeld W. Left ventricular relaxation and filling pattern in different forms of left ventricular hypertrophy: an echocardiographic study. The American journal of cardiology. 1980;45(1):15-23. Epub 1980/01/01.

20. Soufer R, Wohlgelernter D, Vita NA, Amuchestegui M, Sostman HD, Berger HJ, et al. Intact systolic left ventricular function in clinical congestive heart failure. The American journal of cardiology. 1985;55(8):1032-6. Epub 1985/04/01.

21. Zile MR, Baicu CF, Gaasch WH. Diastolic heart failure--abnormalities in active relaxation and passive stiffness of the left ventricle. The New England journal of medicine. 2004;350(19):1953-9. Epub 2004/05/07.

22. van Heerebeek L, Borbely A, Niessen HW, Bronzwaer JG, van der Velden J, Stienen GJ, et al. Myocardial structure and function differ in systolic and diastolic heart failure. Circulation. 2006;113(16):1966-73. Epub 2006/04/19.

23. Kitzman DW, Little WC, Brubaker PH, Anderson RT, Hundley WG, Marburger CT, et al. Pathophysiological characterization of isolated diastolic heart failure in comparison to systolic heart failure. Jama. 2002;288(17):2144-50. Epub 2002/11/07.

24. Bhatia RS, Tu JV, Lee DS, Austin PC, Fang J, Haouzi A, et al. Outcome of heart failure with preserved ejection fraction in a population-based study. The New England journal of medicine. 2006;355(3):260-9. Epub 2006/07/21.

25. Santhanakrishnan R, Chong JP, Ng TP, Ling LH, Sim D, Leong KT, et al. Growth differentiation factor 15, ST2, high-sensitivity troponin $\mathrm{T}$, and $\mathrm{N}$-terminal pro brain natriuretic peptide in heart failure with preserved vs. reduced ejection fraction. European journal of heart failure. 2012;14(12):1338-47. Epub 2012/08/08.

26. van Kimmenade RR, Januzzi JL, Jr. Emerging biomarkers in heart failure. Clinical chemistry. 2012;58(1):127-38. Epub 2011/11/17.

27. van Veldhuisen DJ, Linssen GC, Jaarsma T, van Gilst WH, Hoes AW, Tijssen JG, et al. B-type natriuretic peptide and prognosis in heart failure patients with preserved and reduced ejection fraction. Journal of the American College of Cardiology. 2013;61(14):1498-506. Epub 2013/03/19.

28. Gaggin HK, Januzzi JL, Jr. Biomarkers and diagnostics in heart failure. Biochimica et biophysica acta. 2013;1832(12):2442-50. Epub 2013/01/15.

29. Brouwers FP, de Boer RA, van der Harst P, Voors AA, Gansevoort RT, Bakker SJ, et al. Incidence and epidemiology of new onset heart failure with preserved vs. reduced ejection fraction in a community-based cohort: 11-year follow-up of PREVEND. European heart journal. 2013;34(19):1424-31. Epub 2013/03/09.

30. Nagueh SF, Appleton CP, Gillebert TC, Marino PN, Oh JK, Smiseth OA, et al. Recommendations for the evaluation of left ventricular diastolic function by echocardiography. European journal of echocardiography : the journal of the Working Group on Echocardiography of the European Society of Cardiology. 2009;10(2):165-93. Epub 2009/03/10.

31. Ammar KA, Jacobsen SJ, Mahoney DW, Kors JA, Redfield MM, Burnett JC, Jr., et al. Prevalence and prognostic significance of heart failure stages: application of the American College of Cardiology/American Heart Association heart failure staging criteria in the community. Circulation. 2007;115(12):1563-70. Epub 2007/03/14.

32. Phillips MI, Schmidt-Ott KM. The Discovery of Renin 100 Years Ago. News in physiological sciences : an international journal of physiology produced jointly by the International Union of Physiological Sciences and the American Physiological Society. 1999;14:271-4. Epub 2001/06/08.

33. Cohn JN, Levine TB, Francis GS, Goldsmith S. Neurohumoral control mechanisms in congestive heart failure. American heart journal. 1981;102(3 Pt 2):509-14. Epub 1981/09/01.

34. Unger $\mathrm{T}$, Li J. The role of the renin-angiotensin-aldosterone system in heart failure. Journal of the renin-angiotensin-aldosterone system : JRAAS. 2004;5 Suppl 1:S7-10. Epub 2004/11/05. 
35. von Lueder TG, Sangaralingham SJ, Wang BH, Kompa AR, Atar D, Burnett JC, Jr., et al. Reninangiotensin blockade combined with natriuretic peptide system augmentation: novel therapeutic concepts to combat heart failure. Circulation Heart failure. 2013;6(3):594-605. Epub 2013/05/23.

36. Weber KT, Brilla CG. Pathological hypertrophy and cardiac interstitium. Fibrosis and reninangiotensin-aldosterone system. Circulation. 1991;83(6):1849-65. Epub 1991/06/01.

37. Effects of enalapril on mortality in severe congestive heart failure. Results of the Cooperative North Scandinavian Enalapril Survival Study (CONSENSUS). The New England journal of medicine. 1987;316(23):1429-35. Epub 1987/06/04.

38. Yusuf S, Pitt B, Davis CE, Hood WB, Cohn JN. Effect of enalapril on survival in patients with reduced left ventricular ejection fractions and congestive heart failure. The New England journal of medicine. 1991;325(5):293-302. Epub 1991/08/01.

39. Cohn JN, Tognoni G. A randomized trial of the angiotensin-receptor blocker valsartan in chronic heart failure. The New England journal of medicine. 2001;345(23):1667-75. Epub 2002/01/05.

40. McMurray JJ, Ostergren J, Swedberg K, Granger CB, Held P, Michelson EL, et al. Effects of candesartan in patients with chronic heart failure and reduced left-ventricular systolic function taking angiotensin-converting-enzyme inhibitors: the CHARM-Added trial. Lancet. 2003;362(9386):767-71. Epub 2003/09/19.

41. Pitt B, Zannad F, Remme WJ, Cody R, Castaigne A, Perez A, et al. The effect of spironolactone on morbidity and mortality in patients with severe heart failure. Randomized Aldactone Evaluation Study Investigators. The New England journal of medicine. 1999;341(10):709-17. Epub 1999/09/02.

42. Pitt B, Remme W, Zannad F, Neaton J, Martinez F, Roniker B, et al. Eplerenone, a selective aldosterone blocker, in patients with left ventricular dysfunction after myocardial infarction. The New England journal of medicine. 2003;348(14):1309-21. Epub 2003/04/02.

43. McMurray JJ, Packer M, Desai AS, Gong J, Lefkowitz MP, Rizkala AR, et al. Angiotensinneprilysin inhibition versus enalapril in heart failure. The New England journal of medicine. 2014;371(11):993-1004. Epub 2014/09/02.

44. Swedberg K, Hjalmarson A, Waagstein F, Wallentin I. Prolongation of survival in congestive cardiomyopathy by beta-receptor blockade. Lancet. 1979;1(8131):1374-6. Epub 1979/06/30.

45. Packer M, Bristow MR, Cohn JN, Colucci WS, Fowler MB, Gilbert EM, et al. The effect of carvedilol on morbidity and mortality in patients with chronic heart failure. U.S. Carvedilol Heart Failure Study Group. The New England journal of medicine. 1996;334(21):1349-55. Epub 1996/05/23.

46. The Cardiac Insufficiency Bisoprolol Study II (CIBIS-II): a randomised trial. Lancet. 1999;353(9146):9-13. Epub 1999/02/19.

47. Effect of metoprolol $\mathrm{CR} / \mathrm{XL}$ in chronic heart failure: Metoprolol $\mathrm{CR} / \mathrm{XL}$ Randomised Intervention Trial in Congestive Heart Failure (MERIT-HF). Lancet. 1999;353(9169):2001-7. Epub 1999/06/22.

48. Poole-Wilson PA, Swedberg K, Cleland JG, Di Lenarda A, Hanrath P, Komajda M, et al. Comparison of carvedilol and metoprolol on clinical outcomes in patients with chronic heart failure in the Carvedilol Or Metoprolol European Trial (COMET): randomised controlled trial. Lancet. 2003;362(9377):7-13. Epub 2003/07/11.

49. Kannel WB, Kannel C, Paffenbarger RS, Jr., Cupples LA. Heart rate and cardiovascular mortality: the Framingham Study. American heart journal. 1987;113(6):1489-94. Epub 1987/06/01.

50. Bohm M, Swedberg K, Komajda M, Borer JS, Ford I, Dubost-Brama A, et al. Heart rate as a risk factor in chronic heart failure (SHIFT): the association between heart rate and outcomes in a randomised placebo-controlled trial. Lancet. 2010;376(9744):886-94. Epub 2010/08/31. 
51. Aleong RG, Mulvahill MJ, Halder I, Carlson NE, Singh M, Bloom HL, et al. Left Ventricular Dilatation Increases the Risk of Ventricular Arrhythmias in Patients With Reduced Systolic Function. Journal of the American Heart Association. 2015;4(8):e001566. Epub 2015/08/02.

52. Moss AJ, Hall WJ, Cannom DS, Daubert JP, Higgins SL, Klein H, et al. Improved survival with an implanted defibrillator in patients with coronary disease at high risk for ventricular arrhythmia. Multicenter Automatic Defibrillator Implantation Trial Investigators. The New England journal of medicine. 1996;335(26):1933-40. Epub 1996/12/26.

53. Moss AJ, Zareba W, Hall WJ, Klein H, Wilber DJ, Cannom DS, et al. Prophylactic implantation of a defibrillator in patients with myocardial infarction and reduced ejection fraction. The New England journal of medicine. 2002;346(12):877-83. Epub 2002/03/22.

54. Yusuf S, Pfeffer MA, Swedberg K, Granger CB, Held P, McMurray JJ, et al. Effects of candesartan in patients with chronic heart failure and preserved left-ventricular ejection fraction: the CHARM-Preserved Trial. Lancet. 2003;362(9386):777-81. Epub 2003/09/19.

55. Cleland JG, Tendera M, Adamus J, Freemantle N, Polonski L, Taylor J. The perindopril in elderly people with chronic heart failure (PEP-CHF) study. European heart journal. 2006;27(19):233845. Epub 2006/09/12.

56. Massie BM, Carson PE, McMurray JJ, Komajda M, McKelvie R, Zile MR, et al. Irbesartan in patients with heart failure and preserved ejection fraction. The New England journal of medicine. 2008;359(23):2456-67. Epub 2008/11/13.

57. Hernandez AF, Hammill BG, O'Connor CM, Schulman KA, Curtis LH, Fonarow GC. Clinical effectiveness of beta-blockers in heart failure: findings from the OPTIMIZE-HF (Organized Program to Initiate Lifesaving Treatment in Hospitalized Patients with Heart Failure) Registry. Journal of the American College of Cardiology. 2009;53(2):184-92. Epub 2009/01/10.

58. Khatibzadeh S, Farzadfar F, Oliver J, Ezzati M, Moran A. Worldwide risk factors for heart failure: a systematic review and pooled analysis. Int J Cardiol. 2013;168(2):1186-94.

59. Yang H, Negishi K, Otahal P, Marwick TH. Clinical prediction of incident heart failure risk: a systematic review and meta-analysis. Open Heart. 2015;2(1):e000222.

60. Campbell DJ, Coller JM, Gong FF, McGrady M, Prior DL, Boffa U, et al. Risk factor management in a contemporary Australian population at increased cardiovascular disease risk. Intern Med J. 2018;48(6):688-98.

61. Gong FF, Jelinek MV, Castro JM, Coller JM, McGrady M, Boffa U, et al. Risk factors for incident heart failure with preserved or reduced ejection fraction, and valvular heart failure, in a community-based cohort. Open Heart. 2018;5(2):e000782.

62. Sullivan PW, Morrato EH, Ghushchyan V, Wyatt HR, Hill JO. Obesity, inactivity, and the prevalence of diabetes and diabetes-related cardiovascular comorbidities in the U.S., 20002002. Diabetes Care. 2005;28(7):1599-603.

63. Chawla A, Chawla R, Jaggi S. Microvasular and macrovascular complications in diabetes mellitus: Distinct or continuum? Indian J Endocrinol Metab. 2016;20(4):546-51.

64. Laakso M. Heart in diabetes: a microvascular disease. Diabetes Care. 2011;34 Suppl 2:S145-9.

65. Haffner SM, Lehto S, Ronnemaa T, Pyorala K, Laakso M. Mortality from coronary heart disease in subjects with type 2 diabetes and in nondiabetic subjects with and without prior myocardial infarction. N Engl J Med. 1998;339(4):229-34.

66. (IDF) IDF. IDF Diabetes Atlas - 8th edition2017.

67. WHO. Global report on diabetes. 1 ed: World Health Organization; May 2016. 86 p.

68. Collaboration NCDRF. Worldwide trends in diabetes since 1980: a pooled analysis of 751 population-based studies with 4.4 million participants. Lancet. 2016;387(10027):1513-30.

69. Seuring T, Archangelidi O, Suhrcke M. The Economic Costs of Type 2 Diabetes: A Global Systematic Review. Pharmacoeconomics. 2015;33(8):811-31.

70. Bloom D.E. CET, Jané-Llopis E., Abrahams-Gessel S., Bloom L.R., Fathima S., Feigl A.B., Gaziano T., Mowafi M., Pandya A., Prettner K., Rosenberg L., Seligman B., Stein A.Z., \& Weinstein C. The 
Global Economic Burden of Noncommunicable Diseases. Geneva: World Economic Forum. 2011.

71. Laios K, Karamanou M, Saridaki Z, Androutsos G. Aretaeus of Cappadocia and the first description of diabetes. Hormones (Athens). 2012;11(1):109-13.

72. Atkinson MA, Eisenbarth GS, Michels AW. Type 1 diabetes. Lancet. 2014;383(9911):69-82.

73. Kahn SE, Cooper ME, Del Prato S. Pathophysiology and treatment of type 2 diabetes: perspectives on the past, present, and future. Lancet. 2014;383(9922):1068-83.

74. Brophy S, Yderstraede K, Mauricio D, Hunter S, Hawa M, Pozzilli P, et al. Time to insulin initiation cannot be used in defining latent autoimmune diabetes in adults. Diabetes Care. 2008;31(3):439-41.

75. Morris AP, Voight BF, Teslovich TM, Ferreira T, Segre AV, Steinthorsdottir V, et al. Large-scale association analysis provides insights into the genetic architecture and pathophysiology of type 2 diabetes. Nat Genet. 2012;44(9):981-90.

76. Tuomi T, Santoro N, Caprio S, Cai M, Weng J, Groop L. The many faces of diabetes: a disease with increasing heterogeneity. Lancet. 2014;383(9922):1084-94.

77. Cervin C, Lyssenko V, Bakhtadze E, Lindholm E, Nilsson P, Tuomi T, et al. Genetic similarities between latent autoimmune diabetes in adults, type 1 diabetes, and type 2 diabetes. Diabetes. 2008;57(5):1433-7.

78. Hawa MI, Thivolet C, Mauricio D, Alemanno I, Cipponeri E, Collier D, et al. Metabolic syndrome and autoimmune diabetes: action LADA 3. Diabetes Care. 2009;32(1):160-4.

79. Turner R, Stratton I, Horton V, Manley S, Zimmet P, Mackay IR, et al. UKPDS 25: autoantibodies to islet-cell cytoplasm and glutamic acid decarboxylase for prediction of insulin requirement in type 2 diabetes. UK Prospective Diabetes Study Group. Lancet. 1997;350(9087):1288-93.

80. Hawa MI, Kolb H, Schloot N, Beyan H, Paschou SA, Buzzetti R, et al. Adult-onset autoimmune diabetes in Europe is prevalent with a broad clinical phenotype: Action LADA 7. Diabetes Care. 2013;36(4):908-13.

81. Pearson ER, Starkey BJ, Powell RJ, Gribble FM, Clark PM, Hattersley AT. Genetic cause of hyperglycaemia and response to treatment in diabetes. Lancet. 2003;362(9392):1275-81.

82. Metzger BE, Buchanan TA, Coustan DR, de Leiva A, Dunger DB, Hadden DR, et al. Summary and recommendations of the Fifth International Workshop-Conference on Gestational Diabetes Mellitus. Diabetes Care. 2007;30 Suppl 2:S251-60.

83. Lauenborg J, Hansen T, Jensen DM, Vestergaard H, Molsted-Pedersen L, Hornnes $P$, et al. Increasing incidence of diabetes after gestational diabetes: a long-term follow-up in a Danish population. Diabetes Care. 2004;27(5):1194-9.

84. Bian X, Gao P, Xiong X, Xu H, Qian M, Liu S. Risk factors for development of diabetes mellitus in women with a history of gestational diabetes mellitus. Chin Med J (Engl). 2000;113(8):75962.

85. Yogev $\mathrm{Y}$, Xenakis $\mathrm{EM}$, Langer $\mathrm{O}$. The association between preeclampsia and the severity of gestational diabetes: the impact of glycemic control. Am J Obstet Gynecol. 2004;191(5):165560 .

86. Ehrenberg HM, Mercer BM, Catalano PM. The influence of obesity and diabetes on the prevalence of macrosomia. Am J Obstet Gynecol. 2004;191(3):964-8.

87. Mitanchez D. Foetal and neonatal complications in gestational diabetes: perinatal mortality, congenital malformations, macrosomia, shoulder dystocia, birth injuries, neonatal complications. Diabetes Metab. 2010;36(6 Pt 2):617-27.

88. Hay WW, Jr. Care of the infant of the diabetic mother. Curr Diab Rep. 2012;12(1):4-15.

89. Boney CM, Verma A, Tucker R, Vohr BR. Metabolic syndrome in childhood: association with birth weight, maternal obesity, and gestational diabetes mellitus. Pediatrics. 2005;115(3):e290-6. 
90. Rizzo T, Metzger BE, Burns WJ, Burns K. Correlations between antepartum maternal metabolism and intelligence of offspring. N Engl J Med. 1991;325(13):911-6.

91. Huang C, Florez JC. Pharmacogenetics in type 2 diabetes: potential implications for clinical practice. Genome Med. 2011;3(11):76.

92. Harris GW. Electrical stimulation of the hypothalamus and the mechanism of neural control of the adenohypophysis. The Journal of physiology. 1948;107(4):418-29. Epub 1948/09/30.

93. Saffran M, Schally AV. The release of corticotrophin by anterior pituitary tissue in vitro. Canadian journal of biochemistry and physiology. 1955;33(3):408-15. Epub 1955/05/01.

94. Guillemin R, Rosenberg B. Humoral hypothalamic control of anterior pituitary: a study with combined tissue cultures. Endocrinology. 1955;57(5):599-607. Epub 1955/11/01.

95. Vale W, Spiess J, Rivier C, Rivier J. Characterization of a 41-residue ovine hypothalamic peptide that stimulates secretion of corticotropin and beta-endorphin. Science. 1981;213(4514):13947. Epub 1981/09/18.

96. Vaughan J, Donaldson C, Bittencourt J, Perrin MH, Lewis K, Sutton S, et al. Urocortin, a mammalian neuropeptide related to fish urotensin I and to corticotropin-releasing factor. Nature. 1995;378(6554):287-92. Epub 1995/11/16.

97. Reyes TM, Lewis K, Perrin MH, Kunitake KS, Vaughan J, Arias CA, et al. Urocortin II: a member of the corticotropin-releasing factor (CRF) neuropeptide family that is selectively bound by type 2 CRF receptors. Proceedings of the National Academy of Sciences of the United States of America. 2001;98(5):2843-8. Epub 2001/02/28.

98. Lewis K, Li C, Perrin MH, Blount A, Kunitake K, Donaldson C, et al. Identification of urocortin III, an additional member of the corticotropin-releasing factor (CRF) family with high affinity for the CRF2 receptor. Proceedings of the National Academy of Sciences of the United States of America. 2001;98(13):7570-5. Epub 2001/06/21.

99. Hsu SY, Hsueh AJ. Human stresscopin and stresscopin-related peptide are selective ligands for the type 2 corticotropin-releasing hormone receptor. Nature medicine. 2001;7(5):605-11. Epub 2001/05/01.

100. Lovejoy DA, de Lannoy L. Evolution and phylogeny of the corticotropin-releasing factor (CRF) family of peptides: expansion and specialization in the vertebrates. Journal of chemical neuroanatomy. 2013;54:50-6. Epub 2013/10/01.

101. Fekete EM, Zorrilla EP. Physiology, pharmacology, and therapeutic relevance of urocortins in mammals: ancient CRF paralogs. Frontiers in neuroendocrinology. 2007;28(1):1-27. Epub 2006/11/07.

102. Adao R, Santos-Ribeiro D, Rademaker MT, Leite-Moreira AF, Bras-Silva C. Urocortin 2 in cardiovascular health and disease. Drug discovery today. 2015;20(7):906-14. Epub 2015/03/10.

103. Grace CR, Perrin MH, Cantle JP, Vale WW, Rivier JE, Riek R. Common and divergent structural features of a series of corticotropin releasing factor-related peptides. Journal of the American Chemical Society. 2007;129(51):16102-14. Epub 2007/12/07.

104. Skelton $\mathrm{KH}$, Owens MJ, Nemeroff CB. The neurobiology of urocortin. Regulatory peptides. 2000;93(1-3):85-92. Epub 2000/10/18.

105. Smagin GN, Heinrichs SC, Dunn AJ. The role of CRH in behavioral responses to stress. Peptides. 2001;22(5):713-24. Epub 2001/05/05.

106. Hillhouse EW, Grammatopoulos DK. The molecular mechanisms underlying the regulation of the biological activity of corticotropin-releasing hormone receptors: implications for physiology and pathophysiology. Endocrine reviews. 2006;27(3):260-86. Epub 2006/02/18.

107. Takahashi K. Distribution of urocortins and corticotropin-releasing factor receptors in the cardiovascular system. International journal of endocrinology. 2012;2012:395284. Epub 2012/06/08. 
108. Chen P, Hover CV, Lindberg D, Li C. Central urocortin 3 and type 2 corticotropin-releasing factor receptor in the regulation of energy homeostasis: critical involvement of the ventromedial hypothalamus. Frontiers in endocrinology. 2012;3:180. Epub 2013/01/15.

109. Li C, Vaughan J, Sawchenko PE, Vale WW. Urocortin III-immunoreactive projections in rat brain: partial overlap with sites of type 2 corticotrophin-releasing factor receptor expression. The Journal of neuroscience : the official journal of the Society for Neuroscience. 2002;22(3):991-1001. Epub 2002/02/05.

110. Cavalcante JC, Sita LV, Mascaro MB, Bittencourt JC, Elias CF. Distribution of urocortin 3 neurons innervating the ventral premammillary nucleus in the rat brain. Brain research. 2006;1089(1):116-25. Epub 2006/04/28.

111. Takahashi K, Totsune K, Murakami O, Saruta M, Nakabayashi M, Suzuki T, et al. Expression of urocortin III/stresscopin in human heart and kidney. The Journal of clinical endocrinology and metabolism. 2004;89(4):1897-903. Epub 2004/04/09.

112. Onorati F, Chen-Scarabelli C, Knight R, Stephanou A, Mohanti B, Santini F, et al. Targeting urocortin signaling pathways to enhance cardioprotection: is it time to move from bench to bedside? Cardiovascular drugs and therapy. 2013;27(5):451-63. Epub 2013/07/05.

113. Li C, Chen P, Vaughan J, Lee KF, Vale W. Urocortin 3 regulates glucose-stimulated insulin secretion and energy homeostasis. Proceedings of the National Academy of Sciences of the United States of America. 2007;104(10):4206-11. Epub 2007/03/16.

114. Kimura Y, Takahashi K, Totsune K, Muramatsu Y, Kaneko C, Darnel AD, et al. Expression of urocortin and corticotropin-releasing factor receptor subtypes in the human heart. The Journal of clinical endocrinology and metabolism. 2002;87(1):340-6. Epub 2002/01/15.

115. Wiley KE, Davenport AP. CRF2 receptors are highly expressed in the human cardiovascular system and their cognate ligands urocortins 2 and 3 are potent vasodilators. British journal of pharmacology. 2004;143(4):508-14. Epub 2004/09/24.

116. Nishikimi T, Miyata A, Horio T, Yoshihara F, Nagaya N, Takishita S, et al. Urocortin, a member of the corticotropin-releasing factor family, in normal and diseased heart. American journal of physiology Heart and circulatory physiology. 2000;279(6):H3031-9. Epub 2000/11/22.

117. Seres J, Bornstein SR, Seres P, Willenberg HS, Schulte KM, Scherbaum WA, et al. Corticotropinreleasing hormone system in human adipose tissue. The Journal of clinical endocrinology and metabolism. 2004;89(2):965-70. Epub 2004/02/07.

118. Davidson SM, Rybka AE, Townsend PA. The powerful cardioprotective effects of urocortin and the corticotropin releasing hormone (CRH) family. Biochemical pharmacology. 2009;77(2):141-50. Epub 2008/09/27.

119. Huang Y, Chan FL, Lau CW, Tsang SY, He GW, Chen ZY, et al. Urocortin-induced endotheliumdependent relaxation of rat coronary artery: role of nitric oxide and $\mathrm{K}+$ channels. British journal of pharmacology. 2002;135(6):1467-76. Epub 2002/03/22.

120. Ng LL, Loke IW, O'Brien RJ, Squire IB, Davies JE. Plasma urocortin in human systolic heart failure. Clin Sci (Lond). 2004;106(4):383-8. Epub 2003/12/04.

121. Watanabe F, Oki Y, Ozawa M, Masuzawa M, Iwabuchi M, Yoshimi T, et al. Urocortin in human placenta and maternal plasma. Peptides. 1999;20(2):205-9. Epub 1999/07/28.

122. Davis ME, Pemberton CJ, Yandle TG, Lainchbury JG, Rademaker MT, Nicholls MG, et al. Urocortin-1 infusion in normal humans. The Journal of clinical endocrinology and metabolism. 2004;89(3):1402-9. Epub 2004/03/06.

123. Wright SP, Doughty RN, Frampton CM, Gamble GD, Yandle TG, Richards AM. Plasma urocortin 1 in human heart failure. Circulation Heart failure. 2009;2(5):465-71. Epub 2009/10/08.

124. Florio $\mathrm{P}$, Reis FM, Torres PB, Calonaci F, Toti $\mathrm{P}$, Bocchi C, et al. Plasma urocortin levels in the diagnosis of ovarian endometriosis. Obstetrics and gynecology. 2007;110(3):594-600. Epub 2007/09/04. 
125. Celik O, Celik E, Yilmaz E, Celik N, Turkcuoglu I, Ulas M, et al. Effect of ovarian stimulation with recombinant follicle-stimulating hormone, gonadotropin-releasing hormone agonist and antagonists, on follicular fluid stem cell factor and serum urocortin 1 levels on the day of oocyte retrieval. Archives of gynecology and obstetrics. 2013;288(6):1417-22. Epub 2013/06/27.

126. Davis ME, Pemberton CJ, Yandle TG, Fisher SF, Lainchbury JG, Frampton CM, et al. Urocortin 2 infusion in healthy humans: hemodynamic, neurohormonal, and renal responses. Journal of the American College of Cardiology. 2007;49(4):461-71. Epub 2007/01/30.

127. Topal E, Yagmur J, Otlu B, Atas H, Cansel M, Acikgoz N, et al. Relationship of urocortin-2 with systolic and diastolic functions and coronary artery disease: an observational study. Anadolu kardiyoloji dergisi : AKD = the Anatolian journal of cardiology. 2012;12(2):115-20. Epub 2012/01/28.

128. Temur M, Yilmaz O, Aksun S, Ozun Ozbay P, Calan M, Kume T, et al. Increased circulating urocortin-3 levels is associated with polycystic ovary syndrome. Gynecological endocrinology : the official journal of the International Society of Gynecological Endocrinology. 2016;32(3):218-22. Epub 2015/10/22.

129. Pepels PP, Spaanderman ME, Hermus AR, Lotgering FK, Sweep CG. Placental urocortin-2 and 3: endocrine or paracrine functioning during healthy pregnancy? Placenta. 2010;31(6):475-81. Epub 2010/05/11.

130. Pisarchik A, Slominski A. Molecular and functional characterization of novel CRFR1 isoforms from the skin. European journal of biochemistry. 2004;271(13):2821-30. Epub 2004/06/23.

131. Kostich WA, Chen A, Sperle K, Largent BL. Molecular identification and analysis of a novel human corticotropin-releasing factor (CRF) receptor: the CRF2gamma receptor. Mol Endocrinol. 1998;12(8):1077-85. Epub 1998/08/26.

132. Van Pett K, Viau V, Bittencourt JC, Chan RK, Li HY, Arias C, et al. Distribution of mRNAs encoding $\mathrm{CRF}$ receptors in brain and pituitary of rat and mouse. The Journal of comparative neurology. 2000;428(2):191-212. Epub 2000/11/07.

133. Karteris E, Randeva HS, Grammatopoulos DK, Jaffe RB, Hillhouse EW. Expression and coupling characteristics of the $\mathrm{CRH}$ and orexin type 2 receptors in human fetal adrenals. The Journal of clinical endocrinology and metabolism. 2001;86(9):4512-9. Epub 2001/09/11.

134. Pisarchik A, Slominski AT. Alternative splicing of CRH-R1 receptors in human and mouse skin: identification of new variants and their differential expression. FASEB journal : official publication of the Federation of American Societies for Experimental Biology. 2001;15(14):2754-6. Epub 2001/10/19.

135. Radulovic M, Dautzenberg FM, Sydow S, Radulovic J, Spiess J. Corticotropin-releasing factor receptor 1 in mouse spleen: expression after immune stimulation and identification of receptor-bearing cells. J Immunol. 1999;162(5):3013-21. Epub 1999/03/11.

136. Heinrich N, Meyer MR, Furkert J, Sasse A, Beyermann M, Bonigk W, et al. Corticotropinreleasing factor (CRF) agonists stimulate testosterone production in mouse leydig cells through CRF receptor-1. Endocrinology. 1998;139(2):651-8. Epub 1998/02/04.

137. Asakura H, Zwain IH, Yen SS. Expression of genes encoding corticotropin-releasing factor (CRF), type 1 CRF receptor, and CRF-binding protein and localization of the gene products in the human ovary. The Journal of clinical endocrinology and metabolism. 1997;82(8):2720-5. Epub 1997/08/01.

138. Di Blasio AM, Pecori Giraldi F, Vigano P, Petraglia F, Vignali M, Cavagnini F. Expression of corticotropin-releasing hormone and its $\mathrm{R} 1$ receptor in human endometrial stromal cells. The Journal of clinical endocrinology and metabolism. 1997;82(5):1594-7. Epub 1997/05/01.

139. Grammatopoulos D, Dai Y, Chen J, Karteris E, Papadopoulou N, Easton AJ, et al. Human corticotropin-releasing hormone receptor: differences in subtype expression between 
pregnant and nonpregnant myometria. The Journal of clinical endocrinology and metabolism. 1998;83(7):2539-44. Epub 1998/07/14.

140. Karteris E, Grammatopoulos D, Dai Y, Olah KB, Ghobara TB, Easton A, et al. The human placenta and fetal membranes express the corticotropin-releasing hormone receptor 1alpha (CRH1alpha) and the $\mathrm{CRH}-\mathrm{C}$ variant receptor. The Journal of clinical endocrinology and metabolism. 1998;83(4):1376-9. Epub 1998/04/29.

141. Agelaki S, Tsatsanis C, Gravanis A, Margioris AN. Corticotropin-releasing hormone augments proinflammatory cytokine production from macrophages in vitro and in lipopolysaccharideinduced endotoxin shock in mice. Infection and immunity. 2002;70(11):6068-74. Epub 2002/10/16.

142. Kageyama K, Gaudriault GE, Suda T, Vale WW. Regulation of corticotropin-releasing factor receptor type 2beta mRNA via cyclic AMP pathway in A7r5 aortic smooth muscle cells. Cellular signalling. 2003;15(1):17-25. Epub 2002/10/29.

143. Perrin M, Donaldson C, Chen R, Blount A, Berggren T, Bilezikjian L, et al. Identification of a second corticotropin-releasing factor receptor gene and characterization of a cDNA expressed in heart. Proceedings of the National Academy of Sciences of the United States of America. 1995;92(7):2969-73. Epub 1995/03/28.

144. Simoncini T, Apa R, Reis FM, Miceli F, Stomati M, Driul L, et al. Human umbilical vein endothelial cells: a new source and potential target for corticotropin-releasing factor. The Journal of clinical endocrinology and metabolism. 1999;84(8):2802-6. Epub 1999/08/12.

145. Miki I, Seya K, Motomura S, Furukawa K. Role of corticotropin-releasing factor receptor type 2 beta in urocortin-induced vasodilation of rat aortas. Journal of pharmacological sciences. 2004;96(2):170-6. Epub 2004/10/07.

146. Smith GW, Aubry JM, Dellu F, Contarino A, Bilezikjian LM, Gold LH, et al. Corticotropin releasing factor receptor 1-deficient mice display decreased anxiety, impaired stress response, and aberrant neuroendocrine development. Neuron. 1998;20(6):1093-102. Epub 1998/07/09.

147. Timpl P, Spanagel R, Sillaber I, Kresse A, Reul JM, Stalla GK, et al. Impaired stress response and reduced anxiety in mice lacking a functional corticotropin-releasing hormone receptor 1. Nature genetics. 1998;19(2):162-6. Epub 1998/06/10.

148. Bale TL, Contarino A, Smith GW, Chan R, Gold LH, Sawchenko PE, et al. Mice deficient for corticotropin-releasing hormone receptor-2 display anxiety-like behaviour and are hypersensitive to stress. Nature genetics. 2000;24(4):410-4. Epub 2000/03/31.

149. Kishimoto T, Radulovic J, Radulovic M, Lin CR, Schrick C, Hooshmand F, et al. Deletion of crhr2 reveals an anxiolytic role for corticotropin-releasing hormone receptor-2. Nature genetics. 2000;24(4):415-9. Epub 2000/03/31.

150. Coste SC, Kesterson RA, Heldwein KA, Stevens SL, Heard AD, Hollis JH, et al. Abnormal adaptations to stress and impaired cardiovascular function in mice lacking corticotropinreleasing hormone receptor-2. Nature genetics. 2000;24(4):403-9. Epub 2000/03/31.

151. Catalano RD, Kyriakou T, Chen J, Easton A, Hillhouse EW. Regulation of corticotropin-releasing hormone type 2 receptors by multiple promoters and alternative splicing: identification of multiple splice variants. Mol Endocrinol. 2003;17(3):395-410. Epub 2003/01/30.

152. Hashimoto K, Nishiyama M, Tanaka Y, Noguchi T, Asaba K, Hossein PN, et al. Urocortins and corticotropin releasing factor type 2 receptors in the hypothalamus and the cardiovascular system. Peptides. 2004;25(10):1711-21. Epub 2004/10/13.

153. Kuizon E, Pearce EG, Bailey SG, Chen-Scarabelli C, Yuan Z, Abounit K, et al. Mechanisms of action and clinical implications of cardiac urocortin: a journey from the heart to the systemic circulation, with a stopover in the mitochondria. International journal of cardiology. 2009;137(3):189-94. Epub 2009/05/02. 
154. Chen CY, Doong ML, Rivier JE, Tache Y. Intravenous urocortin II decreases blood pressure through CRF(2) receptor in rats. Regulatory peptides. 2003;113(1-3):125-30. Epub 2003/04/11.

155. Dieterle T, Meili-Butz S, Buhler K, Morandi C, John D, Buser PT, et al. Immediate and sustained blood pressure lowering by urocortin 2: a novel approach to antihypertensive therapy? Hypertension. 2009;53(4):739-44. Epub 2009/02/11.

156. Meili-Butz S, Buhler K, John D, Buser P, Vale WW, Peterson KL, et al. Acute effects of urocortin 2 on cardiac function and propensity for arrhythmias in an animal model of hypertensioninduced left ventricular hypertrophy and heart failure. European journal of heart failure. 2010;12(8):797-804. Epub 2010/04/15.

157. Rademaker MT, Charles CJ, Espiner EA, Frampton CM, Lainchbury JG, Richards AM. Endogenous urocortins reduce vascular tone and renin-aldosterone/endothelin activity in experimental heart failure. European heart journal. 2005;26(19):2046-54. Epub 2005/04/12.

158. Kageyama K, Furukawa K, Miki I, Terui K, Motomura S, Suda T. Vasodilative effects of urocortin II via protein kinase $A$ and a mitogen-activated protein kinase in rat thoracic aorta. Journal of cardiovascular pharmacology. 2003;42(4):561-5. Epub 2003/09/26.

159. Chan YC, Yao XQ, Lau CW, Chan FL, He GW, Bourreau JP, et al. The relaxant effect of urocortin in rat pulmonary arteries. Regulatory peptides. 2004;121(1-3):11-8. Epub 2004/07/17.

160. Lau CW, Chan YC, Yao X, Chan FL, Chen ZY, Huang Y. Nickel inhibits urocortin-induced relaxation in the rat pulmonary artery. European journal of pharmacology. 2004;488(1-3):16972. Epub 2004/03/27.

161. Smani T, Dominguez-Rodriguez A, Hmadcha A, Calderon-Sanchez E, Horrillo-Ledesma A, Ordonez A. Role of $\mathrm{Ca}^{2+}$-independent phospholipase $\mathrm{A} 2$ and store-operated pathway in urocortin-induced vasodilatation of rat coronary artery. Circulation research. 2007;101(11):1194-203. Epub 2007/09/22.

162. Diaz I, Smani T. New insights into the mechanisms underlying vascular and cardiac effects of urocortin. Current vascular pharmacology. 2013;11(4):457-64. Epub 2013/08/03.

163. Rademaker MT, Charles CJ, Nicholls MG, Richards AM. Urocortin 2 combined with angiotensinconverting enzyme inhibition in experimental heart failure. Clin Sci (Lond). 2008;114(10):63542. Epub 2007/12/07.

164. Rademaker MT, Charles CJ, Espiner EA, Fisher S, Frampton CM, Kirkpatrick CM, et al. Beneficial hemodynamic, endocrine, and renal effects of urocortin in experimental heart failure: comparison with normal sheep. Journal of the American College of Cardiology. 2002;40(8):1495-505. Epub 2002/10/24.

165. Rademaker MT, Cameron VA, Charles CJ, Richards AM. Integrated hemodynamic, hormonal, and renal actions of urocortin 2 in normal and paced sheep: beneficial effects in heart failure. Circulation. 2005;112(23):3624-32. Epub 2005/12/07.

166. Rademaker MT, Cameron VA, Charles CJ, Richards AM. Urocortin 3: haemodynamic, hormonal, and renal effects in experimental heart failure. European heart journal. 2006;27(17):2088-98. Epub 2006/07/11.

167. Yang C, Liu X, Li S. Effect of long-term treatment with urocortin on the activity of somatic angiotensin-converting enzyme in spontaneously hypertensive rats. Canadian journal of physiology and pharmacology. 2010;88(2):168-76. Epub 2010/03/20.

168. Grossini E, Molinari C, Mary DA, Marino P, Vacca G. The effect of urocortin II administration on the coronary circulation and cardiac function in the anaesthetized pig is nitric-oxidedependent. European journal of pharmacology. 2008;578(2-3):242-8. Epub 2007/10/16.

169. Terui K, Higashiyama A, Horiba N, Furukawa KI, Motomura S, Suda T. Coronary vasodilation and positive inotropism by urocortin in the isolated rat heart. The Journal of endocrinology. 2001;169(1):177-83. Epub 2001/03/16. 
170. Chen ZW, Huang Y, Yang Q, Li X, Wei W, He GW. Urocortin-induced relaxation in the human internal mammary artery. Cardiovascular research. 2005;65(4):913-20. Epub 2005/02/22.

171. Sanz E, Fernandez N, Monge L, Climent B, Dieguez G, Garcia-Villalon AL. Relaxation by urocortin of rat renal arteries: effects of diabetes in males and females. Cardiovascular research. 2003;58(3):706-11. Epub 2003/06/12.

172. Sanz E, Monge L, Fernandez N, Climent B, Dieguez G, Garcia-Villalon AL. Mechanisms of relaxation by urocortin in renal arteries from male and female rats. British journal of pharmacology. 2003;140(5):1003-7. Epub 2003/10/01.

173. Smani T, Calderon E, Rodriguez-Moyano M, Dominguez-Rodriguez A, Diaz I, Ordonez A. Urocortin-2 induces vasorelaxation of coronary arteries isolated from patients with heart failure. Clinical and experimental pharmacology \& physiology. 2011;38(1):71-6. Epub 2010/11/26.

174. Sanz E, Monge L, Fernandez N, Martinez MA, Martinez-Leon JB, Dieguez G, et al. Relaxation by urocortin of human saphenous veins. British journal of pharmacology. 2002;136(1):90-4. Epub 2002/04/27.

175. Bale TL, Giordano FJ, Hickey RP, Huang Y, Nath AK, Peterson KL, et al. Corticotropin-releasing factor receptor 2 is a tonic suppressor of vascularization. Proceedings of the National Academy of Sciences of the United States of America. 2002;99(11):7734-9. Epub 2002/05/29.

176. Borges LE, Bloise E, Dela Cruz C, Massai L, Ciarmela P, Apa R, et al. Expression, localization and control of activin A release from human umbilical vein endothelial cells. Growth Factors. 2015;33(4):243-9. Epub 2015/09/05.

177. Wan R, Liu Y, Li L, Zhu C, Jin L, Li S. Urocortin increased endothelial ICAM1 by cPLA2-dependent NF-kappaB and PKA pathways in HUVECs. Journal of molecular endocrinology. 2014;52(1):4353. Epub 2013/12/24.

178. Honjo T, Inoue N, Shiraki R, Kobayashi S, Otsui K, Takahashi M, et al. Endothelial urocortin has potent antioxidative properties and is upregulated by inflammatory cytokines and pitavastatin. Journal of vascular research. 2006;43(2):131-8. Epub 2005/12/13.

179. Tsatsanis C, Androulidaki A, Dermitzaki E, Gravanis A, Margioris AN. Corticotropin releasing factor receptor 1 (CRF1) and CRF2 agonists exert an anti-inflammatory effect during the early phase of inflammation suppressing LPS-induced TNF-alpha release from macrophages via induction of COX-2 and PGE2. Journal of cellular physiology. 2007;210(3):774-83. Epub 2006/11/23.

180. Tsatsanis C, Androulidaki A, Dermitzaki E, Charalampopoulos I, Spiess J, Gravanis A, et al. Urocortin 1 and Urocortin 2 induce macrophage apoptosis via CRFR2. FEBS letters. 2005;579(20):4259-64. Epub 2005/08/02.

181. Novembri R, Torricelli M, Bloise E, Conti N, Galeazzi LR, Severi FM, et al. Effects of urocortin 2 and urocortin 3 on IL-10 and TNF-alpha expression and secretion from human trophoblast explants. Placenta. 2011;32(12):969-74. Epub 2011/10/18.

182. Novembri R, De Clemente C, Funghi L, Torricelli M, Voltolini C, Challis JR, et al. Corticotropin releasing hormone and Urocortin 2 activate inflammatory pathways in cultured trophoblast cell lines. European journal of obstetrics, gynecology, and reproductive biology. 2015;195:2005. Epub 2015/11/21.

183. Cureton EL, Ereso AQ, Victorino GP, Curran B, Poole DP, Liao M, et al. Local secretion of urocortin 1 promotes microvascular permeability during lipopolysaccharide-induced inflammation. Endocrinology. 2009;150(12):5428-37. Epub 2009/10/13.

184. Makarewich CA, Troupes CD, Schumacher SM, Gross P, Koch WJ, Crandall DL, et al. Comparative effects of urocortins and stresscopin on cardiac myocyte contractility. J Mol Cell Cardiol. 2015;86:179-86. 
185. Chen S, Wang Z, Xu B, Mi X, Sun W, Quan N, et al. The Modulation of Cardiac Contractile Function by the Pharmacological and Toxicological Effects of Urocortin2. Toxicol Sci. 2015;148(2):581-93.

186. Yang LZ, Kockskamper J, Khan S, Suarez J, Walther S, Doleschal B, et al. cAMP- and Ca(2)(+) /calmodulin-dependent protein kinases mediate inotropic, lusitropic and arrhythmogenic effects of urocortin 2 in mouse ventricular myocytes. Br J Pharmacol. 2011;162(2):544-56.

187. Calderon-Sanchez E, Delgado C, Ruiz-Hurtado G, Dominguez-Rodriguez A, Cachofeiro V, Rodriguez-Moyano $\mathrm{M}$, et al. Urocortin induces positive inotropic effect in rat heart. Cardiovasc Res. 2009;83(4):717-25.

188. Walther S, Pluteanu F, Renz S, Nikonova Y, Maxwell JT, Yang LZ, et al. Urocortin 2 stimulates nitric oxide production in ventricular myocytes via Akt- and PKA-mediated phosphorylation of eNOS at serine 1177. Am J Physiol Heart Circ Physiol. 2014;307(5):H689-700.

189. Gao MH, Lai NC, Miyanohara A, Schilling JM, Suarez J, Tang T, et al. Intravenous adenoassociated virus serotype 8 encoding urocortin- 2 provides sustained augmentation of left ventricular function in mice. Human gene therapy. 2013;24(9):777-85. Epub 2013/08/13.

190. Lai NC, Gao MH, Giamouridis D, Suarez J, Miyanohara A, Parikh J, et al. Intravenous AAV8 Encoding Urocortin-2 Increases Function of the Failing Heart in Mice. Human gene therapy. 2015;26(6):347-56. Epub 2015/03/12.

191. Parkes DG, Vaughan J, Rivier J, Vale W, May CN. Cardiac inotropic actions of urocortin in conscious sheep. Am J Physiol. 1997;272(5 Pt 2):H2115-22.

192. Bale TL, Hoshijima M, Gu Y, Dalton N, Anderson KR, Lee KF, et al. The cardiovascular physiologic actions of urocortin II: acute effects in murine heart failure. Proceedings of the National Academy of Sciences of the United States of America. 2004;101(10):3697-702. Epub 2004/03/03.

193. Adao R, Mendes-Ferreira P, Santos-Ribeiro D, Maia-Rocha C, Pimentel LD, Monteiro-Pinto C, et al. Urocortin-2 improves right ventricular function and attenuates pulmonary arterial hypertension. Cardiovasc Res. 2018;114(8):1165-77.

194. Chen J, Tao J, Zhang R, Xu Y, Soong T, Li S. Urocortin inhibits mesenteric arterial remodeling in spontaneously hypertensive rats. Peptides. 2009;30(6):1117-23.

195. Liu C, Liu X, Yang J, Duan Y, Yao H, Li F, et al. The effects of vasoactive peptide urocortin 2 on hemodynamics in spontaneous hypertensive rat and the role of L-type calcium channel and CRFR2. Pharmacol Rep. 2015;67(2):394-8.

196. Tezval H, Jurk S, Atschekzei F, Becker JU, Jahn O, Serth J, et al. Urocortin and corticotropinreleasing factor receptor 2 in human renal cell carcinoma: disruption of an endogenous inhibitor of angiogenesis and proliferation. World J Urol. 2009;27(6):825-30.

197. Rademaker MT, Charles CJ, Nicholls G, Richards M. Urocortin 2 sustains haemodynamic and renal function during introduction of beta-blockade in experimental heart failure. J Hypertens. 2011;29(9):1787-95.

198. Rademaker MT, Charles CJ, Nicholls MG, Richards AM. Interactions of enhanced urocortin 2 and mineralocorticoid receptor antagonism in experimental heart failure. Circ Heart Fail. 2013;6(4):825-32.

199. Rademaker MT, Charles CJ, Nicholls MG, Richards AM. Urocortin 2 inhibits furosemide-induced activation of renin and enhances renal function and diuretic responsiveness in experimental heart failure. Circ Heart Fail. 2009;2(6):532-40.

200. Parkes DG, Weisinger RS, May CN. Cardiovascular actions of CRH and urocortin: an update. Peptides. 2001;22(5):821-7.

201. Gardiner SM, March JE, Kemp PA, Bennett T. A comparison between the cardiovascular actions of urocortin 1 and urocortin 2 (stresscopin-related peptide) in conscious rats. J Pharmacol Exp Ther. 2007;321(1):221-6. 
202. Charles CJ, Jardine DL, Nicholls MG, Rademaker MT, Richards AM. Urocortin 1 exhibits potent inhibition of cardiac sympathetic nerve activity in conscious sheep. J Hypertens. 2008;26(1):53-60.

203. Charles CJ, Jardine DL, Rademaker MT, Richards AM. Urocortin 2 induces potent long-lasting inhibition of cardiac sympathetic drive despite baroreflex activation in conscious sheep. J Endocrinol. 2010;204(2):181-9.

204. Charles CJ, Jardine DL, Rademaker MT, Richards AM. Urocortin 3 inhibits cardiac sympathetic nerve activity in conscious sheep. J Cardiovasc Pharmacol. 2011;58(4):418-23.

205. Rademaker MT, Richards AM. Urocortins: Actions in health and heart failure. Clin Chim Acta. 2017;474:76-87.

206. Railson JE, Liao Z, Brar BK, Buddle JC, Pennica D, Stephanou A, et al. Cardiotrophin-1 and urocortin cause protection by the same pathway and hypertrophy via distinct pathways in cardiac myocytes. Cytokine. 2002;17(5):243-53.

207. Brar BK, Railson J, Stephanou A, Knight RA, Latchman DS. Urocortin increases the expression of heat shock protein 90 in rat cardiac myocytes in a MEK1/2-dependent manner. J Endocrinol. 2002;172(2):283-93.

208. Brar BK, Jonassen AK, Egorina EM, Chen A, Negro A, Perrin MH, et al. Urocortin-II and urocortin-III are cardioprotective against ischemia reperfusion injury: an essential endogenous cardioprotective role for corticotropin releasing factor receptor type 2 in the murine heart. Endocrinology. 2004;145(1):24-35; discussion 21-3.

209. Knight RA, Chen-Scarabelli C, Yuan Z, McCauley RB, Di Rezze J, Scarabelli GM, et al. Cardiac release of urocortin precedes the occurrence of irreversible myocardial damage in the rat heart exposed to ischemia/reperfusion injury. FEBS Lett. 2008;582(6):984-90.

210. Okosi A, Brar BK, Chan M, D'Souza L, Smith E, Stephanou A, et al. Expression and protective effects of urocortin in cardiac myocytes. Neuropeptides. 1998;32(2):167-71.

211. Townsend PA, Davidson SM, Clarke SJ, Khaliulin I, Carroll CJ, Scarabelli TM, et al. Urocortin prevents mitochondrial permeability transition in response to reperfusion injury indirectly by reducing oxidative stress. Am J Physiol Heart Circ Physiol. 2007;293(2):H928-38.

212. Brar BK, Jonassen AK, Stephanou A, Santilli G, Railson J, Knight RA, et al. Urocortin protects against ischemic and reperfusion injury via a MAPK-dependent pathway. J Biol Chem. 2000;275(12):8508-14.

213. Gordon JM, Dusting GJ, Woodman OL, Ritchie RH. Cardioprotective action of CRF peptide urocortin against simulated ischemia in adult rat cardiomyocytes. Am J Physiol Heart Circ Physiol. 2003;284(1):H330-6.

214. Cong B, Zhu X, Cao B, Xiao J, Wang Z, Ni X. Estrogens protect myocardium against ischemia/reperfusion insult by up-regulation of $\mathrm{CRH}$ receptor type 2 in female rats. Int J Cardiol. 2013;168(5):4755-60.

215. Scarabelli TM, Pasini E, Stephanou A, Comini L, Curello S, Raddino R, et al. Urocortin promotes hemodynamic and bioenergetic recovery and improves cell survival in the isolated rat heart exposed to ischemia/reperfusion. J Am Coll Cardiol. 2002;40(1):155-61.

216. Chanalaris A, Lawrence KM, Townsend PA, Davidson S, Jamshidi Y, Stephanou A, et al. Hypertrophic effects of urocortin homologous peptides are mediated via activation of the Akt pathway. Biochem Biophys Res Commun. 2005;328(2):442-8.

217. Davidson SM, Townsend PA, Carroll C, Yurek-George A, Balasubramanyam K, Kundu TK, et al. The transcriptional coactivator p300 plays a critical role in the hypertrophic and protective pathways induced by phenylephrine in cardiac cells but is specific to the hypertrophic effect of urocortin. Chembiochem. 2005;6(1):162-70.

218. Gruson D, Ginion A, Lause P, Ketelslegers JM, Thissen JP, Bertrand L. Urotensin II and urocortin trigger the expression of myostatin, a negative regulator of cardiac growth, in cardiomyocytes. Peptides. 2012;33(2):351-3. 
219. Ikeda K, Tojo K, Sato S, Ebisawa T, Tokudome G, Hosoya T, et al. Urocortin, a newly identified corticotropin-releasing factor-related mammalian peptide, stimulates atrial natriuretic peptide and brain natriuretic peptide secretions from neonatal rat cardiomyocytes. Biochem Biophys Res Commun. 1998;250(2):298-304.

220. Ellmers LJ, Scott NJ, Cameron VA, Richards AM, Rademaker MT. Chronic urocortin 2 administration improves cardiac function and ameliorates cardiac remodeling after experimental myocardial infarction. J Cardiovasc Pharmacol. 2015;65(3):269-75.

221. Liu X, Liu C, Li J, Zhang X, Song F, Xu J. Urocortin attenuates myocardial fibrosis in diabetic rats via the Akt/GSK-3beta signaling pathway. Endocr Res. 2016;41(2):148-57.

222. Reul JM, Holsboer F. Corticotropin-releasing factor receptors 1 and 2 in anxiety and depression. Curr Opin Pharmacol. 2002;2(1):23-33.

223. Broberger $\mathrm{C}$. Brain regulation of food intake and appetite: molecules and networks. J Intern Med. 2005;258(4):301-27.

224. Bale TL, Anderson KR, Roberts AJ, Lee KF, Nagy TR, Vale WW. Corticotropin-releasing factor receptor-2-deficient mice display abnormal homeostatic responses to challenges of increased dietary fat and cold. Endocrinology. 2003;144(6):2580-7.

225. Carlin KM, Vale WW, Bale TL. Vital functions of corticotropin-releasing factor (CRF) pathways in maintenance and regulation of energy homeostasis. Proc Natl Acad Sci U S A. 2006;103(9):3462-7.

226. Chen A, Brar B, Choi CS, Rousso D, Vaughan J, Kuperman Y, et al. Urocortin 2 modulates glucose utilization and insulin sensitivity in skeletal muscle. Proc Natl Acad Sci U S A. 2006;103(44):16580-5.

227. Li C, Chen P, Vaughan J, Blount A, Chen A, Jamieson PM, et al. Urocortin III is expressed in pancreatic beta-cells and stimulates insulin and glucagon secretion. Endocrinology. 2003;144(7):3216-24.

228. Solinas G, Summermatter S, Mainieri D, Gubler M, Montani JP, Seydoux J, et al. Corticotropinreleasing hormone directly stimulates thermogenesis in skeletal muscle possibly through substrate cycling between de novo lipogenesis and lipid oxidation. Endocrinology. 2006;147(1):31-8.

229. Chao H, Digruccio M, Chen P, Li C. Type 2 corticotropin-releasing factor receptor in the ventromedial nucleus of hypothalamus is critical in regulating feeding and lipid metabolism in white adipose tissue. Endocrinology. 2012;153(1):166-76.

230. Kuperman Y, Issler O, Regev L, Musseri I, Navon I, Neufeld-Cohen A, et al. Perifornical Urocortin-3 mediates the link between stress-induced anxiety and energy homeostasis. Proc Natl Acad Sci U S A. 2010;107(18):8393-8.

231. Chen P, Vaughan J, Donaldson C, Vale W, Li C. Injection of Urocortin 3 into the ventromedial hypothalamus modulates feeding, blood glucose levels, and hypothalamic POMC gene expression but not the HPA axis. Am J Physiol Endocrinol Metab. 2010;298(2):E337-45.

232. Jamieson PM, Cleasby ME, Kuperman Y, Morton NM, Kelly PA, Brownstein DG, et al. Urocortin 3 transgenic mice exhibit a metabolically favourable phenotype resisting obesity and hyperglycaemia on a high-fat diet. Diabetologia. 2011;54(9):2392-403.

233. Roustit MM, Vaughan JM, Jamieson PM, Cleasby ME. Urocortin 3 activates AMPK and AKT pathways and enhances glucose disposal in rat skeletal muscle. J Endocrinol. 2014;223(2):14354.

234. Yildirim E, Keles I, Cakmak HA, Cosansu K, Can G, Ikitimur B. Evaluation of the clinical utility of urocortin 1 in systolic heart failure. Kardiol Pol. 2014;72(5):452-8.

235. Tsuda T, Takefuji M, Wettschureck N, Kotani K, Morimoto R, Okumura T, et al. Corticotropin releasing hormone receptor 2 exacerbates chronic cardiac dysfunction. J Exp Med. 2017;214(7):1877-88. 
236. Liew OW, Yandle TG, Chong JP, Ng YX, Frampton CM, Ng TP, et al. High-Sensitivity Sandwich ELISA for Plasma NT-proUcn2: Plasma Concentrations and Relationship to Mortality in Heart Failure. Clin Chem. 2016;62(6):856-65.

237. Pilbrow AP, Lewis KA, Perrin MH, Sweet WE, Moravec CS, Tang WH, et al. Cardiac CRFR1 Expression Is Elevated in Human Heart Failure and Modulated by Genetic Variation and Alternative Splicing. Endocrinology. 2016;157(12):4865-74.

238. Venkatasubramanian S, Griffiths ME, McLean SG, Miller MR, Luo R, Lang NN, et al. Vascular effects of urocortins 2 and 3 in healthy volunteers. J Am Heart Assoc. 2013;2(1):e004267.

239. Stirrat CG, Venkatasubramanian S, Pawade T, Mitchell AJ, Shah AS, Lang NN, et al. Cardiovascular effects of urocortin 2 and urocortin 3 in patients with chronic heart failure. British journal of clinical pharmacology. 2016;82(4):974-82. Epub 2016/06/09.

240. Davis ME, Pemberton CJ, Yandle TG, Lainchbury JG, Rademaker MT, Nicholls MG, et al. Effect of urocortin 1 infusion in humans with stable congestive cardiac failure. Clin Sci (Lond). 2005;109(4):381-8.

241. Davis ME, Pemberton CJ, Yandle TG, Fisher SF, Lainchbury JG, Frampton CM, et al. Urocortin 2 infusion in human heart failure. Eur Heart J. 2007;28(21):2589-97.

242. Gheorghiade M, Greene SJ, Ponikowski P, Maggioni AP, Korewicki J, Macarie C, et al. Haemodynamic effects, safety, and pharmacokinetics of human stresscopin in heart failure with reduced ejection fraction. European journal of heart failure. 2013;15(6):679-89. Epub 2013/03/09.

243. Chan WY, Frampton CM, Crozier IG, Troughton RW, Richards AM. Urocortin-2 infusion in acute decompensated heart failure: findings from the UNICORN study (urocortin-2 in the treatment of acute heart failure as an adjunct over conventional therapy). JACC Heart failure. 2013;1(5):433-41. Epub 2014/03/14.

244. Patel K, Rademaker MT, Kirkpatrick CM, Charles CJ, Fisher S, Yandle TG, et al. Comparative pharmacokinetics and pharmacodynamics of urocortins 1, 2 and 3 in healthy sheep. British journal of pharmacology. 2012;166(6):1916-25. Epub 2012/02/22.

245. Sambrook J, Westphal H, Srinivasan PR, Dulbecco R. The integrated state of viral DNA in SV40transformed cells. Proc Natl Acad Sci U S A. 1968;60(4):1288-95.

246. Friedmann T, Roblin R. Gene therapy for human genetic disease? Science. 1972;175(4025):949-55.

247. Cline MJ, Stang H, Mercola K, Morse L, Ruprecht R, Brown J, et al. Gene transfer in intact animals. Nature. 1980;284(5755):422-5.

248. Wade N. UCLA gene therapy racked by friendly fire. Science. 1980;210(4469):509-11.

249. Anderson WF, Blaese RM, Culver K. The ADA human gene therapy clinical protocol: Points to Consider response with clinical protocol, July 6, 1990. Hum Gene Ther. 1990;1(3):331-62.

250. Nelson D, Weiss R. Penn researchers sued in gene therapy death: teen's parents also name ethicist as defendant. Washington Post. 2000:A3.

251. Pearson S, Jia H, Kandachi K. China approves first gene therapy. Nat Biotechnol. 2004;22(1):34.

252. Yla-Herttuala S. Endgame: glybera finally recommended for approval as the first gene therapy drug in the European union. Mol Ther. 2012;20(10):1831-2.

253. Lin H, Parmacek MS, Morle G, Bolling S, Leiden JM. Expression of recombinant genes in myocardium in vivo after direct injection of DNA. Circulation. 1990;82(6):2217-21.

254. Zaccolo M. cAMP signal transduction in the heart: understanding spatial control for the development of novel therapeutic strategies. Br J Pharmacol. 2009;158(1):50-60.

255. Lai NC, Roth DM, Gao MH, Tang T, Dalton N, Lai YY, et al. Intracoronary adenovirus encoding adenylyl cyclase $\mathrm{VI}$ increases left ventricular function in heart failure. Circulation. 2004;110(3):330-6. 
256. Roth DM, Bayat H, Drumm JD, Gao MH, Swaney JS, Ander A, et al. Adenylyl cyclase increases survival in cardiomyopathy. Circulation. 2002;105(16):1989-94.

257. Timofeyev V, He Y, Tuteja D, Zhang Q, Roth DM, Hammond HK, et al. Cardiac-directed expression of adenylyl cyclase reverses electrical remodeling in cardiomyopathy. J Mol Cell Cardiol. 2006;41(1):170-81.

258. Hammond HK, Penny WF, Traverse JH, Henry TD, Watkins MW, Yancy CW, et al. Intracoronary Gene Transfer of Adenylyl Cyclase 6 in Patients With Heart Failure: A Randomized Clinical Trial. JAMA Cardiol. 2016;1(2):163-71.

259. del Monte F, Harding SE, Schmidt U, Matsui T, Kang ZB, Dec GW, et al. Restoration of contractile function in isolated cardiomyocytes from failing human hearts by gene transfer of SERCA2a. Circulation. 1999;100(23):2308-11.

260. Lyon AR, Bannister ML, Collins T, Pearce E, Sepehripour AH, Dubb SS, et al. SERCA2a gene transfer decreases sarcoplasmic reticulum calcium leak and reduces ventricular arrhythmias in a model of chronic heart failure. Circ Arrhythm Electrophysiol. 2011;4(3):362-72.

261. Kawase $Y$, Ly HQ, Prunier F, Lebeche D, Shi Y, Jin H, et al. Reversal of cardiac dysfunction after long-term expression of SERCA2a by gene transfer in a pre-clinical model of heart failure. J Am Coll Cardiol. 2008;51(11):1112-9.

262. Jessup M, Greenberg B, Mancini D, Cappola T, Pauly DF, Jaski B, et al. Calcium Upregulation by Percutaneous Administration of Gene Therapy in Cardiac Disease (CUPID): a phase 2 trial of intracoronary gene therapy of sarcoplasmic reticulum $\mathrm{Ca}^{2+}$-ATPase in patients with advanced heart failure. Circulation. 2011;124(3):304-13.

263. Greenberg B, Yaroshinsky A, Zsebo KM, Butler J, Felker GM, Voors AA, et al. Design of a phase $2 b$ trial of intracoronary administration of AAV1/SERCA2a in patients with advanced heart failure: the CUPID 2 trial (calcium up-regulation by percutaneous administration of gene therapy in cardiac disease phase 2b). JACC Heart Fail. 2014;2(1):84-92.

264. Greenberg B, Butler J, Felker GM, Ponikowski P, Voors AA, Desai AS, et al. Calcium upregulation by percutaneous administration of gene therapy in patients with cardiac disease (CUPID 2): a randomised, multinational, double-blind, placebo-controlled, phase $2 \mathrm{~b}$ trial. Lancet. 2016;387(10024):1178-86.

265. Most P, Seifert H, Gao E, Funakoshi H, Volkers M, Heierhorst J, et al. Cardiac S100A1 protein levels determine contractile performance and propensity toward heart failure after myocardial infarction. Circulation. 2006;114(12):1258-68.

266. Boerries M, Most P, Gledhill JR, Walker JE, Katus HA, Koch WJ, et al. $\mathrm{Ca}^{2+}$-dependent interaction of S100A1 with F1-ATPase leads to an increased ATP content in cardiomyocytes. Mol Cell Biol. 2007;27(12):4365-73.

267. Pleger ST, Shan C, Ksienzyk J, Bekeredjian R, Boekstegers P, Hinkel R, et al. Cardiac AAV9S100A1 gene therapy rescues post-ischemic heart failure in a preclinical large animal model. Sci Transl Med. 2011;3(92):92ra64.

268. Weber C, Neacsu I, Krautz B, Schlegel P, Sauer S, Raake P, et al. Therapeutic safety of high myocardial expression levels of the molecular inotrope S100A1 in a preclinical heart failure model. Gene Ther. 2014;21(2):131-8.

269. Bry M, Kivela R, Leppanen VM, Alitalo K. Vascular endothelial growth factor-B in physiology and disease. Physiol Rev. 2014;94(3):779-94.

270. Li Y, Zhang F, Nagai N, Tang Z, Zhang S, Scotney P, et al. VEGF-B inhibits apoptosis via VEGFR1-mediated suppression of the expression of $\mathrm{BH} 3$-only protein genes in mice and rats. J Clin Invest. 2008;118(3):913-23.

271. Zentilin L, Puligadda U, Lionetti V, Zacchigna S, Collesi C, Pattarini L, et al. Cardiomyocyte VEGFR-1 activation by VEGF-B induces compensatory hypertrophy and preserves cardiac function after myocardial infarction. FASEB J. 2010;24(5):1467-78. 
272. Pepe M, Mamdani M, Zentilin L, Csiszar A, Qanud K, Zacchigna S, et al. Intramyocardial VEGFB167 gene delivery delays the progression towards congestive failure in dogs with pacinginduced dilated cardiomyopathy. Circ Res. 2010;106(12):1893-903.

273. Woitek F, Zentilin L, Hoffman NE, Powers JC, Ottiger I, Parikh S, et al. Intracoronary Cytoprotective Gene Therapy: A Study of VEGF-B167 in a Pre-Clinical Animal Model of Dilated Cardiomyopathy. J Am Coll Cardiol. 2015;66(2):139-53.

274. Penn MS, Pastore J, Miller T, Aras R. SDF-1 in myocardial repair. Gene Ther. 2012;19(6):583-7.

275. Askari AT, Unzek S, Popovic ZB, Goldman CK, Forudi F, Kiedrowski M, et al. Effect of stromalcell-derived factor 1 on stem-cell homing and tissue regeneration in ischaemic cardiomyopathy. Lancet. 2003;362(9385):697-703.

276. Penn MS, Mendelsohn FO, Schaer GL, Sherman W, Farr M, Pastore J, et al. An open-label dose escalation study to evaluate the safety of administration of nonviral stromal cell-derived factor-1 plasmid to treat symptomatic ischemic heart failure. Circ Res. 2013;112(5):816-25.

277. Chung ES, Miller L, Patel AN, Anderson RD, Mendelsohn FO, Traverse J, et al. Changes in ventricular remodelling and clinical status during the year following a single administration of stromal cell-derived factor-1 non-viral gene therapy in chronic ischaemic heart failure patients: the STOP-HF randomized Phase II trial. Eur Heart J. 2015;36(33):2228-38. 



\section{Chapter

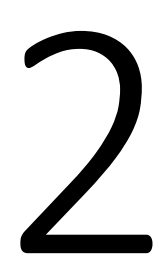

\section{Effects of Urocortin 2 vs Urocortin 3 Gene Transfer on Left Ventricular Function and Glucose Disposal}

Dimosthenis Giamouridis, Mei Hua Gao, N. Chin Lai, Zhen Tan, Young Chul Kim, Tracy Guo, Atsushi Miyanohara, W. Matthijs Blankesteijn, Erik A. L. Biessen, H. Kirk Hammond 


\section{ABSTRACT}

Objective. We tested the hypothesis that sustained elevation of plasma urocortin-2 (Ucn2) and urocortin-3 (Ucn3) via gene transfer would have dissimilar effects on cardiovascular function and glucose disposal.

Background. Intravenous infusion of Ucn2 and Ucn3 peptides have been used in clinical heart failure (HF), but duration of benefits is limited by the peptide's short half-lives, a problem thwarted, potentially, by gene transfer.

Methods. We examined effects of Ucn2 vs Ucn3 gene transfer on cardiovascular function in mice using telemetry, echocardiography, direct measures of left ventricular (LV) systolic and diastolic function, $\mathrm{Ca}^{2+}$ transient measurements, and cardiac expression of key signaling proteins. We also measured fasting glucose and conducted glucose tolerance testing.

Results. Ucn2 and Ucn3 gene transfer lowered blood pressure without increasing heart rate. Both Ucn2 and Ucn3 gene transfer increased ejection fraction (Ucn2>Ucn3; echocardiography), and both were associated with similar enhancements in LV peak $+d P / d t$, slope of ESPVR, peak -dP/dt, Tau and cardiac output. Both transgenes had beneficial effects on $\mathrm{Ca}^{2+}$ transients and increased LV SERCA2a expression. Fasting glucose was reduced and glucose clearance increased only after Ucn2 gene transfer.

Conclusions. Ucn2 and Ucn3 gene transfer show similar beneficial effects on LV systolic and diastolic function, mediated by increased LV SERCA2a expression and increased $\mathrm{Ca}^{2+}$ handling. Ucn2 but not Ucn3 gene transfer reduced fasting glucose and increased glucose disposal. These findings support Ucn2 and Ucn3 gene transfer as potential treatments for heart failure, and indicate that Ucn2 may be an optimal selection in patients with diabetes and heart failure.

Key Words: gene therapy; insulin sensitivity; contractile function; diastolic function; Adenoassociated virus 


\section{CONDENSED ABSTRACT}

Ucn2 and Ucn3 peptides have recently been infused to treat patients with HF, but are limited by their short half-lives. A one-time IV injection of virus vectors encoding Ucn2 or Ucn3 provided sustained increases in plasma concentrations of the peptides. This was associated with increases in both systolic and diastolic LV function, mediated by increased LV SERCA2a expression and $\mathrm{Ca}^{2+}$ handling. Ucn2 but not Ucn3 gene transfer reduced fasting glucose and increased glucose disposal. These findings support Ucn2 and Ucn3 gene transfer as potential treatments for $\mathrm{HF}$, and indicate that Ucn2 may be an optimal selection in patients with diabetes and HF. 


\section{ABBREVIATIONS}

\begin{tabular}{|c|c|}
\hline AAV & adeno-associated virus \\
\hline$A C$ & adenylyl cyclase \\
\hline ANF & atrial natriuretic factor \\
\hline ATP & adenosine triphosphate (ATP) \\
\hline AV & atrio-ventricular \\
\hline$\beta A R$ & $\beta$-adrenergic receptor \\
\hline BNP & brain natriuretic peptide \\
\hline CamKII & $\mathrm{Ca}^{2+} /$ calmodulin-dependent protein kinase II \\
\hline CAMP & $3^{\prime}, 5^{\prime}$-cyclic adenosine monophosphate \\
\hline CMLCK & cardiac myosin light chain kinase \\
\hline CRHR1 & corticotropin releasing hormone receptor 1 \\
\hline CRHR2 & corticotropin releasing hormone receptor 2 \\
\hline CRF & corticotropin releasing factor \\
\hline ECG & electrocardiogram \\
\hline EDD & end-diastolic diameter \\
\hline ESD & end-systolic diameter \\
\hline $\mathrm{HF}$ & heart failure \\
\hline IGF-BP3 & IGF binding protein 3 \\
\hline IGF-1 & insulin-like growth factor 1 \\
\hline IP & intraperitoneal \\
\hline Iso & isoproterenol \\
\hline IV & intravenous \\
\hline LV & left ventricle, left ventricular \\
\hline$L V+d P / d t$ & first derivative of LV pressure development \\
\hline$L V-d P / d t$ & first derivative of LV pressure decline \\
\hline
\end{tabular}


MHC myosin heavy chain

MLC2v myosin light chain 2v

RYR2 ryanodine receptor 2

SERCA2a sarco/endoplasmic reticulum $\mathrm{Ca}^{2+}$-ATPase

Uen2 urocortin 2

Ucn3 urocortin 3

VCFc velocity of circumferential fiber shortening 


\section{INTRODUCTION}

Cardiovascular disease is the most common cause of death in the US with 300,000 deaths and 550,000 new cases every year. Heart failure (HF) affects 6 million people in the US and, in those with severe symptoms, $40 \%$ die within 4-5 years of onset despite optimal therapy $(1,2)$. Because of this poor prognosis, new approaches, including gene transfer, are warranted. Many cardiovascular deaths are related to diabetes mellitus $->35 \%$ of patients with coronary disease have diabetes (3). More effective therapies for cardiovascular disease and for diabetes are needed.

The corticotropin releasing factor (CRF) family includes CRF and urocortins 1 (Ucn1), 2 (Ucn2) and 3 (Ucn3). Because of the potential deleterious effects of long-term exposure to CRF and Ucn1 (4,5), we have focused on Ucn2 and Ucn3 in our studies. In normal humans, expression of Ucn 2 mRNA is found predominantly in skin and endometrium (6); Ucn3 mRNA is found in the gastrointestinal tract and endometrium (7). Circulating levels of Ucn2 and Ucn3 peptide in normal humans are rarely reported due to their low concentrations. Plasma Ucn2 in normal males is $<0.3 \mathrm{ng} / \mathrm{ml}$ (68 pmol/L) (8), and in normal adult females, serum samples showed mean Ucn3 concentrations of $0.2 \mathrm{ng} / \mathrm{ml}$ (51 pmol/L) (9).

The actions of Ucn1, Ucn2, and Ucn3 are governed by the tissue distribution of their receptors, corticotropin releasing hormone receptors 1 (CRHR1) and 2 (CRHR2). Ucn1 has similar affinity for CRHR1 and CRHR2 but Ucn2 and Ucn3 have high affinity for CRHR2 alone. CRHR1 is predominantly expressed in brain, while CRHR2 is expressed in peripheral tissues, including vascular smooth muscle, the gastrointestinal tract, skeletal muscle and myocardium $(9,10)$. Ucn2 and Ucn3 peptide infusion have beneficial cardiovascular effects, and Ucn2 and stresscopin (an Ucn3 homologue) have been used to treat patients with HF in early stage clinical trials $(11,12)$.

Ucn2 has beneficial inotropic effects, with modest effects on cardiac myocyte cAMP production. In preclinical studies in murine $\mathrm{HF}$, infusion of Ucn2 peptide increased LV contractile function (13). Studies in large animals (14) and clinical trials $(11,12)$ have demonstrated the safety and beneficial effects of Ucn2 peptide infusion on LV function. Ucn3 peptide infusion, less studied, is also reported to have beneficial cardiovascular effects (15).

An unanticipated and previously unrecognized effect of sustained elevation of plasma Ucn2 is increased insulin sensitivity and glucose disposal, features that recently were shown to provide long term resolution of insulin resistance in two murine models (16). It is unknown whether Ucn2 or Ucn3 gene transfer influences glucose disposal in normal animals.

A direct comparison of the cardiovascular effects between brief Ucn2 and Ucn3 peptide infusions in human males with and without HF was only recently conducted (15). This study compared the cardiovascular effects of brief intra-arterial infusion of Ucn2 and Ucn3 peptide. Both peptides resulted in arterial vasodilation, although Ucn3 showed tachycardia associated with reduced diastolic blood pressure at the highest infused dose, (15) suggesting variations in the effects of Ucn2 vs Ucn3, despite their similar affinities for CRHR2. This study did not include measures of LV pressure. 
The major impediment in using Ucn2 and Ucn3 peptide infusions in clinical settings as therapeutic agents is their short half-life (minutes) (17). This limits duration of treatment to a few hours. Gene transfer would circumvent this shortcoming. In this approach, one would construct a virus vector encoding Ucn2 or Ucn3, and deliver the vector systemically. Using proper vectors one could efficiently transfect the liver and other organs, which then would serve as sources for sustained synthesis of Ucn2 or Ucn3, enabling sustained elevation of plasma Ucn2 and Ucn3, circumventing the need for constant infusion and hospitalization. Our laboratory has shown in preclinical studies that such an approach, using gene transfer of Ucn2, is feasible and beneficial for heart function. Specifically, we have shown that a single intravenous (IV) injection of adeno-associated virus type 8 encoding Ucn2 (AAV8.Ucn2), increases plasma Ucn2 for up to 7 months, increases function of normal and failing hearts in mice $(18,19)$, and normalizes insulin sensitivity in two animal models of insulin resistance (16).

There are two unanswered questions that we address in the current study. First, does sustained elevation of plasma Ucn2 vs Ucn3 have different effects on LV function and LV $\mathrm{Ca}^{2+}$ handling? Second, does Ucn3 gene transfer, similar to Ucn2 gene transfer, affect glucose disposal? Our hypothesis was that sustained elevation of plasma Ucn3, achieved via gene transfer, would be dissimilar to the effects of sustained elevation of plasma Ucn2 on cardiovascular function and glucose disposal.

\section{METHODS}

AAV8 Vector Production. For the production of the AAV8 vectors encoding murine Ucn2 and Ucn3 driven by a chicken $\beta$-actin (CBA) promoter (AAV8.CBA.Ucn2; and AAV8.CBA.Ucn3; Fig. 1D). Virus titers were determined by real-time qPCR with virus genome DNA prepared from purified virus. Details of vector manufacture have been reported previously $(16,18)$.

Animal Studies. The Animal Use and Care Committee of the VA San Diego Healthcare System approved the studies. One hundred thirty male C57BL/6J mice (Jackson Laboratories, Bar Harbor, ME) 11.5 \pm 0.3 weeks old weighing $26.5 \pm 0.2$ grams were used. One animal (Ucn3 group) died during surgical implantation of the telemetry unit (severe bleeding), and 4 animals ( 3 saline and 1 Ucn2) were found dead 1-3 days after the procedure. Data were obtained $9 \pm 0.2$ weeks after gene transfer.

Heart Rate and Blood Pressure in Conscious Mice. Telemetry transmitters (HD-X11, Data Sciences International, St. Paul, MN) were implanted following the manufacturer's guidelines). A fluid filled pressure transducer line was inserted through the left carotid artery into the proximal aorta distal to the subclavian artery. Recording commenced 5 or more days after implantation. Data transmitted from the telemetry units enabled continuous recording of the electrocardiogram (ECG), phasic arterial blood and activity (Ponemah software, Data Sciences International, St. Paul, MN). ECG, blood pressure and activity were recorded continuously for $72 \mathrm{hr}$. Data were averaged over two 4-hr periods: 


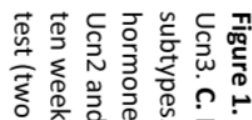

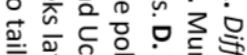

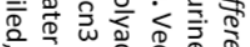

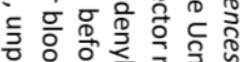

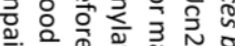

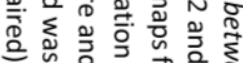

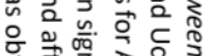

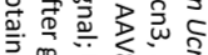
贾

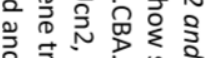
음

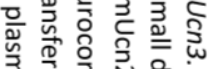

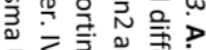

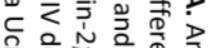

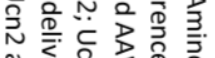

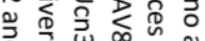
슨 品业全

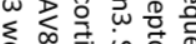

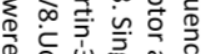

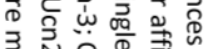
蛋 N 㻤

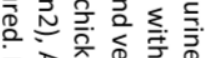

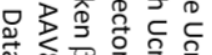

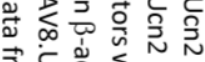

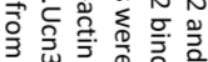

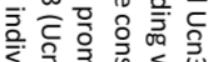
s. 峛

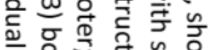
年

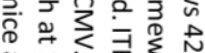

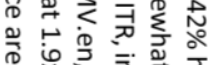

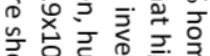

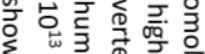

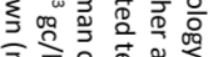

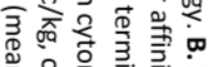
岸옹 豙

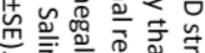
论

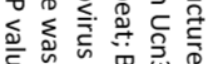

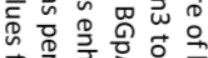

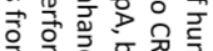

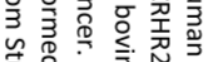

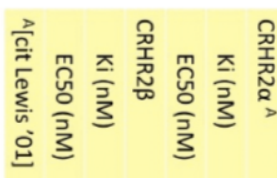
11

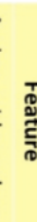

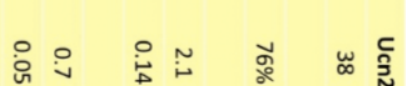

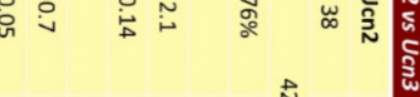

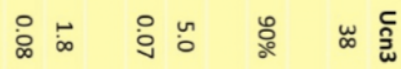
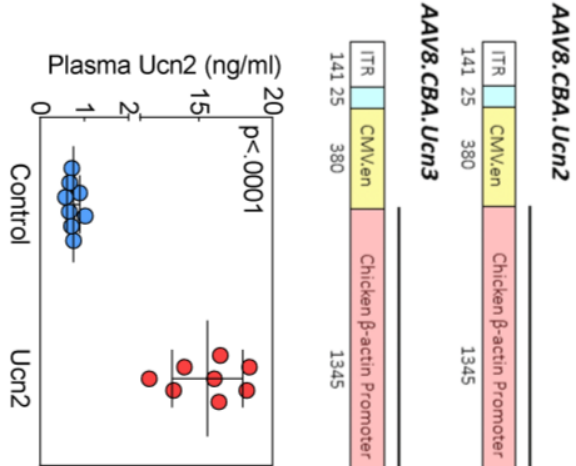

Plasma Ucn3 (ng/ml)

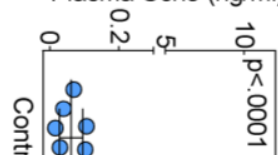

흐 के

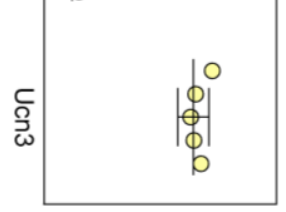

ก
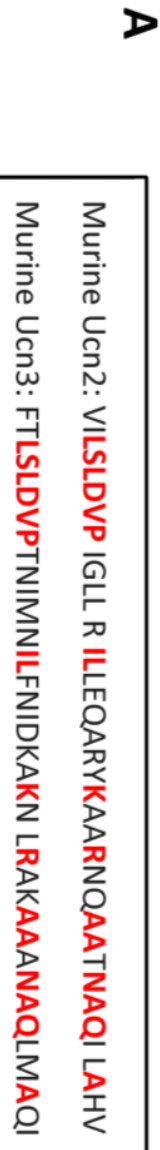

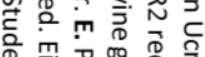

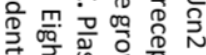

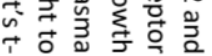
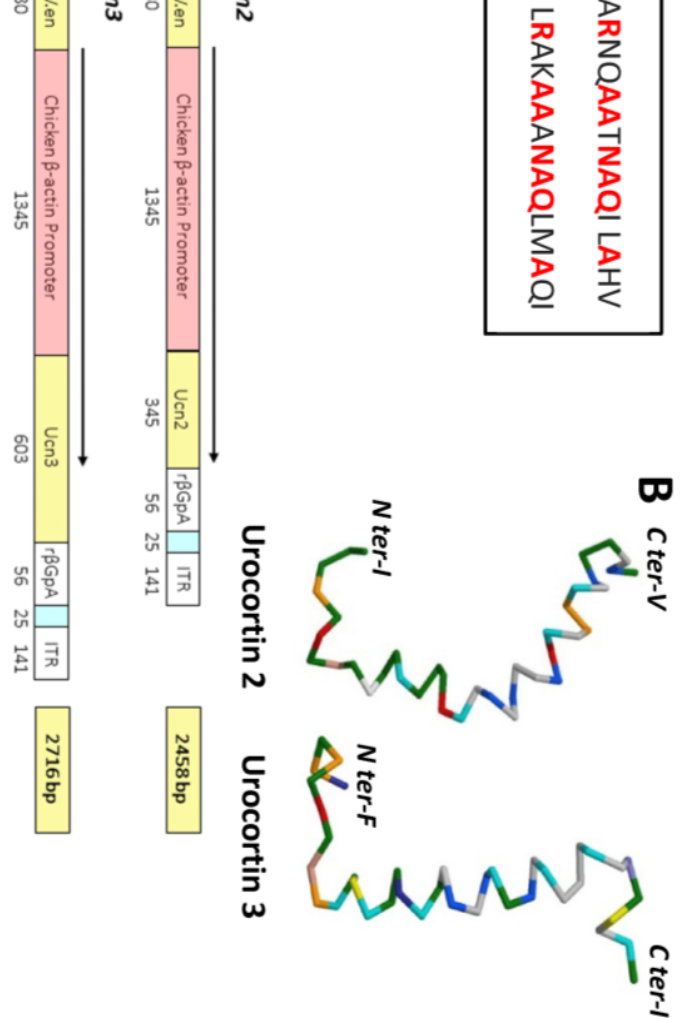
10 AM-2 PM (day cycle) and 10 PM-2 AM (night cycle). Activity was quantified over each 4hr period (day and night), and is reported as mean movements during each 5 min interval.

Vector Delivery. Mice were anesthetized (1.5\% isoflurane) and a jugular vein exposed through a small incision on the neck. A final volume of $100 \mu \mathrm{L}$ saline containing AAV8.Ucn2

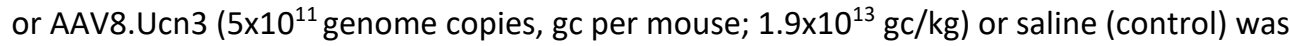
delivered IV via a 31-gauge needle.

Echocardiography. Echocardiography was performed using a Vevo 2100 system with a MS550s (32-56 MHz) transducer (Visualsonics, Toronto, Canada), as previously described (18). To examine mitral inflow, mice were injected intraperitoneally (IP) with $10 \mu \mathrm{g} / \mathrm{kg}$ ivabradine hydrochloride (Sigma-Aldrich, St. Louis, $\mathrm{MO}$ ) in $\mathrm{dd}_{2} \mathrm{O}$, to reduce heart rate without affecting contractile function (20). Using pulsed-wave and tissue Doppler, mitral inflow and mitral annulus velocities were acquired from a 2-chamber view. Vevo software (Visualsonics, Toronto, Canada) was used for measurement and analysis.

LV Function. Sodium pentobarbital ( $80 \mathrm{mg} / \mathrm{kg}$, IP) was used for anesthesia. LV pressure was measured using a 1.4F micromanometer catheter (SPR 839, Millar Instruments, Houston, TX) as previously described (18). LV systolic and diastolic function was assessed using the first derivative of $L V$ pressure development $(+d P / d t)$ and decay $(-d P / d t)$, respectively. Tau, the time constant of LV pressure decline, was also measured as an added assessment of diastolic function. To determine whether increases in peak $\mathrm{LV}+\mathrm{dP} / \mathrm{dt}$ and ejection fraction were associated with relatively load-independent changes in LV contractile function, we measured the slope of the end-systolic pressure-volume relationship and cardiac output, as previously described (21)

Fasting Glucose and Glucose Tolerance Testing. To determine if Ucn2 and Ucn3 gene transfer was associated with alterations in glucose disposal similarly in normal mice, we measured fasting glucose and glucose tolerance $9.0 \pm 0.2$ weeks after Ucn2 and Ucn3 gene transfer in normal male mice. They were provided (ad libitum) a cereal-based diet (Harlan Teklad Lab, Madison, WI, USA). Mice were housed $\left(20-21^{\circ} \mathrm{C}\right)$ with lights off from 6 PM to 6 AM daily. Normal mice received IV saline $(n=12)$, AAV8.Ucn2 $\left(1.9 \times 10^{13} \mathrm{gc} / \mathrm{kg}, \mathrm{n}=10\right)$ or AAV8.Ucn3 $\left(1.9 \times 10^{13} \mathrm{gc} / \mathrm{kg}, \mathrm{n}=12\right)$. Eight to 10 weeks later, fasting (12 hr) glucose was determined and glucose tolerance testing was performed as previously described (16). Area under the curve (AUC) was calculated for individual animals using the AUC analysis software in GraphPad Prism. We then used these data (mean \pm SE) to test for between group differences.

Necropsy and Tissue Collection. Anesthetized mice underwent a terminal procedure during which blood was collected in EDTA tubes (BD biosciences, San Jose, CA) for plasma extraction after centrifugation for 10 minutes at $4000 \mathrm{rpm}$ and $4^{\circ} \mathrm{C}$. Organs were collected, weighted and a part of each was fast frozen in liquid nitrogen and stored in $-80^{\circ} \mathrm{C}$, while another part was fixed in $10 \%$ formalin and transferred to $70 \%$ EtOH 24 hours later.

Cardiac Myocyte Isolation and Size Assessment. Isolation of cardiac myocytes was done using methods previously described (22). Viable cardiac myocytes underwent cAMP and PKA assays and $\mathrm{Ca}^{2+}$ transient measurement. A portion of cardiac myocytes were fixed ( $10 \%$ formalin, $10 \mathrm{~min}$ ), washed twice with PBS, stained with eosin for $10 \mathrm{~min}$, washed twice with 
PBS and plated. Photographs were taken (10X magnification) and the size of $120 \pm 11$ cardiac myocytes per animal was quantified using ImageJ (NIH, Bethesda, MD). Group identity was unknown to the examiner. Cells that were spherical (non-viable) and those overlaid or attached to other cells (viable cell clusters) were excluded. Length and width were measured (Fig. 7B). Cell volume was calculated assuming a cylindrical model:

$$
\text { Volume }=\text { Length } X \pi(\text { Width } / 2)^{2}
$$

$\mathrm{Ca}^{2+}$ Transients. $\mathrm{Ca}^{2+}$ transient measurement was performed as previously described (18). Multiple cardiac myocytes from each of four hearts per group were used.

Adenylyl Cyclase and Protein Kinase A Activity Assays. Adenylyl cyclase activity was determined by measuring the amount of cAMP in isolated cardiac myocytes as previously described (23).

Immunoblotting and LV mRNA Screening. Western blots were performed as described previously $(18,19)$. Sources for antibodies include: anti-p286-CAMKIl $\alpha$ (Santa Cruz Biotechnology, Dallas, TX); anti-p2808-RYR2 (Abcam, Cambridge, MA); anti-GAPDH (Cell Signaling, Danvers, MA); anti-vinculin (Sigma-Aldrich, St. Louis, MO). To evaluate alterations in LV mRNA expression we used focus gene array for CAMP and $\mathrm{Ca}^{2+}$ signaling pathways (Qiagen, Germantown, MD), which screens expression of 84 proteins responsive to cAMP or $\mathrm{Ca}^{2+}$.

Histology. Transmural sections of the LV and liver samples were fixed in $10 \%$ formalin (Sigma-Aldrich, St. Louis, MO), paraffin-embedded, sliced into 5 micron sections, mounted and counterstained with hematoxylin and eosin and with Masson's trichrome. The slides were scanned using an Axio Scan Z1 (Zeiss, Oberkochen, Germany). Quantitative assessment was performed using ImageJ (NIH, Bethesda, MD).

Statistical Analysis. Data acquisition and analysis were done without knowledge of group identity. Group sizes were determined by power calculations. GraphPad Prism V6.07 was used for statistical analysis. Data represent mean \pm SE; one-way ANOVA and Kruskal-Walis tests were used to detect differences in the three groups. Sidak's and Dunn's multiple comparison tests were then used to test for between-group differences (Ucn2 vs Ucn3). In some instances, when comparisons were made between 2 groups, Student's t-test was used (unpaired, two-tailed). The null hypothesis was rejected when $\mathrm{p}<0.05$.

\section{RESULTS}

Plasma Peptide Concentration after Gene Transfer. Ucn2 and Ucn3 plasma levels were measured 9.0 \pm 0.2 weeks after gene transfer. Mice that received AAV8.Ucn2 $\left(1.9 \times 10^{13} \mathrm{gc} / \mathrm{kg}\right.$, IV) had a 20 -fold increase in plasma Ucn2 levels: Control $(n=8): 0.8 \pm 0.1 \mathrm{ng} / \mathrm{mL}(181 \mathrm{pmol} / \mathrm{L})$; Ucn2 ( $n=8): 16 \pm 1 \mathrm{ng} / \mathrm{mL}$ (3627 pmol/L); $\mathrm{p}<0.0001$, Fig. 1E). Mice that received AAV8.Ucn3 $\left(1.9 \times 10^{13} \mathrm{gc} / \mathrm{kg}\right.$, IV) had a 70 -fold elevation in plasma Ucn3 level: Control $(n=8): 0.1 \pm 0.1$ $\mathrm{ng} / \mathrm{mL}$ (26 pmol/L); Ucn3 ( $\mathrm{n}=6)$ : $7 \pm 0.4 \mathrm{ng} / \mathrm{mL}$ (1785 pmol/L; $p<0.0001$, Fig. 1E). 
Heart Rate and Blood Pressure. Heart rate and blood pressure were obtained from untethered conscious, unsedated mice via telemetry. The anticipated increase in nocturnal activity was associated with increases in heart rate and blood pressure during the night compared to daytime when the animals were roughly $50 \%$ less active (Table 1). However, no overall group differences were seen in heart rate or in activity levels. Daytime diastolic $(p=0.05)$ and mean blood pressures $(p=0.039)$ were decreased similarly in Ucn2 and Ucn3 groups. Although there was a reduction in systolic blood pressure of Ucn2 and Ucn3 animals, it was not significant during daytime $(p=0.07)$. At night, systolic $(p=0.034)$, diastolic $(p=0.047)$ and mean blood pressure $(p=0.02)$ were decreased in Ucn2 and Ucn3 mice with no between group differences (Table 1 ).

\begin{tabular}{|c|c|c|c|c|c|c|c|c|}
\hline & \multicolumn{2}{|c|}{ Control (9) } & \multicolumn{2}{|c|}{ Ucn2 (10) } & \multicolumn{2}{|c|}{ Ucn3 (8) } & \multicolumn{2}{|c|}{$p$} \\
\hline & Day & Night & Day & Night & Day & Night & Day & Night \\
\hline $\begin{array}{c}H R \\
(\mathrm{bpm})\end{array}$ & $550 \pm 10$ & $605 \pm 14$ & $534 \pm 12$ & $580 \pm 14$ & $555 \pm 9$ & $605 \pm 11$ & .3 & .3 \\
\hline $\begin{array}{c}\text { Systolic BP } \\
(\mathrm{mmHg})\end{array}$ & $127 \pm 5$ & $142 \pm 5$ & $116 \pm 3$ & $123 \pm 6$ & $116 \pm 2$ & $128 \pm 3$ & .07 & .034 \\
\hline $\begin{array}{l}\text { Diastolic BP } \\
(\mathrm{mmHg})\end{array}$ & $99 \pm 6$ & $110 \pm 6$ & $89 \pm 2$ & $97 \pm 3$ & $84 \pm 3$ & $96 \pm 3$ & .05 & .047 \\
\hline $\begin{array}{c}\text { MAP } \\
(\mathrm{mmHg})\end{array}$ & $112 \pm 5$ & $125 \pm 5$ & $102 \pm 2$ & $109 \pm 4$ & $99 \pm 3$ & $112 \pm 3$ & .039 & .02 \\
\hline $\begin{array}{c}\text { Activity } \\
\text { (Avg mobility/5 min) }\end{array}$ & $11 \pm 2$ & $33 \pm 6$ & $10 \pm 3$ & $21 \pm 3$ & $11 \pm 2$ & $28 \pm 6$ & .9 & .3 \\
\hline \multicolumn{9}{|c|}{$\begin{array}{l}\text { Data obtained 8-12 weeks after IV delivery of AAV8.Ucn2, AAV8.Ucn3 (both at } 1.9 \times 10^{13} \mathrm{gc} / \mathrm{kg} \text { ), or saline } \\
\text { (Control). Data are mean } \pm \text { SE from } 4 \text { continuous hours: Day, } 10 \text { AM-2 PM; Night, } 10 \text { PM-2 AM. P values from 1- } \\
\text { way ANOVA. Ucn2 and Ucn3 gene transfer were associated with similar reductions in systolic, diastolic and } \\
\text { mean blood pressures vs Control. Ucn2, urocortin-2; Ucn3, urocortin-3; HR, heart rate; bpm, beats per } \\
\text { minute; BP, blood pressure; MAP, mean arterial pressure }\end{array}$} \\
\hline
\end{tabular}

Echocardiography. Eight to ten weeks after Ucn2 or Ucn3 gene transfer, ejection fraction $(E F, p<0.0001)$ and velocity of circumferential fiber shortening corrected for heart rate (VCFc, $p<0.0001$ ) were increased in both Ucn2 and Ucn3 groups compared to control (Table 2). Ucn 2 had a greater effect than Ucn3 on EF $(p=0.0013)$ and VCFc $(p<0.0001)$. There was an overall reduction in EDD and ESD ( $p<0.0001$ for both, Table 2$)$, with reduced EDD and ESD greater after Ucn 2 than $U c n 3$ gene transfer $(p=0.0007$ and $<0.0002$, respectively). Both Ucn2 and Ucn3 transgenes increased passive mitral inflow (MV E-wave). Ucn2 or Ucn3 gene transfer did not affect the ratio of passive to active mitral inflow (E/A). 
LV Function. Ucn2 vs Ucn3 gene transfer resulted in a 1.5-fold and 1.4-fold increase in the peak rate of $\mathrm{LV}$ pressure development $(+\mathrm{dP} / \mathrm{dt}$ ) compared to control, respectively (Control: $5448 \pm 277 \mathrm{mmHg} / \mathrm{s}, \mathrm{n}=18 ; \mathrm{Ucn} 2: 8314 \pm 340 \mathrm{mmHg} / \mathrm{s}, \mathrm{n}=8 ;$ Ucn3: $7553 \pm 388 \mathrm{mmHg} / \mathrm{s}, \mathrm{n}=20$; $\mathrm{p}<0.0001$, Fig. 2A). Ucn2 gene transfer increased the slope of the ESPVR by $90 \%$ and Ucn 3 gene transfer increased the slope of the ESPVR by $63 \%$ (Control: $4 \pm 0.3 \mu \mathrm{L} / \mathrm{min}, \mathrm{n}=9$; Ucn2: 7.6 $\pm 1.2 \mu \mathrm{L} / \mathrm{min}, \mathrm{n}=6$; Ucn3: $6.5 \pm 1.1 \mu \mathrm{L} / \mathrm{min}, \mathrm{n}=8 ; \mathrm{p}=0.02$, Fig. $2 \mathrm{~B}$ ). Both transgenes increased

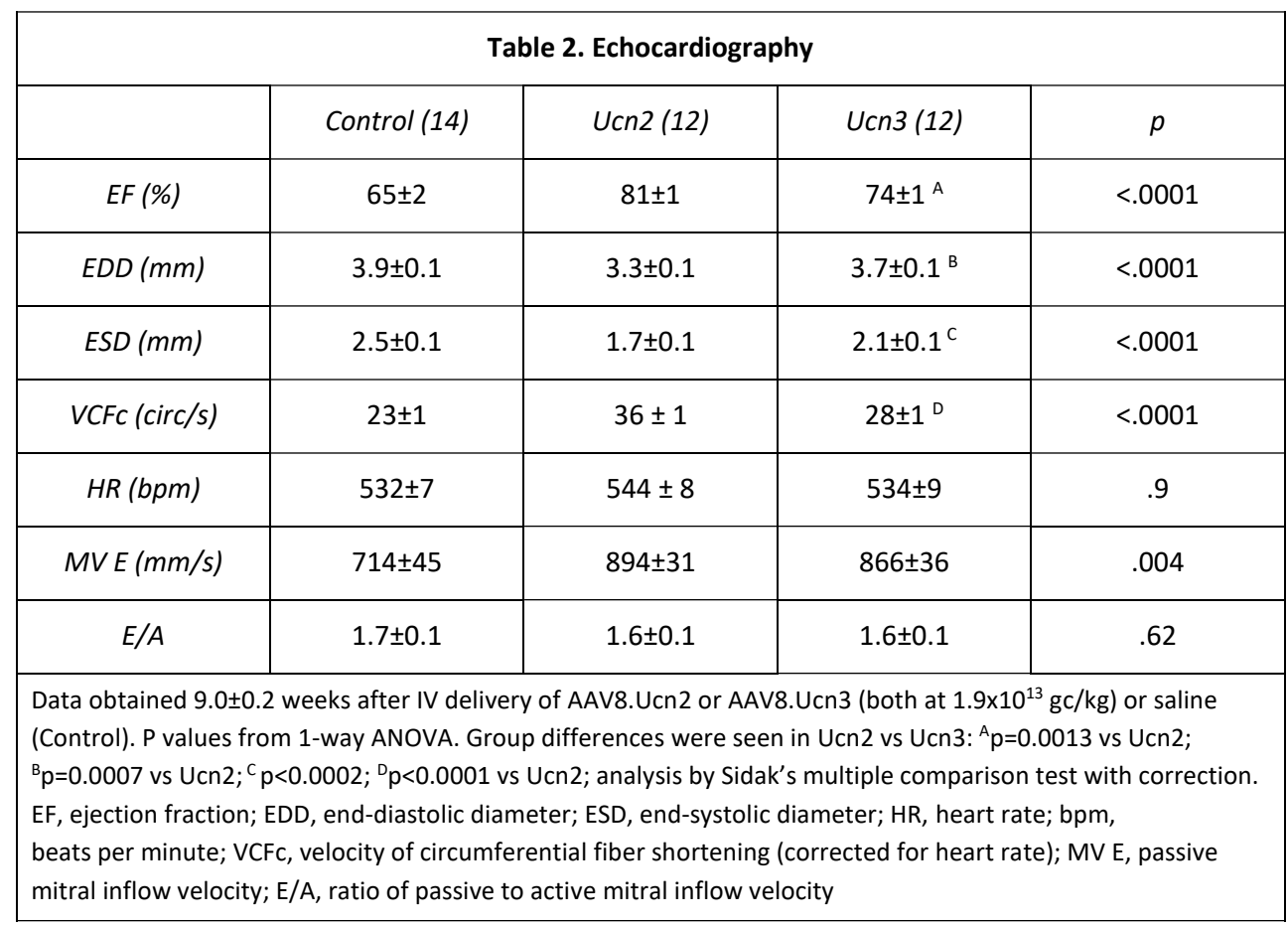

the peak rate of $\mathrm{LV}$ pressure decay $(-\mathrm{dP} / \mathrm{dt})$, with $\mathrm{Ucn} 2$ resulting to a 1.3 -fold increase and Ucn3 a 1.2-fold increase (Control: $-5597 \pm 292 \mathrm{mmHg} / \mathrm{s}, \mathrm{n}=18$; Ucn2: $-7212 \pm 357 \mathrm{mmHg} / \mathrm{s}$, $\mathrm{n}=8$; Ucn3: $-6859 \pm 342 \mathrm{mmHg} / \mathrm{s}, \mathrm{n}=20 ; \mathrm{p}=0.006$, Fig. $2 \mathrm{C}$ ). The time constant of relaxation (Tau) was reduced $31 \%$ and $24 \%$ by Ucn 2 and Ucn3 gene transfer, respectively (Control: 8.6 $\pm 0.3 \mathrm{~ms}, \mathrm{n}=9$; Ucn2: 5.9 $\pm 0.6 \mathrm{~ms}, \mathrm{n}=8$; Ucn3: $6.5 \pm 0.6 \mathrm{~ms}, \mathrm{n}=8 ; \mathrm{p}=0.002$, Fig. 2D). Cardiac output (CO) was increased by Ucn2 and Ucn3 gene transfer by $65 \%$ and $50 \%$, respectively (Control: $3.69 \pm 0.35 \mathrm{~mL} / \mathrm{min}, \mathrm{n}=9$; Ucn2: $6.10 \pm .0 .66 \mathrm{~mL} / \mathrm{min}, \mathrm{n}=8$; Ucn3: $5.53 \pm 0.81 \mathrm{~mL} / \mathrm{min}$, $\mathrm{n}=8 ; \mathrm{p}=0.03$, Fig. 2E). LV developed pressure showed no group differences (Fig. 2F). Heart rate under anesthesia was increased in mice that had received Ucn2 or Ucn3 gene transfer (Control: 391 \pm 10 bpm, $n=18$; Ucn2: 457 \pm 13 bpm, $n=8$; Ucn3: 416 \pm 14 bpm, $n=20 ; p=0.01$, Fig. 2G). There were no group differences between Ucn2 and Ucn3 effects on $+d P / d t$ $(p=0.2)$, ESPVR slope $(p=0.4),-d P / d t(p=0.5)$, Tau $(p=0.4)$, CO $(p=0.5)$, or HR $(p=0.06)$.

Cytosolic $\mathrm{Ca}^{2+}$ Transients. Cardiac myocytes were isolated 9.0 \pm 0.2 weeks after gene transfer or saline injection and used for $\mathrm{Ca}^{2+}$ transient assessment. There were group differences in 

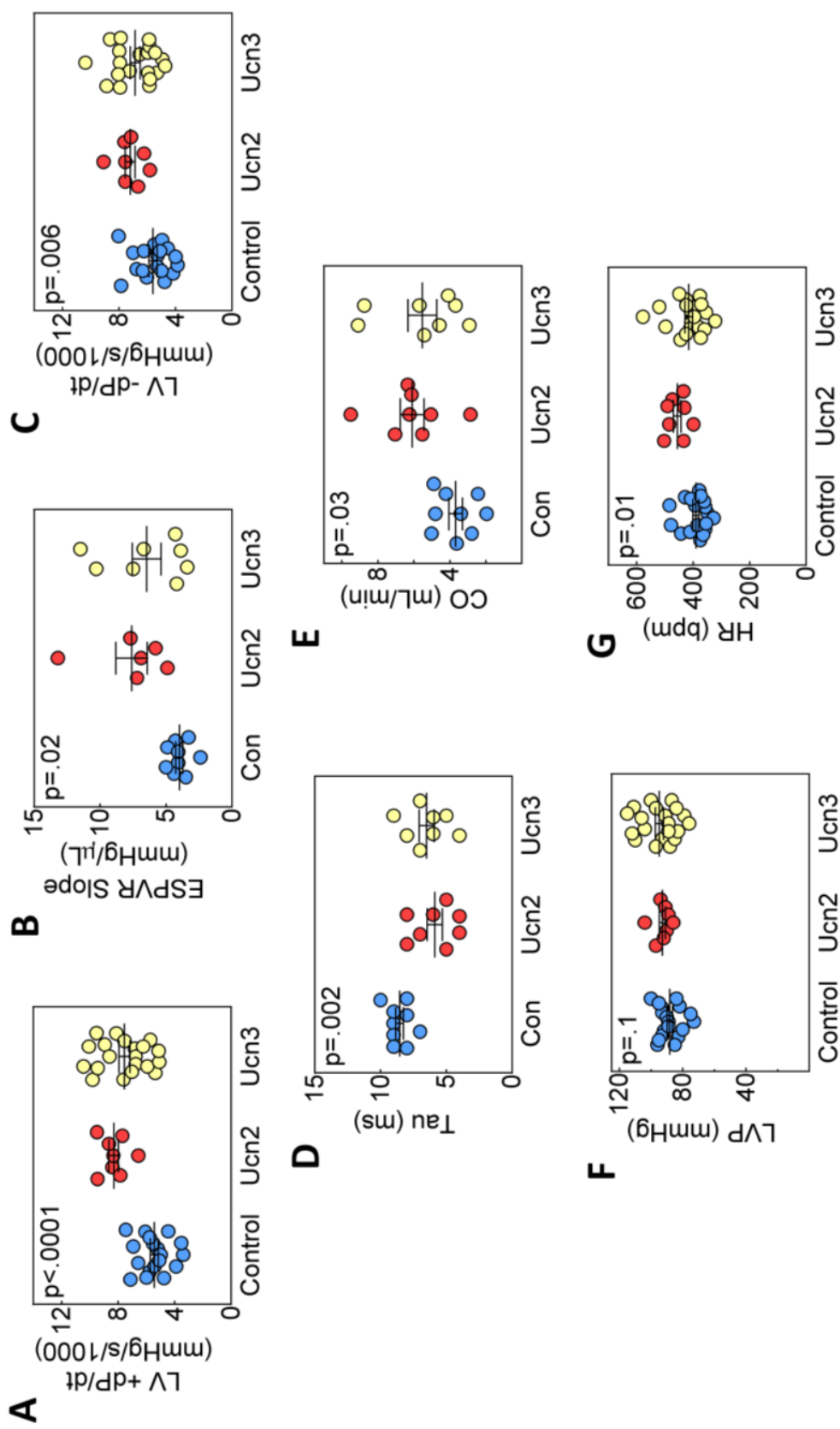

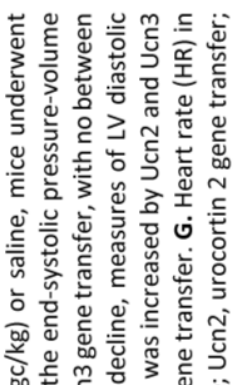

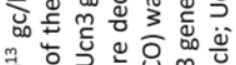

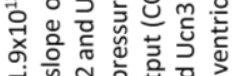
는 흔흏원 m

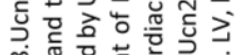

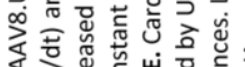

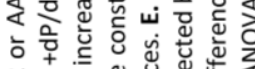

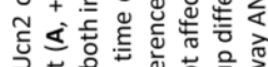

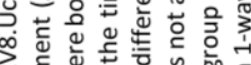

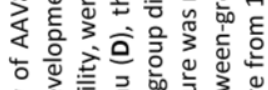

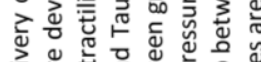

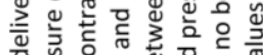

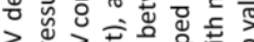

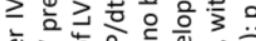

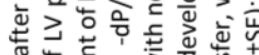

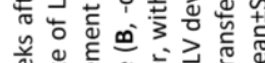

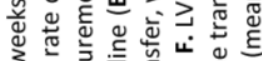

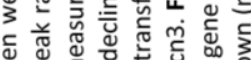

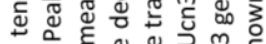

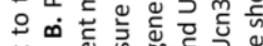

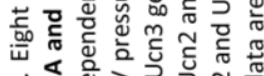
ปั่

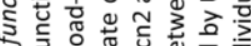
$\geq 3$ 는

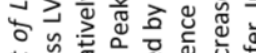

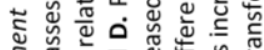
ह

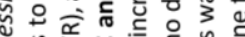
ڤั

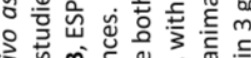
วิ

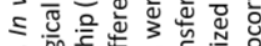

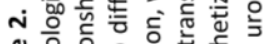

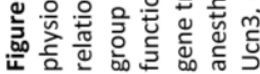


peak cytosolic $\mathrm{Ca}^{2+}$ concentration ( $p<0.007$; Figs. 3A and 3B). Both Ucn2 and Ucn3 increased peak cytosolic $\mathrm{Ca}^{2+}$ concentration, although there was no between group difference in Ucn2 vs Ucn3 ( $p=0.19)$. Tau, the time constant for LV pressure decline and a measure of LV diastolic function, showed a group difference ( $p=0.0003$; Fig. $3 C)$. Ucn2 and Ucn3 gene transfer reduced the time constant similarly (Control: $0.16 \pm 0.006 \mathrm{sec}, \mathrm{n}=52$; Ucn2: $0.14 \pm 0.005 \mathrm{sec}, \mathrm{n}=54$; Ucn3: $0.14 \pm 0.004 \mathrm{sec}, \mathrm{n}=61$ ). The time to peak cytosolic $\mathrm{Ca}^{2+}$ concentration showed no group difference (Fig. 3D).

\begin{tabular}{|c|c|c|c|c|c|}
\hline \multicolumn{6}{|c|}{ Table 3. Expression of Key Proteins (mRNA) } \\
\hline & \multirow{2}{*}{ Control (4) } & \multicolumn{2}{|c|}{ Fold Control } & \multicolumn{2}{|c|}{$p$} \\
\hline & & AAV8.Ucn2 (4) & AAV8.Ucn3 (4) & ANOVA & Ucn2 vs Ucn3 \\
\hline ANF & $1.0 \pm .18$ & $.49 \pm .1$ & $.79 \pm .14$ & .08 & - \\
\hline$B N P$ & $1.0 \pm .18$ & $.34 \pm .05$ & $.49 \pm .12$ & .03 & .43 \\
\hline$\alpha$-Skeletal actin & $1.0 \pm .2$ & $.36 \pm .07$ & $.35 \pm .02$ & .01 & .84 \\
\hline Cardiac actin & $1.0 \pm .06$ & $1.03 \pm .1$ & $.94 \pm .06$ & .75 & - \\
\hline$\alpha-M H C$ & $1.0 \pm .04$ & $.87 \pm .06$ & $1.08 \pm .07$ & .16 & - \\
\hline$\beta-M H C$ & $1.0 \pm .12$ & $.64 \pm .16$ & $.82 \pm .15$ & .2 & - \\
\hline$M L C 2 v$ & $1.0 \pm .07$ & $.77 \pm .02$ & $.93 \pm .07$ & .06 & - \\
\hline$c M L C K$ & $1.0 \pm .03$ & $1.19 \pm .57$ & $1.42 \pm .1$ & .006 & .042 \\
\hline IGF-1 & $1.0 \pm .5$ & $.38 \pm .11$ & $.83 \pm .33$ & .75 & - \\
\hline IGF-BP3 & $1.0 \pm .06$ & $.68 \pm .03$ & $1.19 \pm 0.06$ & .0012 & .0033 \\
\hline Ucn2 & $1.0 \pm .1$ & $209 \pm 49$ & $1.3 \pm 0.1$ & .0012 & .08 \\
\hline Ucn3 & $1.0 \pm .2$ & $18 \pm 13$ & $2020 \pm 121$ & .0012 & .24 \\
\hline FGFG $^{A}$ & $1.0 \pm .3$ & $.09 \pm .01$ & $.32 \pm .07$ & .0005 & .1 \\
\hline $\mathrm{NpY}^{\mathrm{A}}$ & $1.0 \pm .4$ & $.09 \pm .04$ & $.38 \pm .12$ & .01 & .09 \\
\hline$N p Y 1 r^{B}$ & $1.0 \pm .3$ & $.97 \pm .08$ & $.95 \pm .18$ & 1 & - \\
\hline Ucn2 (Liver) & $1.0 \pm .4$ & $5173 \pm 1452$ & $3.5 \pm 1.3$ & .0002 & .12 \\
\hline Ucn3 (Liver) & $1.0 \pm .6$ & $.4 \pm .1$ & $4836 \pm 504$ & .0002 & .0017 \\
\hline \multicolumn{6}{|c|}{$\begin{array}{l}\text { Fold control ( } \pm \text { SE) in left ventricular (LV) mRNA levels of key proteins } 9.0 \pm 0.2 \text { weeks after AAV8.Ucn2 vs } \\
\text { AAV8.Ucn3 gene transfer }\left(1.9 \times 10^{13} \mathrm{gc} / \mathrm{kg} \text {, IV). Also shown (bottom } 2 \text { rows) are Ucn2 and Ucn3 expression in liver. }\right. \\
\text { Control mice received IV saline ( } \mathrm{n}=4 \text { for all } 3 \text { groups). Ucn2, urocortin-2; Ucn3, urocortin-3; ANF, atrial } \\
\text { natriuretic factor; BNP, brain natriuretic peptide; MHC, myosin heavy chain; MLC2v, myosin light chain } 2 \mathrm{v} \text {; } \\
\text { cMLCK, cardiac myosin light chain kinase; IGF-1, insulin-like growth factor } 1 ; \text { IGF-BP3, IGF binding protein } 3 \text {; } \\
\text { FGF6, fibroblast growth factor } 6 \text {; NpY, Neuropeptide Y; NpY1r, Neuropeptide Y receptor type } 1 ; \mathrm{p} \text { values } \\
\text { from Kruskal-Wallis test, Ucn2 vs Ucn3 } p \text { value from Dunn's multiple comparison test with correction. }{ }^{\mathrm{A}} \text { mRNA } \\
\text { levels were found to be reduced by focused gene array, confirmed by RT-PCR; }{ }^{B} \mathrm{NpY} 1 \mathrm{r} \text { was examined because of } \\
\text { changes seen in NpY }\end{array}$} \\
\hline
\end{tabular}




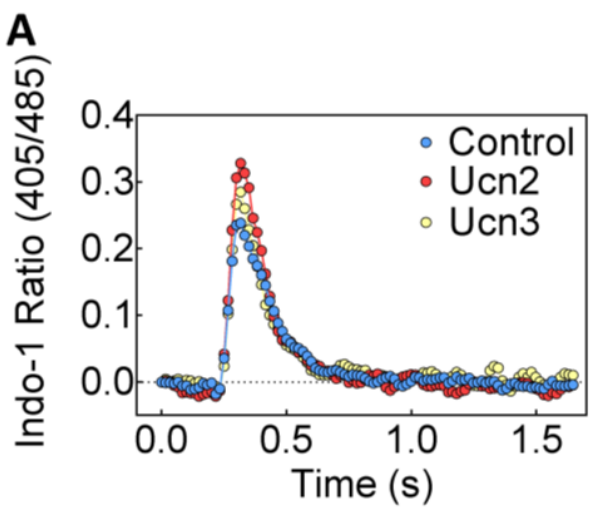

C

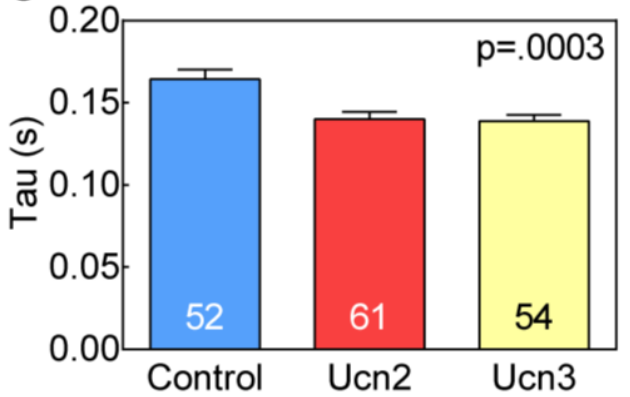

B

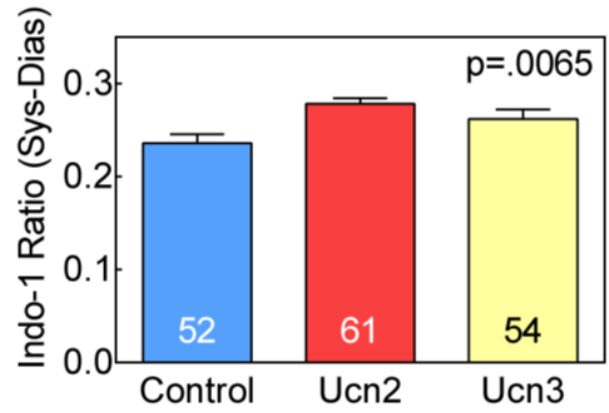

D

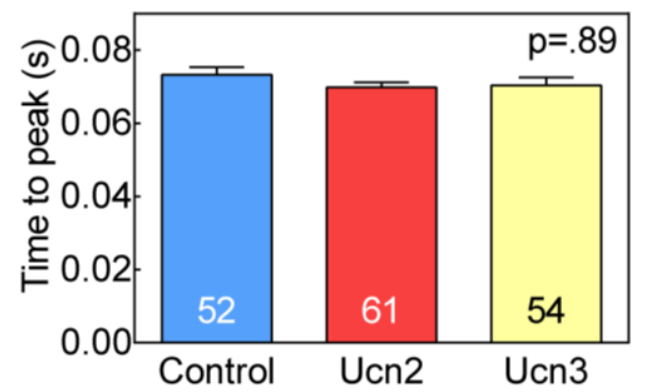

Figure 3. Cytosolic $\mathrm{Ca}^{2+}$ transients. Cardiac myocytes isolated from mice $9.0 \pm 0.2$ weeks after IV delivery AAV8.Ucn2 or AAV8.Ucn3, both at $1.9 \times 10^{13} \mathrm{gc} / \mathrm{kg}$, or saline (control, Con). A. Representative Indo- $1 \mathrm{Ca}^{2+}$ transient recordings from cardiac myocytes from one heart in each group. B. Mean peak $\mathrm{Ca}^{2+}$ transients from multiple cardiac myocytes from each group, showing increased peak $\mathrm{Ca}^{2+}$ transients in cardiac myocytes isolated form mice following Ucn2 and Ucn3 gene transfer. There was no group difference between Ucn2 and Ucn3. C. Time constant of cytosolic $\mathrm{Ca}^{2+}$ decline (Tau) showing reduced Tau (more rapid decline) in cardiac myocytes isolated from mice following Ucn2 and Ucn3 gene transfer. There was no group difference between Ucn2 and Ucn3. D. Time-to-peak cytosolic $\mathrm{Ca}^{2+}$ concentration showed no group differences. In B-D, summary data from cardiac myocytes isolated from 4 mice per group; Numbers in bars denote the number of cardiac myocytes per group; $p$ values are from 1-way ANOVA. Bars denote mean and SE.

LV Signaling. There were no group differences in LV cAMP levels or PKA activity (Fig. 4A and 4B). LV levels of phosphorylated $\mathrm{Ca}^{2+} /$ calmodulin-dependent protein kinase II (CamKII, isoform $\alpha$ ) were reduced ( $p=0.0024)$ by both Ucn2 (71\% reduction) and Ucn3 gene transfer (55\% reduction) (Fig. 4C). Phosphorylated ryanodine receptor 2 (RYR2) protein levels showed group differences ( $p=0.013$; Fig. 4D), solely attributable to a $59 \%$ reduction associated with Ucn2 gene transfer. LV sarcoplasmic endoplasmic reticulum calcium $\left(\mathrm{Ca}^{2+}\right)$ ATPase (SERCA2a) protein levels were increased similarly in Ucn2 and Ucn3 groups ( $p=0.04$, Fig. 4E).

We also measured LV mRNA expression of key signaling proteins (Table 3 ), which revealed some differences in the effects of Ucn2 vs Ucn3 gene transfer. For example, although cardiac myosin light chain kinase (cMLCK) expression was increased by gene transfer of Ucn2 and Ucn3 ( $p=0.006)$, the increase following Ucn3 gene transfer was 


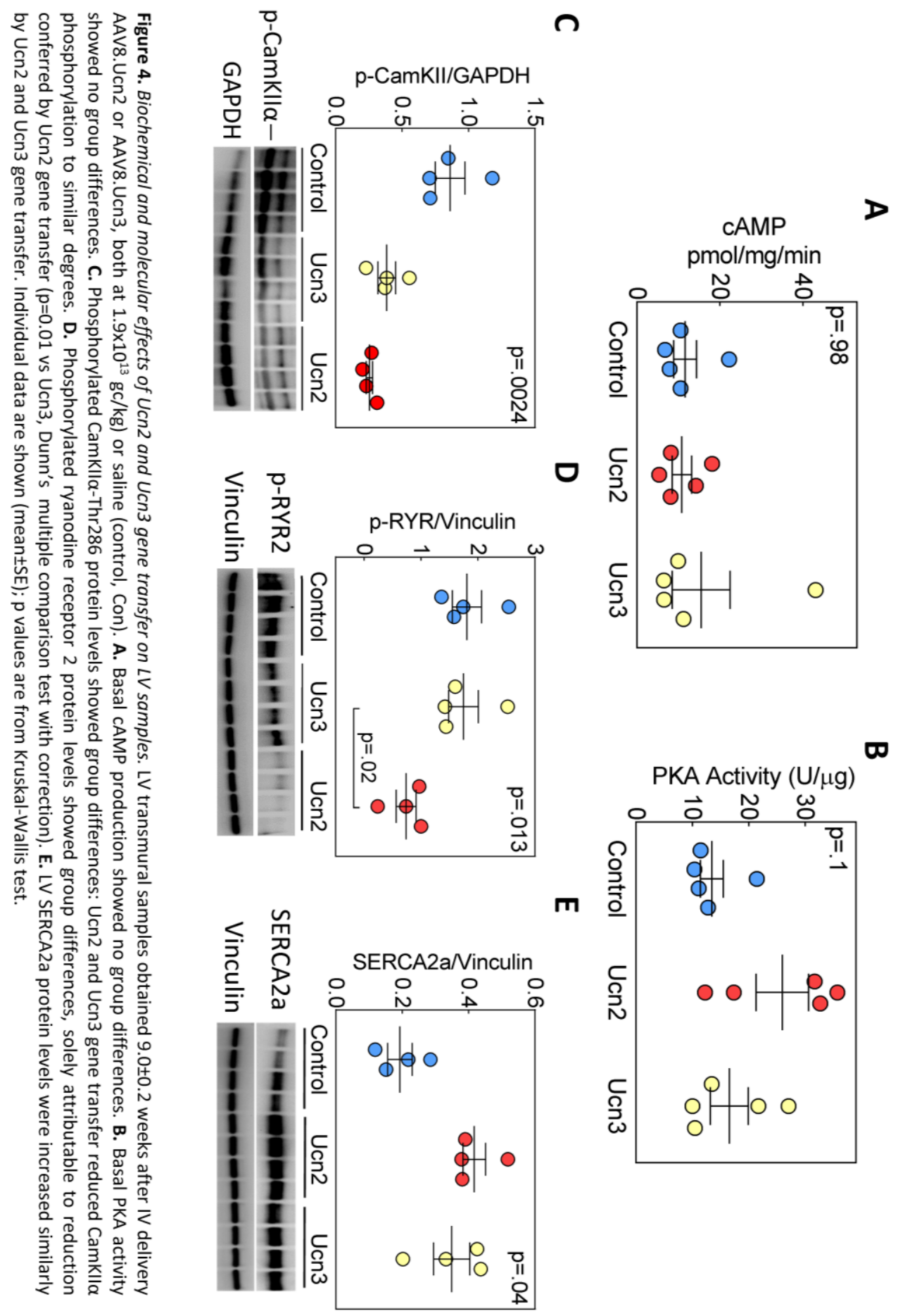


somewhat greater in degree (Ucn2: 1.2-fold control; Ucn3: 1.4-fold control; $p=0.042$ ). In addition, insulin-like growth factor binding protein 3 mRNA was reduced $32 \%$ by Ucn2, but increased $19 \%$ by Ucn3 gene transfer (group difference: $p=0.0033$ ). The LV expression of an additional 84 proteins in the $\mathrm{CAMP} / \mathrm{Ca}^{2+}$ signaling pathway, showed that fibroblast growth factor 6 (FGF6) and neuropeptide $\mathrm{Y}$ (NpY) were decreased by Ucn2 and Ucn3 gene transfer similarly, while NpY1 receptor expression was unchanged. These findings were confirmed by RT-PCR (Table 3). LV and liver Ucn2 mRNA increased (209-fold and 5173-fold, respectively). The extent of Ucn 2 and Ucn3 expression in liver was similar, but LV expression was somewhat higher for Ucn3 than Ucn2 (Table 3).

Fasting Glucose and Glucose Tolerance Testing. We previously showed that Ucn2 gene transfer was associated with increased insulin sensitivity and increased glucose disposal (16). We therefore tested whether Ucn2 and Ucn3 gene transfer affected glucose disposal in normal mice. We used two measures to quantify glucose disposal: fasting blood glucose, and glucose tolerance testing. Eight to 10 weeks after Ucn2 and Ucn3 gene transfer, fasting (12 hr) glucose was reduced in mice that had received Ucn2 gene transfer $(p<0.002$ vs Control; $p<0.001$ vs Ucn3; Fig. 5). Ucn3 gene transfer had no effect on fasting glucose. In addition, glucose tolerance testing confirmed a group difference in glucose clearance. The area under the glucose-time curve showed an overall group difference $(p=0.015)$, which was solely attributable to increased glucose clearance in mice that had received Ucn2 gene transfer ( $p=0.02$ vs Control; $p<0.02$ vs Ucn3). Ucn3 gene transfer, in contrast, had no effect on glucose disposal (Fig. 5).

A

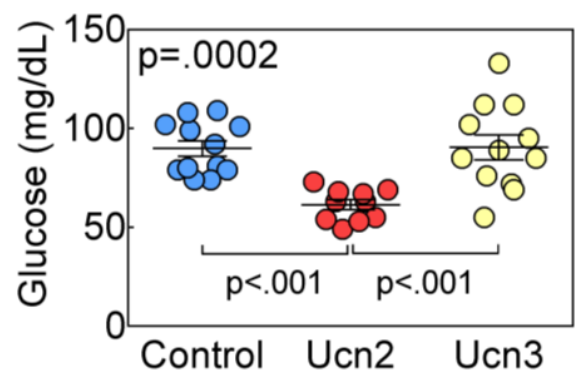

B

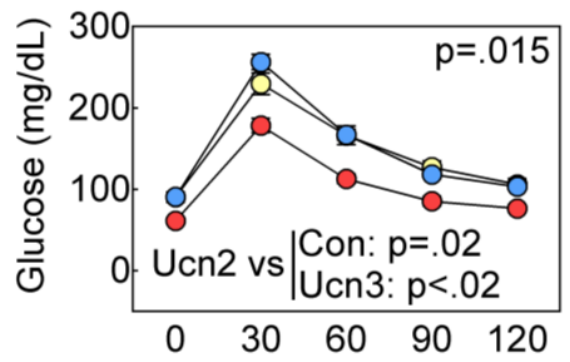

Minutes after glucose injection

○ Control (12) ○ Ucn2 (10) ○ Ucn3 (12)

Figure 5. Fasting blood glucose and glucose tolerance test. Normal mice received IV saline ( $n=12)$, AAV8.Ucn2 $\left(1.9 \times 10^{13} \mathrm{gc} / \mathrm{kg}, \mathrm{n}=10\right)$ or AAV8.Ucn3 $\left(1.9 \times 10^{13} \mathrm{gc} / \mathrm{kg}, \mathrm{n}=12\right)$. Nine \pm 0.2 weeks later, fasting (12 hr) glucose was determined and glucose tolerance testing was performed. A. A group difference in fasting blood glucose was detected (ANOVA, $p=0.0002$ ). Mice that had received Ucn2 gene transfer showed reduced fasting glucose ( $p<0.001$ vs Control; $p<0.001$ vs Ucn3). Individual mouse data are shown, and mean $\pm S E$ are indicated. B. Glucose tolerance testing showed a difference in glucose clearance (ANOVA, $p=0.015$ ). The area under the glucose-time curve was reduced in animals that had received Ucn 2 gene transfer ( $p=0.02$ vs Control; $p<0.02$ vs Ucn3). Between-group comparisons are from Sidak's multiple comparison test with correction.

Necropsy. Mice showed no group differences in body, liver or lung weight (Table 4). However, Ucn2 and Ucn3 gene transfer was associated with a reduction in LV weight 
( $p=0.006$; Table 4). This reduction persisted when LV weight was normalized to body weight $(p=0.0001)$ and was similarly reduced in mice that had received Ucn2 or Ucn3 gene transfer.

Histology and Cardiac Myocyte Size. Histological inspection of transmural samples of LV and liver samples from all three groups showed no abnormalities in inflammatory cell infiltrates or fibrosis. Quantification of fibrosis showed no group differences (Fig. 6). There were differences in cardiac myocyte volume ( $p<0.02,1$-Way ANOVA; Fig. 7$)$. The mean values of $120 \pm 11$ cells measured from each individual animal were: Control: $36.6 \pm 1.1 \mathrm{pL}$, $n=5 ;$ Ucn2: $31.2 \pm 1.4$ pL, $n=5$; Ucn3: $30.1 \pm 1.8, n=5$ ( $p<0.02$; Fig. 7). Thus, cardiac myocytes from control mice were $15 \%$ larger than those from Ucn 2 mice $(p=0.06)$ and $18 \%$ larger than those from Ucn3 mice $(p<0.03)$. Cardiac myocytes from Ucn2 and Ucn3 groups had similar volumes. Cardiac myocytes from control mice were 13-16\% wider (Control: $20.9 \pm 1.8 \mu \mathrm{m}$, $\mathrm{n}=6$; Ucn2: $18.1 \pm 0.6 \mu \mathrm{m}, \mathrm{n}=5$; Ucn3: $17.5 \pm 0.5 \mu \mathrm{m}, \mathrm{n}=5 ; \mathrm{p}=0.1$ ), but minimally longer (Control: 128.1 $\pm 1.9 \mu \mathrm{m}, \mathrm{n}=6$; Ucn2: $120.4 \pm 3.0 \mu \mathrm{m}, \mathrm{n}=5$; Ucn3: 124.6 $\pm 3.2 \mu \mathrm{m}, \mathrm{n}=5 ; \mathrm{p}=0.26$ ).

\section{DISCUSSION}

Sustained elevation of plasma concentrations of Ucn2 vs Ucn3, achieved via gene transfer, has pronounced beneficial effects on LV systolic and LV diastolic function (Fig. 2). These beneficial effects were associated with equivalent enhancement of $\mathrm{Ca}^{2+}$ handling in cardiac myocytes (Fig. 3), and comparable increases in LV SERCA2a expression and reductions in CaMKII phosphorylation (Fig. 4). Ucn2 but not Ucn3 gene transfers reduced LV RYR2 phosphorylation (Fig. 4). However, despite $42 \%$ amino acid sequence homology and binding the same receptors (CRHR2) with similar affinity (Figs. 1A-C), Ucn3 does not affect glucose disposal, while Ucn2 gene transfer does.

LV Function. Indications that Ucn2 gene transfer may have a greater benefit on systolic function than Ucn3 gene transfer were seen in echocardiographic assessment. LV EF and VCFc were increased more by Ucn 2 than by Ucn3 gene transfer $(p=0.0013$ and $p<0.0001$, respectively; Table 2). The comparable beneficial effects of Ucn2 and Ucn3 gene transfer on $\mathrm{Ca}^{2+}$ transients and SERCA2a expression does not explain the differences seen on echocardiography. Given the similarity in LV peak $+d P / d t$ (Fig. 2), which is less loaddependent than EF, the echocardiography differences may reflect small differences in loading conditions rather than differences in LV contractility per se.

In a previously published study we reported that LV $-\mathrm{dP} / \mathrm{dt}$ was not altered 6 weeks after Ucn2 gene transfer in normal mice, (18) but was at 4 months. In the present study we saw increased LV peak $-\mathrm{dP} / \mathrm{dt} 9.0 \pm 0.2$ weeks after gene transfer of either Ucn2 or Ucn3. Both transgenes also reduced the time constant of relaxation (Tau), confirming an important effect on LV diastolic function, which was similar for both transgenes. The percent increase in LV peak +dP/dt vs Control (Ucn2: 53\%; Ucn3: 39\%), which was confirmed by increases in the ESPVR slope (Ucn2: 90\%; Ucn3: 63\%), and in CO (Ucn2: 65\%; Ucn3: 50\% would be anticipated to have important physiological effects, especially in the setting of HF. 
Differences in Plasma Levels of Ucn2 vs Ucn3. One could argue that differences in the effects of Ucn2 vs Ucn3 gene transfer (on RYR2 phosphorylation and EF, for example) simply reflect differences in plasma levels of transgene: plasma Ucn2: $16 \mathrm{ng} / \mathrm{ml}(3.6 \mathrm{nmol} / \mathrm{L})$ was higher than plasma Ucn3: $7 \mathrm{ng} / \mathrm{ml}(1.8 \mathrm{nmol} / \mathrm{L})$ (Fig. 1C). However, the relative changes were greater after Ucn3 gene transfer (70-fold increase) than after Ucn2 gene transfer (20fold increase). The affinity of Ucn2 and Ucn3 for the CRHR2 receptor is comparable, and their ability to stimulate cAMP in cells stably transfected with CRHR2 $\beta$ is similar (Fig. 1C; EC50 $0.05-0.08 \mathrm{nmol} / \mathrm{L}$ for CAMP production) (24). In contrast, the EC50 for Ucn2 and Ucn3 activation of CRHR1 is $>100 \mathrm{nmol} / \mathrm{L}(24)$, a concentration far in excess of what was achieved in the present study $(1.8-3.6 \mathrm{nmol} / \mathrm{L})$. It therefore seems likely that CRHR2 receptors were saturated, CRHR1 receptors minimally activated, and that downstream effects of activation were maximal at the plasma concentrations obtained. It is possible that the effects measured were not receptor-dependent. However, in a previous study we have shown the

A
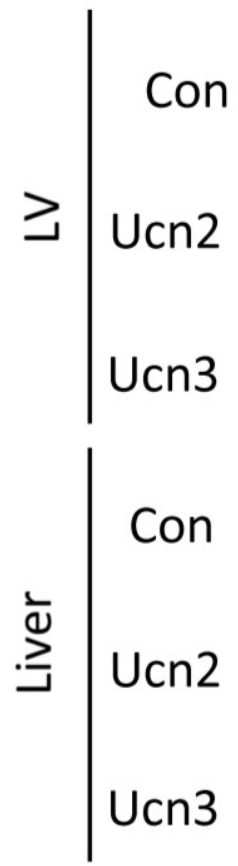

H\&E Trichrome
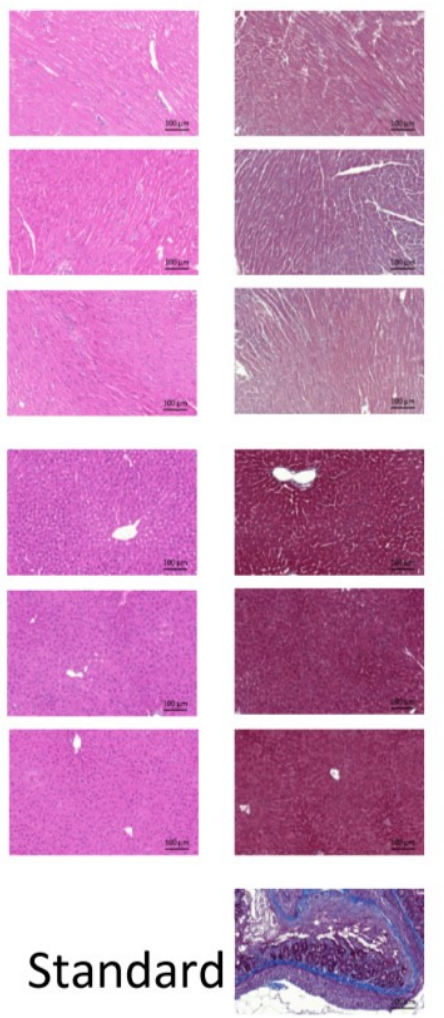

$\cdot$

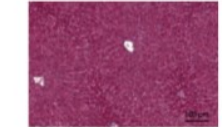

B
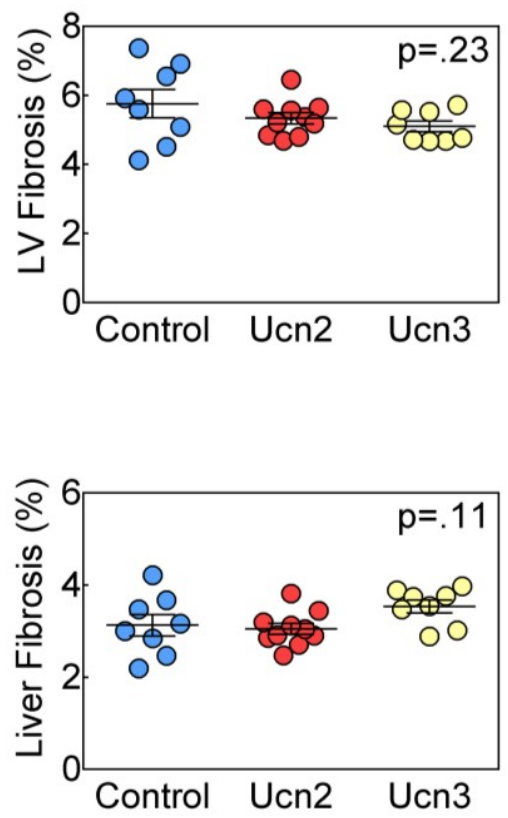

Figure 6. Histological analysis of left ventricle (LV) and liver. A. Hematoxylin and eosin (H\&E) and Masson's trichrome staining were performed on liver and transmural sections of LV (original magnification 20X; presented image magnification 7X), 9.0 \pm 0.2 weeks after intravenous injection of saline, AAV8.Ucn2 $\left(1.9 \times 10^{13} \mathrm{gc} / \mathrm{kg}\right) \mathrm{and}$ AAV8.Ucn3 $\left(1.9 \times 10^{13} \mathrm{gc} / \mathrm{kg}\right)$. B. Evaluation of fibrosis was performed using ImageJ software. AAV8.Ucn2 and AAV8.Ucn3 delivery were not associated with histological abnormalities. Standard, control for Masson's trichrome. 
effects of Ucn2 gene transfer on glucose disposal are dose-dependent and absent in CRHR2deleted mice (16). An important consideration is whether or not there are variations in the clearance of these peptides from plasma, but we could find no data regarding the specific peptidases involved. A structure analysis excludes the likelihood that neprilysin, or neurolysin are involved. Endothelin converting enzyme-1, which can cleave CRF and Ucn1 at high agonist concentrations at CRHR1 (25) are not known to play a role in Ucn2 and Ucn3 degradation.

Heart Rate and Blood Pressure. Although the anticipated reductions in blood pressure were seen, the reductions were equivalent following Ucn2 and Ucn3 gene transfer, and no differences in heart rate were observed (Table 1). These data, obtained in untethered unsedated mice provide persuasive evidence that unlike the case with IV infusion of Ucn3 in human subjects (26), we do not see abnormally low blood pressure is not seen with Ucn2 or Ucn3 gene transfer, and there is no increase in heart rate. A plausible explanation, given that Ucn2 and Ucn3 peptide lower systemic vascular resistance, $(8,14,15)$ is that sustained high plasma levels of these peptides are associated with blunting of vasodilator and chronotropic effects.

Effects on LV Signaling. Ucn 2 and Ucn3 gene transfer equivalently reduced phosphorylation of CamKII in LV samples (Fig. 4). While such a finding does not provide a mechanism by which the differences in the effects of Ucn2 vs Ucn3 can be explained, it may have contributed to the comparable increases in LV function observed after gene transfer. CaMKII expression and activation are important determinants of cardiac function, and its inhibition enhances LV function (27) We previously showed that Ucn2 gene transfer reduces LV CaMKII expression in HF in mice (19). Although we speculate that reduced Thr286 phosphorylation of CaMKII may have contributed to increased LV function, we did not determine the mechanism by which increased Ucn2 or Ucn3 evokes this change.

We found that Ucn2 but not Ucn3 gene transfer reduced LV RYR2 phosphorylation (Fig. 4). Although the consequences of variations in RYR2 phosphorylation on LV function are debated (28), a 59\% reduction in LV RYR2 phosphorylation is a distinctive difference in the effects of Ucn2 vs Ucn3 gene transfer, and RYR2 phosphorylation has been linked to reduced arrhythmias, and increased LV function in $\mathrm{HF}(29,30)$. Although we screened LV expression of 84 signaling proteins in the $\mathrm{cAMP} / \mathrm{Ca}^{2+}$ pathway, there were none that showed significant directionally opposite effects of Ucn2 vs Ucn3 gene transfer.

Reduced LV Mass. Ucn2 and Ucn3 gene transfer were associated with similar reductions in LV mass. The reduction, which was $14 \%$ for both Ucn2 and Ucn3 gene transfer, was significant ( $p=0.006$; Table 4 ), and correlated closely with similar $15-18 \%$ reductions in cardiac myocyte volume (Fig. 7). Reduced cardiac myocyte volume was mostly due to reduced cardiac myocyte width with less reduction in length. The mean cardiac myocyte volume in control mice $(36.6 \pm 1.1 \mathrm{pL})$ is somewhat higher than those reported in rabbits $(30.4 \pm 1.4 \mathrm{pL})$, ferrets $(30.9 \pm 1.9 \mathrm{pL})$ and rats $(34.4 \pm 1.5 \mathrm{pL})$, measured by the same techniques (31).

The absence of fibrosis and the architecture of the cardiac myocytes is compatible with a physiological rather than a pathophysiological process. The reduction in blood pressure 
vs control conferred by both Ucn2 and Ucn3 gene transfer (Table 1) is a possible explanation for reduced LV mass. Indeed, the mass difference may reflect, at least in part, relative systolic hypertension in control mice vs Ucn2 and Ucn3 mice, especially during nocturnal activity (Control: 142 $\pm 5 \mathrm{mmHg}$; Ucn2: $123 \pm 6 \mathrm{mmHg}$; Ucn3: $128 \pm 3 \mathrm{mmHg}$ ) may have contributed to an increased LV mass in the control animals. The reduction in LV CamKII phosphorylation seen following Ucn2 and Ucn3 gene transfer (Fig. 4) may also have played a role in the reduction of LV mass. For example, pharmacological inhibition of CaMKII reduces hypertension-induced LVH (32).

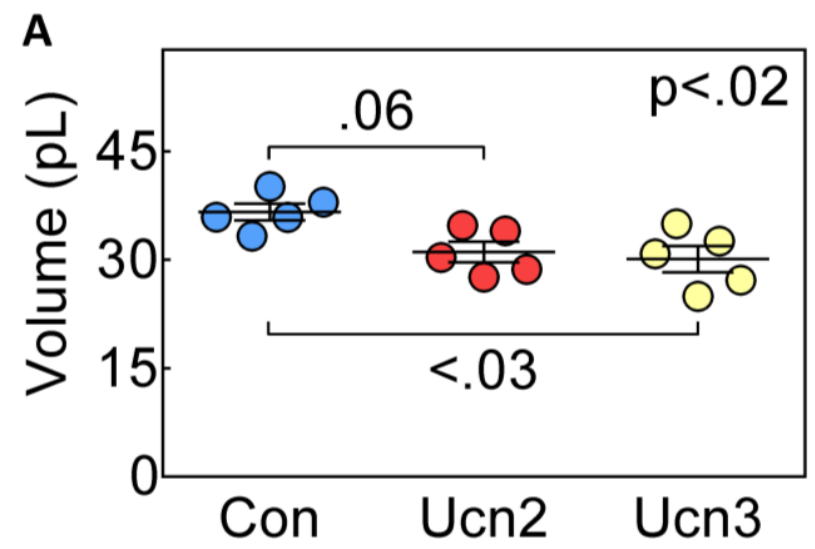

\section{B}

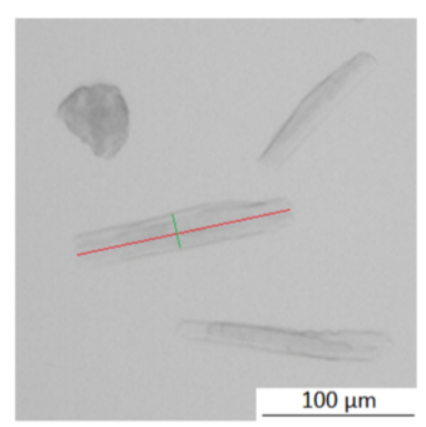

Figure 7. Cardiac Myocyte Volume. Cardiac myocytes were isolated $9.0 \pm 0.2$ weeks after intravenous delivery of saline, AAV8.Ucn $2\left(1.9 \times 10^{13} \mathrm{gc} / \mathrm{kg}\right)$ or AAV8.Ucn $3\left(1.9 \times 10^{13} \mathrm{gc} / \mathrm{kg}\right)$. Viable isolated cardiac myocytes were fixed in $10 \%$ formalin, stained with eosin and their size was measured using Image J software. A. Each symbol represents the mean volume of $120 \pm 11$ cardiac myocytes measured per mouse. Measures were made blinded to group identity. B. Representative isolated cardiac myocytes, indicating cardiac myocyte length (red) and width (green) measurement. There was an overall group difference in cardiac myocyte volume ( $p=0.02$, Kruskal-Wallis) due to larger volume in cardiac myocytes from control mice. Between group comparisons are from Dunn's multiple comparison test.

Glucose Disposal. A key difference in the effects of Ucn2 vs Ucn3 gene transfer was that Ucn2 gene transfer-but not Ucn3 gene transfer-reduced fasting blood glucose and increased glucose disposal in normal mice. These data confirm those that we previously published (16) regarding the effects of Ucn2 gene transfer on glucose disposal, but extend the findings to indicate that the effect is Ucn2-specific, occurs even in normal animals, and is not seen with Ucn3 gene transfer. Why Ucn3 does not have this effect was not addressed in the current study, but is a focus on ongoing studies. Although the assessment of insulin resistance is usually conducted in the setting of obesity and pre-diabetes or diabetes, it is a continuous variable and can be influenced by physiological interventions in normal subjects. For example, sedentary non-diabetic men showed significant reductions in insulin sensitivity 24 weeks after moderate intensity dynamic exercise training (33). In the present study, mice that received Ucn2 gene transfer experienced a reduction in glucose disposal that likely reflects an increase in insulin sensitivity (Fig. 5). 
Variations in Effects. Ucn2 and Ucn3 peptides have 42\% sequence homology, and bind the same receptors with comparable affinities (CRHR2 $\alpha$ and CRHR2 $\beta$; Fig. 1C) (24). Why then do we see differences in the effects of Ucn2 vs Ucn3 gene transfer? Although similar, the

\begin{tabular}{|c|c|c|c|c|}
\hline \multicolumn{2}{|c|}{ Control (12) } & Ucn2 (8) & Ucn3 (12) & $p$ value \\
\hline$B W(g)$ & $29 \pm 1$ & $29 \pm 2$ & $29 \pm 1$ & 0.95 \\
\hline$L V(m g)$ & $98 \pm 4$ & $86 \pm 2$ & $84 \pm 2$ & 0.006 \\
\hline$L V / B W(\mathrm{mg} / \mathrm{g})$ & $3.4 \pm 0.1$ & $3.0 \pm 0.0$ & $151 \pm 5$ & 0.0001 \\
\hline Lung (mg) & $149 \pm 4$ & $142 \pm 4$ & $1301 \pm 66$ & 0.32 \\
\hline Liver (mg) & $1349 \pm 44$ & $1224 \pm 40$ & & 0.32 \\
\hline $\begin{array}{l}\text { Necropsy data obtained 9.0 } \\
\text { saline (control). P values from 1-way ANOVA. There was no group difference between Ucn2 and Ucn3. BW, body } \\
\text { weight; LV, left ventricle }\end{array}$ \\
\hline
\end{tabular}

affinities of Ucn2 for the two CRHR2 subtypes are somewhat tighter (Ki at CRHR2 $\alpha$ : Ucn2, $2.1 \mathrm{nM}$; Ucn3, $5.0 \mathrm{nM}$; Ki at CRHR2 $\beta$ : Ucn2, $0.7 \mathrm{nM}$; Ucn3, $1.8 \mathrm{nM}$ ). These small differences may be associated with variations in physiological responsiveness. Others have demonstrated that variation in 3-dimensional conformation of the two peptides can alter agonist-receptor interaction and thereby influence downstream effects (34). In particular, the 3-dimensional stuctures of CRF family peptides, including Ucn2 and Ucn3, possess $\alpha$ helical backbones with a turn (described as a kink) at residues 25-27, resulting in a helixloop-helix morphology-these two helices may play important roles in receptor binding and affinity (35). Ucn2 shows a more acute angle between helices compared to Ucn3, and this may, at least in theory, alter receptor activation (35). Finally, Ucn3 but not Ucn2, is required for glucose- and incretin-stimulated insulin secretion and is expressed in pancreatic $\beta$ cells (36). However, if transgene Ucn3 increased insulin secretion in the present study, it had no apparent effect on glucose disposal.

Implication for HF Therapy. As has been reported before, Ucn2 and Ucn3 (or its homologue, stresscopin) have shown beneficial cardiovascular effects in preclinical and clinical HF $(11,12,14,15)$. In those studies, Ucn2 and Ucn3 peptides were infused IV or, in one case, intra-arterially (15). This approach, due to the short half-life of the peptides, provided benefits of limited duration. We have previously shown that Ucn2 gene transfer provides sustained increases in both plasma Ucn2 and cardiac function in normal mice and in mice with heart failure $(18,19)$. The current study confirms the previous studies of Ucn2 gene transfer in normal mice, and extends the findings to Ucn3 gene transfer where we also see sustained increases in LV function.

Conclusions. Ucn2 and Ucn3 gene transfer reduce blood pressure without increasing heart rate in untethered and unsedated mice. LV mass is reduced by Ucn 2 and Ucn3 gene transfer, a possible sequalea of reduced blood pressure and diminished LV CaMKII phosphorylation. 
Similar and substantial increases in measures of LV systolic and diastolic function are seen with Ucn2 and Ucn3 gene transfer, mediated by increased LV SERCA2a expression and increased $\mathrm{Ca}^{2+}$ handling. Ucn2 but not Ucn3 gene transfer reduced fasting glucose and increased glucose disposal. These findings suggest that Ucn2 and Ucn3 may be effective treatments for $\mathrm{HF}$, and indicate that Ucn2 may be an optimal selection in patients with diabetes and HF. It remains to be determined whether Ucn3 gene transfer, like Ucn2 gene transfer (19) increases function of the failing heart. Further investigation into precise molecular pathways by which Ucn2 and Ucn3 gene transfer influence $\mathrm{Ca}^{2+}$ handling and key $\mathrm{Ca}^{2+}$ handling proteins are underway.

\section{PERSPECTIVES}

Clinical Competencies. HF and diabetes are two of the most prevalent disorders encountered clinically, and both diseases have poor outcomes despite recent advances in therapy. New strategies to treat HF and diabetes urgently are needed. Data from the current study indicate that gene transfer of Ucn2 and Ucn3 increase systolic and diastolic function of the normal heart, and that Ucn2 gene transfer, but not Ucn3 gene transfer increases glucose disposal.

Translational Outlook. The present paper is an important step in translating Ucn2 and Ucn3 gene transfer to clinical applications, and adds to our knowledge regarding the specificity of Ucn2 gene transfer in increasing glucose disposal. There are two potential obstacles to translation to clinical settings. First, will sustained increases in plasma Ucn2 or Ucn3 be well tolerated? A biodistribution and toxicology study of the long term and dose-related effects of Ucn2 gene transfer is underway. Second, will Ucn3 gene transfer, like Ucn2 gene transfer, have a favorable impact in $\mathrm{HF}$, and will Ucn3 have a favorable impact in diabetes? We have recently shown that Ucn2 gene transfer increases function of the failing heart (19) and also restores insulin sensitivity in two models of insulin resistance (16). However, the effects of Ucn3 gene transfer in preclinical HF have not been tested. An exciting aspect of the present data is the possibility that Ucn2 or Ucn3 gene transfer-via a single IV administrationmight provide prolonged improvement in LV diastolic function in patients with HF and preserved ejection fraction, a clinical problem that has been resilient to effective therapy.

\section{FUNDING SOURCES}

This work was supported by NIH grants P01 HL066941 and R42HL122038; an NHLBI Gene Therapy Resource Program grant (HHSN268201200041C); and VA Merit grants $1101 \mathrm{BX} 001515$ and 1101BX003774. 


\section{REFERENCES}

1. Levy $D$, Kenchaiah S, Larson MG, et al. Long-term trends in the incidence of and survival with heart failure. New Engl J Med.2002;347:1397-2402.

2. Lloyd-Jones D, Adams RJ, Brown TM, et al. Executive summary: heart disease and stroke statistics--2010 update: a report from the American Heart Association. Circulation.2010;121:948-954.

3. Boden WE, O'Rourke RA, Teo KK, et al. Optimal medical therapy with or without PCI for stable coronary disease. New Engl J Med.2007;356:1503-1516.

4. Overman EL, Rivier JE, Moeser AJ. CRF induces intestinal epithelial barrier injury via the release of mast cell proteases and TNF-alpha. PLoS One.2012;7(6):e39935.

5. Cureton EL, Ereso AQ, Victorino GP, et al. Local secretion of urocortin 1 promotes microvascular permeability during lipopolysaccharide-induced inflammation. Endocrinology.2009;150:5428-5437.

6. Urocortin 2 (Homo Sapiens). https://www.ncbi.nlm.nih.gov/gene/90226.

7. Urocortin 3 (Homo Sapiens). https://www.ncbi.nlm.nih.gov/gene/114131.

8. Davis ME, Pemberton CJ, Yandle TG, et al. Urocortin 2 infusion in healthy humans: hemodynamic, neurohormonal, and renal responses. J Amer Coll Cardiol.2007;49:461-471.

9. Davidson SM, Rybka AE, Townsend PA. The powerful cardioprotective effects of urocortin and the corticotropin releasing hormone (CRH) family. Biochem Pharmacol.2009;77:141-150.

10. Wiley KE, Davenport AP. CRF2 receptors are highly expressed in the human cardiovascular system and their cognate ligands urocortins 2 and 3 are potent vasodilators. Brit J Pharm.2004;143:508-514.

11. Chan WY, Frampton CM, Crozier IG, Troughton RW, Richards AM. Urocortin-2 infusion in acute decompensated heart failure: findings from the UNICORN study (urocortin-2 in the treatment of acute heart failure as an adjunct over conventional therapy). JACC Heart failure.2013;1:433441.

12. Gheorghiade $M$, Greene SJ, Ponikowski $P$, et al. Haemodynamic effects, safety, and pharmacokinetics of human stresscopin in heart failure with reduced ejection fraction. Eur J Heart Fail.2013;15:679-689.

13. Bale TL, Hoshijima M, Gu Y, et al. The cardiovascular physiologic actions of urocortin II: acute effects in murine heart failure. Proc Natl Acad Sci.2004;101:3697-3702.

14. Rademaker MT, Charles CJ, Ellmers LJ, Lewis LK, Nicholls MG, Richards AM. Prolonged urocortin 2 administration in experimental heart failure: sustained hemodynamic, endocrine, and renal effects. Hypertension.2011;57:1136-1144.

15. Stirrat CG, Venkatasubramanian S, Pawade T, et al. Cardiovascular effects of urocortin 2 and urocortin 3 in patients with chronic heart failure. Brit J Clin Pharmacol. 2016;82:974-782.

16. Gao MH, Giamouridis D, Lai NC, et al. One-time injection of AAV8 encoding urocortin 2 provides long-term resolution of insulin resistance. JCI insight.2016;1(15):e88322.

17. Patel K, Rademaker MT, Kirkpatrick CM, et al. Comparative pharmacokinetics and pharmacodynamics of urocortins 1, 2 and 3 in healthy sheep. Brit J Pharmacol.2012;166:19161925.

18. Gao MH, Lai NC, Miyanohara A, et al. Intravenous adeno-associated virus serotype 8 encoding urocortin-2 provides sustained augmentation of left ventricular function in mice. Hum Gene Ther.2013;24:777-785.

19. Lai NC, Gao MH, Giamouridis D, et al. Intravenous AAV8 encoding urocortin-2 increases function of the failing heart in mice. Hum Gene Ther.2015;26:347-56. 
20. Du XJ, Feng X, Gao XM, Tan TP, Kiriazis H, Dart AM. I(f) channel inhibitor ivabradine lowers heart rate in mice with enhanced sympathoadrenergic activities. $\mathrm{Br} J$ Pharmacol. 2004;142:107-112.

21. Lai NC, Tang T, Gao MH, Saito M, et al. Activation of cardiac adenylyl cyclase expression increases function of the failing ischemic heart in mice. J Am Coll Cardiol. 2008;51:1490-1497.

22. Gao MH, Lai NC, Roth DM, et al. Adenylylcyclase increases responsiveness to catecholamine stimulation in transgenic mice. Circulation.1999;99:1618-1622.

23. Gao MH, Lai NC, Tang T, et al. Preserved cardiac function despite marked impairment of cAMP generation. PLoS One. 2013;8(9):e72151.

24. Lewis $\mathrm{K}, \mathrm{Li} \mathrm{C}$, Perrin $\mathrm{MH}$, et al. Identification of urocortin III, an additional member of the corticotropin-releasing factor (CRF) family with high affinity for the CRF2 receptor. Proc Natl Acad Sci. 2001;98:7570-7575.

25. Hasdemir B, Mahajan S, Bunnett NW, Liao M, Bhargava A. Endothelin-converting enzyme-1 actions determine differential trafficking and signaling of corticotropin-releasing factor receptor 1 at high agonist concentrations. Mol Endocrinol. 2012;26:681-695.

26. Venkatasubramanian S, Griffiths ME, McLean SG, et al. Vascular effects of urocortins 2 and 3 in healthy volunteers. 2013;2(1):e004267.

27. Swaminathan PD, Purohit A, Hund TJ, Anderson ME. Calmodulin-dependent protein kinase II: linking heart failure and arrhythmias. Circ Res.2012;110:1661-1677.

28. Marks AR. Cardiac intracellular calcium release channels: role in heart failure. Circ Res.2000;87:8-11.

29. Marx SO, Reiken S, Hisamatsu Y, et al. PKA phosphorylation dissociates FKBP12.6 from the calcium release channel (ryanodine receptor): defective regulation in failing hearts. Cell. 2000;101:365-376.

30. Lehnart SE, Wehrens XH, Reiken S, et al. Phosphodiesterase 4D deficiency in the ryanodinereceptor complex promotes heart failure and arrhythmias. Cell.2005;123:25-35

31. Satoh H, Delbridge LM, Blatter LA, Bers DM. Surface:volume relationship in cardiac myocytes studied with confocal microscopy and membrane capacitance measurements: speciesdependence and developmental effects. Biophys J. 1996;70:1494-1504.

32. Cipolletta E, Rusciano MR, Maione AS, et al. Targeting the CaMKII/ERK interaction in the heart prevents cardiac hypertrophy. PLoS One.2015;10(6):e0130477.

33. O'Donovan G, Kearney EM, Nevill AM, Woolf-May K, Bird SR. The effects of 24 weeks of moderate- or high-intensity exercise on insulin resistance. Eur J Appl Physiol. 2005;95:522528

34. Hoare SR, Sullivan SK, Fan J, Khongsaly K, Grigoriadis DE. Peptide ligand binding properties of the corticotropin-releasing factor (CRF) type 2 receptor: pharmacology of endogenously expressed receptors, G-protein-coupling sensitivity and determinants of CRF2 receptor selectivity. Peptides.2005;26:457-470.

35. Grace CRR, Perin MH, Cantle JP, Vale WW, Rivier JE, Reik R. Common and divergent structural features of a series of corticotropin releasing factor-related peptides. J Am Chem Soc. 2007; 129:16102-16114.

36. Li C, Chen P, Vaughan J, Lee KF, Vale W. Urocortin 3 regulates glucose-stimulated insulin secretion and energy homeostasis. Proc Natl Acad Sci.2007;104:4206-42 



\section{Chapter}

\section{Urocortin 3 Gene Transfer Increases Function of the Failing Murine Heart}

Dimosthenis Giamouridis, Mei Hua Gao, N. Chin Lai, Zhen Tan, Young Chul Kim, Tracy Guo, Atsushi Miyanohara, W. Matthijs Blankesteijn, Erik A. L. Biessen, H. Kirk Hammond 


\section{ABSTRACT}

Background. Peptide infusions of the corticotropin releasing factor family, including urocortin 2, stresscopin, and urocortin 3 (Ucn3) have favorable acute effects in clinical heart failure (HF), but their short half-lives make them unsuited for chronic therapy. Here we ask whether Ucn3 gene transfer, which provides sustained elevation of plasma Ucn3 levels, increases function of the failing heart.

Methods. HF was induced by transmural left ventricular (LV) cryoinjury in mice. LV function was assessed 3 weeks later by echocardiography; those with ejection fractions (EF) $<40 \%$ received intravenous (IV) saline, or IV adeno-associated virus type-8 encoding murine Ucn3 (AAV8.mUcn3; $1.9 \times 10^{13}$ genome copies $(\mathrm{gc}) / \mathrm{kg}$ ). Five weeks after randomization, repeat echocardiography, assessment of LV function $(+d P / d t,-d P / d t)$, and quantification of $\mathrm{Ca}^{2+}$ transients and sarcomere shortening in isolated cardiac myocytes were conducted, and assessment of $\mathrm{LV} \mathrm{Ca}^{2+}$ handling and stress proteins was performed.

Results. Three weeks after MI, prior to treatment, EFs were reduced (mean 31\%, from 63\% in sham-operated animals). Mice randomized to receive Ucn3 gene transfer (GT) showed increased plasma Ucn3 (from $0.1 \pm .01 \mathrm{ng} / \mathrm{mL}$ in saline group to $5.6 \pm 1.1 \mathrm{ng} / \mathrm{mL} ; \mathrm{n}=12$ each group; $p<.0001)$. Compared to mice that received saline, Ucn3 gene transfer was associated with higher values for: EF $(p=.0006)$; LV $+d P / d t(p<.0001)$ and LV $-d P / d t(p<.0001)$. Cardiac myocytes from mice that received $\mathrm{Ucn} 3$ gene transfer showed higher peak $\mathrm{Ca}^{2+}$ transients $(p=.0005)$, lower time constant of cytosolic $\mathrm{Ca}^{2+}$ decline (Tau, $\left.\mathrm{p}<.0001\right)$, and higher rates of sarcomere shortening $(+d L / d t, p=.03)$ and lengthening $(-d L / d t, p=.04)$. LV samples from mice that received Ucn3 gene transfer contained higher levels of SERCA2a ( $p=.0004$ vs HF) and increased amounts of phosphorylated troponin I ( $p=.04$ vs HF).

Conclusion. Ucn3 gene transfer is associated with improved $\mathrm{Ca}^{2+}$ handling and $\mathrm{LV}$ function in mice with $\mathrm{HF}$ and reduced $\mathrm{EF}$.

Gene Therapy Heart Failure with Reduced EF SERCA2a AAV8 


\section{INTRODUCTION}

Cardiovascular disease is the most common cause of death in the US. Heart failure (HF) affects 6 million people in the US and has a dismal outlook despite optimal therapy (1). Because of such a poor prognosis, new approaches, including gene transfer, are warranted. Urocortin 3 (Ucn3), is a 38-amino acid peptide in the corticotropin-releasing factor (CRF) family that binds with high affinity to corticotropin-releasing hormone receptor-2 (CRHR2). Intravenous infusion of urocortin 2 (Ucn2) peptide, which has $42 \%$ sequence homology with Ucn3 (2), has beneficial cardiovascular effects (3), but Ucn3 has not been studied as extensively for its cardioprotective activity. In preclinical studies Ucn3 peptide infusion provided cardiac protection against ischemia-reperfusion injury (4). Stresscopin, which has $96 \%$ sequence homology with Ucn3, is efficacious when briefly infused in clinical HF (5). A recent study, in healthy individuals and HF patients, showed that Ucn2 and Ucn3 peptide infusions have beneficial effects including reduced systemic vascular resistance and increased cardiac output (6).

The major impediment to the translation of these reports to use in clinical HF is the short half-life (10 minutes) of these peptides (7). Sustained hemodynamic effect of these short-acting peptides would require continuous IV infusion, which hampers their clinical usefulness in chronic therapy for HF. A solution for such a problem would be using gene transfer to provide sustained plasma levels of the peptide. In animal studies, we have used such an approach to achieve sustained increases plasma peptide concentration, and increases in cardiac function $(8,9)$. Our laboratory has shown in preclinical studies that such an approach, using IV delivery of an adeno-associated virus type 8 (AAV8) encoding Ucn2 provided sustained increases in plasma Ucn2 and also is beneficial for the normal and failing heart $(8,9)$.

We recently published data comparing the long term cardiovascular effects of chronic exposure to sustained high plasma levels of Ucn2 vs Ucn3 using gene transfer in normal animals (10). We found similar beneficial effects on cardiac function. However, Ucn2 gene transfer increased glucose disposal and resulted in a significant decline in fasting glucosean effect not shared by Ucn3 gene transfer. These data indicate that Ucn2 gene transfer may be an optimal selection for patients with diabetes and heart failure, while Ucn3 may be better suited for the majority of patients with HF that are not diabetic. However, no previous studies have established that chronic elevation of plasma Ucn3 is effective in the treatment of HF. In the present study we tested the hypothesis that Ucn3 gene transfer would improve function of the failing heart.

\section{MATERIALS AND METHODS}

AAV8.Ucn3 Vector. HEK293T cells were transfected with the pRep2/Cap8 and pAd-Helper plasmid (11), to produce a helper-virus free AAV8 vector encoding murine urocortin-3 
(Ucn3) driven by a chicken $\beta$-actin (CBA) promoter (AAV8.CBA.mUcn3; Fig 1). Plasmid pRep2/Cap8 was obtained from the University of Pennsylvania Vector Core. Virus vectors were then purified and concentrated as previously described $(9,12)$. Virus titers were determined by real-time qPCR with virus genome DNA prepared from purified virus.

Animal Use. The Animal Use and Care Committee of the VA San Diego Healthcare System approved the studies. Eighty-eight C57BL/6J mice (51M, 37F), 8-12 weeks old, $24.5 \pm 0.4 \mathrm{~g}$ were obtained (Jackson Laboratories, Bar Harbor, ME, USA). Twenty of these mice $(9 \mathrm{M}, 11 \mathrm{~F})$ underwent thoracotomy and heart manipulation but no cryoinjury; 68 underwent cryoinjury to induce HF.

Heart Failure Model. We used cryoinjury to induce anterior wall myocardial infarction (MI) and subsequent LV chamber dilation and reduced function as previously described (13). Animals were intubated and mechanically ventilated with oxygen and $1.5 \%$ Isoflurane. To expose the heart a thoracotomy was performed at the fourth left intercostal space and the pericardium was opened. A cryoprobe of $3.5 \mathrm{~mm}$ diameter (Brymill, Ellington, CT) was applied to the LV anterior free wall for 10 seconds, followed by rinsing ( $25^{\circ} \mathrm{C}$ saline) to avoid traumatic detachment from the LV. This process was then repeated. Three weeks after cryoinjury, echocardiography was performed to assess heart function. Those with LV ejection fraction (EF) $<40 \%$ were included in the study and received IV saline or IV AAV8.Ucn3 $\left(1.9 \times 10^{13}\right.$ genome copies $\left.(\mathrm{gc}) / \mathrm{kg}\right)$.

Ucn3 Gene Transfer. Under anesthesia (1.5\% isoflurane via nosecone), the jugular vein was exposed and a syringe with a 31-gauge needle inserted to deliver AAV8.Ucn3 $\left(1.9 \times 10^{13} \mathrm{gc} / \mathrm{kg}\right.$ in $\left.100 \mu \mathrm{l}\right)$ or a similar volume of saline.

Echocardiography. Echocardiography was performed as previously described (14). Three weeks after myocardial infarction mice were anesthetized initially with $5 \%$ and then maintained at 1-1.5\% Isoflurane, and using a Vevo 3100 ultrasound system (FUJIFILM Visualsonics, Toronto, Canada) echocardiography was performed to document reduced LV function (EF $<40 \%$ ) and to record LV chamber dimensions. Echocardiographic assessment of heart function was then repeated 5 weeks after randomization of mice to receive intravenous delivery of AAV8.Ucn3 or saline.

LV Systolic and Diastolic Function. Sodium pentobarbital ( $80 \mathrm{mg} / \mathrm{kg}$, ip) was used to anesthetize the animals and a 1.4F micromanometer catheter (SPR 839, Millar Instruments, Houston, Texas) was advanced via the right carotid artery across the aortic valve and into the LV cavity. Left ventricular pressure was recorded, stored digitally and then processed (IOX V2.9.5 Emka Technologies, Christchurch, VA) as previously reported (14). Subsequently, blood and tissue samples were obtained. The first derivative of LV pressure development $(\mathrm{LV}+\mathrm{dP} / \mathrm{dt}$ ) and decline $(\mathrm{LV}-\mathrm{dP} / \mathrm{dt}$ ) were used to assess LV systolic and diastolic function, respectively, in a manner that was relatively load-independent and a more accurate estimate of contractility than EF.

RT-PCR, Immunoblotting. LV and liver samples were collected and stored at $-80^{\circ} \mathrm{C}$ for quantitative RT-PCR and Western blotting. Total RNA was isolated and reverse transcribed 
into CDNA that has been used in quantitative PCR as previously described (8). The gene specific primers used in PCR are listed in Table 1. Immunoblotting was performed as described previously (8). The following antibodies were used: Phospho-PKA-RIla, phosphorPKA-RIIb, CamKII, phosphor-CamKII, and CARP (Santa Cruz Biotechnology, Santa Cruz, CA); phospho-PKA catalytic subunit, total PKA, p-Tnl, total Tnl (Cell Signaling Technology, Danvers, MA); PLB (Thermo Fisher Scientific, Waltham, MA); Ser 16 and Thr 17-phosphoPLB (Badrilla, Ltd, Leeds, UK); SERCA2a (Enzo Life Sciences, Farmingdale, NY); phospho-RYR2 and MYLK3 (Abcam, San Francisco, CA).

Cardiac Myocyte Isolation and $\mathrm{Ca}^{2+}$ Transients. Cardiac myocytes were isolated as previously described (14). Mice were heparinized (5000 U/kg, IP), then anesthetized with sodium pentobarbital $(150 \mathrm{mg} / \mathrm{kg}$, IP) and hearts were extracted and quickly cannulated via the aorta for perfusion. Using a peristaltic pump, a calcium-free medium containing Joklikmodified minimal essential medium (Gibco-BRL, Thermo Fisher Scientific, Waltham, MA) was perfused for 3 minutes $(3 \mathrm{~mL} / \mathrm{min}$ ), followed by perfusion of the same buffer with

\begin{tabular}{|c|c|c|}
\hline Gene & Forward & Reverse \\
\hline$\alpha-\mathrm{MHC}$ & 5'-AAAGGCTGAGAGGAACTACC & 5'-ACCAGCCTTCTCCTCTGC \\
\hline$\beta-\mathrm{MHC}$ & 5'-GCTGAAAGCAGAAAGAGATTATC & 5'-TGGAGTTCTTCTCTTCTGGAG \\
\hline$\alpha$-SK-actin & 5'-GTGTCACCCACAACGTGC & 5'-AGGGCCACATAGCACAGC \\
\hline ANF & 5'-CCTCGTCTTGGCCTTTTGG & 5'-CATCTTCTACCGGCATCTTC \\
\hline BNP & 5'-GAAGTCCTAGCCAGTCTCC & 5'-CAGCTTGAGATATGTGTCACC \\
\hline CARP & 5'-CTGAACCTGTGGATGTGCC & 5'-GGCTCCAGCCTCCATTAACT \\
\hline FHL-1 & 5'-TGCAACAAGTGCGCTACTCG & 5'-CAATGTTTGGCGAACTTGGTC \\
\hline Coll1 $\alpha 1$ & 5'-GCCAAGAAGACATCCCTGAAG & 5'-GGGTCCCTCGACTCCTAC \\
\hline Coll3 $3 \alpha 1$ & 5'-GCACAGCAGTCCAACGTAGA & 5'-TCTCCAAATGGGATCTCTGG \\
\hline MMP8 & 5'-GACTCTGGTGATTTCTTGCTAAC & 5'-CACCATGGTCTCTTGAGACG \\
\hline MMP9 & 5'-CGTCGTGATCCCCACTTACT & 5'-GAACACACAGGGTTTGCCTTC \\
\hline TIMP1 & 5'-GACAGCTTTCTGCAACTCGG & 5'-CTTGTGGACATATCCACAGAGG \\
\hline IL-1b & 5'-CCСАTСCTCTGTGACTCATG & 5'-AAGGCCACAGGTATTTTTGTCG \\
\hline IL-6 & 5'-CGGAGAGGAGACTTCACAG & 5'-TTCTGCAAGTGCATCATCGTC \\
\hline IL-10 & 5'-GCTCTTACTGACTGGCATGAG & 5'-CGCAGCTCTAGGAGCATGTG \\
\hline Ucn3 & 5'-ACGCACCTCCAGATCAAAAG & 5'-AATTCTTGGCCTTGTCGATG \\
\hline \multicolumn{3}{|c|}{$\begin{array}{l}\alpha-M H C \text {, alpha-myosin heavy chain; } \beta-M H C \text {, beta-myosin heavy chain; } \alpha \text {-SK-actin, alpha-skeletal actin; } \\
\text { ANF, atrial natriuretic peptide; BNP, brain natriuretic peptide; CARP, cardiac ankyrin repeat protein; FHL- } \\
1 \text {, Four and a half LIM domains protein } 1 ; \text { Coll, collagen; MMP, matrix metalloproteinase; TIMP1, tissue } \\
\text { inhibitor of metalloproteinase } 1 ; I L \text {, interleukin; Ucn3, urocortin } 3\end{array}$} \\
\hline
\end{tabular}


addition of $20 \mu \mathrm{M} \mathrm{CaCl}_{2}$ and collagenase Type II (Worthington Biochemical Corporation, NJ) for another 12-13 minutes. Hearts were then placed into a beaker with digestion solution, atria were removed, and ventricles were sliced into pieces and mixed gently with a widenozzle pipette (3-4 minutes) to dissociate myocytes. Isolated cardiac myocytes were plated onto laminin pre-coated glass coverslips and loaded with Indo-1/AM (with $0.02 \%$ pluronic F-127) for $20 \mathrm{~min}$. Coverslips then were placed in a field stimulation perfusion chamber, rinsed to remove stain excess and mounted on a Nikon TMD inverted microscope (Nikon, Melville, NY) equipped with a 40x objective interfaced to a PMT based fluorescence measure system (PTI, Edison, NJ). During the measurements, cardiac myocytes were continuously perfused with $\mathrm{KRH}$ solution $\left(125 \mathrm{mM} \mathrm{NaCl}, 5 \mathrm{mM} \mathrm{KCl}, 1.2 \mathrm{mM} \mathrm{NaH}_{2} \mathrm{PO}_{4}, 6 \mathrm{mM}\right.$ glucose, $1.2 \mathrm{mM} \mathrm{MgCl}_{2}$ and $25 \mathrm{mM}$ HEPES, $\mathrm{pH}$ 7.37-7.38) containing $2 \mathrm{mM} \mathrm{CaCl}_{2}$ and they were field-stimulated at $0.3 \mathrm{~Hz}$. Using an excitation wavelength of $365 \mathrm{~nm}$ via a monochromator, fluorescent emission was slit and directed to two photomultiplier tubes through $20 \mathrm{~nm}$ band-pass filters centered at 405 and $485 \mathrm{~nm}$, respectively. Indicator of the $\left[\mathrm{Ca}^{2+}\right] \mathrm{i}$ is the ratio $\mathrm{F} 405 / 485$. Multiple cardiac myocytes from each heart of the 3-5 per group were used to obtain the $\mathrm{Ca}^{2+}$ transient data.

Quantification of Fibrosis, LV Apoptosis and Infarct Size. Fibrosis. Samples of liver and viable (uninfarcted) transmural LV samples were formalin-fixed and paraffin-embedded. Five-micron sections were mounted and counterstained with hematoxylin and eosin and with Masson's trichrome.

Infarct size. A separate group of animals $(n=5)$, underwent cryoinjury and 8 days later hearts were arrested in diastole $(0.6 \% \mathrm{KCl})$, the right ventricle removed, and $\mathrm{LV}$ (including septum) was pressed between two microscopic slides (1.2 mm apart) and scanned using an EPSON V850 pro scanner (EPSON, Japan). Using ImageJ V1.49 software, the area of transmural infarct was measured and recorded as percent of total LV. Apoptosis. Paraffin-embedded tissue sections were rehydrated and then microwaved for $5 \mathrm{~min}$ in $10 \mathrm{mM}$ sodium citrate buffer ( $\mathrm{pH}$ 6.0) for epitope retrieval. After quenching of endogenous peroxidase activity and blocking with normal goat serum, the tissue sections were incubated $\left(18 \mathrm{hr}, 4^{\circ} \mathrm{C}\right)$ with anticleaved caspase- 3 antibody (1:200, Cell Signaling Technology, Danvers, MA) to assess apoptosis. After washing, the immunostaining was performed using an ImmPRESS HRP kit (Vector Laboratories, Burlingame, CA) according to the manufacturer's instructions.

Statistical Analysis. Data acquisition and analysis were performed without knowledge of group identity. Group sizes were determined by power calculations, and male and female mice were used. Since the hypothesis was that Ucn3 gene transfer would improve function of the failing heart, the key statistical comparison was between mice with HF that received IV saline and those that received Ucn3 gene transfer, and Student's t-test was used (unpaired, two-tailed). In order to confirm the presence of LV dysfunction we included a sham-operated age- and sex-matched control group, and, when appropriate, performed additional between group t-tests (Control vs HF), with Bonferroni correction. Data represent mean \pm SE. Analyses were performed using GraphPad Prism (GraphPad Software, Inc., San Diego, CA). The null hypothesis was rejected when $p<.05$. 


\section{RESULTS}

Plasma Urocortin 3 Levels. Plasma levels of Ucn3 were measured 5 weeks after gene transfer. Mice that received Ucn3 gene transfer showed increased plasma Ucn3

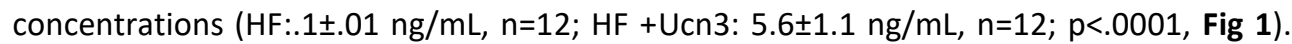
There was no sex difference in plasma Ucn3 concentrations in HF saline injected mice $(p=.5)$, but in mice that received Ucn3 gene transfer, male mice had higher plasma Ucn3 levels than female mice (Male: $8.5 \pm 1 \mathrm{ng} / \mathrm{mL}, \mathrm{n}=6$; Female: $2.7 \pm .8 \mathrm{ng} / \mathrm{mL}, \mathrm{n}=6 ; \mathrm{p}=.001$ ).

A

AAV8.CBA.Ucn3

\begin{tabular}{|c|c|c|c|c|c|c|c|}
\cline { 2 - 6 } & & CMV.en & Chicken $\beta$-actin Promoter & Ucn3 & r $\beta$ GpA & ITR \\
\hline 14125 & 380 & 1345 & 603 & 56 & 25 & 141
\end{tabular}

B

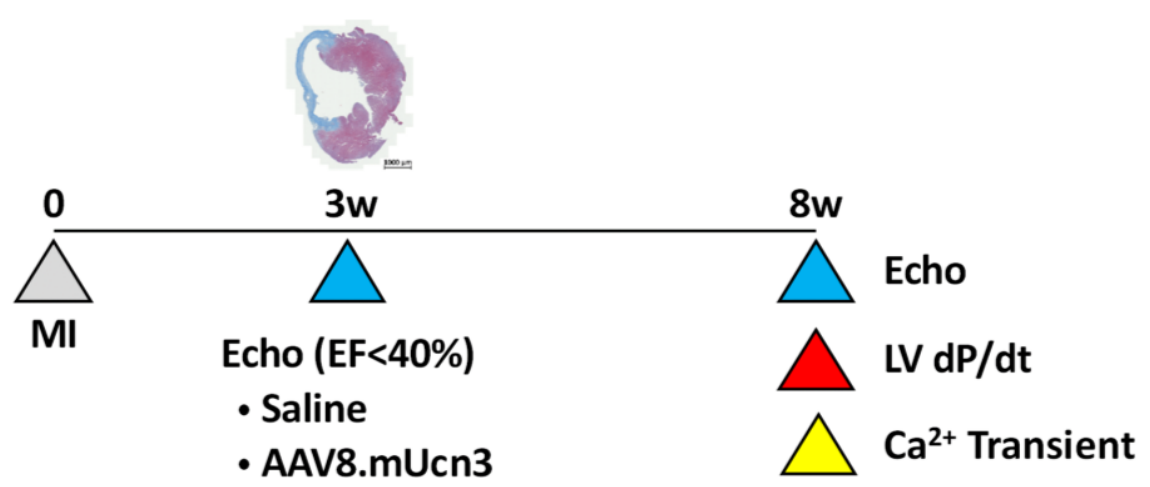

C

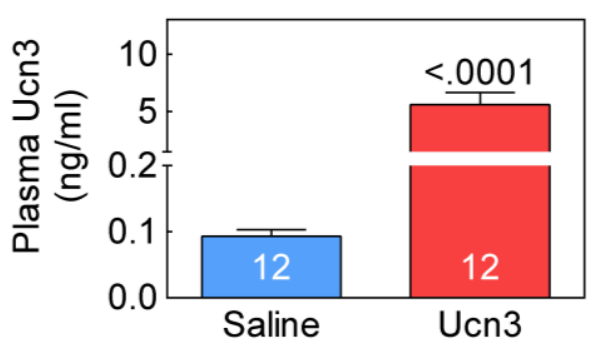

Figure 1. Urocortin 3 transgene and study design. A. AAV8.CBA.mUcn3 vector map. ITR, inverted terminal repeat; CMV.en, cytomegalovirus enhancer; CBA, chicken $\beta$-actin promoter; Ucn3, murine urocortin 3; r $\beta$ GpA, rabbit $\beta$ globin polyadenylation signal; B. Study design. A representative cross-section of the LV following cryoinjury, which resulted in transmural infarction of $27 \pm 2 \%$ of the LV $(n=5)$. C. Ucn3 plasma levels in mice with heart failure 5 weeks after intravenous saline or IV AAV8. mUcn3 (Ucn3). Mean \pm SE are shown. Numbers in bars denote group size. $P$ value is from Student's t-test (unpaired, two tailed). 
MI-Induced HF. Sixteen mice died in the first 3 weeks after the $\mathrm{MI}$ and 12 did not show EF $<40 \%$. Thus, of 68 mice that underwent infarction by cryoinjury, 40 met enrollment criteria 3 weeks later, for a yield of $59 \%$. This method is superior to coronary occlusion, where the yield can be $<10 \%(15)$.

Infarct size. Cryoinjury resulted in transmural infarction of $27 \pm 2 \%$ of the LV $(n=5)$. Fig $1 B$ shows a representative cross section of the LV following cryoinjury infarction.

Echocardiography. Three weeks after MI (before randomization) we saw reductions in EF $(p<.0001)$ and velocity of circumferential fiber shortening (corrected for heart rate, VCFc; $\mathrm{p}<.0001$; Table 2A). In addition, end-systolic and end-diastolic dimensions (ESD, EDD) were increased among HF mice compared to Controls (Table 2A), confirming that cryoinjuryinduced $\mathrm{MI}$ resulted in $\mathrm{LV}$ chamber dilation and dysfunction. There were no pre-treatment group differences in HF mice in EF, VCFc, EDD or ESD. However, eight weeks after MI (five weeks after saline or Ucn3 gene transfer) we saw beneficial between-group differences conferred by Ucn3 gene transfer on EF. Indeed, the final EF was 9 percentage units higher (a $32 \%$ relative increase) in mice that received Ucn3 gene transfer (HF: $28 \pm 1 \%, \mathrm{n}=13$; $\mathrm{HF}$ $+U c n 3$ : $37 \pm 1 \%, n=13 ; p=.0006$; Table 2B). In addition, Ucn3 gene transfer was associated with higher VCFc $(p=.0001$; Table 2B).

\begin{tabular}{|c|c|c|c|c|}
\hline \multicolumn{5}{|c|}{ Table 2A. Echocardiography 3 Weeks After MI (No Treatment) } \\
\hline & Control (16) & HF (13) & $H F+U c n 3(13)$ & $\begin{array}{c}p \\
\text { Control vs HF }\end{array}$ \\
\hline HR (bpm) & $541 \pm 6$ & $535 \pm 5$ & $544 \pm 6$ & .5 \\
\hline $\operatorname{EDD}(\mathrm{mm})$ & $3.7 \pm .1$ & $4.5 \pm .1$ & $4.6 \pm .1$ & $<.0001$ \\
\hline $\operatorname{ESD}(\mathrm{mm})$ & $2.4 \pm .1$ & $3.8 \pm .1$ & $4.0 \pm .1$ & $<.0001$ \\
\hline IVSd (mm) & $.7 \pm .03$ & $.8 \pm .02$ & $.8 \pm .03$ & $<.0001$ \\
\hline LVEF (\%) & $63 \pm 2$ & $31 \pm 2$ & $30 \pm 2$ & $<.0001$ \\
\hline VCFc (circ/s) & $22.2 \pm .9$ & $9.6 \pm .6$ & $9.8 \pm .6$ & $<.0001$ \\
\hline \multicolumn{5}{|c|}{$\begin{array}{l}\text { Echocardiographic measurements } 3 \text { weeks after MI (prior randomization). HR, heart rate; bpm, } \\
\text { beats per minute; EDD, LV end-diastolic diameter; ESD, LV end-systolic diameter; IVSd, } \\
\text { interventricular septum thickness in diastole; LVEF, left ventricular ejection; VCFc, velocity of } \\
\text { circumferential fiber shortening (corrected for heart rate); Control, sham operated animals; p values } \\
\text { from Student's t-test with Bonferroni correction for multiple comparisons; numbers in parenthesis } \\
\text { indicate group size. }\end{array}$} \\
\hline
\end{tabular}

LV Function. Eight weeks after MI, mice with HF that received Ucn3 gene transfer showed an elevation in LV peak $+\mathrm{dP} / \mathrm{dt}$ (HF: $3941 \pm 159 \mathrm{mmHg} / \mathrm{s}, \mathrm{n}=11 ; \mathrm{HF}+\mathrm{Ucn} 3: 7353 \pm 582$ $\mathrm{mmHg} / \mathrm{s}, \mathrm{n}=12 ; \mathrm{p}<.0001$, Fig. 2A), LV peak -dP/dt (HF: $-3713 \pm 211 \mathrm{mmHg} / \mathrm{s}, \mathrm{n}=11 ; \mathrm{HF}+\mathrm{Ucn} 3$ : $-6302 \pm 270 \mathrm{mmHg} / \mathrm{s}, \mathrm{n}=12 ; \mathrm{p}<.0001$, Fig. 2B) and developed LV pressure (HF: $76 \pm 2 \mathrm{mmHg} / \mathrm{s}$, 
$\mathrm{n}=11 ; \mathrm{HF}+\mathrm{Ucn} 3: 95 \pm 4 \mathrm{mmHg} / \mathrm{s}, \mathrm{n}=12 ; \mathrm{p}=.0006$, Fig. $2 \mathrm{C})$. Heart rates of the HF saline treated group were lower than HF Ucn3 treated groups (HF: $350 \pm 13 \mathrm{mmHg} / \mathrm{s}, \mathrm{n}=11 ; \mathrm{HF}+\mathrm{Ucn} 3$ : $440 \pm 20 \mathrm{mmHg} / \mathrm{s}, \mathrm{n}=12 ; \mathrm{p}=.001$, Fig. 2D). After Ucn3 gene transfer, there were no sex differences in LV peak +dP/dt (Male: $7288 \pm 586 \mathrm{mmHg} / \mathrm{s}, \mathrm{n}=7$; Female: $7444 \pm 1228 \mathrm{mmHg} / \mathrm{s}$, $\mathrm{n}=5 ; \mathrm{p}=.9$ ) or in LV peak $-\mathrm{dP} / \mathrm{dt}$ (Male: $-6457 \pm 303 \mathrm{mmHg} / \mathrm{s}, \mathrm{n}=7$; Female: $-6086 \pm 519$ $\mathrm{mmHg} / \mathrm{s}, \mathrm{n}=5 ; \mathrm{p}=.5$ ).

\begin{tabular}{|c|c|c|c|c|c|}
\hline \multicolumn{6}{|c|}{ Table 2B. Echocardiography 5 Weeks After Ucn3 Gene Transfer } \\
\hline & \multirow{2}{*}{$\begin{array}{c}\text { Control } \\
\text { (16) }\end{array}$} & \multirow{2}{*}{$\begin{array}{l}\text { HF } \\
\text { (13) }\end{array}$} & \multirow{2}{*}{$\begin{array}{c}\text { HF +Ucn3 } \\
\text { (13) }\end{array}$} & \multicolumn{2}{|c|}{$\mathbf{p}$} \\
\hline & & & & Con vs HF & HF vs HF +Ucn3 \\
\hline HR (bpm) & $544 \pm 6$ & $535 \pm 7$ & $539 \pm 6$ & .6 & 1 \\
\hline $\operatorname{EDD}(\mathrm{mm})$ & $3.6 \pm .1$ & $4.6 \pm .1$ & $4.6 \pm .2$ & $<.0002$ & 1 \\
\hline $\operatorname{ESD}(\mathrm{mm})$ & $2.4 \pm .1$ & $4.0 \pm .1$ & $3.8 \pm .2$ & $<.0002$ & .4 \\
\hline IVSd (mm) & $.7 \pm .02$ & $.9 \pm .05$ & $.8 \pm .06$ & $<.0002$ & .8 \\
\hline LVEF (\%) & $62 \pm 3$ & $28 \pm 1$ & $37 \pm 1$ & $<.0002$ & .0006 \\
\hline VCFc (circ/s) & $21.8 \pm 1$ & $9.3 \pm .5$ & $12.3 \pm .5$ & $<.0002$ & .001 \\
\hline \multicolumn{6}{|c|}{$\begin{array}{l}\text { Echocardiographic measurements } 5 \text { weeks after saline (HF) or AAV8.Ucn3 (HF +Ucn3) administration } \\
\text { in mice with HF. HR, heart rate; bpm, beats per minute; EDD, LV end-diastolic diameter; ESD, LV end- } \\
\text { systolic diameter; IVSd, interventricular septum thickness in diastole; LVEF, left } \\
\text { ventricular ejection; VCFc, velocity of circumferential fiber shortening (corrected for heart rate); } \\
\text { Control, sham operated animals; } p \text { values from Student's t-test with Bonferroni correction for } \\
\text { multiple comparisons; numbers in parenthesis indicate group size. }\end{array}$} \\
\hline
\end{tabular}

Cytosolic $\mathrm{Ca}^{2+}$ Transients and Sarcomere Length. Cardiac myocytes were isolated 8 weeks after MI (5 weeks after randomization to saline or Ucn3 gene transfer) to assess $\mathrm{Ca}^{2+}$ transients. Cardiac myocytes from mice that received Ucn3 gene transfer showed higher peak cytosolic $\mathrm{Ca}^{2+}$ concentration (Figs 3A and 3B; $\mathrm{p}=.0005$ ) and lower Tau (Fig 3D; $\mathrm{p}<.0001)$. Time to peak $\mathrm{Ca}^{2+}$ concentration showed no group difference. We also measured sarcomere shortening in these cardiac myocytes, finding that Ucn3 gene transfer was associated with a higher shortening rate $(+\mathrm{dL} / \mathrm{dt}$; HF: $7.8 \pm .5 \mu \mathrm{m} / \mathrm{s}, \mathrm{n}=39 ; \mathrm{HF}+\mathrm{Ucn} 3: 9.8 \pm .7$ $\mu \mathrm{m} / \mathrm{s}, \mathrm{n}=20 ; \mathrm{p}=.03$, Fig $3 E$ ) and a higher lengthening rate $(-\mathrm{dL} / \mathrm{dt} ; \mathrm{HF}: 6.7 \pm .4 \mu \mathrm{m} / \mathrm{s}, \mathrm{n}=39 ; \mathrm{HF}$ $+U c n 3: 8.3 \pm .6 \mu \mathrm{m} / \mathrm{s}, \mathrm{n}=20 ; \mathrm{p}=.04$, Fig 3F). These data are consistent with group differences in $\mathrm{Ca}^{2+}$ transients and pressure development and decline in vivo (Figs $\mathbf{2 A - 2 C}$ ).

Necropsy. Body and liver weights showed no group differences (Table 3). HF mice compared to Control mice showed higher weights of LV ( $p=.002)$ and LV/BW ratio $(p<.0002)$, which were increased similarly after $\mathrm{MI}$ in $\mathrm{HF}$ and $\mathrm{HF}+\mathrm{Ucn} 3$ groups (Table 3 ). 


\begin{tabular}{|c|c|c|c|c|c|}
\hline \multicolumn{2}{|c|}{ Table 3. Necropsy } \\
\hline & Con (15) & HF (16) & HF +Ucn3 (13) & \multicolumn{2}{|c|}{ p } \\
\cline { 4 - 6 } & & & & Con vs HF & HF vs HF +Ucn3 \\
\hline BW (g) & $26.9 \pm 1.1$ & $26.5 \pm 0.7$ & $26.7 \pm 0.9$ & 1 & 1 \\
\hline LV (mg) & $84 \pm 4$ & $110 \pm 6$ & $102 \pm 5$ & .002 & .8 \\
\hline LV/BW (mg/g) & $3.1 \pm .1$ & $5.0 \pm 0.2$ & $4.8 \pm 0.3$ & $<.0002$ & 1 \\
\hline Liver/BW (mg/g) & $45 \pm 1$ & $45 \pm 1$ & $43 \pm 1$ & 1 & .8 \\
\hline $\begin{array}{l}\text { Necropsy data 5 weeks post saline or AAV8.Ucn3 administration in mice with HF. BW, body weight; LV, } \\
\text { left ventricle; p values from Student's t-test with Bonferroni correction for multiple comparisons; } \\
\text { numbers in parenthesis indicate group size. }\end{array}$ \\
\hline
\end{tabular}

LV Ca ${ }^{2+}$ Handling Protein Expression. After MI, LV content of sarco/endoplasmic reticulum $\mathrm{Ca}^{2+}$ ATPase (SERCA2a) protein was higher after Ucn3 gene transfer (HF: .41 $\pm .02, \mathrm{n}=4$; HF

A

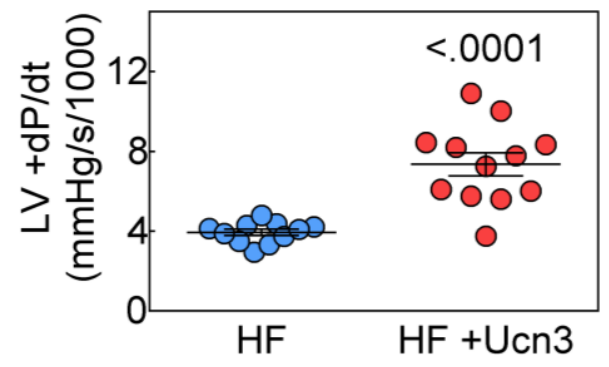

C

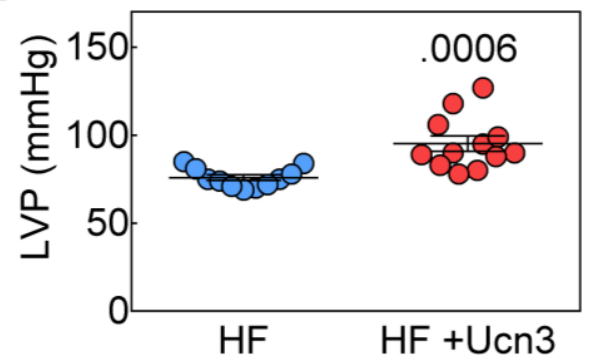

B

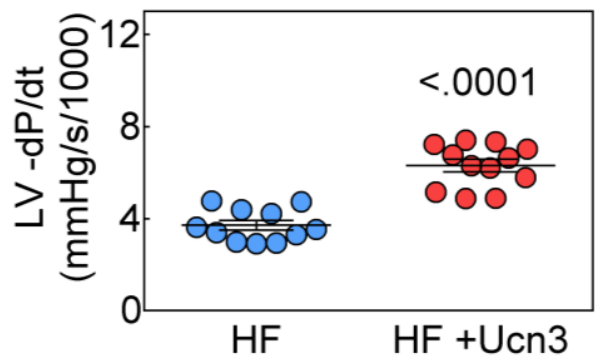

D

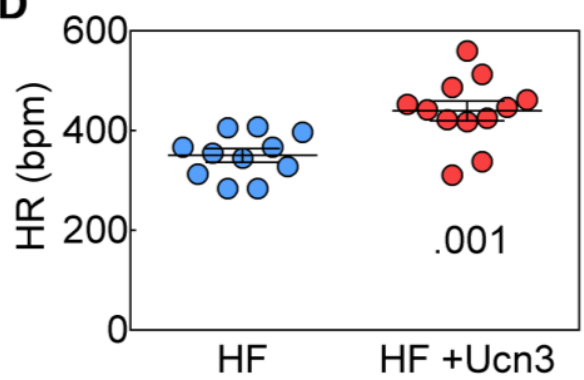

Figure 2. In vivo assessment of LV function. Eight weeks after MI ( 5 weeks after IV delivery of AAV8.Ucn3 (1.9x10 13 $\mathrm{gc} / \mathrm{kg} ; \mathrm{HF}+\mathrm{Ucn} 3$ ) or saline (HF), mice underwent physiological studies to assess LV function. A and B. Peak rate of LV pressure development $(A,+d P / d t)$ and peak rate of LV pressure decline $(B,-d P / d t)$. These data indicate Ucn3 gene transfer increased both peak $+d P / d t$ and peak $-d P / d t$ in mice with heart failure, indicating increased systolic and diastolic LV function. C. LV developed pressure (LVP) was increased by Ucn3 gene transfer. D. Heart rate (HR) in anesthetized animals was lower in the saline group. LV, left ventricle. Individual data are shown (mean $\pm S E$ are indicated); $p$ values are from Student's t-test (unpaired, two tailed). 
$+U c n 3: .52 \pm .01, n=4 ; p=.0004 ;$ Fig 4A). LV content of phosphorylated troponin I ( $p-T n l)$ was lower after $\mathrm{MI}(\mathrm{p}=.01)$ but was normalized after Ucn3 gene transfer. We found that $\mathrm{p}-\mathrm{TnI}$

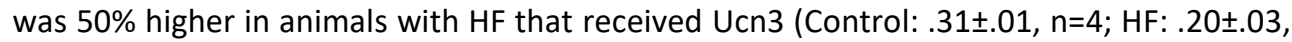
$n=4 ; H F+U c n 3: .30 \pm .02 n=4 ; p=.04$ Fig 4B). Selected additional proteins relevant to $\mathrm{Ca}^{2+}$ handling showed reduced phosphorylation ( $p$-RYR2, p-16-PLB, p17-PLB) after MI, but no HF vs $\mathrm{HF}+\mathrm{Ucn} 3$ group differences were seen (Table 4).

LV mRNA Expression of Markers of Hypertrophy and Fibrosis (Table 5). As expected, there were group differences in LV mRNA expression of several markers of LV stress $8 \mathrm{w}$ after MI. However, BNP $(p=.006)$, ANF ( $p=.05)$, $\alpha$-skeletal actin $(p=.02)$, and CARP $(p=.01)$ were lower in $\mathrm{HF}+\mathrm{Ucn} 3$ than in HF mice. The levels of LV $\beta-\mathrm{MHC}$ mRNA were lower in HF $+\mathrm{Ucn} 3$ vs HF mice $(p<.01$, Table 5$)$. Although several genes related to fibrosis showed increased LV mRNA expression in HF vs Control mice, their expression was not altered by Ucn3 gene transfer.

\begin{tabular}{|c|c|c|c|c|c|}
\hline \multicolumn{6}{|c|}{ Table 4. LV Protein Levels (Immunoblotting) } \\
\hline \multirow{2}{*}{ Protein } & \multirow{2}{*}{ Con (4) } & \multirow{2}{*}{$H F(4)$} & \multirow{2}{*}{$H F+U c n 3(4)$} & \multicolumn{2}{|c|}{$\mathbf{p}$} \\
\hline & & & & Con vs HF & HF vs HF +Ucn3 \\
\hline p-PKA-RIIa & $.6 \pm .1$ & $.7 \pm .1$ & $.6 \pm .1$ & 1 & .6 \\
\hline p-PKA-RIIb & $.3 \pm .15$ & $.3 \pm .03$ & $.2 \pm .03$ & 1 & .8 \\
\hline Total-PKA & $.4 \pm .01$ & $.3 \pm .02$ & $.3 \pm .02$ & 1 & .8 \\
\hline p-PKA/Total & $1.8 \pm .3$ & $2.0 \pm .10$ & $1.9 \pm .1$ & 1 & 8 \\
\hline CamKII & $.6 \pm .1$ & $.5 \pm .1$ & $.6 \pm .1$ & 1 & .8 \\
\hline p-CamKII & $.5 \pm .1$ & $.4 \pm .02$ & $.6 \pm .1$ & .8 & .2 \\
\hline p-CamKII/Total & $.9 \pm .15$ & $.9 \pm .1$ & $1.1 \pm .2$ & 1 & 1 \\
\hline p-RYR2/Total & $2.2 \pm .4$ & $.7 \pm .1$ & $1.2 \pm .1$ & .01 & .06 \\
\hline p16-PLB & $.1 \pm .1$ & $.7 \pm .1$ & $.9 \pm .11$ & 1 & .8 \\
\hline p16-PLB/Total & $3.7 \pm .6$ & $1.1 \pm .2$ & $2.1 \pm .5$ & .01 & .2 \\
\hline p17-PLB & $6.3 \pm .7$ & $2.4 \pm .8$ & $2.2 \pm .4$ & .02 & 1 \\
\hline p17-PLB/Total & $28.6 \pm 3.5$ & $3.5 \pm 1.1$ & $5.4 \pm 1.5$ & .001 & .6 \\
\hline CARP & $10.3 \pm 1$ & $14 \pm 1.8$ & $14 \pm 1.1$ & .2 & 1 \\
\hline MYLK3 & $.6 \pm .1$ & $1.0 \pm .3$ & $.7 \pm .1$ & .4 & .8 \\
\hline \multicolumn{6}{|c|}{ 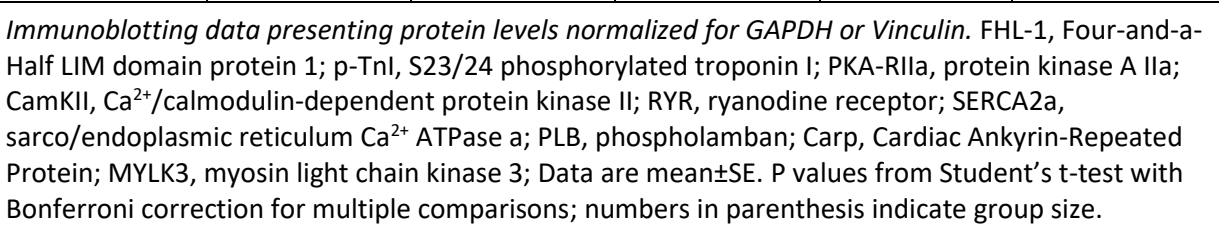 } \\
\hline
\end{tabular}

Fibrosis and LV Apoptosis. Fibrosis. There were no group differences in fibrosis in liver or in the uninfarcted region of LV, and no differences in inflammatory infiltrates (Fig 5A). LV apoptosis. Quantification of active caspase-3 staining showed more apoptosis after $\mathrm{MI}$ $(p<.0001$ ), with similar amounts of apoptosis in HF and HF +Ucn3 mice (Control: .04 $\pm .01 \%$, $n=14 ; \mathrm{HF}: .26 \pm .05 \% \mathrm{n}=8$; HF +Ucn3: .31 $\pm .06 \%, \mathrm{n}=7$; Fig 5B). 


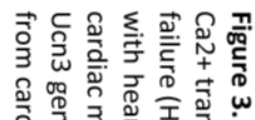

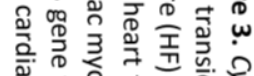

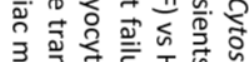

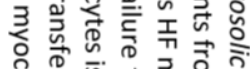

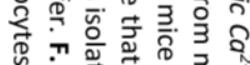

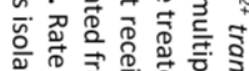

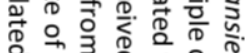

을

3ㅇํㄹ

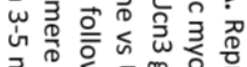

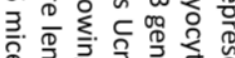

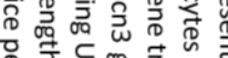

চ

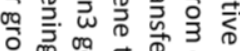

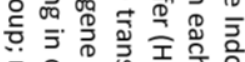

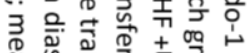

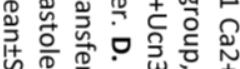

两

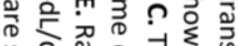

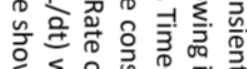

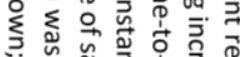

品

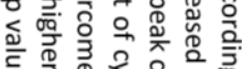

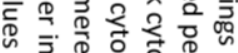

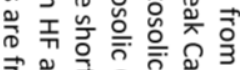

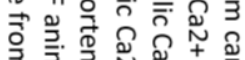

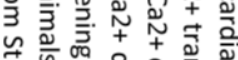

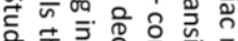

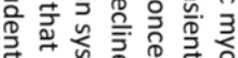

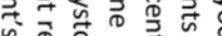

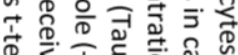

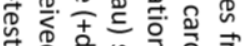

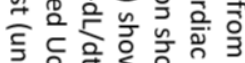

흘.

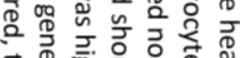

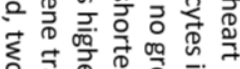

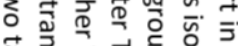

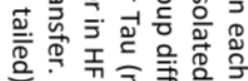

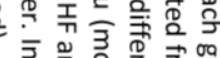

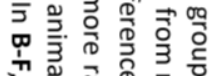

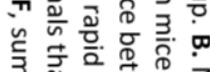

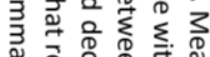

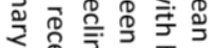

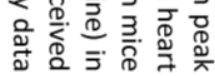
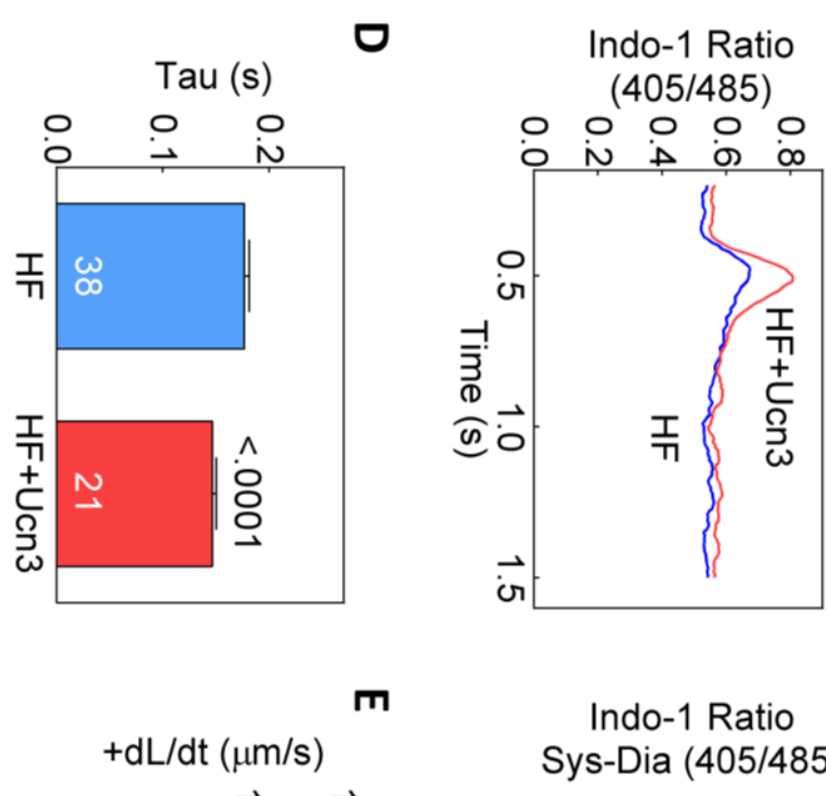

Indo-1 Ratio

Sys-Dia (405/485)
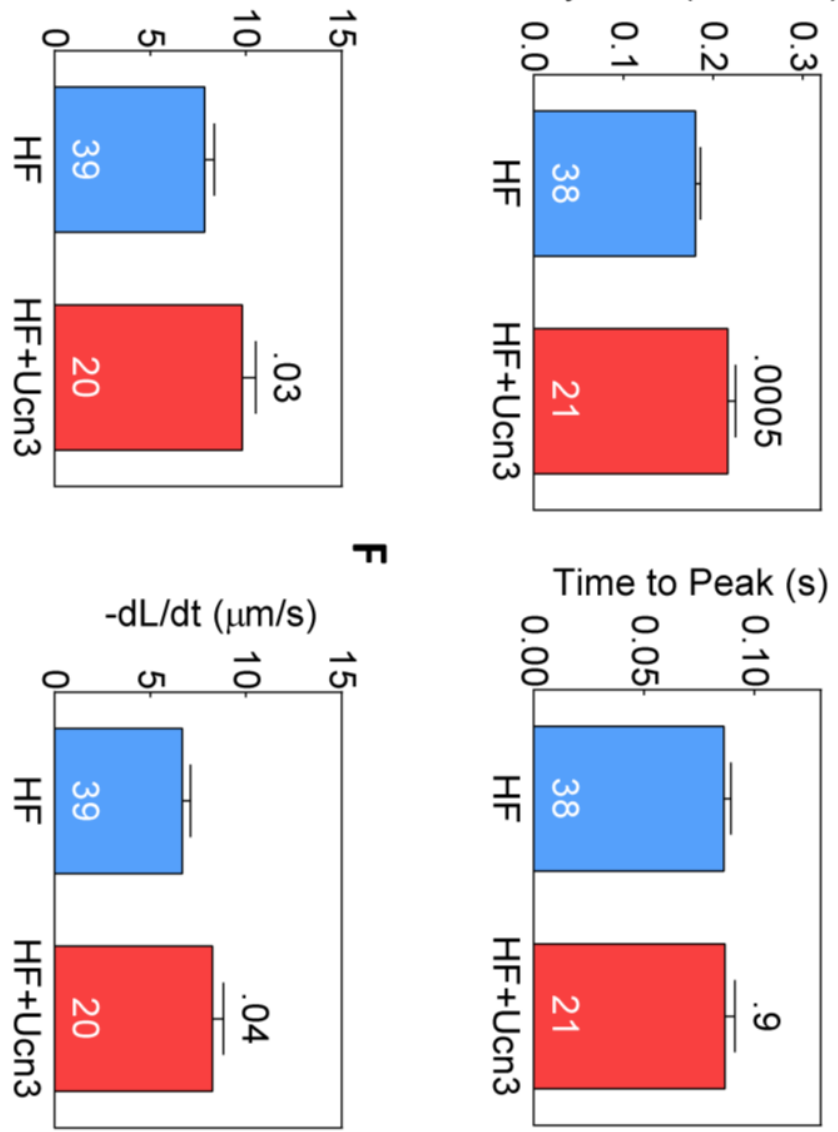

Time to Peak (s)

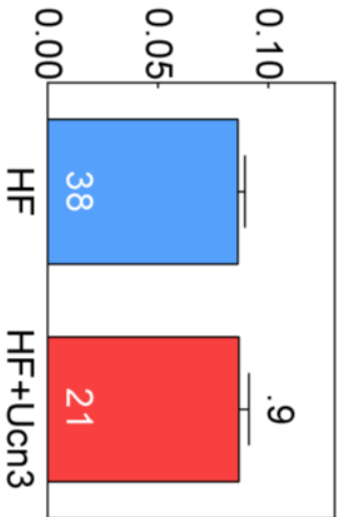




\section{DISCUSSION}

The major finding of this study is that Ucn3 gene transfer increased function of the failing heart. Three weeks after MI, LV EF was reduced from a mean value of $63 \%$ (Control) to $30-31 \%$. Five weeks later, mice that received Ucn3 gene transfer showed increased EF, while those that received saline showed a further decline. The final EF was 9 percentage units higher (32\% relative increase) in mice that received Ucn3 gene transfer $(p=.0006$; Table 2B). Furthermore, LV peak $+d P / d t$ showed a 1.9 -fold increase in $\mathrm{HF}+\mathrm{Ucn} 3$ vs $\mathrm{HF}$ $(p<.0001 ;$ Fig 2A). Finally, LV diastolic function after MI was also enhanced by Ucn3 gene transfer. LV peak - dP/dt, a measure of diastolic function, showed a 1.7-fold increase in HF + Ucn3 vs HF ( $p<.0001$; Fig 2B).

What explains these improvements in function of the failing heart associated with Ucn3 gene transfer? If the evidence for improved function resided in $\mathrm{EF}$ alone, one could propose that the benefit might reflect a vasodilating effect of $\operatorname{Ucn} 3(5,6)$, because a reduction in systemic pressure would be expected to enhance EF. However, the favorable effects of Ucn3 gene transfer also were seen in LV peak $+d P / d t$, an event that occurs prior to aortic valve opening, and therefore is not as affected by systemic pressure. Likewise, isolated cardiac myocytes from HF mice that received Ucn3 gene transfer showed a higher sarcomere shortening rate $(+\mathrm{dL} / \mathrm{dt})$ vs $\mathrm{HF}$ alone, confirming that the benefits reside within the cardiac myocyte per se, and do not reflect vasodilatory enhancement of LV function.

What then might explain intrinsic improvement in function of the LV and cardiac myocytes isolated from failing hearts treated with Ucn3 gene transfer? The rate of cardiac myocyte shortening during systole $(+d L / d t, p=.03$; Fig $3 E)$ and lengthening during diastole $(-d L / d t, p=.04$; Fig $3 F)$ were increased in the HF $+U c n 3$ group vs the HF group. These findings show tight correlations with LV peak $+\mathrm{dP} / \mathrm{dt}$ and peak $-\mathrm{dP} / \mathrm{dt}$, physiological measures of the intact heart. Ucn3 gene transfer increases $\mathrm{Ca}^{2+}$ handling, and subsequently increases LV systolic and diastolic function. We found that cardiac myocytes from $\mathrm{HF}+\mathrm{Ucn} 3$ mice showed increased peak $\mathrm{Ca}^{2+}$ transients $\left(p=.0005\right.$; Fig 3B) and reduced time constant of $\mathrm{Ca}^{2+}$ decline ( $T a u, p<.0001$; Fig 3D) compared to those from HF mice. This may explain the increases in LV systolic and diastolic function.

To determine molecular underpinnings for increased $\mathrm{LV} \mathrm{Ca}^{2+}$ handling, we assessed LV protein expression of key $\mathrm{Ca}^{2+}$ related proteins. LV SERCA2a returns cytosolic $\mathrm{Ca}^{2+}$ to the sarcoplasmic reticulum, and, consequently, increased expression of this protein would increase cytosolic $\mathrm{Ca}^{2+}$ decline, as we observed (Fig 3D). An increase in cytosolic $\mathrm{Ca}^{2+}$ decline, by increasing of $\mathrm{Ca}^{2+}$ availability to myofilaments, could also increase systolic function. We found that LV SERCA2a protein levels were similar in control and HF mice but were higher after Ucn3 gene transfer ( $p=.0004$ vs HF; Fig 4A). Upregulation of SERCA2a would be anticipated to increase peak systolic $\mathrm{Ca}^{2+}$ transient amplitude and rate of $\mathrm{Ca}^{2+}$ decline (Figs 3A, 3B, 3D), and subsequently increase systolic and diastolic function of isolated cardiac myocytes (Figs $\mathbf{3 E}$ and $\mathbf{3 F}$ ) and the intact heart (Figs $\mathbf{2 A}$ and $\mathbf{2 B}$ ). Although increased LV SERCA2a provides a potential mechanism for Ucn3's effects on $\mathrm{LV} \mathrm{Ca}^{2+}$ handling, it does not elucidate the molecular mechanism by which this occurs, which will require further studies. 
Troponin I phosphorylation plays a role in cardiac contractility and relaxation and is impaired under ischemic conditions. In the current study, phosphorylation of $\mathrm{TnI}$ at Serine residues 23 and 24 was reduced in the $\mathrm{HF}$ group but restored to normal by Ucn3 gene transfer ( $\mathrm{HF}$ vs HF $+\mathrm{Ucn} 3, \mathrm{p}=.04$; Fig 4B). The implications of the restoration of LV $\mathrm{p}-\mathrm{Tnl}$ to normal levels vis-à-vis cardiac function and the mechanism by which Ucn3 affected this change were not established in the present study. However, reduction in Tnl phosphorylation at Ser $23 / 24$ is seen in explanted hearts from patients with end-stage HF (16), and Ser 23/24 phosphorylation of $\mathrm{Tnl}$ is associated with more rapid relaxation (17), and therefore may be of mechanistic importance for the enhanced diastolic function conferred by Ucn3 gene transfer in the present study.

A
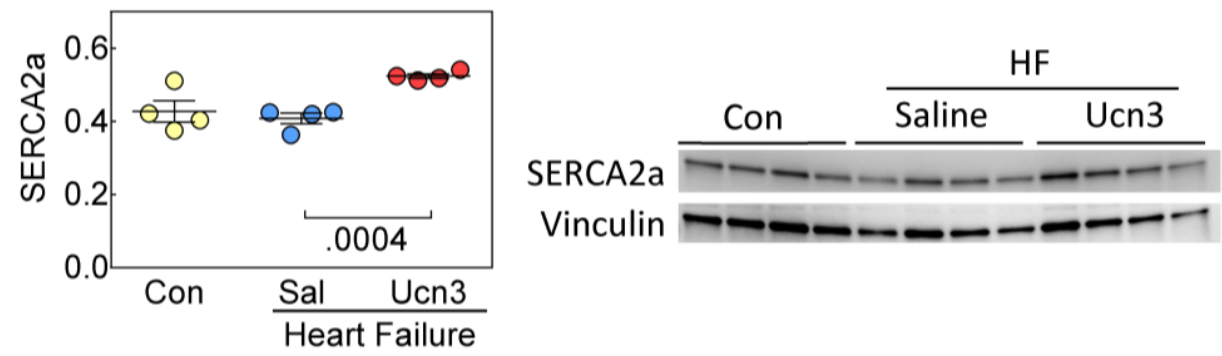

B
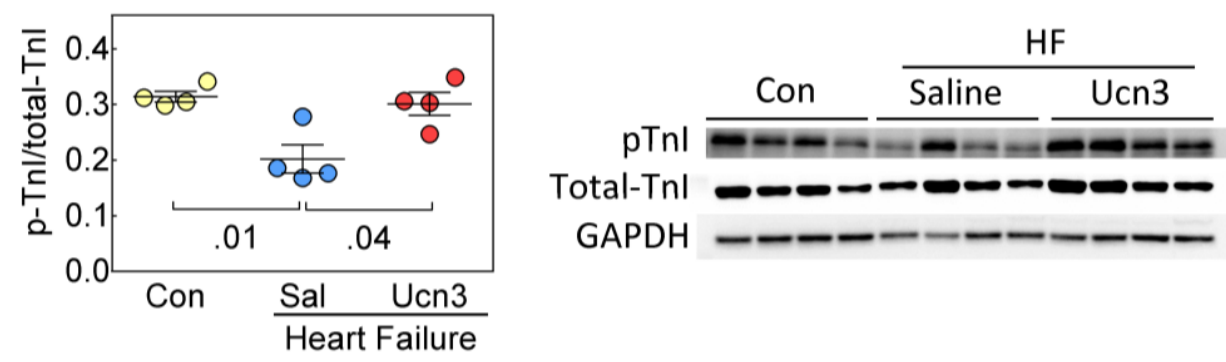

Figure 4. Left ventricular (LV) SERCA2a and phosphorylation of troponin I (TnI) in mice with HF 5 weeks after Ucn3 gene transfer. A. LV SERCA2a content was higher in mice with HF that received Ucn3 gene transfer ( $p=.0004$ vs HF). B. Troponin I (TnI) phosphorylation at serine 23 and 24 was higher in HF mice that received Ucn 3 gene transfer ( $p=.04$ vs HF). Individual mouse data are shown (mean $\pm S E$ are indicated); Con, sham operated animals; Sal, saline. P values are from Student's t-test (unpaired, two tailed) with Bonferroni correction for multiple comparisons.

There were increases in the HF group (vs Control) in ANF, BNP, $\alpha$-skeletal actin and $\beta$ $M H C$, which are molecular markers of hypertrophy and stress (18-20). These markers were significantly less increased after Ucn3 gene transfer (Table 5). These group difference likely are a consequence of improved LV function in HF after Ucn3 gene transfer. LV CARP expression is increased in clinical HF and in many animal models of HF and may exacerbate adverse cardiac remodeling and apoptosis $(21,22)$. We saw increased LV CARP mRNA in HF mice, and somewhat less of an increase in the HF +Ucn3 group $(p=.01$; Table 5$)$. LV mRNA 
expression of $\mathrm{Col}$ 1, Col3 and IL-6 were increased similarly in $\mathrm{HF}$ and $\mathrm{HF}+\mathrm{Ucn} 3$ mice (Table 5).

$\mathrm{HF}$ is associated with protean abnormalities, and it is uncertain whether the benefits we see in mice after Ucn3 gene transfer would also be seen in clinical HF. In the present study, we tested Ucn3 gene transfer in HF with reduced EF on endpoints obtained 5 weeks after initiation of therapy. Will Ucn3 gene transfer have enduring effects, and will such effects be seen in models of HF with preserved EF? Despite these limitations, it is promising that a simple intravenous injection of AAV8.Ucn3 has such benefits on function of the failing heart.

The NIH has requested that preclinical studies be conducted in similar proportions of male and female animals when possible (23), a requirement embraced by the FDA for Investigational New Drug (IND) applications. In the current study, the same amount of AAV8.Ucn3 (1.9 x 10 $13 \mathrm{gc} / \mathrm{kg}$, IV) was associated with 3-fold higher plasma Ucn3 concentrations in male vs female mice. Even so, the mean plasma Ucn3 concentration in females after gene transfer was $>20$-fold higher than that of mice that did not receive vector

\begin{tabular}{|c|c|c|c|}
\hline Gene & $\begin{array}{c}\text { HF (4) } \\
\text { Fold Control }\end{array}$ & $\begin{array}{l}\text { HF +Ucn3 (4) } \\
\text { Fold Control }\end{array}$ & p \\
\hline$\alpha-M H C$ & $.5 \pm .1$ & $.6 \pm .1$ & .40 \\
\hline$\beta-M H C$ & $25 \pm 5$ & $6.6 \pm .5$ & .01 \\
\hline$\alpha$-skeletal actin & $5.3 \pm 1$ & $2.3 \pm .3$ & .02 \\
\hline ANF & $15 \pm 3.8$ & $5.6 \pm .6$ & .05 \\
\hline$B N P$ & $3.4 \pm .4$ & $1.6 \pm .2$ & .006 \\
\hline CARP & $3.5 \pm .3$ & $2.3 \pm .04$ & .01 \\
\hline$F H L-1$ & $1.3 \pm .2$ & $1.6 \pm .1$ & .16 \\
\hline Col1 & $3.8 \pm .7$ & $2.7 \pm .2$ & .21 \\
\hline $\mathrm{Col} 3$ & $3.8 \pm .6$ & $3.0 \pm .3$ & .30 \\
\hline MMP8 & $.4 \pm .1$ & $.5 \pm .2$ & .89 \\
\hline MMP9 & $.4 \pm .1$ & $.4 \pm .1$ & .74 \\
\hline TIMP1 & $.7 \pm .01$ & $.7 \pm .1$ & .46 \\
\hline$I L-1 b$ & $.4 \pm .02$ & $.4 \pm .1$ & .89 \\
\hline$I L-6$ & $3.9 \pm .4$ & $4 \pm 1.3$ & .93 \\
\hline IL-10 & $.8 \pm .1$ & $1.2 \pm .3$ & .17 \\
\hline \multicolumn{4}{|c|}{$\begin{array}{l}\text { RT-PCR data presented as fold Control (Con) after normalizing with GAPDH. } \alpha \text {-MHC, } \alpha \text {-Myosin Heavy } \\
\text { Chain; } \beta \text {-MHC, } \beta \text {-Myosin Heavy Chain; ANF, Atrial Natriuretic Factor; BNP, Brain Natriuretic Peptide; } \\
\text { CARP, Cardiac Ankyrin-Repeated Protein; FHL-1, Four-and-a-Half LIM domain protein 1; Col1, Collagen } \\
\text { 1; Col3, Collagen 3; MMP8, Matrix Metalloproteinase 8; MMP9, Matrix Metalloproteinase 9; TIMP1, } \\
\text { Tissue Inhibitor or Metalloproteinase 1; IL-1b, Interleukin 1b; IL-6, Interleukin 6; IL-10, Interleukin 10; } \\
\text { Data are mean } \pm S E . \text { P values are from Student's t-test; numbers in parenthesis indicate group size. }\end{array}$} \\
\hline
\end{tabular}




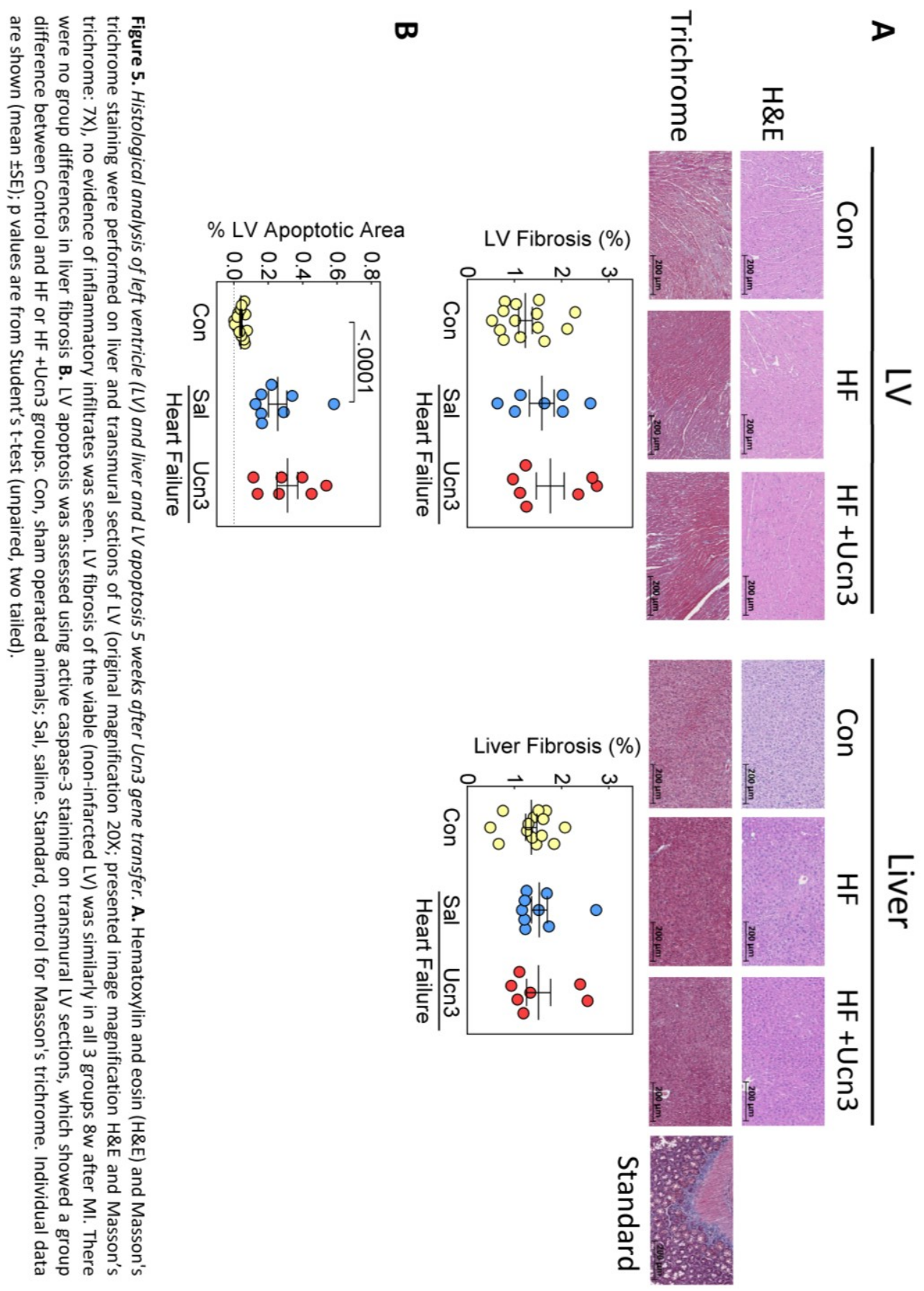


and was a sufficient amount to evoke equivalent $\mathrm{LV}+\mathrm{dP} / \mathrm{dt}$ and $\mathrm{LV}-\mathrm{dP} / \mathrm{dt}$ as was found in male mice. These data indicate that lower doses of AAV8.Ucn3 than used in the current study will suffice to obtain a maximal effect. The dose-response effect of AAV8.Ucn3 in each sex will be addressed in separate studies.

In conclusion, Ucn3 gene transfer increases systolic and diastolic function of the failing heart. These beneficial effects of Ucn3 gene transfer reverberate from $\mathrm{Ca}^{2+}$ transients and sarcomere shortening in isolated cardiac myocytes to measures of LV function in vivo. The mechanism for these benefits can be attributed to improved LV $\mathrm{Ca}^{2+}$ handling, which directly affects sarcomere shortening, and likely a consequence of increased expression of LV SERCA2a and perhaps to restoration of TnI phosphorylation. These studies indicate that chronically increasing plasma levels of Ucn3 may be beneficial in HF with reduced EF. Translating this to possible clinical application will require proof of safety and efficacy and in other models of $\mathrm{HF}$, and studies in larger mammals.

\section{DISCLOSURES AND FUNDING SOURCES}

Disclosure. Dr. Hammond is a founder, board member and unpaid consultant of Renova Therapeutics. Renova had no involvement and played no role in the studies. None of the other authors have disclosures.

Funding Sources. This work was supported by National Institute of Health grant (P01 HL66941) and Merit grants from the Department of Veteran's Affairs (1101 BX001515 and 1101 BX003774). 


\section{REFERENCES}

1. Lloyd-Jones D, Adams RJ, Brown TM, Carnethon M, Dai S, De Simone G, et al. Executive summary: heart disease and stroke statistics--2010 update: a report from the American Heart Association. Circulation. 2010;121:948-954.

2. Lewis K, Li C, Perrin MH, Blount A, Kunitake K, Donaldson C, et al. Identification of urocortin III, an additional member of the corticotropin-releasing factor (CRF) family with high affinity for the CRF2 receptor. Proc Natl Acad Sci. 2001;98:7570-7575.

3 Chan WY, Frampton CM, Crozier IG, Troughton RW, Richards AM. Urocortin-2 infusion in acute decompensated heart failure: findings from the UNICORN study. JACC Heart Failure. 2013;1:433-441.

4. Brar BK, Jonassen AK, Egorina EM, Chen A, Negro A, Perrin MH, et al. Urocortin-II and urocortin-III are cardioprotective against ischemia reperfusion injury: an essential endogenous cardioprotective role for corticotropin releasing factor receptor type 2 in the murine heart. Endocrinology. 2004;145:24-35.

5. Gheorghiade M, Greene SJ, Ponikowski P, Maggioni AP, Korewicki J, Macarie C, et al. Haemodynamic effects, safety, and pharmacokinetics of human stresscopin in heart failure with reduced ejection fraction. European Journal of Heart Failure. 2013;15:679-689.

6. Stirrat CG, Venkatasubramanian S, Pawade T, Mitchell AJ, Shah AS, Lang NN, et al. Cardiovascular effects of urocortin 2 and urocortin 3 in patients with chronic heart failure. British Journal of Clinical Pharmacology. 2016;82:974-982.

7. Patel K, Rademaker MT, Kirkpatrick CM, Charles CJ, Fisher S, Yandle TG, et al. Comparative pharmacokinetics and pharmacodynamics of urocortins 1, 2 and 3 in healthy sheep. British Journal of Pharmacology. 2012;166:1916-1925.

8. Gao MH, Lai NC, Miyanohara A, Schilling JM, Suarez J, Tang T, et al. Intravenous adenoassociated virus serotype 8 encoding urocortin-2 provides sustained augmentation of left ventricular function in mice. Human Gene Therapy. 2013;24:777-785.

9. Lai NC, Gao MH, Giamouridis D, Suarez J, Miyanohara A, Parikh J, et al. Intravenous AAV8 encoding urocortin-2 increases function of the failing heart in mice. Human Gene Therapy. 2015;26:347-356.

10. Giamouridis D, Gao MH, Lai NC, Tan Z, Kim Y-C, Guo T, et al. Effects of urocortin 2 versus urocortin 3 gene transfer on left ventricular function and glucose disposal. JACC: Basic to Translational Science 2018;3:249-264.

11. Xiao X, Li J, Samulski RJ. Production of high-titer recombinant adeno-associated virus vectors in the absence of helper adenovirus. Journal of Virology. 1998;72:2224-2232.

12. Gao G, Qu G, Burnham MS, Huang J, Chirmule N, Joshi B, et al. Purification of recombinant adeno-associated virus vectors by column chromatography and its performance in vivo. Human Gene Therapy. 2000;11:2079-2091.

13. van den Bos EJ, Mees BM, de Waard MC, de Crom R, Duncker DJ. A novel model of cryoinjuryinduced myocardial infarction in the mouse: a comparison with coronary artery ligation. Am J Physiol Heart and Circ Physiol. 2005;289:1291-1230.

14. Gao MH, Lai NC, Roth DM, Zhou J, Zhu J, Anzai T, et al. Adenylylcyclase increases responsiveness to catecholamine stimulation in transgenic mice. Circulation. 1999;99:16181622.

15. Bayat H, Swaney JS, Ander AN, Dalton N, Kennedy BP, Hammond HK, Roth DM. Progressive heart failure after myocardial infarction in mice. Basic Res Cardiol. 2002;97:206-213.

16. Messer AE, Jacques AM, Marston SB. Troponin phosphorylation and regulatory function in human heart muscle: dephosphorylation of Ser23/24 on troponin I could account for the 
contractile defect in end-stage heart failure. Journal of Molecular and Cellular Cardiology. 2007;42:247-259.

17. Salhi HE, Hassel NC, Siddiqui JK, Brundage EA, Ziolo MT, Janssen PM, et al. Myofilament calcium sensitivity: mechanistic insight into Tnl Ser-23/24 and Ser-150 phosphorylation integration. Frontiers in Physiology. 2016;7:567.

18. Battistoni A, Rubattu S, Volpe M. Circulating biomarkers with preventive, diagnostic and prognostic implications in cardiovascular diseases. International Journal of Cardiology. 2012;157:160-168.

19. Krenz M, Robbins J. Impact of beta-myosin heavy chain expression on cardiac function during stress. Journal of the American College of Cardiology. 2004;44:2390-2397.

20. Copeland O, Nowak KJ, Laing NG, Ravenscroft G, Messer AE, Bayliss CR, et al. Investigation of changes in skeletal muscle alpha-actin expression in normal and pathological human and mouse hearts. Journal of Muscle Research and Cell Motility. 2010;31:207-214.

21. Chen C, Shen L, Cao S, Li X, Xuan W, Zhang J, et al. Cytosolic CARP promotes angiotensin II- or pressure overload-induced cardiomyocyte hypertrophy through calcineurin accumulation. PloS One. 2014;9(8):e104040.

22. Shen L, Chen C, Wei X, Li X, Luo G, Zhang J, et al. Overexpression of ankyrin repeat domain 1 enhances cardiomyocyte apoptosis by promoting p53 activation and mitochondrial dysfunction in rodents. Clin Sci (Lond). 2015;128:665-678.

23. Clayton JA, Collins FS. Policy: NIH to balance sex in cell and animal studies. Nature. 2014; 509: 282-283. 



\section{Chapter 4}

\section{One-time Injection of AAV8 Encoding Urocortin 2 Provides Long Term Resolution of Insulin Resistance}

Mei Hua Gao, Dimosthenis Giamouridis, N. Chin Lai, Evelyn Walenta, Vivian Almeida Paschoal, Young Chul Kim, Atsushi Miyanohara, Tracy Guo, Min Liao, Li Liu, Zhen Tan, Theodore P. Ciaraldi, Simon Schenk, Aditi Bhargava, Da Young Oh, H. Kirk Hammond

Journal of Clinical Investigation Insight 2016, 22;1(15):e88322 


\section{ABSTRACT}

Using mice rendered insulin resistant with high fat diets (HFD), we examined blood glucose levels and insulin resistance after intravenous delivery of an adeno-associated virus type 8 encoding murine urocortin 2 (AAV8.Ucn2). A single intravenous injection of AAV8.Ucn2 normalized blood glucose and glucose disposal within weeks, an effect that lasted for months. Hyperinsulinemic-euglycemic clamps showed reduced plasma insulin, increased glucose disposal rates and increased insulin sensitivity following Ucn2 gene transfer. Mice with corticotropin releasing hormone type 2-receptor deletion that were rendered insulin resistant by HFD showed no improvement in glucose disposal after Ucn2 gene transfer, indicating that the effect requires Ucn2's cognate receptor. We also demonstrated increased glucose disposal after Ucn2 gene transfer in $\mathrm{db} / \mathrm{db}$ mice, a second model of insulin resistance. Ucn2 gene transfer reduced fatty infiltration of the liver in both models of insulin resistance. Ucn2 increases Glut4 translocation to the plasma membrane in skeletal myotubes in a manner quantitatively similar to insulin, indicating a novel mechanism through which Ucn2 operates to increase insulin sensitivity. Ucn2 gene transfer, in a dosedependent manner, is insulin sensitizing and effective for months after a single injection. These findings suggest a potential long-term therapy for clinical type-2 diabetes. 


\section{INTRODUCTION}

The corticotropin-releasing hormone (CRH) family peptides, which include urocortin 1 (Ucn1), urocortin 2 (Ucn2), urocortin 3 (Ucn3) and others - stimulate CRH receptors 1 and 2 (CRHR1, CRHR2). Ucn1 binds CRHR1 and CRHR2, but Ucn2 and Ucn3 exclusively bind CRHR2, which are present in brain, heart, vasculature, skeletal muscle, and gastrointestinal tract. CRHR2 activation increases satiety, reduces gut motility, increases heart function and results in vasodilation (1-3).

Ucn2, a 38 amino acid peptide, was discovered in 2001 (1). Studies in animals and human subjects with heart failure (HF) have shown favorable effects of Ucn2 peptide infusion, including increased cardiac output (4). However, because of a short half-life (minutes) the peptide's beneficial effects require continuous intravenous infusion, rendering such therapy impractical except for brief use in hospitalized subjects. We therefore investigated the usefulness of Ucn2 therapy via gene transfer, which would circumvent the need for continuous intravenous infusion and enable long-term outpatient therapy.

We recently demonstrated in mice that intravenous delivery of an adeno-associated virus type 8 vector encoding murine Ucn2 (AAV8.Ucn2) results in increased plasma Ucn2 levels within six weeks, an effect that persists for at least seven months without inflammation or unfavorable hemodynamic effects (5). In the course of these experiments it was noted, serendipitously, that fasting blood glucose levels were significantly reduced in normal mice that had received Ucn2 gene transfer. We therefore conducted studies in two murine models of insulin resistance analogous to clinical type 2 diabetes mellitus (T2DM) testing the hypothesis that a single intravenous injection of AAV8.Ucn2 would increase glucose disposal by promoting insulin sensitivity.

\section{RESULTS}

Ucn2 Gene Transfer: Effects in Normal Mice. The AAV8.Ucn2 vector map is shown in Fig. 1A. Intravenous AAV8.Ucn2 $\left(5 \times 10^{11}\right.$ genome copies, gc) reduced fasting glucose in normal mice maintained on a standard diet. This effect was transgene-specific since AAV8 encoding enhanced green fluorescent protein (EGFP) had no effect on fasting glucose (Fig. 1B). To determine whether glucose effects were dose-related, we used three doses of AAV8.Ucn2: $5 \times 10^{11}, 5 \times 10^{10}$ and $5 \times 10^{9} \mathrm{gc}$, and found that the two higher doses reduced fasting blood glucose (Fig. 1C). We subsequently used $5 \times 10^{11} \mathrm{gc}$ for most of the studies. We found no effect of Ucn2 gene transfer on mean daily heart rate or on basal systolic, diastolic or mean arterial blood pressure 6-8 weeks after gene transfer (Table 1). To assess Ucn2 expression, Ucn2 mRNA was measured (RT-PCR) in brain, heart, liver, lung, pancreas and skeletal muscle. Ucn2 expression was increased only in left ventricle and liver (Table 2). 
Ucn2 Gene Transfer and Glucose Disposal in HFD Model of Insulin Resistance. HFD-fed mice that received $U c n 2$ gene transfer showed consistently lower glucose levels. The area under the curve (AUC) in glucose tolerance tests was reduced by $40-42 \%$ (Fig. 2A; $p=0.003$ ). Similar responses on glucose disposal were seen whether Ucn2 was delivered before or after the onset of hyperglycemia (Fig. 2A), confirming a treatment effect on pre-existing hyperglycemia.

Ucn2 Gene Transfer and Effects on Plasma Insulin in HFD-Induced Insulin Resistance. Ucn2 gene transfer was associated with reduction in plasma insulin levels in nonfasting mice (Fig. 2B; $p<0.007$ ), and promoted insulin-dependent glucose disposal (Fig. 2C; $p=0.0004$ ). Plasma C-peptide levels were similarly reduced (HFD: $5.4 \pm 1.2 \mathrm{ng} / \mathrm{ml}, \mathrm{n}=3 ;$ HFD + Ucn2: $1.0 \pm 0.2$ $\mathrm{ng} / \mathrm{ml}, \mathrm{n}=8 ; \mathrm{p}<0.0002)$.

Table 1. Effects of Ucn2 Gene Transfer on Heart Rate and Basal Blood Pressure in Normal Mice

\begin{tabular}{|c|c|c|c|}
\hline & Control (n) & $\operatorname{Ucn} 2(n)$ & $p$ \\
\hline Heart Rate (beats/min) & $547 \pm 32(4)$ & $548 \pm 26(4)$ & 0.98 \\
\hline Systolic Pressure (mmHg) & $116 \pm 4(5)$ & $132 \pm 7(6)$ & 0.11 \\
\hline Diastolic Pressure (mmHg) & $84 \pm 5(5)$ & $83 \pm 7(6)$ & 0.92 \\
\hline Mean Art Pressure (mmHg) & $94 \pm 5(5)$ & $99 \pm 6(6)$ & 0.53 \\
\hline
\end{tabular}

Table 1. The effects of Ucn2 gene transfer on blood pressure and heart rate (HR) were assessed in

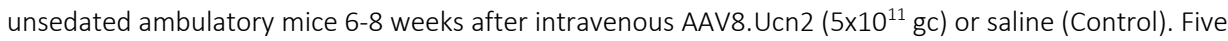
weeks later telemetry units were deployed in the peritoneal cavities enabling acquisition of ambulatory daily mean heart rate 1-2 weeks later. Systolic and diastolic blood pressure was measured by tail cuff, and mean blood pressure calculated. No group differences were seen in heart rate or blood pressure. Data are mean $\pm \mathrm{SE}$, group size in parenthesis. P value from Student's t-test (unpaired, two-tails).

Hyperinsulinemic-Euglycemic Clamp in HFD-Induced Insulin Resistance. The hyperinsulinemic-euglycemic clamp was used to assess insulin sensitivity in normal mice rendered insulin resistant with a HFD. After Ucn2 gene transfer, HFD-fed mice required a 2.6-fold increased glucose infusion rate to maintain blood glucose levels (Fig. $\mathbf{3 A} ; p=0.0003$ ). In addition, there was a 1.5 -fold increase in glucose disposal rate ( $p=0.002$, Fig. 3B), and a 3.8fold increase in insulin-stimulated glucose disposal rate $(p=0.0003$, Fig. $3 C)$, which reflects skeletal muscle insulin sensitivity. Hepatic glucose production (HGP) showed no group difference in the percentage by which insulin suppressed HGP (Control: $21.6 \pm 5.8 \%, n=6$; Ucn2: $22.4 \pm 7.5 \%, n=5 ; p=0.94)$. However, HGP was lower in mice that had received Ucn2 gene transfer both before and after insulin stimulation (Fig. 3D).

Effects of Ucn2 Gene Transfer in HFD-Fed CRHR2 Deleted Mice. CRHR2 deleted mice fed HFD for 17 weeks gained weight (Pre: $22.5 \pm 0.9$ g; 16 weeks: $38.9 \pm 3.0 \mathrm{~g} ; \mathrm{p}=0.0001$ ), and exhibited fasting hyperglycemia (normal chow: $67 \pm 7 \mathrm{mg} / \mathrm{dL}, \mathrm{n}=4$; HFD: $135 \pm 14 \mathrm{mg} / \mathrm{dL}, \mathrm{n}=8$; $\mathrm{p}<0.01)$. CRHR2-deleted mice had the expected increases in plasma Ucn2 after gene transfer ( $>14$-fold increases; Fig. 4A). However, despite this, glucose tolerance testing showed no reduction in hyperglycemia in CRHR2-deleted mice (Fig. 4B). 
Effect of Ucn2 Gene Transfer in db/db Mice. The effects of Ucn2 gene transfer on glucose disposal were studied also in a second model of insulin resistance, the $\mathrm{db} / \mathrm{db}$ mouse (6). Ucn2 expression was documented by a $>450$-fold increase in liver mRNA expression 1 month after intravenous AAV8.Ucn2 $\left(5 \times 10^{11} \mathrm{gc}\right)$ in $\mathrm{db} / \mathrm{db}$ mice (Fig. 5A; $\left.p=0.0016\right)$. One day after gene transfer (Day 1$)$ mice that had received saline $(d b / d b ; n=11)$ and Ucn2 gene transfer $(n=11)$ had similar levels of hyperglycemia (Fig. 5B). Although females tended to have higher pre-Ucn2 glucose levels (female: $218 \pm 39 \mathrm{~g} / \mathrm{dL}, \mathrm{n}=6$; males: $154 \pm 14 \mathrm{mg} / \mathrm{dL}, \mathrm{n}=5$; $\mathrm{p}=0.18$ ), levels 4 weeks after Ucn2 gene transfer were both normal (females: $85 \pm 8 \mathrm{~g} / \mathrm{dL}$, $\mathrm{n}=6$; males: $85 \pm 13 \mathrm{mg} / \mathrm{dL}, \mathrm{n}=5 ; \mathrm{p}=0.97$ ) indicating that $U \mathrm{cn} 2$ increases glucose disposal in both sexes. Glucose tolerance tests in male $\mathrm{db} / \mathrm{db}$ mice indicated that Ucn2 gene transfer was associated with increased glucose disposal (Fig. $\mathbf{5 C}$; $\mathbf{p = 0 . 0 0 3 )}$ ), similar to the results from mice rendered insulin resistant by HFD (Fig. 2A). There were no group differences 5 weeks after gene transfer in body weight (saline: $34.1 \pm 1 \mathrm{~g}, \mathrm{n}=5$; AAV8.Ucn2: $34.2 \pm 2 \mathrm{~g}, \mathrm{n}=5$; $p=0.71$ ) or in 5-week food consumption (saline: $117 \pm 10 \mathrm{~g}, \mathrm{n}=5$; AAV8.Ucn2: $109 \pm 8 \mathrm{~g}, \mathrm{n}=5$; $p=0.54)$.

A

AAV8.CBA.Ucn2

\begin{tabular}{|c|c|c|c|c|c|c|}
\cline { 2 - 6 } ITR & CMV.en & Chicken $\beta$-actin Promoter & Ucn2 & r $\beta$ GpA & ITR \\
\hline 14125 & 380 & 1345 & 345 & 56 & 25 & 141
\end{tabular}

B

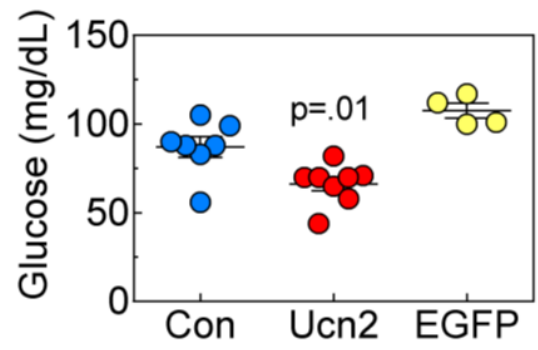

C

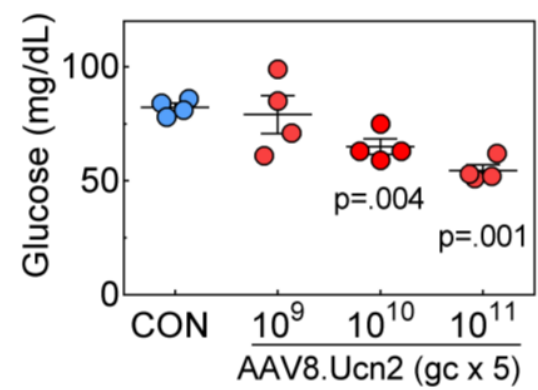

Figure 1. Vector Map and Studies in Normal Mice on Standard Diets. A. AAV8.Ucn2 Map. Initial studies in mice determined that AAV8.CBA.Ucn2 is the optimal AAV serotype and promoter for the proposed studies resulting in a sustained increase in plasma Ucn2 levels over 7 months (5). B. Fasting glucose. Normal mice received intravenous AAV8.Ucn2 $\left(5 \times 10^{11} \mathrm{gc} /\right.$ mouse, $\left.n=8\right)$, saline $(C O N, n=8)$, or AAV9.EGFP $\left(5 \times 10^{11} \mathrm{gc} / \mathrm{mouse}, \mathrm{n}=4\right)$ and standard chow for 3 weeks. A $24 \%$ reduction in fasting glucose was seen after AAV8.Ucn2 gene transfer $(p=0.01)$. C. AAV8.Ucn2 Dose-Glucose Response Relationship. AAV8.Ucn2 doses of $5 \times 10^{9}-5 \times 10^{11} \mathrm{gc} /$ mouse produced 21 $33 \%$ reduction in fasting glucose levels in normal mice. We selected the highest dose $\left(5 \times 10^{11} \mathrm{gc} / \mathrm{mouse}\right)$ for studies conducted in insulin resistant mice. In all graphs, data are mean $\pm S E ; p$ values are from Student's t-test for unpaired data, 2-tails, unless stated otherwise.

Glut4 Translocation and AMPK Activation. In differentiated L6 skeletal myotubes, Ucn2 peptide $(200 \mathrm{nM})$ induced plasma membrane translocation of Glut4 transporter as shown 


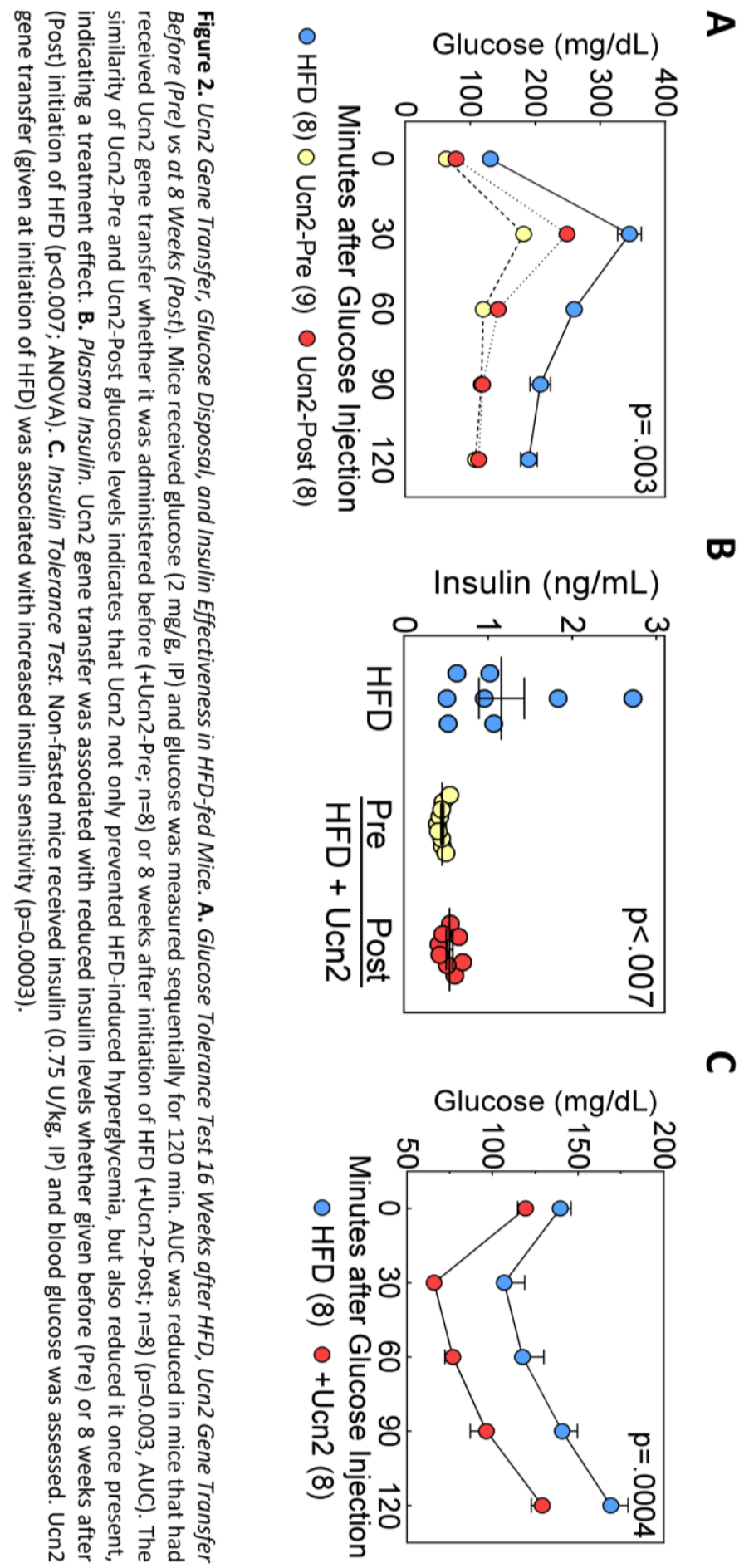


by immunofluorescence staining (Fig. 6A, left) and by immunoblotting analysis (Fig. 6A, right). Ucn2 peptide also activated AMP kinase in cultured L6 myotubes (Fig. 6B), but Akt phosphorylation at Ser-473 was reduced vs control, an effect directionally opposite to insulin.

Skeletal Muscle Glucose Uptake in HFD-Induced Insulin Resistance. HFD-fed mice that received Ucn2 gene transfer showed a 1.9-fold increased uptake of glucose in skeletal muscle ( $p<0.02$; Fig. 6C).

Energy Content in Stool. There was no group difference in energy loss in stool (HFD: $3.73 \pm 0.07 \mathrm{kcal} / \mathrm{g}, \mathrm{n}=6 ; \mathrm{HFD}+U \mathrm{cn} 2: 3.84 \pm 0.07 \mathrm{kcal} / \mathrm{g}, \mathrm{n}=6 ; \mathrm{p}=0.28$ ).

Metabolic Assessment. The Comprehensive Laboratory Animal Monitoring System (CLAMS) was used to assess the effects of Ucn2 on metabolic features of HFD-fed mice. No group differences were seen in mean rates of oxygen consumption, carbon dioxide production, activity or heat generation. HFD-fed mice that received Ucn2 gene transfer showed small $(2.4 \%)$ but statistically significant increases in respiratory exchange ratio (Table 3).

A

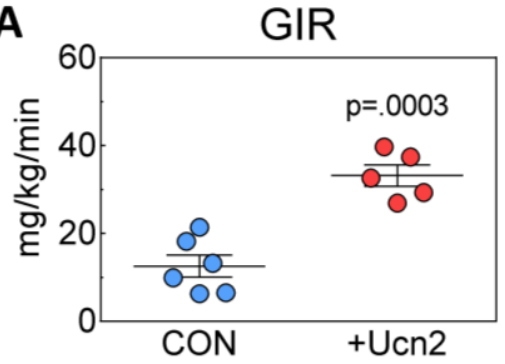

C

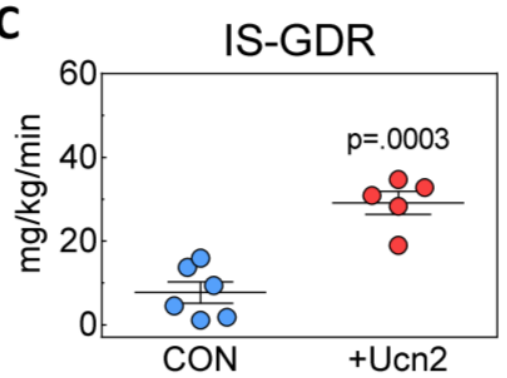

B

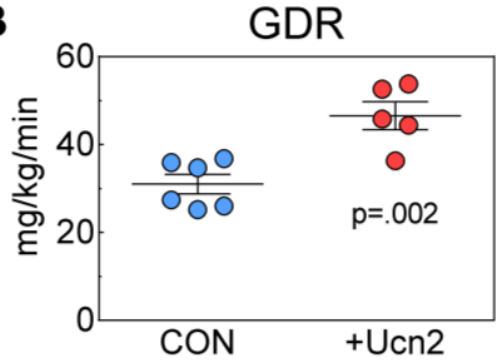

D

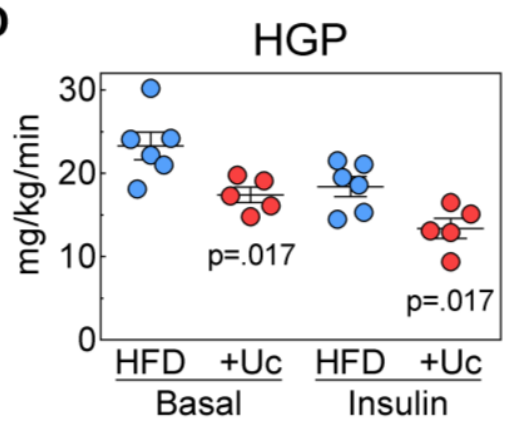

Figure 3. Hyperinsulinemic-Euglycemic Clamp. Fasted ( $6 \mathrm{hr}$ ) HFD-fed mice received constant infusion of insulin and ${ }^{3} \mathrm{H}$-glucose tracer, but variable glucose infusion rates to maintain blood glucose levels. Glucose infusion rate was recorded for $2 \mathrm{hr}$ during the clamp and blood was obtained before and after the clamp. Mice fed HFD and subsequent Ucn2 gene transfer: A. required higher glucose infusion rates (GIR) to maintain euglycemia during the clamp. B. showed increased glucose disposal rate (GDR). C. showed increased insulin-stimulated glucose disposal rate (IS-GDR), indicating increased insulin sensitivity. D. showed reductions in hepatic glucose production (HGP) before and after insulin stimulation. The relative reductions in HGP during insulin stimulation showed no group difference. HFD, high fat diet; Ucn2, UC: urocortin-2 gene transfer 


\begin{tabular}{|c|c|c|c|c|}
\hline & HFD (6) & $\mathrm{HFD}+\mathrm{Ucn} 2(6)$ & $\%$ Change & $\mathrm{p}$ \\
\hline VO2 (ml/kg/hr) & $3350 \pm 102$ & $3578 \pm 143$ & $+6.8 \%$ & 0.20 \\
\hline $\mathrm{VCO}_{2}(\mathrm{ml} / \mathrm{kg} / \mathrm{hr})$ & $2511 \pm 90$ & $2734 \pm 105$ & $+8.9 \%$ & 0.11 \\
\hline RER & $0.746 \pm 0.004$ & $0.764 \pm 0.005$ & $+2.4 \%$ & 0.024 \\
\hline Activity (broken photobeams) & $274 \pm 59$ & $291 \pm 62$ & $+6.2 \%$ & 0.85 \\
\hline Heat (Kcal/hr) & $0.680 \pm 0.055$ & $0.668 \pm 0.028$ & $-1.8 \%$ & 0.76 \\
\hline \multicolumn{5}{|c|}{$\begin{array}{l}\text { Table 3. Data were acquired from twelve adult mice fed HFD for } 16 \text { weeks. Six of the twelve received } \\
\text { intravenous AAV8.Ucn2 (HFD }+ \text { Ucn2; } 5 \times 10^{11} \mathrm{gc} \text { ) after week } 8 \text {. Metabolic studies were conducted from } \\
\text { five light-dark cycles ( } 2.5 \text { days), following an acclimatization period. Data are mean } \pm \text { SE. P values from } \\
\text { a 2-way ANOVA with repeated measures. HFD, high-fat diet; Ucn2, urocortin } 2 \text { gene transfer }\left(5 \times 10^{11} \mathrm{gc} \text {, }\right. \\
\text { intravenous); VO2, rate of oxygen consumption; VCO2, rate of carbon dioxide production; RER, } \\
\text { respiratory exchange ratio }\end{array}$} \\
\hline
\end{tabular}

Weight Gain. Ucn2 gene transfer in HFD-fed mice was associated with a trend toward reduced food consumption ( $p=0.10)$ but with a $34 \%$ reduction in weight gained $(p=0.002)$ compared to saline-treated HFD-fed mice (Fig 7A). These mice had similar body weights 8 weeks after HFD was instituted-reduced weight gain did not occur until Ucn2 gene transfer

A

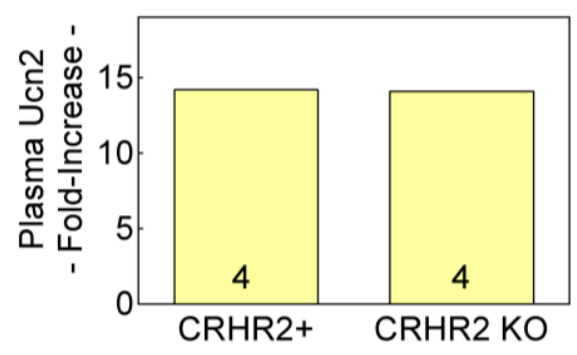

B

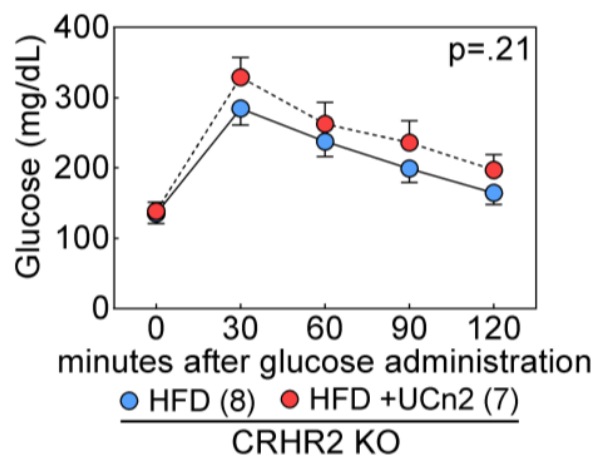

Figure 4. Ucn2 Gene Transfer in HFD-induced Insulin Resistance in CRHR2-Deleted Mice. A. Plasma Ucn2 in CRHR2Deleted Mice. First, we confirmed that intravenous AAV8.Ucn2 $\left(5 \times 10^{11} \mathrm{gc}\right.$, IV) was associated with increased plasma Ucn2 levels in CRHR2-deleted (KO) HFD-fed mice. Plasma Ucn2 peptide was measured in pooled plasma (4 animals per group). High plasma levels of Ucn2 were detected, in amounts similar to what we found in normal mice (5). B. Glucose Tolerance Test 17 Weeks after HFD, Ucn2 Gene Transfer at 8 Weeks. Fasted CRHR2-deleted mice received glucose $(2 \mathrm{mg} / \mathrm{g}, \mathrm{IP})$ and glucose was measured sequentially for $120 \mathrm{~min}$. There was no group difference in blood glucose levels ( $p=0.21, A U C)$, indicating that Ucn2's cognate receptor, CRHR2, is required for $\mathrm{Ucn} 2$ to increase glucose disposal rate. Contrast these data to those shown in Figure $\mathbf{2 A}$, where a pronounced glucose lowering effect of Ucn2 gene transfer is observed. 
was performed. The ratio of gram of weight gained to gram of food consumed, a measure feed efficiency, showed no group difference after 8 weeks of HFD $(p=0.53)$. However, Ucn2 gene transfer, performed at 8 weeks, was associated with reduced feed efficiency for the subsequent 8-week period (HFD: $0.06 \pm 0.01 \mathrm{~g} / \mathrm{g} ; \mathrm{n}=8$; HFD+Ucn2: $0.03 \pm 0.004 \mathrm{~g} / \mathrm{g}, \mathrm{n}=8$; $\mathrm{p}<0.014)$.

Histology. Intravenous AAV8.Ucn2 $\left(5 \times 10^{11} \mathrm{gc}\right)$ was not associated with adverse histological changes in liver, left ventricle, or skeletal muscle-no inflammation or fibrosis was seen. However, untreated HFD-fed mice showed fatty infiltration of the liver (Fig. 7B). Quantitative assessment indicated that Ucn2 gene transfer was associated with a $74 \%$ reduction of fatty infiltration of liver in the HFD model ( $p=0.015 ; n=8$ per group; Fig. 7C), and a $41 \%$ reduction in hepatic triglyceride content ( $p=0.024$; Fig. 7D). A 43\% reduction in fatty infiltration of liver was also seen after Ucn2 gene transfer in $d b / d b$ mice ( $n=3$ per group), even though there was no group difference in weight among $\mathrm{db} / \mathrm{db}$ mice. Skeletal muscle showed a non-significant reduction in triglyceride content (HFD: $30 \pm 3 \mathrm{nmol} / \mathrm{mg}$, $\mathrm{n}=5$; +Ucn2: $24 \pm 3 \mathrm{nmol} / \mathrm{mg} ; \mathrm{p}<0.15)$.

AAV8.Ucn2 Dose-Response Relationship. AAV8.Ucn2 doses in $1 / 2$-log increments from $5 \times 10^{9}$ to $5 \times 10^{11} \mathrm{gc}$ IV delivered to HFD-fed mice were associated, 9 weeks later, with a dose-related increase in plasma Ucn2 levels (Fig 8A; $p<0.0001 ;$ ). A dose of $1.6 \times 10^{10}$ gc increased mean plasma Ucn 2 concentration from $1.1 \pm 0.1 \mathrm{ng} / \mathrm{ml}$ to $4.0 \pm 0.5 \mathrm{ng} / \mathrm{ml}$. The highest vector dose increased mean plasma Ucn 2 to $27.4 \pm 2.2 \mathrm{ng} / \mathrm{ml}$. Dose-related reductions in fasting glucose were seen (Fig. 8B; $p<0.0001$ ). The effects of AAV8.Ucn2 on glucose disposal also were dose-dependent ( $p=0.0036$; Figs. $8 \mathrm{C}$ and $8 D)$. IV saline and AAV8.EGFP $\left(5 \times 10^{11} \mathrm{gc}\right.$, IV) had no effect, as anticipated.

Necropsy. Table 4 shows that mice fed HFD for 16 weeks who had received Ucn2 gene transfer at onset of HFD or 8 weeks later had reduced body weight $(p=0.014)$ and reduced liver weight both in absolute terms $(p=0.018)$ and normalized for tibial length $(p=0.02)$.

\section{DISCUSSION}

The most important finding of the current study is that Ucn2 gene transfer has a profound and enduring effect on insulin sensitivity in HFD-fed mice (Fig. 3). A single intravenous injection of AAV8.Ucn2: 1) prevents hyperglycemia from developing in mice fed a HFD, and increases glucose disposal if delivered after hyperglycemia is present (Fig. 2A); 2 ) increases insulin sensitivity, glucose disposal rate and glucose uptake in skeletal muscle (Figs. 3B, 3C and 6C); 3) reduces fatty infiltration of the liver (Figs. 7B, 7C and 7D); 4) reduces weight gain on prolonged HFD (Fig. 7A); and 5) decreases fasting hyperglycemia and increases glucose disposal in a second model of disordered glucose homeostasis $(\mathrm{db} / \mathrm{db}$ 
mice) (Figs. 5B and 5C). These data confirm the efficacy of Ucn2 gene transfer in reducing insulin resistance. These results have potential clinical application.

Clinical trials of intravenous infusions of Ucn2 peptide (4) or a related peptide, stresscopin (7), in patients with heart failure have not reported reduced blood glucose levels. Perhaps the effects on glucose metabolism conferred by Ucn2 gene transfer are a consequence of longer duration and higher plasma Ucn2 concentrations obtained with gene transfer than with Ucn2 peptide infusion. Indeed, six weeks after Ucn2 gene transfer $\left(5 \times 10^{11} \mathrm{gc}, \mathrm{IV}\right)$ in mice, mean plasma levels were 15 -fold control (5), while peak Ucn2 levels in human subjects during 1-4 hour peptide infusions $(5-30 \mathrm{ng} / \mathrm{kg} / \mathrm{min}$ ) were 3-fold control and were short-lived, rapidly declining after termination of the infusion (4). However, it is unlikely that the high plasma Ucn2 levels attained in the present study are required for an effect on glucose metabolism. Our dose-response data indicate that AAV8.Ucn2 amounts 30-fold lower provide a glucose lowering effect (Figs. 8A-D), which corresponds to a plasma Ucn2 level of $4.0 \pm 0.5 \mathrm{ng} / \mathrm{ml}$, 4-fold above normal (Fig. 8A). The present study documents the effects of Ucn2 gene transfer on glucose disposal in two murine models of insulin resistance. Although the study was primarily conducted in male mice, female $\mathrm{db} / \mathrm{db}$ mice also showed normalization of fasting glucose after Ucn2 gene transfer, suggesting that the effect occurs in both sexes.

\begin{tabular}{|c|c|c|c|c|}
\hline \multicolumn{5}{|c|}{ Table 4. Necropsy HFD Mice } \\
\hline & Control (8) & Ucn2 Pre (9) & Ucn2 Post (8) & $\mathrm{p}$ \\
\hline Body Weight (g) & $39.3 \pm 1.4$ & $33.3 \pm 0.9$ & $35.8 \pm 1.6$ & 0.014 \\
\hline Tibial Length (mm) & $17.9 \pm 0.1$ & $17.9 \pm 0.1$ & $17.9 \pm 0.1$ & 0.84 \\
\hline Left Ventricle (mg) & $105 \pm 2$ & $97 \pm 4$ & $99 \pm 3$ & 0.15 \\
\hline $\mathrm{LV} / \mathrm{TL}(\mathrm{mg} / \mathrm{mm})$ & $5.9 \pm 0.1$ & $5.4 \pm 0.2$ & $5.5 \pm 0.2$ & 0.16 \\
\hline Liver (mg) & $1265 \pm 89$ & $1058 \pm 25$ & $1022 \pm 51$ & 0.018 \\
\hline Liver/TL (mg/mm) & $71 \pm 5$ & $59 \pm 1$ & $57 \pm 3$ & 0.02 \\
\hline Lung (mg) & $157 \pm 8$ & $156 \pm 4$ & $156 \pm 4$ & 0.92 \\
\hline \multicolumn{5}{|c|}{$\begin{array}{l}\text { Table 4. Mice received IV saline or AAV8.Ucn2 }\left(5 \times 10^{11} \mathrm{gc}\right) \text { at the beginning (Ucn2 Pre) or } 8 \text { weeks after } \\
\text { high fat diet (Ucn2 Post). After a total of } 16 \text { weeks on HFD, organs were collected and weighed. Values } \\
\text { represent mean } \pm \text { SE. P values are from 1-way ANOVA. TL, tibial length }\end{array}$} \\
\hline
\end{tabular}

Mechanism. Our data show beneficial effects of Ucn2 gene transfer on glucose uptake in skeletal muscle in the basal state (Fig. 6C), and augmentation of glucose disposal upon insulin stimulation (Fig. 3C). Therefore, skeletal muscle clearly contributes to the increased insulin sensitivity observed. Ucn2 gene transfer also was associated with a $20 \%$ reduction 


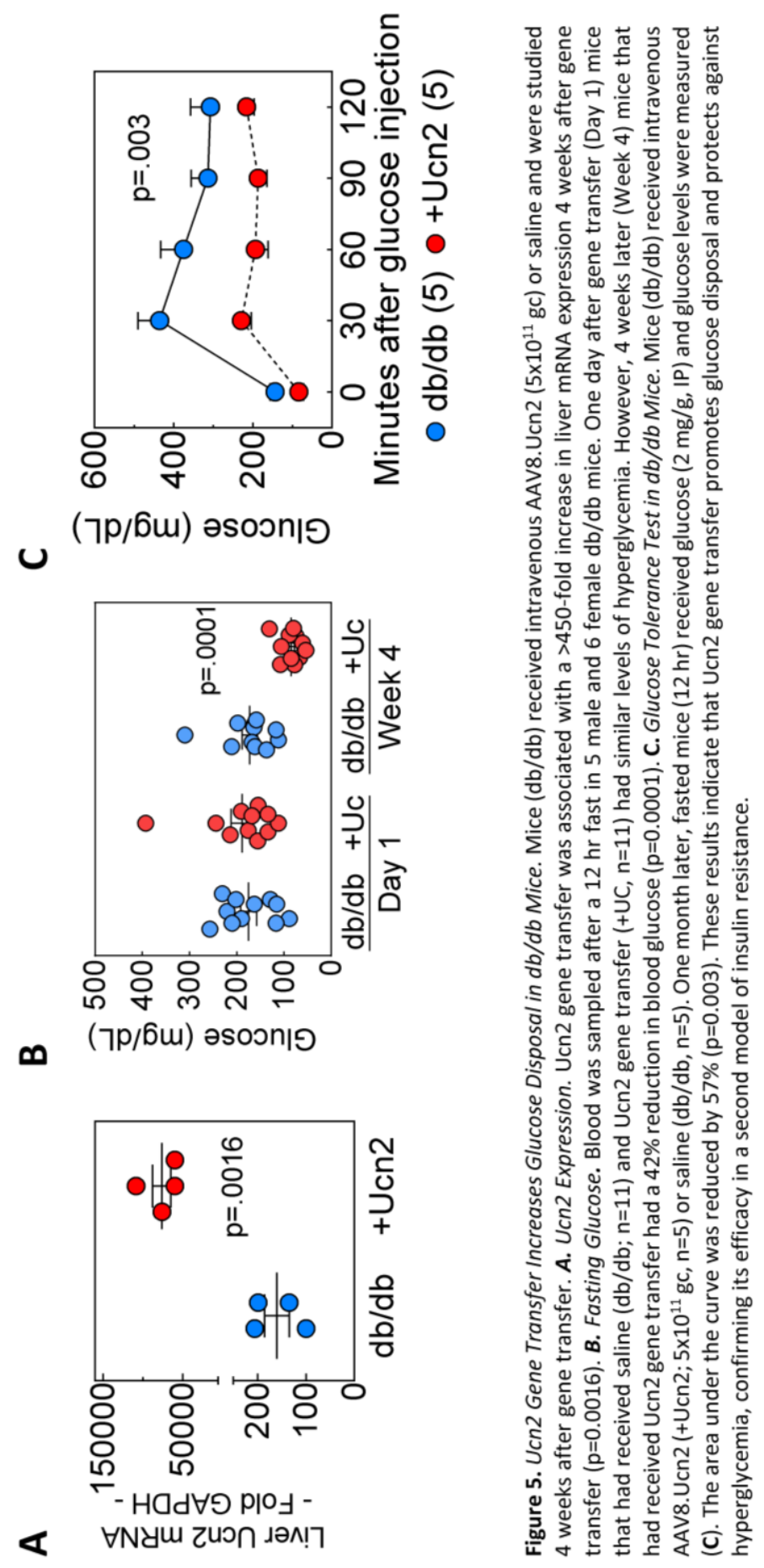


in hepatic glucose production (Fig. 3D), which may have contributed to improved glucose homeostasis.

Insulin acts by increasing Akt phosphorylation of Ser-473, which promotes Glut4 translocation to the plasma membrane and increased glucose disposal. Ucn2 peptide increases Glut4 translocation similarly to insulin (Fig. 6B) but, in contrast to insulin, phosphorylation of Ser-473-Akt is decreased (Fig. 6B), indicating a novel pathway for Ucn2related Glut4 translocation and increased glucose disposal. Glut4 translocation is associated with AMPK phosphorylation (Fig. 6B) (8) and is an expected consequence of CRHR2 receptor activation, which triggers CAMP-PKA signaling $(1,2)$. That Ucn2 gene transfer did not increase glucose disposal in CRHR2-deleted mice rendered insulin resistant by HFD (Fig. 4B) supports this idea. A previous study (9) found no change in fasting blood glucose after 4 weeks of HFD in a different CRHR2-deleted line, which may reflect a difference in line or an inadequate duration of HFD (4 weeks vs 8-18 weeks in the current study).

Metabolic Effects. Ucn2 activation of CRHR2 receptors in brain and the gastrointestinal tract can alter satiety and thereby reduce food consumption (3). Although we saw nonsignificant reductions in food consumption (5\%; $p=0.10)$, there was a $34 \%$ reduction in weight gain $(p<0.002)$ in Ucn2 mice on HFD (Fig. 7A). However, $d b / d b$ mice showed similar increases in glucose disposal after Ucn2 gene transfer but no change in food consumption or weight gain, indicating that Ucn2's effects on glucose disposal are not due to reduced weight alone. Metabolic studies of mice fed HFD for 16-17 weeks indicated that Ucn2 gene transfer did not increase total activity, heat generation, or the rates of oxygen consumption or carbon dioxide production (Table 3). The biological importance of a $2.4 \%$ increase in respiratory exchange ratio following Ucn2 gene transfer is unknown, although it indicates a small increase in metabolism of carbohydrate vs fat.

Gross malabsorption was not evident, but to evaluate this possibility we performed bomb calorimetric studies on stool from HFD-fed mice. We found that Ucn2 gene transfer had no effect on energy loss in stool, which makes malabsorption unlikely. We then evaluated feed efficiency, a measure of weight gained per food consumed (10) and documented that Ucn2 gene transfer was associated with a $50 \%$ reduction in feed efficiency $(p<0.014)$. The values for feed efficiency in mice on HFD $(0.06 \pm 0.01 \mathrm{~g} / \mathrm{g})$ are in line with previous reports, where a mean feed efficiency of $0.06 \mathrm{~g} / \mathrm{g}$ was reported (10). A treatment for T2DM that increases insulin sensitivity and glucose disposal while attenuating weight gain and reducing fatty infiltration of liver would be a welcome addition to current clinical therapy. Reduced fatty infiltration of the liver appeared to be independent of weight gain: it also was seen after Ucn2 gene transfer in $\mathrm{db} / \mathrm{db}$ mice despite no group difference in weight. HFD mice that received Ucn2 gene transfer had reduced hepatic triglyceride content and reduced liver weight.

Previous Studies. Elevation in plasma Ucn2 increased insulin sensitivity, an unanticipated and previously unreported phenomenon. Indeed, Ucn2 deletion was reported to increase skeletal muscle glucose clearance (11). However, deletion of a gene is not the opposite of its expression vis-à-vis overall physiological integration. For example, this finding, which seems to contradict our studies, may reflect centrally mediated effects. In a transgenic line 
with general Ucn3 over expression, increased glucose clearance in HFD-fed mice was reported (12). However, these Ucn3 expressing mice, unlike the mice that received Ucn2 gene transfer in the present study, showed no change in insulin sensitivity. The mechanism for increased glucose clearance in the Ucn3 transgenic line may relate to phenotypic features of the line, which included increased skeletal muscle mass and body weight. In addition, that study found a 44-fold increase in brain Ucn3, which confounds data interpretation because of central effects of Ucn3. In our study, Ucn2 expression was not increased in brain (Table 2).

Ucn3 but not Ucn2 is expressed in pancreatic beta cells and is required for glucose- and incretin-stimulated insulin secretion (13). High levels of transgene Ucn2 may activate CRHR2 receptors in pancreatic beta cells and thereby influence insulin release. However, Ucn2 gene transfer reduced plasma insulin levels in HFD mice (Fig. 2B; p <0.007). The normalization of fasting hyperglycemia combined with increased glucose disposal (HFD: Fig. 2A, $p=0.003 ; d b / d b$ : Fig. $5 C, p=0.003$ ) and increased insulin sensitivity (Fig. 2C; $p=0.0004$ ), indicate that Ucn2 gene transfer reduced insulin resistance, as confirmed by hyperinsulinemic-euglycemic clamp studies (Fig. 3).

Gene and Cell Therapy. The potential safety of intravenous delivery of an AAV8 vector was demonstrated in an early-phase gene transfer clinical trial in patients with hemophilia $B$ (14). Although we can find no previous reports using gene transfer of an insulin-sensitizing peptide to treat insulin resistance or T2DM, there have been reports of other novel therapies. For example, Islet-cell transplantation has been successful clinically (15), although donors are difficult to procure and rejection has been a problem. An early phase clinical trial showed that polyclonal regulatory $T$ cell immunotherapy might be effective in treating type 1 diabetes (16). Gene transfer has been successful in preclinical models of diabetes. For example, insulin and glucokinase gene transfer (17) and gene transfer of both the NK1 fragment of hepatocyte growth factor (HGF/NK1) and glucagon-like peptide-1 (GLP-1), which appears to promote Islet generation (18), have been successful in preclinical studies. However, these therapies have focused on insulin deficiency - type 1 and late stage T2DM. In contrast, the current studies focused on earlier stage insulin resistance using a transgene that increases insulin sensitivity.

Cardiac Effects of Urocortin 2. We have demonstrated that Ucn2 gene transfer in normal mice has beneficial effects on LV contractile function through augmentation of $\mathrm{Ca}^{2+}$ handling (5). The safety and efficacy of Ucn2 peptide infusion has been confirmed in large animal models of HF (19) and in patients with HF (4). A clinical HF study using infusion of an Ucn2-related peptide, stresscopin, found similar results (7). We also recently showed that Ucn2 gene transfer increases function of the failing heart in mice (20). T2DM is commonly present in patients with HF. In patients with both HF and T2DM, Ucn2 gene transfer could, in theory, resolve insulin resistance and increase LV function concurrently.

In clinical trials, Ucn2 peptide infusion has been bedeviled with hypotension and reflex tachycardia. In the present study we saw no group differences in mean daily heart rate assessed by continuous telemetry or in basal blood pressure assessed by tail cuff (Table 1). This may reflect tachyphylaxis to vasodilation associated with long duration and gradual 


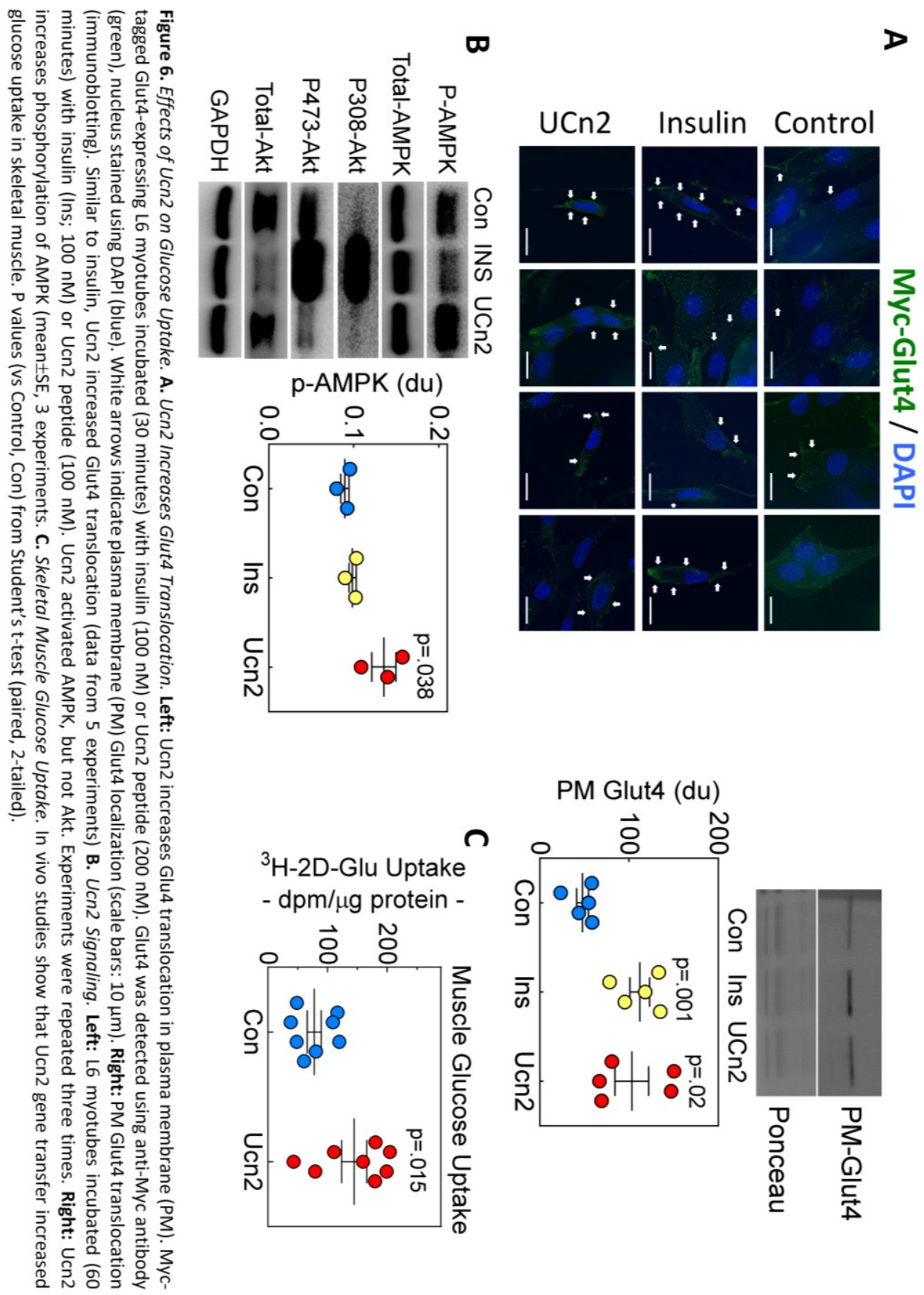


onset Ucn2 exposure. In contrast, the effects of Ucn2 gene transfer on blood glucose persisted for the duration of testing (16-17 weeks) without decrement in degree of effect. The absence of basal hypotension and tachycardia is reassuring vis-à-vis prospects for future clinical trials.

Translation to Clinical Application. AAV8.Ucn2 dose-response data (Figs. 8A-D) indicate that a dose of $5 \times 10^{10} \mathrm{gc}\left(1.9 \times 10^{12} \mathrm{gc} / \mathrm{kg}\right)$ is associated with a $44 \%$ reduction in AUC, and a dose of $1.6 \times 10^{10} \mathrm{gc}\left(6 \times 10^{11} \mathrm{gc} / \mathrm{kg}\right)$ with an $18 \%$ reduction in AUC (Figs. 8C and 8D). Previous studies have shown that a $20 \%$ reduction in AUC is efficacious in treating clinical T2DM (21), suggesting that a dose of $6 \times 10^{11} \mathrm{gc} / \mathrm{kg}, 30$-fold lower than the highest dose used in the present study, may be effective in clinical settings. This would limit adverse effects that may be associated with higher doses of AAV8. These doses $\left(1.9 \times 10^{12} \mathrm{gc} / \mathrm{kg}\right.$ and $\left.6 \times 10^{11} \mathrm{gc} / \mathrm{kg}\right)$ are similar to the highest two doses of an AAV8 vector encoding Factor IX used safely in a gene transfer trial in human subjects with Hemophilia $B\left(2 \times 10^{12} \mathrm{gc} / \mathrm{kg}\right.$, and $6 \times 10^{11} \mathrm{gc} / \mathrm{kg}$, IV) (14).

Clinical Implications. Diabetes was reported to affect $12-14 \%$ of the US adult population in 2011-2012 (22), 95\% of whom have T2DM. T2DM is a major risk factor for stroke, neuropathy, kidney failure, blindness, myocardial infarction and heart failure. Few diseases affect so many organs or are as prevalent. The discovery and development of more effective therapies is imperative. Intravenous delivery of an AAV vector encoding Ucn2 provides numerous possible advantages over oral T2DM agents and insulin: 1) The insulin sensitizing effect of Ucn2 gene transfer would be anticipated to preserve beta-cell function, a goal in the management of patients with early T2DM; 2) Some oral T2DM agents, including thiazolidinediones, appear to be hazardous in patients with coronary artery disease or $\mathrm{HF}$ (23). In contrast, Ucn2 has beneficial effects on the heart $(2,4,5,19,20)$; 3 ) Repeated insulin injections or frequent oral medications are a nuisance for many patients - Ucn2 gene transfer would circumvent this with a one-time treatment; 4) Insulin and some oral T2DM agents are associated with weight gain. In contrast, Ucn2 gene transfer is associated with reduced weight gain in mice fed HFD (Fig. 7A); 5) Ucn2 gene transfer reduced fatty infiltration of the liver in both models of insulin resistance (Figs. 7B and 7C). Non-alcoholic fatty liver disease is a rapidly increasing problem, particularly among patients with T2DM and metabolic syndrome, and is a common cause for liver transplantation (24). So this effect of Ucn2 gene transfer in the setting of insulin resistance has important clinical implications.

Limitations. The precise molecular pathways beyond Glut4 translocation that explain the favorable and novel effects of Ucn2 gene transfer on glucose disposal will require additional studies. Elevation of Ucn2, an endogenous peptide hormone, could potentially have adverse consequences in humans that are not apparent in mice. However, T2DM is a lifethreatening disease, and, despite many currently available medical options, few appear to effectively reduce its morbidity and mortality. The proposed therapy would serve an unmet medical need. Studies in nonhuman primates with T2DM will be initiated soon, and, if insulin sensitivity and glucose disposal are safely increased in these studies, we hope to initiate a clinical trial.

Conclusion. A one-time intravenous injection of an AAV8 vector encoding urocortin 2 increases insulin sensitivity and glucose disposal, provides long-lasting resolution of 


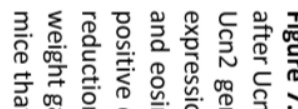

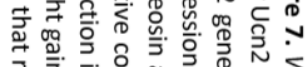

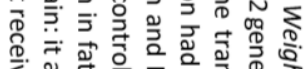

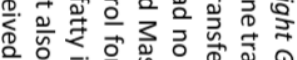

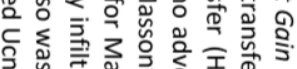

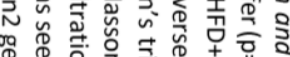

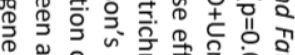

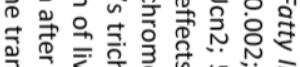

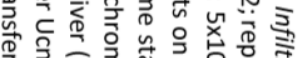

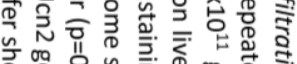

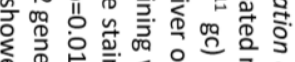

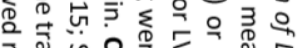

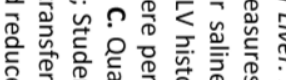

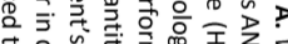

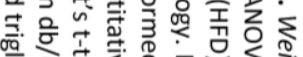

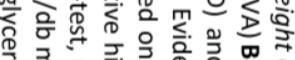

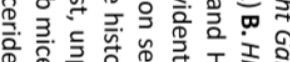

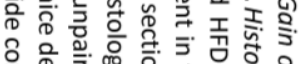

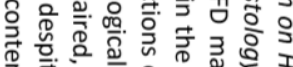

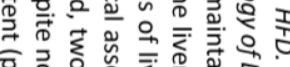

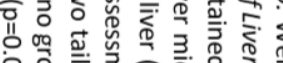

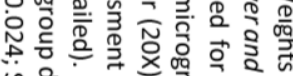

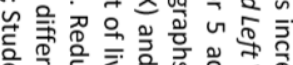

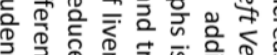

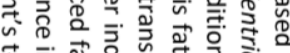

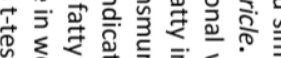

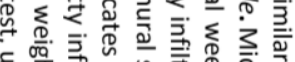

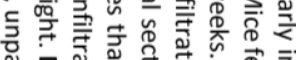

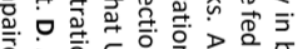

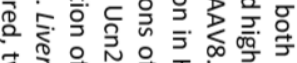

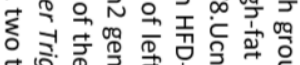

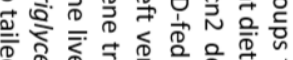

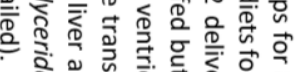

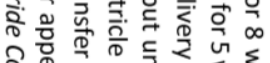

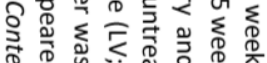

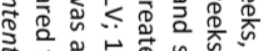

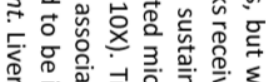

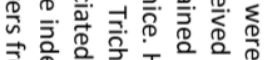

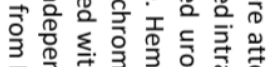

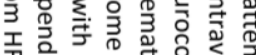

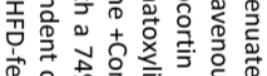

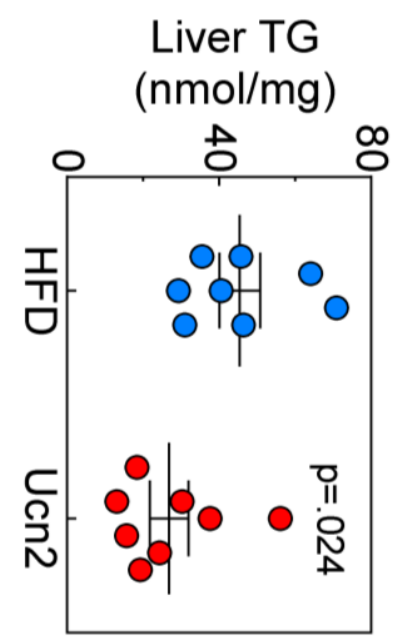

Fat infiltration (\%)

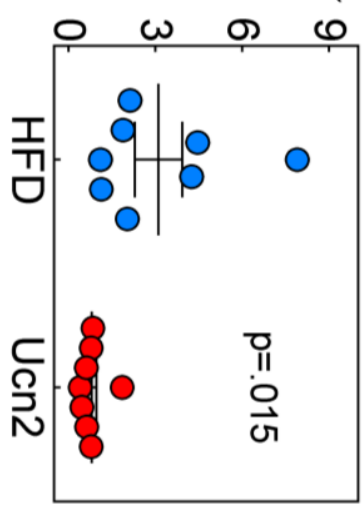

ก
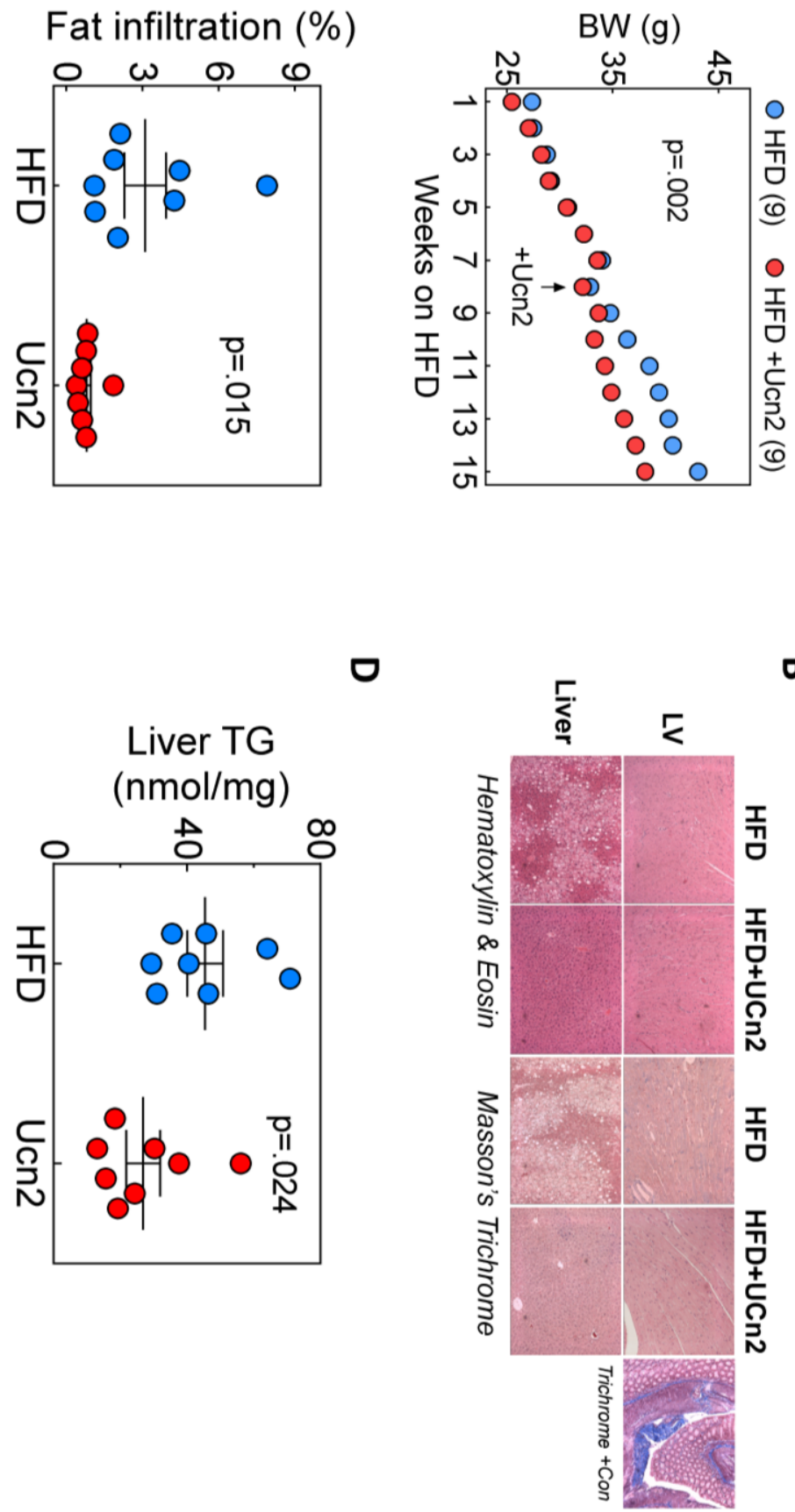

ర

퓸

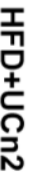

꼼

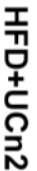

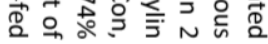


abnormal glucose homeostasis, and reduces fatty infiltration of liver in two murine models of insulin resistance, suggesting a potential long-term therapy in clinical type-2 diabetes.

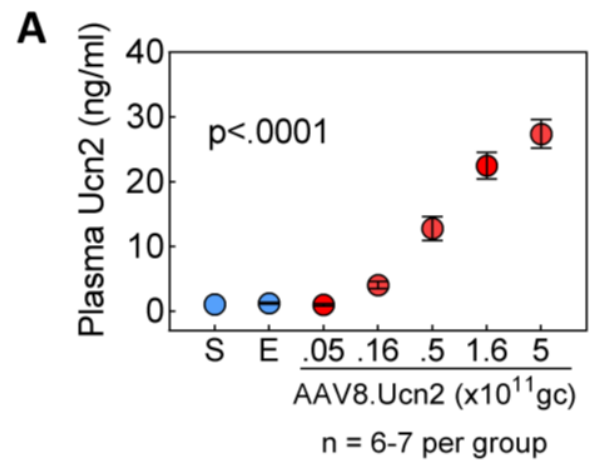

C

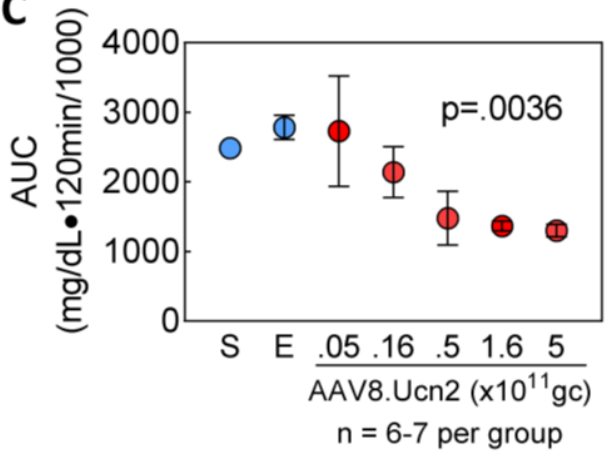

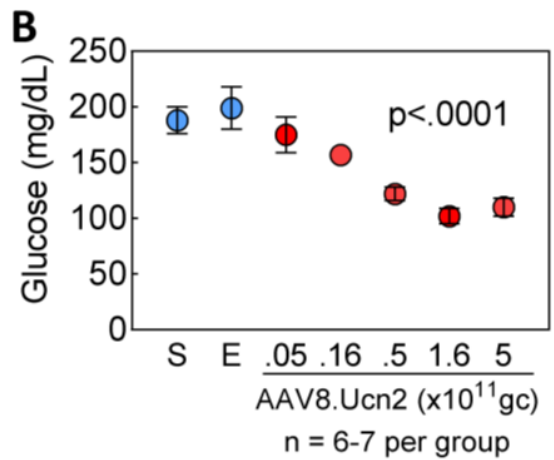

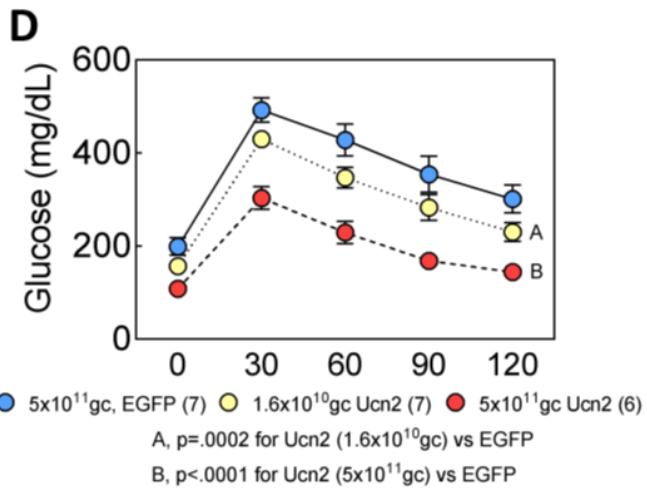

Figure 8. AAV8.Ucn2 Dose-Response Relationship. The effects of AAV8.Ucn2 dose on plasma levels of Ucn2 and glucose disposal were examined 9 weeks after institution of HFD. A. AAV8.Ucn2 Dose vs Plasma Ucn2 Concentration. AAV8.Ucn2 doses of $5 \times 10^{9}-5 \times 10^{11}$ gc IV produced a dose-related increase in plasma Ucn2 levels $(p<0.0001,1$-way ANOVA). Plasma obtained $75 \pm 5$ days after delivery. B. Fasting Glucose. Fasting blood glucose was related to AAV8.Ucn2 dose ( $p<0.0001,1$-way ANOVA). C. Vector Dose and Glucose Tolerance Testing. The effects of AAV8.Ucn2 on glucose disposal were dose-dependent ( $p=0.0036,1$-way ANOVA). Shown is area under the glucose-time curve for each dose. D. Highest and Lowest Effective AAV8.Ucn2 Dose. Shown are glucose concentrations after IV glucose load in 3 of the 7 groups shown in panel C: AAV8.EGFP (control, $5 \times 10^{11} \mathrm{gc}, \mathrm{IV}$ ), and two doses of AAV8.Ucn2, IV: $5 \times 10^{11} \mathrm{gc}$ (the highest dose) and $1.6 \times 10^{10} \mathrm{gc}$, the lowest effective dose. In A-C, $\mathrm{S}$, saline; E, AAV8.EGFP $5 \times 10^{11} \mathrm{gc}$ IV

\section{MATERIALS \& METHODS}

AAV8.Ucn2 Vector Production. An AAV8 vector encoding murine Ucn2 with a chicken $\beta$ actin (CBA) promoter (Fig. 1A) was produced as detailed previously (5). Plasmid pRep2/Cap8 was obtained from the University of Pennsylvania Vector Core. 
Animal Use. The 'Principles of laboratory animal care' (NIH publication no. 85-23, revised 1985) were followed and the Animal Use and Care Committees of the VA San Diego Healthcare System and the University of California San Francisco approved the studies. The numbers of animals used in each set of experiments, their weights, ages, sex, and animals that died or had unusable data are outlined in Table 5. There were 203 mice used, ranging in age from 5-16 weeks, weighing 27.7 to 35.6 grams depending on the protocol. All but 12 animals were male. Thirteen mice were excluded: 8 due to unusable data (determination made prior to unblinding) and 5 due to death during anesthesia or surgery; 4 prior to vector delivery (Table 5). Animal numbers are stated also in Figure legends and Tables.

Studies in Normal Mice on Normal Diets. Fifty-nine normal mice on normal chow were used to evaluate the effects of Ucn2 gene transfer on fasting blood glucose, blood pressure and heart rate. AAV9 encoding enhanced green fluorescence protein (AAV9.EGFP) was used as an additional control to ensure the effect on blood glucose was Ucn2-specific. Normal mice received intravenous AAV9.EGFP $\left(5 \times 10^{11} \mathrm{gc}\right)$, saline or AAV8.Ucn2 in doses ranging from $5 \times 10^{9}$ to $5 \times 10^{11} \mathrm{gc}$. The effects of Ucn2 gene transfer on blood pressure and heart rate were assessed in unsedated ambulatory mice 6-8 weeks after Ucn 2 gene transfer $\left(5 \times 10^{11} \mathrm{gc}\right.$, IV). To accomplish this, five weeks after gene transfer or saline PhysioTel ${ }^{\circ}$ ETA-F20 transmitters (Data Sciences International, St. Paul, MN) were implanted intraperitoneally, and continuous electrocardiographic recording was initiated 1 week later and continued for 5 days to enable acquisition of ambulatory daily mean heart rate as previously reported (25). Systolic and diastolic blood pressure wasmeasured by tail cuff (Visitech Systems, Apex, $\mathrm{NC})$, and mean blood pressure calculated.

High-Fat Diet-Induced Insulin Resistance. To determine the effect of Ucn2 gene transfer on glucose disposal, we used HFD to induce insulin resistance and hyperglycemia in normal mice. Mice were provided (ad libitum) a cereal-based diet (Harlan Teklad Lab, Madison, WI, USA) for 5 weeks and then switched to a HFD (60 kcal\%; Research Diets, New Brunswick NJ, USA) for durations and group sizes indicated in individual experiments. Mice received intravenous AAV8.Ucn2 $\left(5 \times 10^{11} \mathrm{gc}\right)$ or saline either at the initiation of HFD or 8 weeks later. Mice were housed $\left(20-21^{\circ} \mathrm{C}\right)$ with lights off from $6 \mathrm{PM}$ to $6 \mathrm{AM}$ daily. Food consumption and body weight were recorded weekly. A second group of normal mice was fed HFD for 16 weeks. After week 8 , they received IV injection of: saline, AAV8.EGFP $\left(5 \times 10^{11} \mathrm{gc}\right)$, or AAAV8.Ucn2 in 1 of 5 doses from $5 \times 10^{9} \mathrm{gc}$ to $5 \times 10^{11} \mathrm{gc}$ in $1 / 2 \mathrm{log}$ increments. These data were used to determine the relationship between AAV8.Ucn2 dose and plasma Ucn2 concentration and glucose disposal via glucose tolerance testing.

Murine Genetic Model of Insulin Resistance. B6.BKS(D)-Lepr $<d b>/ J$ diabetic mice (db/db) maintain increased plasma insulin levels and insulin resistance until late in life, providing a suitable T2DM model (6). Mice (10 male; 12 female) received intravenous AAV8.Ucn2 $\left(5 \times 10^{11} \mathrm{gc} ; n=11\right)$ or saline $(n=11)$. They were provided (ad libitum) a cereal-based diet (Harlan Teklad Lab, Madison WI, USA) for 6 weeks. Mice were housed $\left(20-21^{\circ} \mathrm{C}\right.$ ) with lights off from 6 PM to 6 AM daily. Food consumption and body weight were recorded weekly.

AAV8.Ucn2 Delivery. Under anesthesia (1.5\% isoflurane via nose cone) a small incision was made on the neck to expose the jugular vein for intravenous delivery. Mice were injected 


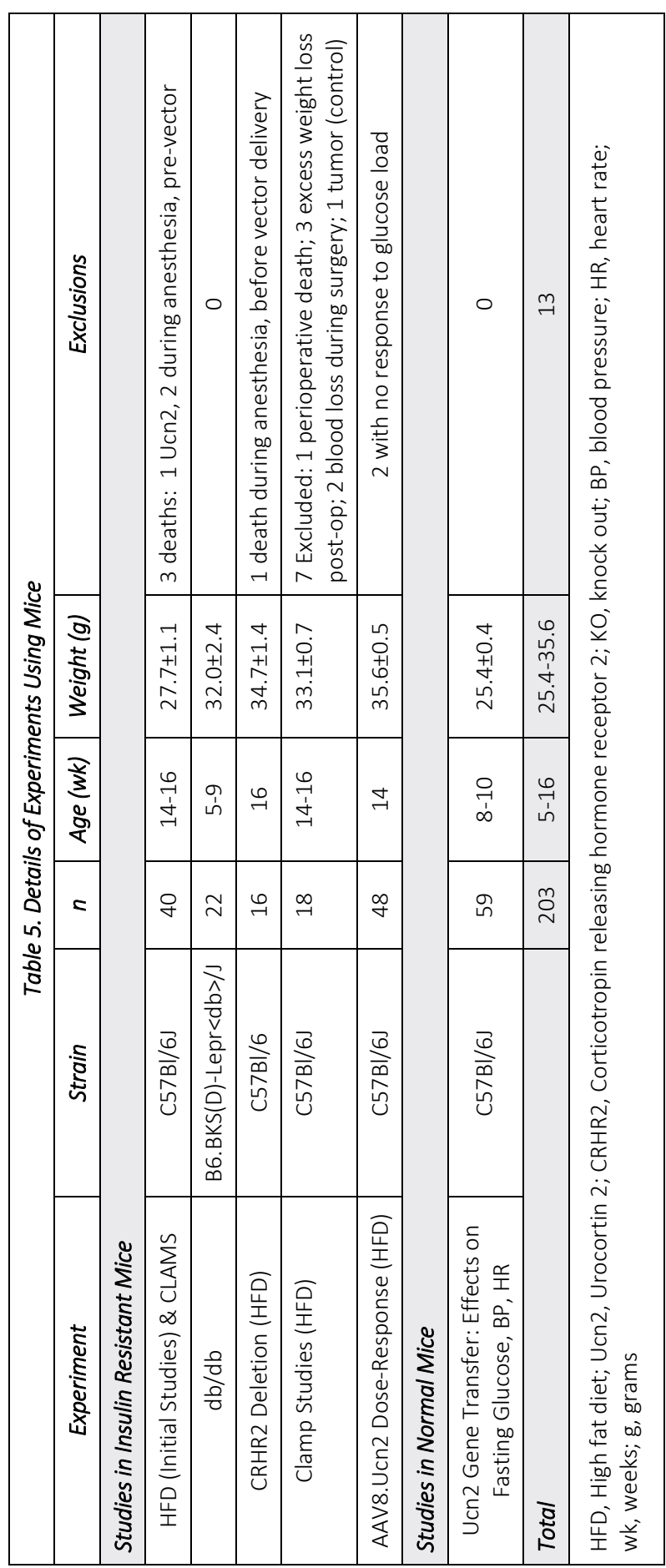


with AAV8.Ucn2 (in $50 \mu \mathrm{PBS}$ ) or an equivalent volume of saline (control).

Glucose Tolerance Test. Mice were fasted for $12 \mathrm{hr}$ and received glucose $(2 \mathrm{~g} / \mathrm{kg}$, IP). Blood glucose levels were measured before and 30, 60, 90, and 120 min after glucose injection. Blood was collected via a small tail incision and glucose was measured using Contour ${ }^{\circledR}$ Blood Glucose Meter via Blood Glucose Test Strips (Bayer, Whippany NJ).

Insulin Tolerance Test (ITT). Nonfasted mice received insulin ( 0.75 units $/ \mathrm{kg}$, IP) and blood glucose levels were measured before and 30, 60, 90, and 120 min later.

ELISA. Plasma insulin was measured using the Mouse Insulin ELISA Kit (Crystal Chem Inc, Downers Grove IL). Plasma C-peptide level was determined using the Mouse C-peptide ELISA Kit (Alpco, Salem, NH).

Hyperinsulinemic-Euglycemic Clamps. These studies were performed on HFD-fed mice (8 weeks old; Table 5). Upon receipt, they were continued on HFD and received intravenous Ucn2 gene transfer $\left(5 \times 10^{11} \mathrm{gc} ; n=9\right)$ or intravenous saline $(n=9)$ within 1 week. The two groups underwent clamp studies $17 \pm 1$ weeks after gene transfer, having been sustained on HFD continuously. Clamps were conducted in weight-matched conscious mice after a $6 \mathrm{hr}$ fast as previously described (26). Mice were anesthetized using ketamine (100 mg/kg), acepromazine $(3 \mathrm{mg} / \mathrm{kg})$, and xylazine $(10 \mathrm{mg} / \mathrm{kg})$ and jugular vein cannulation placed 4 days before clamp measurement. On the day of the clamp, body weight was recorded and blood glucose measured ( $6 \mathrm{hr}$ fasting). Mice then were placed in a Lucite restrainer (Braintree Scientific, Braintree, MA) and blood samples obtained (-60 min) for plasma insulin concentration. Equilibrating $\left[3-{ }^{3} \mathrm{H}\right] \mathrm{D}$-glucose tracer solution (PerkinElmer; $41.6 \mu \mathrm{Ci}{ }^{3} \mathrm{H} / \mathrm{ml}$ ) was then infused ( $2 \mu \mathrm{l} / \mathrm{min} \mathrm{IV}, 60 \mathrm{~min})$. At the end of the equilibration period $(\mathrm{t}=0 \mathrm{~min})$, two $15 \mu$ l blood samples were obtained and deproteinized using $125 \mu \mathrm{ZnSO}(0.3 \mathrm{~N})$ and $125 \mu \mathrm{l} \mathrm{BaOH}(0.3 \mathrm{~N})$ for assessment of tracer-specific activity and basal glucose disposal rate. To clamp after the equilibration period, a cocktail containing $8 \% \mathrm{BSA}$, insulin (Humulin R, Eli Lilly and Company, $10.0 \mathrm{mU} / \mathrm{kg} / \mathrm{min})$, and tracer $(41.6 \mu \mathrm{Ci} / \mathrm{ml})$ was infused at a constant rate $(2.0 \mu \mathrm{l} / \mathrm{min}$ ) along with a variable glucose infusion ( $50 \%$ dextrose, $454 \mathrm{mg} / \mathrm{ml}$ ). Blood glucose was assessed using blood glucose meter and test strips every $10 \mathrm{~min}$, and infusion rate was adjusted until steady-state blood glucose $(120 \pm 10 \mathrm{mg} / \mathrm{dl})$ was achieved. The clamp was terminated when steady-state conditions were maintained for $\geq 20 \mathrm{~min}$ ( $120 \mathrm{~min}$ ), at which time two $15 \mu \mathrm{l}$ blood samples were obtained for assessment of tracerspecific activity and insulin-stimulated glucose disposal rate ( $\sim 120 \mathrm{~min}$ ). Blood (70 $\mu \mathrm{l})$ was collected before and after the clamp for measurement of plasma insulin concentration.

CRHR2 Deleted Mice. To determine whether Ucn2 effects on glucose disposal were mediated through its cognate receptor, CRHR2, Ucn2 gene transfer was performed in CRHR2-deleted mice 8 weeks after initiation of HFD, which was continued for a total of 17 weeks (9 weeks after gene transfer). CRHR2+/- $\times$ CRHR2+/- mice and CRHR2-/- $\times$ CRHR2/- (C57BL/6 background) were bred to obtain CRHR2+/+ (wild type, WT) and CRHR2-/- mice (27). Mice were housed in a temperature and light-controlled room $\left(22-24^{\circ} \mathrm{C} ; 12 \mathrm{hr}\right.$ light $/ 12$ hr dark) and were bred at a University of California, San Francisco housing facility. 
After assessment of baseline glucose levels, CRHR2-/- littermates (10-12 weeks of age; $34.7 \pm 1.4$ grams) were put on a HFD for 8 weeks. Mice then underwent glucose tolerance testing and subsequently received either intravenous saline or AAV8.Ucn2 $\left(5 \times 10^{11} \mathrm{gc}\right)$. Mice were assigned to two groups: 1) HFD + AAV8.Ucn2 (n=8); 2$)$ HFD + saline ( $n=8)$. Nine weeks after AAV8.Ucn2 or saline injection, mice again underwent glucose tolerance testing.

Skeletal Muscle Glucose Uptake. Normal mice received intravenous Ucn2 gene transfer $\left(5 \times 10^{11} \mathrm{gc}, \mathrm{n}=6\right)$ or intravenous saline $(\mathrm{n}=6)$ and underwent glucose uptake studies 6 weeks later. A mixture of glucose $(2.5 \mathrm{~g} / \mathrm{kg}),\left[{ }^{3} \mathrm{H}\right]$-2-deoxy glucose $(10 \mu \mathrm{Ci} /$ mouse $)$, and $\left[{ }^{14} \mathrm{C}\right]-\mathrm{L}-$ glucose ( $1 \mu \mathrm{Ci} /$ mouse) was administrated intraperitoneally $60 \mathrm{~min}$ before harvesting samples of gastrocnemius muscle. Tissues were homogenized in water and then were added to scintillation fluid to be counted. $\left[{ }^{3} \mathrm{H}\right]$-2-dexoy-glucose uptake was corrected for non-specific trapping of extracellular space by $\left[{ }^{14} \mathrm{C}\right]$-L-glucose and divided by the $\left[{ }^{3} \mathrm{H}\right]-$ radioactivity of plasma glucose.

Glut4 Translocation Assay. Plasma Membrane Isolation. L6-mycGlut4 cells (Kerafast, USA) were differentiated by culturing in $2 \%$ FBS + MEM for seven days. Cells were incubated in serum-free medium for $3 \mathrm{hr}$ and then incubated with insulin (100 nM, $30 \mathrm{~min}$ ) or urocortin 2 (200 nM, $30 \mathrm{~min}$ ). Cells were washed once with cold DPBS and plasma membrane was isolated using Qproteome Plasma Membrane Protein Kit (Qiagen, USA). Glut4 Translocation. L6-mycGlut4 cells were prepared as outlined in the preceding section and washed once with cold DPBS containing $\mathrm{Ca}^{2+} / \mathrm{Mg}^{2+}$ and fixed with cold $4 \%$ PFA in DPBS for 15 min followed by three DPBS washes. Fixed cells were blocked with $5 \%$ goat serum in DPBS $\left(21^{\circ} \mathrm{C}, 30 \mathrm{~min}\right)$ and then incubated with anti-myc tag antibody (clone 9B11, Cell Signaling Technology, USA) in DPBS $\left(4^{\circ} \mathrm{C}, 8 \mathrm{hr}\right)$. After washing with DPBS, epitope-bound primary antibodies were detected using Alexa 488-conjugated anti-mouse IgG antibodies. Images were acquired using a Deltavision RT deconvolution microscope.

Energy Content in Stool. To determine if Ucn2 gene transfer affected absorption of food, 12 mice were placed on HFD (33 weeks). At week 13, 6 of 12 received intravenous Ucn2 gene transfer $\left(5 \times 10^{11} \mathrm{gc}\right)$. The energy content in fecal samples was measured by Kinetica, Inc (Franklin $\mathrm{OH}$ ). Stool samples (stored at $-20^{\circ} \mathrm{C}$ ) were dried in a convection oven $\left(100^{\circ} \mathrm{C}, 6\right.$ $\mathrm{hr}$ ). Energy content for each stool specimen was determined from the heat of combustion measured with an oxygen bomb calorimeter. Testing was conducted according to standard guidelines (28).

Metabolic Studies. The Comprehensive Laboratory Animal Monitoring System (CLAMS, Columbus Instruments, Columbus $\mathrm{OH}$ ) was used to assess oxygen consumption and activity level in 12 normal mice fed HFD for 16 weeks. Six of the 12 mice received intravenous AAV8.Ucn2 $\left(5 \times 10^{11} \mathrm{gc}\right)$ midway through the 16 -week HFD period. Mice were placed in standard metabolic cages for 5 days while measurements were continuously acquired. Data from 5 light-dark cycles following a 1.5-day acclimation period were used in the analysis.

RT-PCR and Immunoblotting was conducted as previously described (6). The antibodies to the phosphorylated forms of AMPK, phosphatidylinositol-3-kinase (PI3K), protein kinase B (Akt), glycogen synthase kinase 3 (GSK3) and p70S6K were purchased from Cell Signaling 
(Billerica MA) and antibody to phosphorylated peroxisome proliferator-activated receptor Y (PPARY) was purchased from Santa Cruz Biotechnologies (Santa Cruz CA).

Histology. A subset of mice fed HFD for 8 weeks received intravenous Ucn2 gene transfer $\left(5 \times 10^{11} \mathrm{gc}, \mathrm{n}=8\right)$ or saline $(\mathrm{n}=8)$, continued 8 additional weeks on HFD and then killed. Samples of liver and transmural sections of the left ventricular (LV) free wall were formalinfixed and paraffin-imbedded. Five micron sections were mounted and counterstained with hematoxylin and eosin and with Masson's trichrome and examined for fibrosis and inflammation. To quantify fatty infiltration of liver, slides were scanned (NanoZoomer 2.0HT Slide Scanner; Hamamatsu, Japan), planimetered and reported as percentage of total area.

Hepatic and Skeletal Muscle Triglyceride Content. Hepatic and skeletal muscle triglyceride content was determined using a colorimetric/fluoro-metric kit (Biovision Inc, Milpitas, CA). Liver and skeletal muscle samples (100 mg) were homogenized in $1 \mathrm{ml}$ of water containing $5 \%$ NP-40 using Tissuemiser (Thermo Fisher Scientific, CA). Lysates were heated $\left(100^{\circ} \mathrm{C}, 5\right.$ min) cooled $\left(25^{\circ} \mathrm{C}\right)$ twice. After centrifugation $(15000 \times \mathrm{g}, 2 \mathrm{~min})$ the supernatant was assayed for triglyceride content, which was reported as nmol per $\mathrm{mg}$ of liver or skeletal muscle (wet weight).

Necropsy. Body, liver, lung and LV weight (including interventricular septum) and tibial length were recorded. A short axis midwall LV ring, a short-axis sample of skeletal muscle at mid-calf level, and samples of liver were obtained and portions quickly frozen in liquid nitrogen and stored at $-80^{\circ} \mathrm{C}$ or fixed in formalin and embedded in paraffin.

Statistical Analysis. Data represent mean \pm SE; group differences were tested for significance using Student's $t$ test (unpaired, 2-tailed) or repeated measures ANOVA. In glucose tolerance tests, the trapezoidal rule was applied to determine area under the curve (AUC). The null hypothesis was rejected when $p<0.05$. Analyses were performed using GraphPad Prism (GraphPad Software, Inc. San Diego CA, USA). Those collecting and analyzing data obtained from physiological experiments were blinded to group identity.

Study approval. The 'Principles of laboratory animal care' (NIH publication no. 85-23, revised 1985) were followed and the Animal Use and Care Committees of the VA San Diego Healthcare System and the University of California San Francisco approved the studies. 


\section{ACKNOWLEDGEMENTS}

We thank Ruoying Tang for her technical expertise and the UC San Diego Animal Care Program Phenotyping Core for performing the metabolic cage experiments. We thank Dr. Tamsin Lisa Kelly for reviewing the manuscript and providing helpful criticisms.

Funding: This work was supported by National Institute of Health grants (P01 HL66941, HL088426 and DK080787); an NHLBI Gene Therapy Resource Program grant (HHSN268201200041C); VA Merit grant (1101BX001515); and UCSD School of Medicine Light Microscopy Facility (grant number NS047101) for imaging. 


\section{REFERENCES}

1. Reyes TM, et al. Urocortin II: a member of the corticotropin-releasing factor (CRF) neuropeptide family that is selectively bound by type 2 CRF receptors. Proc Natl Acad Sci. 2001; 98:2843-2848.

2. Davidson SM, Yellon DM. Urocortin: a protective peptide that targets both the myocardium and vasculature. Pharmacol Rep. 2009; 61:172-182.

3. Zorrilla EP, et al. Human urocortin 2, a corticotropin-releasing factor (CRF) 2 agonist, and ovine CRF, a CRF1 agonist, differentially alter feeding and motor activity. J Pharmacol Exp Ther. 2004; 310:1027-1034.

4. Chan WY, Frampton CM, Crozier IG, Troughton RW, Richards AM. Urocortin 2 Infusion in acute decompensated heart failure: findings from the UNICORN study (Urocortin 2 in the treatment of acute heart failure as an adjunct over conventional therapy). JACC Heart Fail. 2013; 1:433-441.

5. Gao MH, et al. Intravenous adeno-associated virus serotype 8 encoding urocortin 2 provides sustained augmentation of left ventricular function in mice. Hum Gene Ther. 2013; 24:777785.

6. Kodama H, Fujita M, Yamaguchi I. Development of hyperglycaemia and insulin resistance in conscious genetically diabetic (C57BL/KsJ-db/db) mice. Diabetologia. 1994; 37:739-744.

7. Gheorghiade $M$, et al. Haemodynamic effects, safety, and pharmacokinetics of human stresscopin in heart failure with reduced ejection fraction. Eur J Heart Fail. 2013; 15:679689.

8. Kurth-Kraczek EJ, Hirshman MF, Goodyear LJ, Winder WW. 5' AMP-activated protein kinase activation causes GLUT4 translocation in skeletal muscle. Diabetes. 1999; 48:1667-1671.

9. Bale TL, Anderson KR, Roberts AJ, Lee K-F, Nagy TR, Vale WW. Corticotropin-releasing factor receptor-2-deficient mice display abnormal homeostatic responses to challenges of increased dietary fat and cold. Endocrinology. 2003; 144: 2580-2587.

10. Parekha PI, Petroa AE, Tillera JM, Feinglosa MN, Surwit RS. Reversal of diet-induced obesity and diabetes in C57BL/6J mice. Metabolism. 1998; 47:1089-1096

11. Chen $A$, et al. Urocortin 2 modulates glucose utilization and insulin sensitivity in skeletal muscle. Proc Natl Acad Sci. 2006; 103:16580-16585.

12. Jamieson PM, et al. Urocortin 3 transgenic mice exhibit a metabolically favourable phenotype resisting obesity and hyperglycaemia on a high-fat diet. Diabetologia. 2011; 54:2392-2403.

13. Li C, Chen P, Vaughan J, Lee KF, Vale W. Urocortin 3 regulates glucose-stimulated insulin secretion and energy homeostasis. Proc Natl Acad Sci. 2007; 104:4206-4211.

14. Nathwani AC, et al. Adenovirus-associated virus vector-mediated gene transfer in hemophilia B. N Engl J Med. 2011; 365:2357-2365.

15. Robertson RP. Islet transplantation a decade later and strategies for filling a half-full glass. Diabetes. 2010; 59:1285-1291.

16. Bluestone JA, et al. Type 1 diabetes immunotherapy using polyclonal regulatory T cells. Sci Transl Med. 2015; 7:315ra189.

17. Callejas $D$, et al. Treatment of diabetes and long-term survival after insulin and glucokinase gene therapy. Diabetes. 2013; 62:1718-1729. 
18. Gaddy DF, Riedel MJ, Pejawar-Gaddy S, Kieffer TJ, Robbins PD. In vivo expression of HGF/NK1 and GLP-1 from dsAAV vectors enhances pancreatic ß-cell proliferation and improves pathology in the $\mathrm{db} / \mathrm{db}$ mouse model of diabetes. Diabetes. 2010; 59:3108-3116.

19. Rademaker MT, Charles CJ, Ellmers LJ, Lewis LK, Nicholls MG, Richards AM. Prolonged urocortin 2 administration in experimental heart failure: sustained hemodynamic, endocrine, and renal effects. Hypertension. 2011; 57:1136-1144.

20. Lai NC, et al. Intravenous AAV8 encoding urocortin-2 increases function of the failing heart in mice. Hum Gene Ther. 2015; 26:347-356.

21. Kautzky-Willer A, et al. Insulin sensitivity during oral glucose tolerance test and its relations to parameters of glucose metabolism and endothelial function in type 2 diabetic subjects under metformin and thiazolidinedione. Diabetes Obes. Metab. 2006; 8:561-567.

22. Menke A, Casagrande S, Geiss L, Cowie CC. Prevalence of and trends in diabetes among adults in the United States, 1988-2012. JAMA. 2015; 314:1021-1029.

23. Graham DJ, et al. Risk of acute myocardial infarction, stroke, heart failure, and death in elderly Medicare patients treated with rosiglitazone or pioglitazone. JAMA. 2010; 304:411418.

24. Zezos P, Renner EL. Liver transplantation and non-alcoholic fatty liver disease. World J Gastroenterol. 2014; 20:15532-15538.

25. Roth DM, Drumm JD, Bhargava V, Swaney JS, Gao MH, Hammond HK. Cardiac-directed expression of adenylyl cyclase and heart rate regulation. Basic Res Cardiol. 2003; 98:380387.

26. Schenk $S$, et al. Sirt1 enhances skeletal muscle insulin sensitivity in mice during caloric restriction. J Clin. Invest. 2011; 121:4281-4288.

27. Coste SC, et al. Abnormal adaptations to stress and impaired cardiovascular function in mice lacking corticotropin-releasing hormone receptor-2. Nat Genet. 2000; 24:403-409.

28. ASTM D4809. Standard test method for heat of combustion of liquid hydrocarbon fuels by bomb calorimeter (precision method). 2013; ASTM International. http://www.astm.org/Standards/D4809.htm 



\section{Chapter}

\section{Urocortin 2 Gene Transfer Increases Diastolic Function in Aged Mice}

Dimosthenis Giamouridis, Mei Hua Gao, N Chin Lai, Tracy Guo, Atsushi Miyanohara, W Matthijs Blankesteijn, Erik A L Biessen,, H Kirk Hammond 


\section{ABSTRACT}

Background. Heart failure with preserved ejection fraction (HFpEF) increases with aging. We previously reported that Ucn2 gene transfer increases function of the failing left ventricle (LV) in mice with HFrEF. Here we test the hypotheses that 1) Ucn2 gene transfer increases LV diastolic function in aged mice; and 2) Ucn2 gene transfer given in early life prevents age-related diastolic dysfunction.

Methods. C57BI/6 mice underwent 2 parallel studies: treatment and prevention. $24 \mathrm{~m}$-old (treatment strategy) and 3m-old (prevention strategy) mice received urocortin 2 (Ucn2) gene transfer or saline and LV dimensions and ejection fraction (EF) were assessed serially (echocardiography). The peak rates of LV pressure development and decay were measured in terminal studies.

Results. Treatment strategy: Among aged mice, 3-4 months after Ucn2 gene transfer we saw increased EF $(p<.0002)$ and reduced end-diastolic and end-systolic diameters (EDD: $\mathrm{p}=.004 ; \mathrm{ESD}, \mathrm{p}<.0002)$. Ucn2 gene transfer increased both peak $-\mathrm{dP} / \mathrm{dt}(\mathrm{p}=.004)$, and peak $+\mathrm{dP} / \mathrm{dt}(\mathrm{p}<.0002)$. Prevention strategy. Among mice that received Ucn2 gene transfer when $3 \mathrm{~m}$-old, $20 \mathrm{~m}$ after Ucn2 gene transfer we saw increased EF ( $p=.0002)$ and reduced ESD $(p=.002)$. Ucn2 gene transfer increased both peak LV $-d P / d t(p=.03)$, and peak $L V+d P / d t$ $(p<.0005)$. Ucn2 gene transfer was associated with higher levels of LV SERCA2a protein, and reduced levels of LV phosphorylation of CamKIla, and $\alpha$-skeletal actin mRNA.

Conclusions. Ucn2 gene transfer restores normal diastolic function in mice with age-related impairment in LV filling, and prevents development of diastolic dysfunction. 


\section{INTRODUCTION}

Heart failure (HF), a major cause of death, affects 6 million people in the US and its prevalence increases with age (1). In recent decades it has become apparent that patients with preserved left ventricular (LV) ejection fraction (EF) but symptoms of HF (HFpEF) should be considered separately from those with HF and reduced EF (HFrEF) (2). Patients with HFpEF comprise up to $50 \%$ of the HF population (3) and have abnormal ventricular filling, often due to hypertension and associated hypertrophy and increased stiffness of the myocardium which is associated with diabetes and with advanced age $(3,4)$.

Patients with HFrEF have several interventions (pharmacological and devices) that reduce hospitalization rates and mortality, although outlook remains poor even with optimal therapy. In contrast, patients with HFpEF do not respond to similar interventions-in general pharmacological therapies have provided some symptom relief, but have not influenced clinical outcomes such as hospitalizations for HF or mortality (4). New therapies for HFpEF are needed. In the current study we test the effectiveness of urocortin 2 (Ucn2) gene transfer in mice as a treatment for and prevention of age-related diastolic dysfunction.

Urocortin 2, a member of the corticotropin releasing factor (CRF) family, is a 38-amino acid peptide that binds with high affinity to the corticotropin releasing hormone receptor 2 (CRHR2). The inotropic effects of Ucn2 have been shown in preclinical studies in which Ucn2 peptide infusion increased LV contractile function in mice with HFrEF (5). This study also reported improvement in LV diastolic function. Additionally, studies in large animals (6) and humans (7-9) have confirmed the safety and the beneficial effects of Ucn2 peptide infusion on measures of heart function in HFrEF. To our knowledge, no studies have investigated the effects of Ucn2 in the setting of HFpEF.

Considering the short half-life of Ucn2 (15 minutes) (10), continuous intravenous (IV) infusion of Ucn2 peptide would be necessary in order to have sustained effects on the failing heart. This limitation diminishes the clinical usefulness of Ucn2 peptide infusion as a viable HF treatment. To overcome this impediment, we have proposed Ucn2 gene transfer to provide increased and sustained plasma levels of Ucn2. We previously demonstrated in preclinical studies that such an approach is feasible. For example, intravenous (IV) delivery of an adeno-associated virus vector encoding Ucn2 (AAV8.Ucn2), elevated plasma Ucn2 levels, and increased systolic and diastolic LV function in normal mice and in mice with HFrEF (11-13). However, Ucn2 gene transfer has not previously been tested in mice with impaired diastolic function and preserved EF. A second goal of the present study was to determine whether Ucn2 gene transfer performed in early life (3m-old) could thwart agerelated HFpEF in late life. Since many heart failure patients are of advanced age, this is particularly relevant. Therefore, in the present study we test two hypotheses: 1) Ucn2 gene transfer increases LV diastolic function in aged mice; and 2) Ucn2 gene transfer in early life prevents age-related diastolic dysfunction. 


\section{MATERIALS AND METHODS}

AAV8.Ucn2 Vector. HEK293T cells were transfected with the pRep2/Cap8 and pAd-Helper plasmid (13), for the production of an AAV8 vector encoding murine urocortin-2 (Ucn2) driven by a chicken $\beta$-actin (CBA) promoter (AAV8.CBA.Ucn2; Fig 1). Plasmid pRep2/Cap8 was obtained from the University of Pennsylvania Vector Core. Virus vectors were then purified and concentrated as previously described $(12,14)$. Real-time PCR with virus genome DNA prepared from purified virus was used to quantify virus titers.

Animal Use. The Animal Use and Care Committee of the VA San Diego Healthcare System approved the studies. In this study to answer our first hypothesis we used 10 male mice

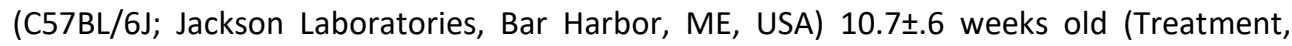

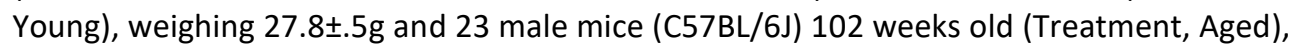

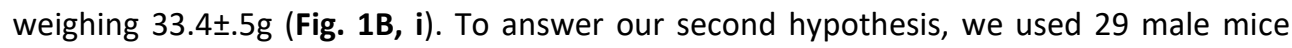

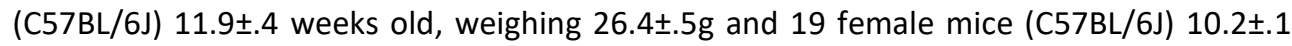
weeks old (Prevention), weighing 18.5 $\pm .2 \mathrm{~g}$ (Fig. 1B, ii). From those 48 mice, 5 that received saline and 6 that received AAV8.mUcn2 died before the terminal study. All of the mice were provided (ad libitum) a cereal-based diet (Harlan Teklad Lab, Madison, WI, USA) and tap water. Mice were housed $\left(20-21^{\circ} \mathrm{C}\right)$ with lights off from 6 PM to 6 AM daily.

Ucn2 Gene Transfer. Under anesthesia (1.5\% isoflurane via nose cone), the jugular vein was exposed. AAV8.Ucn2 $\left(1.9 \times 10^{13} \mathrm{gc} / \mathrm{kg}\right.$ in $\left.100 \mu \mathrm{l}\right)$ or a similar volume of saline was delivered using a syringe with a 31-gauge needle.

Plasma Urocortin 2. In a terminal study under anesthesia, the carotid artery was bled and blood was collected (with EDTA) and centrifuged ( $1600 \times \mathrm{g}, 15 \mathrm{~min})$. Plasma was collected and stored at $-80^{\circ} \mathrm{C}$. Plasma Ucn 2 levels were measured using a mouse urocortin 2 enzyme immunoassay (EIA) kit (Kamiya Biomedical, Seattle, WA).

Echocardiography. Echocardiography was performed as previously described (11), using a Vevo 3100 ultrasound system (Visualsonics, Toronto, Canada) and an MX550s transducer, to document LV function and to record LV chamber dimensions.

LV Function. Using a 1.4F micromanometer catheter (SPR 839, Millar Instruments, Houston, Texas) that was advanced, via the right carotid artery across the aortic valve, into the LV cavity, left ventricular pressure signal was recorded, stored digitally and then processed (IOX V2.9.5 Emka Technologies, Christchurch, VA) as previously reported (15). The first derivative of LV pressure development $(\mathrm{LV}+\mathrm{dP} / \mathrm{dt})$ and decline $(\mathrm{LV}-\mathrm{dP} / \mathrm{dt})$ were used to assess LV systolic and diastolic function, respectively.

RT-PCR, Immunoblotting. LV and liver samples were collected and stored at $-80^{\circ} \mathrm{C}$. Total RNA was isolated and reverse transcribed into CDNA which was used in quantitative PCR as previously described (11). All gene specific primers used in PCR are listed in Table 1. 
Immunoblotting was performed as described previously (11). The following antibodies were used: phospho-CamKII (Santa Cruz Biotechnology, Santa Cruz, CA); and SERCA2a (Enzo Life Sciences, Farmingdale, NY).

\begin{tabular}{|c|c|c|}
\hline \multicolumn{3}{|c|}{ Table 1. Primers } \\
\hline Gene & Forward & Reverse \\
\hline$\beta 1 A R$ & 5'-TCGTGTGCACCGTGTGGGCC & 5'-AGGAAACGGCGCTCGCAGCTGTCG \\
\hline$\beta 2 A R$ & 5'-AGGAGGGTTTGGGGAAGTTTA & 5'-CATGATCCTCTCGTTCAAAGCC \\
\hline$A C 5$ & 5'-СТСАТСТTСТССТGСАССААС & 5'-GGAAGGACAGACAGCAGGAG \\
\hline AC6 & 5'-TGGGCCTCTCTACTCTGCAT & 5'-TGGATGTAACCTCGGGTCTC \\
\hline AT1aR & 5'-AACAGCTTGGTGGTGATCGTC & 5'-CATAGCGGTATAGACAGCCCA \\
\hline Serca2a & 5'-CTGTGGAGACCCTTGGTTGT & 5'-CAGAGCACAGATGGTGGCTA \\
\hline$B C l-2$ & 5'-AAGCCGGGAGAACAGGGTAT & 5'-CAGGTATGCACCCAGAGTGAT \\
\hline$C x-43$ & 5'-TTGACTTCAGCCTCCAAGG & 5'-AATGAAGAGCACCGACAGC \\
\hline$A N F$ & 5'-CCTCGTCTTGGCCTTTTTGG & 5'-CATCTTCTACCGGCATCTTC \\
\hline$B N P$ & 5'-GAAGTCCTAGCCAGTCTCC & 5'-CAGCTTGAGATATGTGTCACC \\
\hline$\alpha-M H C$ & 5'-AAAGGCTGAGAGGAACTACC & 5'-ACCAGCCTTCTCCTCTGC \\
\hline$\beta-M H C$ & 5'-GCTGAAAGCAGAAAGAGATTATC & 5'-TGGAGTTCTTCTCTTCTGGAG \\
\hline CARP & 5'-CTGAACCTGTGGATGTGCC & 5'-GGCTCCAGCCTCCATTAACT \\
\hline$F H L-1$ & 5'-TGCAACAAGTGCGCTACTCG & 5'-CAATGTTTGGCGAACTTGGTC \\
\hline$\alpha$-cardiac actin & 5'-GTGTTACGTCGCCCTTGATT & 5'-TGAAAGAGGGCTGGAAGAGA \\
\hline$\alpha$-skeletal actin & 5'-GTGTCACCCACAACGTGC & 5'-AGGGCCACATAGCACAGC \\
\hline$M M P 2$ & 5'-GAGTTGCAACCTCTTTGTGC & 5'-CAGGTGTGTAACCAATGATCC \\
\hline MMP8 & 5'-GACTCTGGTGATTTCTTGCTAAC & 5'-CACCATGGTCTCTTGAGACG \\
\hline TIMP1 & 5'-GACAGCTTTCTGCAACTCGG & 5'-CTTGTGGACATATCCACAGAGG \\
\hline TIMP2 & 5'-TCAGAGCCAAAGCAGTGAGC & 5'-GCCGTGTAGATAAACTCGATGTC \\
\hline TIMP3 & 5'-CTTCTGCAACTCCGACATCGT & 5'-GGGGCATCTTACTGAAGCCTC \\
\hline TIMP4 & 5'-TGTGGCTGCCAAATCACCA & 5'-TCATGCAGACATAGTGCTGGG \\
\hline Coll1 $1 \alpha 1$ & 5'-GCCAAGAAGACATCCCTGAAG & 5'-GGGTCCCTCGACTCCTAC \\
\hline Coll $3 \alpha 1$ & 5'-GCACAGCAGTCCAACGTAGA & 5'-TCTCCAAATGGGATCTCTGG \\
\hline OSF2/periostin & 5'-CCAGTCAAGAGCATCAGCAA & 5'-TAAGTAGTGCAGCCCGGAGT \\
\hline Fibronectin & 5'-AATGGAAAAGGGGAATGGACC & 5'-CTCGGTTGTCCTTCTTGCTC \\
\hline$m U c n 2$ & 5'-АСТССТАТССССАССТТССА & 5'-AAGATCCGTAGGAGGCCAAT \\
\hline GAPDH & 5'-CATGTTCCAGTATGACTCCACTC & 5'-GGCCTCACCCCATTTGATGT \\
\hline $\begin{array}{l}\beta 1 A R, \beta 1 \text { Adrenergic } \\
\text { Angiotensin subtype } \\
\text { 43, Connexin 43; } A N / \\
\beta \text {-Myosin Heavy Chai } \\
\text { Matrix Metalloprotei } \\
\text { Col1, Collagen 1; Col } \\
\text { Glyceraldehyde 3-ph }\end{array}$ & $\begin{array}{l}\text { eptor; } \beta 2 A R, \beta 2 \text { Adrenergic receptor; } \\
\text { receptor; Serca2a, Sarco/endoplasmic } r \\
\text { trial Natriuretic Factor; } B N P \text {, Brain Natri } \\
C A R P, \text { Cardiac Ankyrin-Repeated Protein } \\
\text { 2; MMP8, Matrix Metalloproteinase } 8 \\
\text { ollagen 3; OSF2, Osteoblast Specific tran } \\
\text { hate dehydrogenase. }\end{array}$ & $\begin{array}{l}\text { nylyl cyclase } 5 ; A C 6 \text {, Adenylyl cyclase } 6 ; A T 1 a R \text {, } \\
\text { Ca2+ ATPase 2a; BCl-2, B-cell lymphoma 2; CX- } \\
\text { ptide; } \alpha-M H C, \alpha-M y o s i n \text { Heavy Chain; } \beta-M H C \text {, } \\
\text { our-and-a-Half LIM domain protein } 1 ; M M P 2 \text {, } \\
\text { 4, Tissue Inhibitor or Metalloproteinase 1-4; } \\
\text { Factor } 2 ; m U c n 2, \text { murine Urocortin } 2 ; \text { GAPDH, }\end{array}$ \\
\hline
\end{tabular}

Necropsy and Histology. Body, liver, lung and LV weight (including interventricular septum) were recorded. Samples of liver and transmural LV were formalin-fixed and paraffin- 
embedded. Five-micron sections were mounted and counterstained with hematoxylin and eosin and with Masson's trichrome. Slides were then scanned using an Axio Scan Z1 slide scanner (Zeiss, Oberkochen, Germany) and analyzed with Image J V1.49 software (Bethesda, MD, USA).

Statistical Analysis. Data acquisition and analysis were done without knowledge of group identity. Group sizes were determined by power calculations. We used only male mice because aged female mice were not available from the vendor. The hypothesis was that Ucn2 gene transfer would effectively treat LV diastolic dysfunction in aged mice. We therefore needed to compare young vs aged mice to establish that LV diastolic dysfunction was present, and then determine whether Ucn2 gene transfer in aged mice was associated with increased LV diastolic function. To test for group differences, Student's t test (unpaired, two-tailed) was used. Bonferroni correction was used for multiple testing. Analyses were performed using GraphPad Prism V6.07 (GraphPad Software, Inc., San Diego, CA). The null hypothesis was rejected when $p<.05$.

\section{RESULTS}

Plasma Urocortin 2 (Fig. 1C). Plasma Ucn2 was measured 4m after delivery of saline or AAV8.Ucn2 (Treatment study), and 20m after delivery of saline or AAV8.Ucn2 (Prevention study). In addition, plasma Ucn 2 was measured in $27 \mathrm{w}$-old mice that received saline. Plasma Ucn2 levels were similar in $27 \mathrm{w}$-old mice, aged mice that received saline (and in aged mice $20 \mathrm{~m}$ after saline injection (Fig. 1C). Treatment Study. Ucn2 gene transfer resulted in a 13fold increase of plasma Ucn2 (Saline: $2.3 \pm .1 \mathrm{ng} / \mathrm{mL}, \mathrm{n}=11$; Ucn2: $29.1 \pm 3 \mathrm{ng} / \mathrm{mL}, \mathrm{n}=12$; p<.0001, Fig. 1C).

Prevention Study. Ucn2 gene transfer resulted in a 4-fold increase in plasma Ucn2 (Saline: $2.7 \pm .1 \mathrm{ng} / \mathrm{mL}, \mathrm{n}=12 ; \mathrm{Ucn} 2: 10.4 \pm 1.4 \mathrm{ng} / \mathrm{mL}, \mathrm{n}=11 ; \mathrm{p}<.0001$, Fig. 1C).

\section{Echocardiography}

Treatment Study. Three months after gene transfer, echocardiography was performed to assess LV dimensions and EF. With the exception of an aging-related increase in posterior wall thickness, there were no differences between young mice and aged mice that received saline. Ucn2 gene transfer in aged mice was associated with increased EF $(p<.0002)$ and increased velocity of circumferential fiber shortening (VCFc, $p<.0002$ ) (Table 2A). LV EDD $(p=.004)$ and ESD $(p<.0002)$ were reduced in aged mice that received Ucn2 gene transfer. Heart rate was lower in the Ucn2 group (Table $2 \mathrm{a}$ ).

Prevention Study. Ucn2 gene transfer, performed at 11 weeks of age, was associated $20 \mathrm{~m}$ later with increased EF $(p=.0002)$ and VCFc $(p=.0003)$ and reduced ESD $(p=.002)$ (Table $\mathbf{2 b})$.

\section{Function}


Treatment Study. Four months after aged mice received Ucn2 gene transfer or saline injection, the peak rates of LV pressure development $(L V+d P / d t)$ and decline $(L V-d P / d t)$ were determined from LV pressure catheters. Aging was associated with a $37 \%$ mean reduction in $\mathrm{LV}$ peak $+d P / d t(p=.0004$, Fig. $2 A)$ and in a $39 \%$ reduction in $L V$ peak $-d P / d t$ $(p=.001$, Fig. 2B). Also seen were age-related reductions in LV developed pressure $(p<.0002$, Fig. 2C). These data indicate age-related decrements in LV systolic and diastolic function. After Ucn2 gene transfer, aged mice had a 2 -fold more rapid LV peak $+d P / d t(p<.0002$, Fig. 2A) and a 1.7-fold more rapid LV peak $-d P / d t ~(p=.004$, Fig. 2B). Heart rates were lower in aged mice vs young mice ( $p=.05 ;$ Fig. 2D), and were higher in aged mice that received Ucn2 gene transfer ( $p=.0006$, Fig. 2D).

\begin{tabular}{|c|c|c|c|c|}
\hline \multicolumn{5}{|c|}{ Table 2a. Treatment Study, Echocardiography } \\
\hline & \multirow{2}{*}{ Young (10) } & \multicolumn{3}{|c|}{ Aged } \\
\hline & & +Saline (11) & $+U c n 2(12)$ & $\mathbf{p}$ \\
\hline HR (bpm) & $550 \pm 7$ & $545 \pm 7$ & $510 \pm 8$ & .008 \\
\hline $\operatorname{EDD}(\mathrm{mm})$ & $3.9 \pm .1$ & $4.1 \pm .1$ & $3.6 \pm .1$ & .004 \\
\hline $\mathrm{ESD}(\mathrm{mm})$ & $2.6 \pm .1$ & $2.9 \pm .1$ & $1.9 \pm .1$ & $<.0002$ \\
\hline IVSd (mm) & $.8 \pm .01$ & $.8 \pm .02$ & $.9 \pm .03$ & .7 \\
\hline PWd (mm) & $.7 \pm .03$ & $.9 \pm .03^{\mathrm{A}}$ & $.8 \pm .03$ & .2 \\
\hline EF (\%) & $64 \pm 3$ & $58 \pm 3$ & $80 \pm 2$ & $<.0002$ \\
\hline $\mathrm{VCFc}(\mathrm{circ} / \mathrm{s})$ & $23 \pm 2$ & $21 \pm 2$ & $33 \pm 2$ & $<.0002$ \\
\hline GLS (\%) & $-12.5 \pm .6$ & $-9.7 \pm .6^{\mathrm{B}}$ & $-15.3 \pm .9$ & $<.0002$ \\
\hline \multicolumn{5}{|c|}{$\begin{array}{l}\text { Echocardiographic measurements } 3 \text { months after saline (Young; +saline) or AAV8.Ucn2 (+Ucn2, } \\
1.9 \times 10^{13} \mathrm{gc} / \mathrm{kg} \text { ) administration. HR, heart rate; bpm, beats per minute; EDD, LV end-diastolic diameter; } \\
\text { ESD, LV end-systolic diameter; IVSd, intraventricular septum thickness in diastole; PWd, posterior wall } \\
\text { thickness in diastole; EF, ejection fraction; VCFc, velocity of circumferential fiber shortening (corrected } \\
\text { for heart rate); GLS, global longitudinal strain; Young, 3-month-old saline injected normal mice; Aged, } \\
\text { 2-year-old mice; } \mathrm{p} \text { values are from Student's t-test (unpaired, two-tailed) with Bonferroni correction. } \\
\text { Young vs Aged +Saline }{ }^{A} p \text { value }=.0004 ;{ }^{B} p \text { value }=.02 \text {. }\end{array}$} \\
\hline
\end{tabular}

Prevention Study. Ucn2 gene transfer was associated with a 1.7-fold more rapid LV peak $+d P / d t(p=.0005$, Fig. 3A), and a 1.4-fold more rapid LV peak $-d P / d t(p=.03$, Fig. 3B). LV developed pressure was also higher in mice that had received Ucn2 gene transfer $(p=.03$, Fig. 3C). No group difference in heart rates were observed. 
A

AAV8.CBA.Ucn2

B

\begin{tabular}{|c|c|c|c|c|c|c|}
\cline { 2 - 6 } ITR & CMV.en & Chicken $\beta$-actin Promoter & Ucn2 & r $\beta$ GpA & ITR \\
\hline 14125 & 380 & 1345 & 345 & 56 & 25 & 141
\end{tabular}

i.

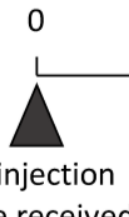

$3 m$

$4 m$

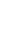

IV injection

3-m.o. mice received saline;

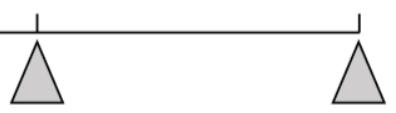

Echocardiography

LV function

2-y.o. mice received

AAV8.Ucn2 or saline (blinded)

ii.

$020 \mathrm{~m}$

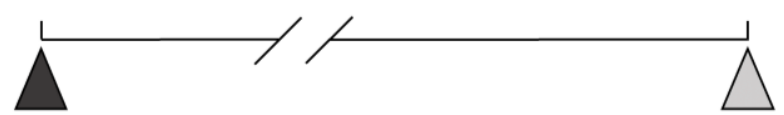

Echocardiography

IV injection

3-m.o. mice received

$\bigwedge$ LV function

AAV8.Ucn2 or saline (blinded)

C

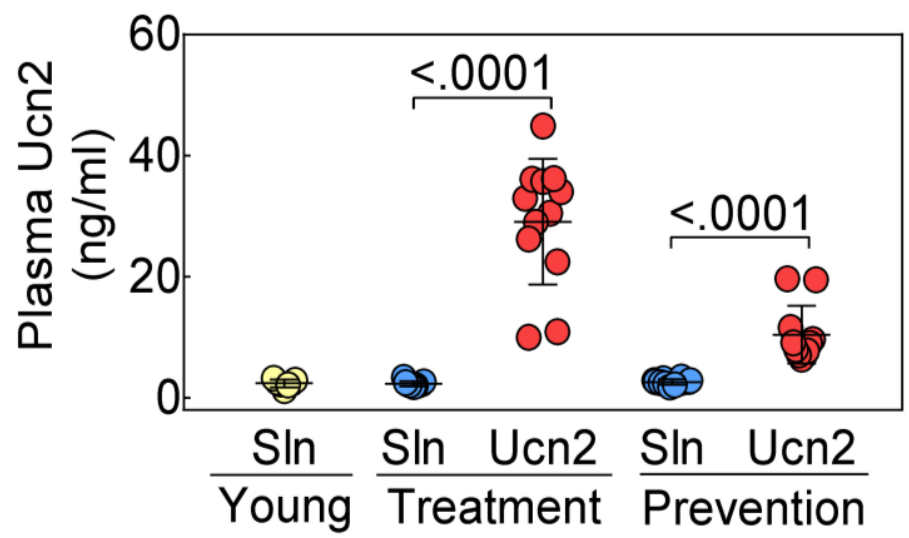

Figure 1. Urocortin 2 vector construct and plasma levels. A. AAV8.CBA.mUcn2 vector map. ITR, inverted terminal repeat; CMV.en, cytomegalovirus enhancer; CBA, chicken $\beta$-actin promoter; Ucn2, murine urocortin $2 ; \beta G p A, \beta$ globin polyadenylation signal; B. Study design; i. Aged mice study; ii. Prevention study; m.o., months old; y.o., years old; C. Ucn2 plasma levels in 3-month-old (Young) and 2-year-old (Aged) mice 4 months after IV delivery of AAV8.Ucn2 (Ucn2, $1.9 \times 10^{13} \mathrm{gc} / \mathrm{kg}$ ) or saline (Sal). Ucn2 plasma levels in 3-month-old mice that were studied 20 months (Prevention) after saline (Sal) or AAV8.Ucn2 (Ucn2, $1.9 \times 10^{13} \mathrm{gc} / \mathrm{kg}$ ) administration. Individual data are shown; mean $\pm S E$ are indicated. $P$ value is from Student's t-test (unpaired, two tailed).

\section{Necropsy}

Treatment Study. Body and liver-body-weight ratios showed no differences among groups (Table 3a). Age-related increases in LV weight (absolute and normalized to body weight) 
and lung-body-weight ratio were seen (Table 3a). There were no saline vs Ucn2 gene transfer group differences in aged mice.

Prevention Study. There were no group differences in body or organ weights 20 months after saline or AAV8.Ucn2 administration (Table $\mathbf{3 b}$ ).

\begin{tabular}{|c|c|c|c|}
\hline \multicolumn{4}{|c|}{ Table 2b. Prevention Study, Echocardiography } \\
\hline & Saline (20) & Ucn2 (16) & $\mathbf{p}$ \\
\hline HR (bpm) & $538 \pm 9$ & $537 \pm 8$ & .94 \\
\hline $\operatorname{EDD}(\mathrm{mm})$ & $3.9 \pm .1$ & $3.6 \pm .1$ & .12 \\
\hline $\operatorname{ESD}(\mathrm{mm})$ & $2.7 \pm .1$ & $2.1 \pm .1$ & .002 \\
\hline IVSd (mm) & $.8 \pm .03$ & $.8 \pm .03$ & .38 \\
\hline PWd (mm) & $.9 \pm .04$ & $.9 \pm .05$ & .73 \\
\hline EF (\%) & $58 \pm 3$ & $72 \pm 2$ & .0002 \\
\hline VCFc (circ/s) & $21 \pm 1$ & $29 \pm 1$ & .0003 \\
\hline GLS (\%) & $-14.8 \pm 1.3$ & $-20.7 \pm 1.2$ & .002 \\
\hline \multicolumn{4}{|c|}{$\begin{array}{l}\text { Echocardiographic measurements } 20 \text { months after saline (Saline) or AAV8.Ucn2 (Ucn2, } 1.9 \times 10^{13} \mathrm{gc} / \mathrm{kg} \text {, } \\
\text { administration. HR, heart rate; bpm, beats per minute; EDD, LV end-diastolic diameter; ESD, LV end- } \\
\text { systolic diameter; EF, ejection fraction; VCFc, velocity of circumferential fiber shortening (corrected } \\
\text { for heart rate); GLS, global longitudinal strain; p values from Student's t-test (unpaired, two-tailed) } \\
\text { with Bonferroni correction }\end{array}$} \\
\hline
\end{tabular}

\section{SERCA2a and CamKII Protein Expression}

Treatment Study. LV sarco/endoplasmic reticulum $\mathrm{Ca}^{2+}$ ATPase (SERCA2a) protein levels were similar in young mice and aged mice that received saline. However, in aged mice, Ucn2 gene transfer was associated with a 3-fold increase in LV SERCA2a ( $p=.0004$, Fig 4A). Calcium/calmodulin dependent protein kinase Ila (CamKIla) phosphorylation was not different between young and aged saline-treated animals. However, in aged mice, Ucn2 gene transfer was associated with a $37 \%$ lower level of $p$-CamKII ( $p=.01$, Fig. 4C).

Prevention Study. In aged mice that had received Ucn2 gene transfer $20 \mathrm{~m}$ prior, LV SERCA2a protein levels were 1.8-fold higher vs mice that received saline ( $p=.01$, Fig. $4 \mathrm{C}$ ). Ucn2 gene transfer was associated with a $39 \%$ lower level of $p$-CamKII ( $p=.05$, Fig. 4D).

LV mRNA Expression of Markers of Hypertrophy and Fibrosis. The mRNA expression of several relevant proteins was determined by RT-PCR. 
A

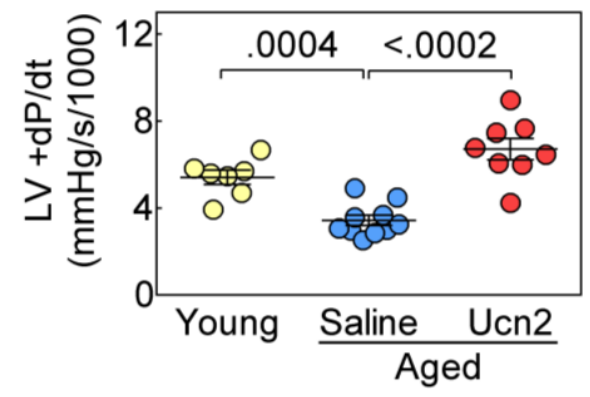

C

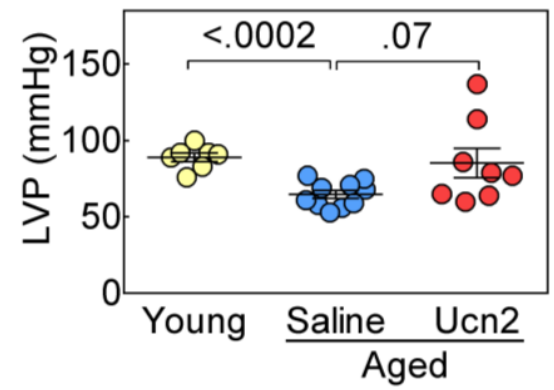

B

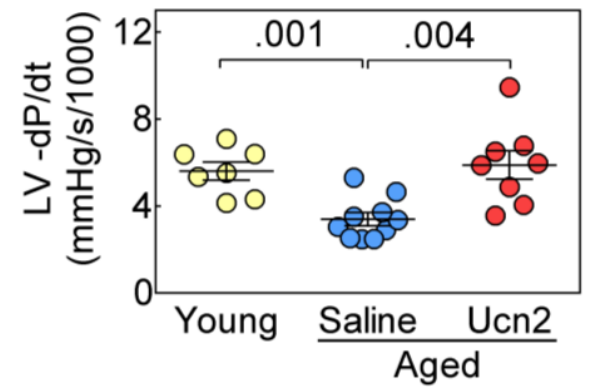

D

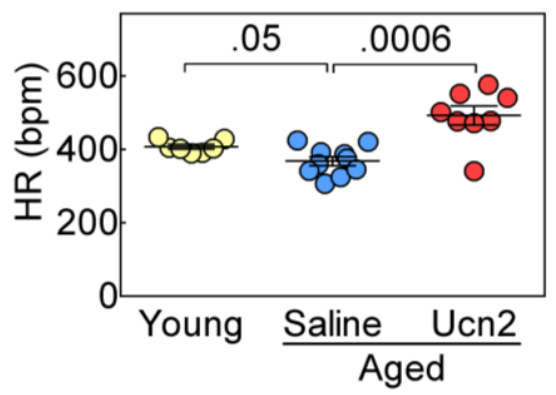

Figure 2. Treatment Study. In vivo assessment of LV function. Young vs aged mice, 4 months after IV delivery of AAV8.Ucn2 $\left(1.9 \times 10^{13} \mathrm{gc} / \mathrm{kg}\right)$ or Saline, underwent physiological studies to assess LV function. A and B. Peak rate of $L V$ pressure development $(\mathbf{A},+d P / d t)$ and peak rate of $L V$ pressure decay $(B,-d P / d t)$. C. LV developed pressure (LVP) was higher in mice that received Ucn2 gene transfer. D. Heart rate (HR) in anesthetized animals was lower in young and aged mice that received saline compared to the aged mice that received Ucn 2 gene transfer. LV, left ventricle; Young, 3-month-old saline-injected mice; Aged, 2-year-old mice. Individual data are shown (mean $\pm \mathrm{SE}$ are indicated); $\mathrm{p}$ values are from Student's t-test (unpaired, two-tailed) with Bonferroni correction for multiple comparisons.

Treatment Study (Table 4a). Ucn2 gene transfer in aged mice resulted in lower LV mRNA levels of AT1aR ( $p=.005)$, B-cell lymphoma $2(B c l-2, p=.008)$, brain natriuretic peptide (BNP, $p=.04)$, and $\alpha$-skeletal actin ( $p=.0008)$. As expected, mRNA expression of murine Ucn2 was increased $(p=.0004)$ in aged mice that received Ucn2 gene transfer. Expression levels of four-and-a-half LIM domain protein 1 was higher in mice that received Ucn2 gene transfer (FHL-1, $\mathrm{p}=.01$ ).

Prevention Study (Table 4b). LV protein expression was assessed $20 \mathrm{~m}$ after saline or AAV8.Ucn2 administration. Ucn2 treated animals had lower mRNA levels of $\alpha$-skeletal actin $(p=.05)$ and increased levels of FHL-1 $(p=.008)$. Murine Ucn2 expression in the LV was elevated $20 \mathrm{~m}$ after gene transfer $(p=.008)$.

\section{Histological Evaluation of LV and Liver}

Treatment Study. Qualitative evaluation of LV and liver tissues showed no differences in inflammatory infiltrates between the three groups. No group difference was found after quantitative evaluation of fibrosis in liver and LV (Fig. 5). 
Prevention Study. No inflammatory infiltrates or differences in the degree of fibrosis were found in LV and liver 20 months after saline or AAV8.Ucn2 injection (Fig. 6).

\begin{tabular}{|c|c|c|c|c|}
\hline \multicolumn{5}{|c|}{ Table 3a. Treatment Study, Necropsy } \\
\hline & \multirow{2}{*}{ Young (10) } & \multicolumn{3}{|c|}{ Aged Mice } \\
\hline & & Saline (11) & Ucn2 (12) & p \\
\hline BW (g) & $31.0 \pm .5$ & $31.1 \pm .6$ & $32.8 \pm .6$ & .1 \\
\hline LV (mg) & $104 \pm 4$ & $121 \pm 5^{\mathrm{A}}$ & $113 \pm 5$ & .6 \\
\hline $\mathrm{LV} / \mathrm{BW}$ (mg/g) & $3.3 \pm .1$ & $3.9 \pm .2^{\mathrm{B}}$ & $3.5 \pm .1$ & .1 \\
\hline Lung/BW (mg/g) & $4.8 \pm .1$ & $5.9 \pm .2^{c}$ & $6 \pm .3$ & 1 \\
\hline Liver/BW (mg/g) & $45 \pm 2$ & $49 \pm 2$ & $50 \pm 3$ & 1 \\
\hline \multicolumn{5}{|c|}{$\begin{array}{l}\left.\text { Necropsy data } 4 \text { months after saline (Young; +saline) or AAV8.Ucn2 (+Ucn2, } 1.9 \times 10^{13} \mathrm{gc} / \mathrm{kg}\right) \\
\text { administration. BW, body weight; LV, left ventricle; Young, 3-month-old saline injected normal mice; } \\
\text { Aged, 2-year-old mice; } \mathrm{p} \text { values are from Student's t-test (unpaired, two-tailed) with Bonferroni } \\
\text { correction. }{ }^{A} \mathrm{p}=.03 ;{ }^{B} \mathrm{p}=.04 ;{ }^{C} \mathrm{p}=.001 .\end{array}$} \\
\hline
\end{tabular}

\section{DISCUSSION}

The two most important findings in the present study are that urocortin 2 gene transfer: 1) increases diastolic function in aged mice; and 2) prevents the development of age-related impairment of LV diastolic function when delivered to young mice. We saw sustained elevation in plasma Ucn2 after a single IV injection of AAV8.Ucn2 (Fig. 1C). In the present study, unlike the case in clinical studies, we cannot evaluate symptoms, but we found impaired LV diastolic function (Fig. 2B), which was an enrollment criterion in the present study. Therefore, our data indicate that Ucn2 gene transfer has beneficial effects in an animal model that shares features of clinical HFpEF. Preserved EF and impaired diastolic function, in combination with symptoms of HF are the characteristics of clinical HFpEF and

\begin{tabular}{|c|c|c|c|}
\hline \multicolumn{4}{|c|}{ Table 3b. Prevention Study, Necropsy } \\
\hline & Saline (21) & Ucn2 (15) & p value \\
\hline BW (g) & $27.8 \pm 1$ & $28 \pm 1.2$ & .94 \\
\hline LV (mg) & $118 \pm 6$ & $115 \pm 8$ & .77 \\
\hline LV/BW (mg/g) & $4.3 \pm .3$ & $4.3 \pm .4$ & .9 \\
\hline Lung/BW (mg/g) & $6.9 \pm .4$ & $6.3 \pm .2$ & .24 \\
\hline Liver/BW (mg/g) & $51.9 \pm 2.3$ & $56 \pm 3.1$ & .29 \\
\hline $\begin{array}{l}\text { Necropsy data 20 months after Saline or AAV8.Ucn2 (Ucn2, 1.9x1013 gc/kg) administration. BW, body } \\
\text { weight; LV, left ventricle; p values are from Student's t-test. }\end{array}$ \\
\hline
\end{tabular}


they are seen with increased prevalence in older patients $(1,3,4)$. It is noteworthy that aging in mice is associated with similar declines in both peak $+\mathrm{dP} / \mathrm{dt}$ (despite normal $\mathrm{EF}$ ) and peak $-\mathrm{dP} / \mathrm{dt}$, and that Ucn2 gene transfer provides a remedy for both impairments. We found no difference in EF between young and old mice (Table 2a), which is analogous to what is seen in clinical age-related HFpEF. Three months after Ucn2 gene transfer in aged mice, EF $(p<.0002)$ and VCFc ( $p<.0002$; an echocardiographic estimate of contractile function) were increased compared to the aged animals that received saline (Table 2a). The increase in EF found in aged mice that received Ucn2 gene transfer was associated with reductions in both EDD and ESD (Table 2a).

In addition to reduced LV volumes and increased EF in the Treatment study (Table 2a), we found group differences in direct measures of LV contraction and relaxation, using micromanometer catheters in the LV cavity. Such data provide less load-dependent measures of LV function than does EF. We found that LV peak $+d P / d t$ was higher in aged mice that had received $U c n 2$ gene transfer $4 \mathrm{~m}$ prior $(p<.0002$, Fig. 2A) indicating increased LV contractile function. In addition, LV peak -dP/dt was higher in mice that received Ucn2 gene transfer ( $p=.004$, Fig. 2B), indicating increased diastolic function. Increased HR can contribute to increased $+\mathrm{dP} / \mathrm{dt}$, and we saw an increase in $\mathrm{HR}$ in aged mice that received Ucn2 gene transfer (vs Saline). However, the force-frequency effect would account for a

A

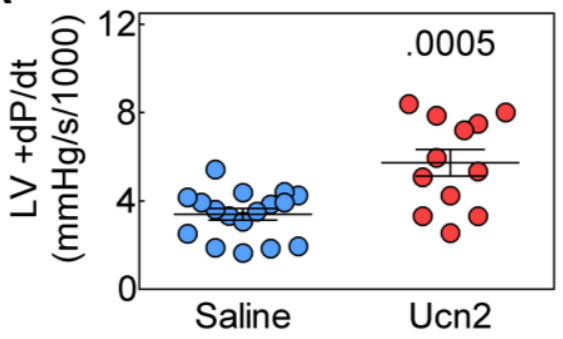

C

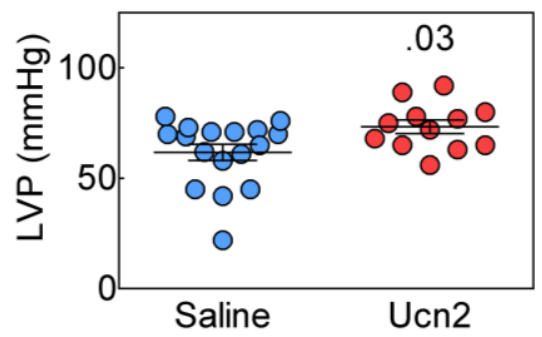

B

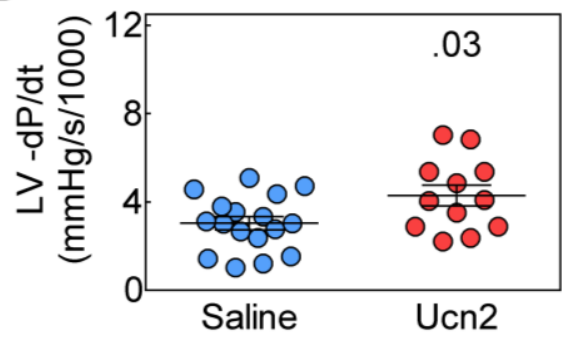

D

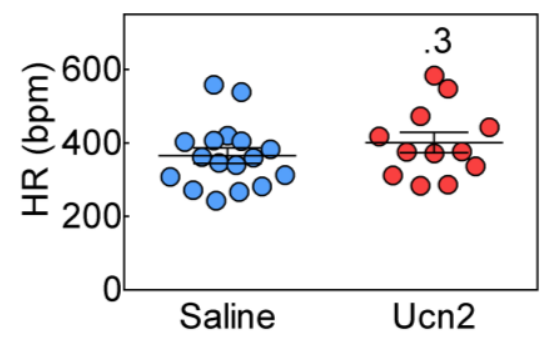

Figure 3. Prevention Study. In vivo assessment of LV function 20 months after saline (Saline) or AAV8.Ucn2 (Ucn2, $\left.1.9 \times 10^{13} \mathrm{gc} / \mathrm{kg}\right)$ administration. A and B. Peak rate of LV pressure development $(\mathbf{A},+\mathrm{dP} / \mathrm{dt})$ and peak rate of LV pressure decay $(\mathbf{B},-\mathrm{dP} / \mathrm{dt})$. These data indicate that Ucn2 gene transfer increased both peak $+\mathrm{dP} / \mathrm{dt}$ and peak $\mathrm{dP} / \mathrm{dt}$. C. LV developed pressure (LVP) was increased by Ucn2 gene transfer. D. Heart rate (HR) was not altered by Ucn 2 gene transfer. LV, left ventricle. Individual mouse data are shown (mean $\pm S E$ are indicated); $p$ values are from Student's t-test (unpaired, two-tailed). 
smaller change (16) than the 2-fold increase we found. Additionally, aged mice that received Ucn2 gene transfer (vs Saline) had lower heart rates during echocardiography (light anesthesia), but higher HR during deeper anesthesia and mechanical ventilation (Table 2a; Fig. 2D), which probably reflects variability vis-à-vis response to anesthetic.

In the Prevention study, we asked whether Ucn2 gene transfer performed early in life might prevent age-related abnormalities in LV function. These studies showed that $20 \mathrm{~m}$ after Ucn2 gene transfer (vs saline), age-related LV dysfunction was thwarted. For example, mice that had received Ucn2 gene transfer at $18 \mathrm{w}$ of age, showed higher EF ( $p=.0002)$, and lower ESD ( $p=.002$ ) when studied $20 \mathrm{~m}$ after randomization (Table $3 \mathrm{~b}$ ). Indeed, the data obtained in aged mice $20 \mathrm{~m}$ after Ucn2 gene transfer in young mice (Table $\mathbf{2 b}$ ) are similar in $\mathrm{EF}, \mathrm{EDD}$, and ESD to what are seen in aged mice that received gene transfer (Table 2a). LV peak $+d P / d t$ was higher in aged mice that had received Ucn2 gene transfer $20 \mathrm{~m}$ prior

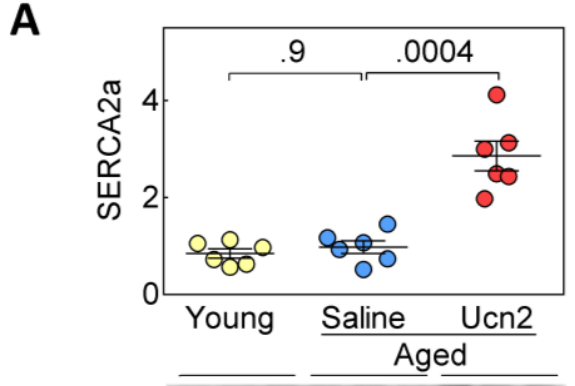

SERCA2a

GAPDH

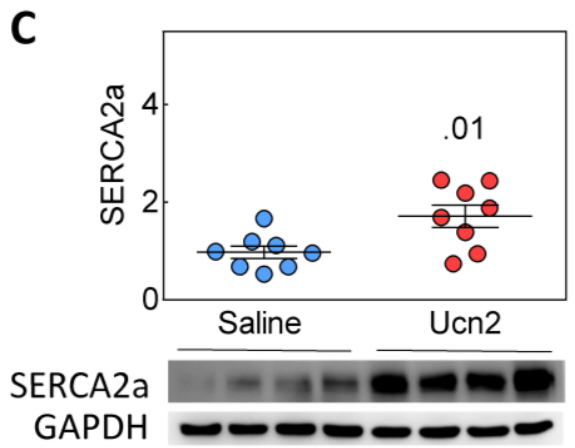

B

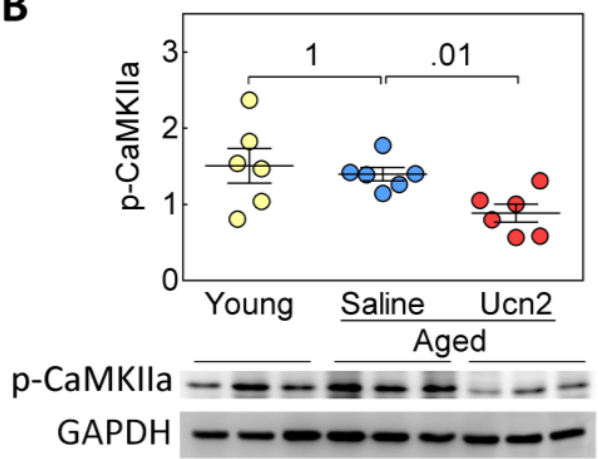

D

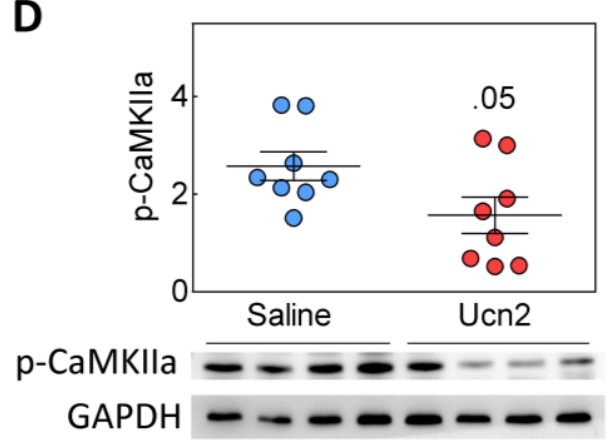

Figure 4. Levels of left ventricular (LV) proteins after IV delivery of AAV8.Ucn2 $\left(1.9 \times 10^{13} \mathrm{gc} / \mathrm{kg}\right)$ or saline. A. LV sarco/endoplasmic reticulum Ca2+ ATPase 2a (SERCA2a) levels were increased in aged mice that received Ucn2 gene transfer ( $p=.0004$ vs Saline). B. LV phosphorylated calcium/calmodulin dependent protein kinase IIa ( $p$ CaMKIIa) was reduced in AAV8.Ucn2 treated aged animals ( $p=.01$ vs Saline). C. LV SERCA2a levels were increased and D. LV p-CaMKIla was reduced 20 months after Ucn2 gene transfer. Data are normalized to GAPDH. Representative immunoblots for the summary data are shown below the graphs. Individual data are shown (mean $\pm S E$ ); Young, 3-month-old saline-injected mice; Aged, 2-year-old mice. P values are from Student's t-test (unpaired, two tailed) with Bonferroni correction for multiple comparisons. 
( $p=.0005$; Fig. 3A) indicating increased LV contractile function. In addition, LV peak $-d P / d t$ was also higher in mice that received Ucn2 gene transfer $20 \mathrm{~m}$ prior ( $p=.03$, Fig. 3B), indicating increased diastolic function.

Table 4a. Treatment Study, LV mRNA Expression of Markers of Hypertrophy and Fibrosis

\begin{tabular}{|c|c|c|c|}
\hline Gene & $\begin{array}{l}\text { Aged +Saline (7) } \\
\text { Fold Control }\end{array}$ & $\begin{array}{l}\text { Aged +Ucn2 (8) } \\
\text { Fold Control }\end{array}$ & $\begin{array}{c}\text { P } \\
\text { Saline vs Ucn2 }\end{array}$ \\
\hline$\beta 1 A R$ & $1.11 \pm .13$ & $.91 \pm .09$ & .4 \\
\hline$\beta 2 A R$ & $1.3 \pm .05^{\mathrm{A}}$ & $1.33 \pm .13$ & 1 \\
\hline$A C 5$ & $.63 \pm .04$ & $.74 \pm .12$ & .9 \\
\hline AC6 & $.88 \pm .05$ & $.94 \pm .06$ & 1 \\
\hline AT1aR & $1.18 \pm .1$ & $.73 \pm .08$ & .005 \\
\hline Serca2a & $.9 \pm .07$ & $.85 \pm .05$ & .57 \\
\hline$B c l-2$ & $1.31 \pm .18$ & $.65 \pm .08$ & .008 \\
\hline$C x-43$ & $1.01 \pm .03$ & $.88 \pm .04$ & .07 \\
\hline$A N F$ & $1.49 \pm .3$ & $.96 \pm .23$ & .4 \\
\hline$B N P$ & $.92 \pm .06$ & $.55 \pm .12$ & .04 \\
\hline$\alpha-M H C$ & $.87 \pm .05$ & $.8 \pm .06$ & .7 \\
\hline$\beta-M H C$ & $2.74 \pm .87$ & $1.1 \pm .26$ & .2 \\
\hline CARP & $1.17 \pm .15$ & $.88 \pm .14$ & .4 \\
\hline$F H L-1$ & $1.14 \pm .04$ & $1.75 \pm .17$ & .01 \\
\hline$\alpha$-cardiac actin & $1.12 \pm .06$ & $.95 \pm .09$ & .3 \\
\hline$\alpha$-skeletal actin & $1.03 \pm .1$ & $.43 \pm .08$ & .0008 \\
\hline$M M P 2$ & $1.1 \pm .04$ & $1.42 \pm .17$ & .2 \\
\hline MMP8 & $1.58 \pm .27$ & $2.65 \pm .89$ & .6 \\
\hline TIMP1 & $.73 \pm .07$ & $.94 \pm .1$ & .2 \\
\hline TIMP2 & $1.31 \pm .1$ & $1.56 \pm .17$ & .5 \\
\hline TIMP3 & $1.01 \pm .07$ & $.81 \pm .1$ & .2 \\
\hline TIMP4 & $1.2 \pm .2$ & $.67 \pm .12$ & .07 \\
\hline Col1 & $.95 \pm .09$ & $1.38 \pm .31$ & .5 \\
\hline $\mathrm{Col} 3$ & $.82 \pm .09$ & $1.6 \pm .37$ & .1 \\
\hline OSF2/periostin & $.6 \pm .08$ & $.61 \pm .08$ & 1 \\
\hline Fibronectin & $.68 \pm .05$ & $1.2 \pm .2$ & .07 \\
\hline$m U c n 2$ & $1.13 \pm .14$ & $4222 \pm 763$ & .0004 \\
\hline
\end{tabular}

$R T$-PCR data presented as fold Control (Young, $n=8$, 3-month-old saline injected normal mice) after normalizing with GAPDH. $\beta 1 A R, \beta 1$ Adrenergic receptor; $\beta 2 A R, \beta 2$ Adrenergic receptor; $A C 5$, Adenylyl cyclase 5; AC6, Adenylyl cyclase 6; AT1aR, Angiotensin subtype 1a receptor; Serca2a, Sarco/endoplasmic reticulum Ca2+ ATPase 2a; Bcl-2, B-cell lymphoma 2; Cx-43, Connexin 43; ANF, Atrial Natriuretic Factor; BNP, Brain Natriuretic Peptide; $\alpha$-MHC, $\alpha$-Myosin Heavy Chain; $\beta$-MHC, $\beta$-Myosin Heavy Chain; CARP, Cardiac Ankyrin-Repeated Protein; FHL-1, Four-and-a-Half LIM domain protein 1; MMP2, Matrix Metalloproteinase 2; MMP8, Matrix Metalloproteinase 8; TIMP1-4, Tissue Inhibitor or Metalloproteinase 1-4; Col1, Collagen 1; Col3, Collagen 3; OSF2, Osteoblast Specific transcription Factor 2; mUcn2, murine Urocortin 2; Aged, 2-year-old mice; p values are from Student's t-test with Bonferroni correction. Data are mean $\pm S E$; numbers in parenthesis indicate group size. ${ }^{A} p=.01$; 
We previously reported beneficial effects of Ucn2 gene transfer on $\mathrm{Ca}^{2+}$ transients in cardiac myocytes isolated from normal young mice and from mice with $\operatorname{HFrEF}(11,12,13)$. However, $\mathrm{Ca}^{2+}$ transient measurements are not feasible in aged mice because of poor viability of isolated cardiac myocytes, and, therefore, were not attempted. We instead focused on LV SERCA2a protein expression, a key $\mathrm{Ca}^{2+}$ handling protein, which pumps cytosolic $\mathrm{Ca}^{2+}$ back to the sarcoplasmic reticulum. We found LV SERCA2a levels were similar in young and aged mice that received saline. However, in the Treatment study, Ucn2 gene transfer mice was associated, $4 \mathrm{~m}$ later, with a 3-fold increase in LV SERCA2a ( $p=.0004$; Fig. 4A). Increased expression of SERCA2a would be expected to increase cytosolic $\mathrm{Ca}^{2+}$ decline

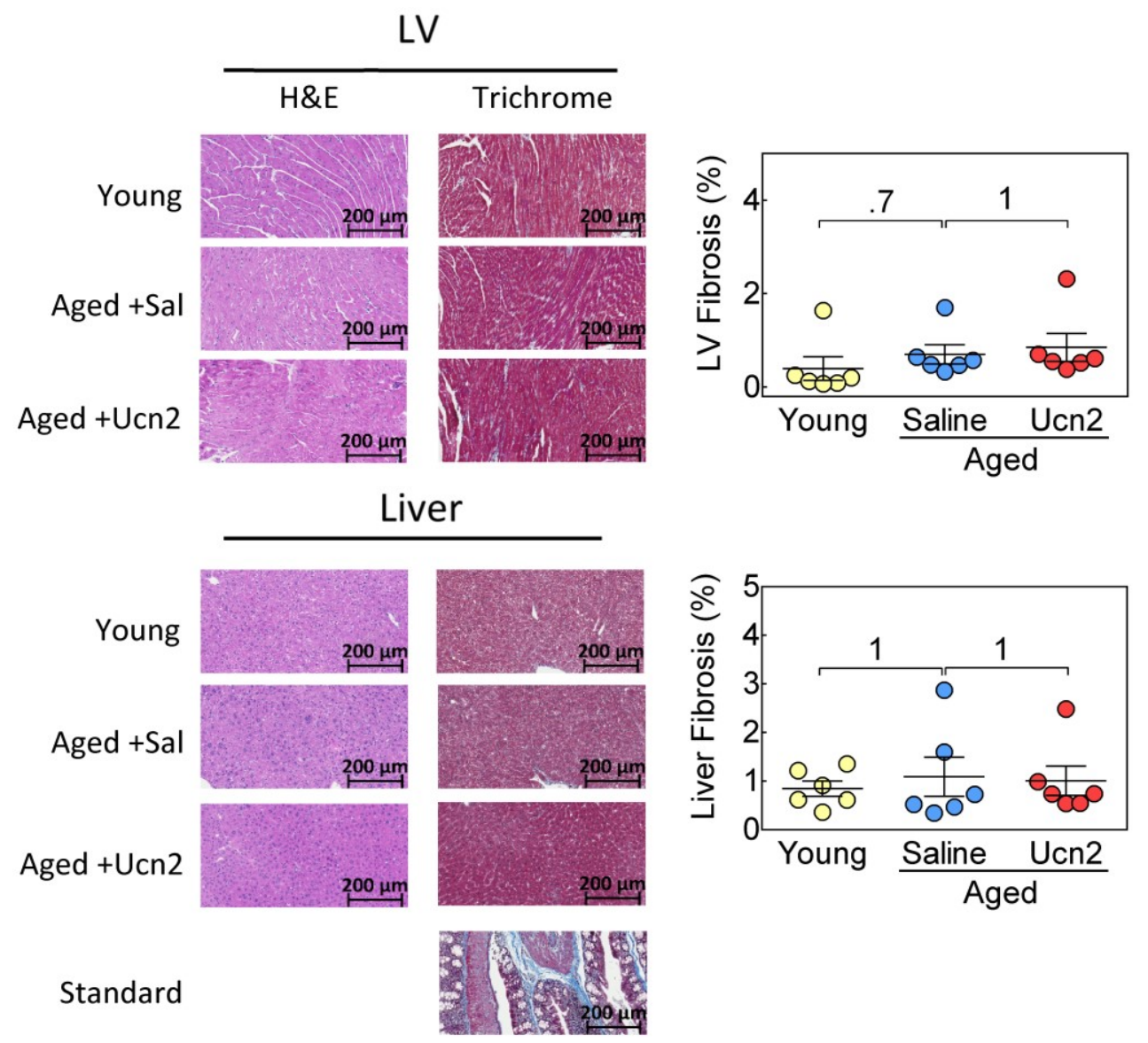

Figure 5. Treatment Study. Histological analysis of left ventricle (LV) and liver 4 months after IV delivery of AAV8.Ucn2 (Ucn2, $1.9 \times 10^{13} \mathrm{gc} / \mathrm{kg}$ ) or saline (Saline). Hematoxylin and eosin (H\&E) and Masson's trichrome staining were performed on liver and transmural sections of LV (original magnification 20X; presented image magnification H\&E and Masson's trichrome: 7X), no evidence of inflammatory infiltrates was seen. LV fibrosis was similar in all 3 groups. There were no group differences in liver fibrosis. Young, 3-month-old saline injected normal mice; Aged, 2-year-old mice. Standard, control for Masson's trichrome. Individual data are shown (mean $\pm S E$ are indicated); $p$ values are from Student's t-test (unpaired, two tailed) with Bonferroni correction for multiple comparisons. 
resulting in improved relaxation and would also contribute to increased systolic function. There was no difference between young and aged saline-treated animals in the

Table 4b. Prevention Study, LV mRNA Expression of Markers of Hypertrophy and Fibrosis

\begin{tabular}{|c|c|c|c|}
\hline Gene & Saline (12) & Ucn2 (12) & $\begin{array}{c}\mathrm{P} \\
\text { Saline vs Ucn2 }\end{array}$ \\
\hline$\beta 1 A R$ & $1 \pm .15$ & $.65 \pm .06$ & .04 \\
\hline$\beta 2 A R$ & $1 \pm .08$ & $.79 \pm .06$ & .05 \\
\hline$A C 5$ & $1 \pm .14$ & $.9 \pm .09$ & .6 \\
\hline AC6 & $1 \pm .06$ & $.96 \pm .06$ & .6 \\
\hline AT1aR & $1 \pm .13$ & $.87 \pm .1$ & .4 \\
\hline Serca2a & $1 \pm .12$ & $.92 \pm .1$ & .6 \\
\hline$B C l-2$ & $1 \pm .17$ & $.93 \pm .13$ & .8 \\
\hline$C x-43$ & $1 \pm .08$ & $.96 \pm .06$ & .7 \\
\hline$A N F$ & $1 \pm .26$ & $1.34 \pm .47$ & .5 \\
\hline$B N P$ & $1 \pm .17$ & $1.35 \pm .46$ & .5 \\
\hline$\alpha-M H C$ & $1 \pm .08$ & $.95 \pm .07$ & .7 \\
\hline$\beta-M H C$ & $1 \pm .2$ & $.78 \pm .23$ & .5 \\
\hline CARP & $1 \pm .11$ & $.97 \pm .18$ & .9 \\
\hline$F H L-1$ & $1 \pm .1$ & $1.49 \pm .14$ & .008 \\
\hline$\alpha$-cardiac actin & $1 \pm .07$ & $1.1 \pm .09$ & .7 \\
\hline$\alpha$-skeletal actin & $1 \pm .16$ & $.64 \pm .06$ & .05 \\
\hline MMP2 & $1 \pm .1$ & $.94 \pm .06$ & .6 \\
\hline MMP8 & $1 \pm .17$ & $1 \pm .14$ & 1 \\
\hline TIMP1 & $1 \pm .18$ & $.84 \pm .08$ & .4 \\
\hline TIMP2 & $1 \pm .06$ & $1.15 \pm .07$ & .1 \\
\hline TIMP3 & $1 \pm .09$ & $.9 \pm .07$ & .4 \\
\hline TIMP4 & $1 \pm .18$ & $.83 \pm .11$ & .4 \\
\hline Col1 & $1 \pm .13$ & $.84 \pm .12$ & .4 \\
\hline $\mathrm{Col3}$ & $1 \pm .2$ & $.71 \pm .13$ & .2 \\
\hline OSF2/periostin & $1 \pm .35$ & $1.35 \pm .29$ & .5 \\
\hline Fibronectin & $1 \pm .09$ & $.93 \pm .14$ & .7 \\
\hline$m U c n 2$ & $1 \pm .23$ & $850 \pm 292$ & .008 \\
\hline \multicolumn{4}{|c|}{ 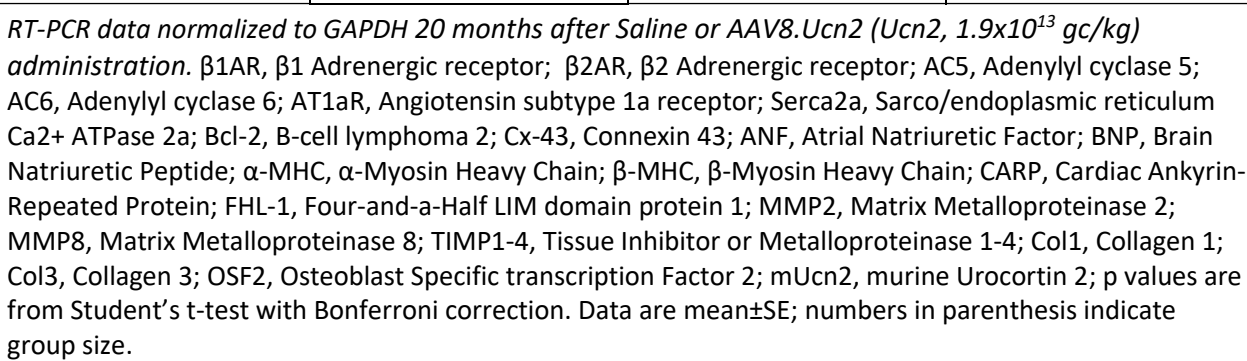 } \\
\hline
\end{tabular}


phosphorylation levels of CaMKIla in LV samples. However, Ucn2 gene transfer reduced pCaMKIla ( $p=.01$, Fig. 4B), an alteration hat can benefit cardiac performance (17). Increased levels of $p$-CaMKIla were found to be associated with heart disease progression by affecting hypertrophic and inflammatory gene expression, and also leading to increased arrhythmias (17). In the Prevention study, $20 \mathrm{~m}$ after Ucn2 gene transfer we saw a 1.9-fold increase in LV SERCA2a (Fig. 4C) and reduced $p$-CaMKIla levels ( $p=.05$, Fig. 4D). Further studies will be required to elucidate the molecular mechanisms underlaying increases in LV SERCA2a and reduced $\mathrm{p}$-CaMKII.

\section{LV}

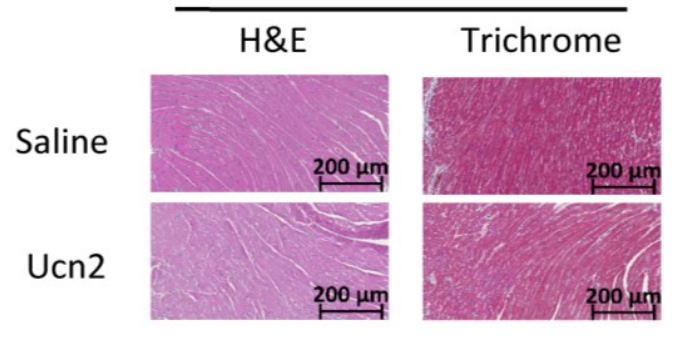

\section{Liver}

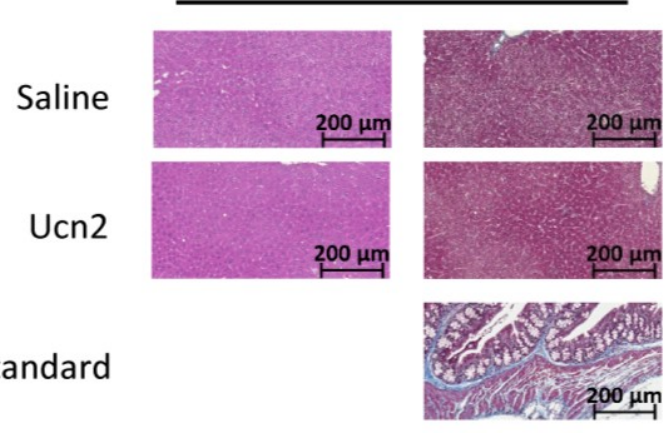

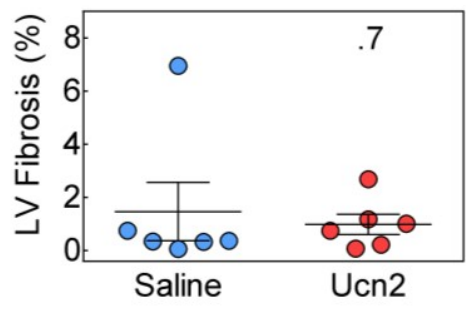

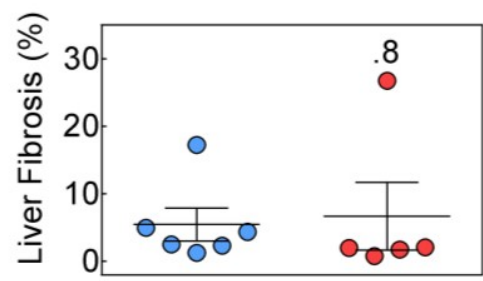

Saline Ucn2

Figure 6. Prevention Study. Histological analysis of left ventricle (LV) and liver 20 months after saline (Saline) or AAV8.Ucn2 (Ucn2, $1.9 \times 10^{13} \mathrm{gc} / \mathrm{kg}$ ) administration. Hematoxylin and eosin (H\&E) and Masson's trichrome staining were performed on liver and transmural sections of LV (original magnification 20X; presented image magnification H\&E and Masson's trichrome: 7X), no evidence of inflammatory infiltrates was seen. LV and liver fibrosis were similar in both groups. Standard, control for Masson's trichrome. Individual data are shown (mean \pm SE are indicated); $p$ values are from Student's t-test (unpaired, two tailed).

In the Treatment study, mRNA expression of proteins related to cardiac hypertrophy and stress showed that only $\beta_{2} A R$ differed in aged vs young mice (a $30 \%$ increase; $p=.01$; Table 4a). However, in aged mice, Ucn2 gene transfer was associated with reductions in AT1 $\alpha$ R (18), -2 (19), BNP (20), $\alpha$-skeletal actin (21,22), and increases in FHL-1 and Ucn2 (as expected). Although reduction of LV weights from aged Ucn2 treated animals was not significant (Table 3a), reductions in BNP, Bcl-2, and $\alpha$-skeletal actin may reflect reduced stress after Ucn2 gene transfer (due to improved LV function). SERCA2a mRNA was 
unchanged, despite a 3-fold elevation in SERCA2a protein after Ucn2 gene transfer-this suggests a change in mRNA stability or reduction in SERCA2a protein turnover after Ucn2 gene transfer.

The absence of an increase in SERCA2a mRNA indicates that the effects of Ucn2 gene transfer would not be comparable with SERCA2a gene transfer which would increase SERCA2a mRNA levels. In the Prevention study, LV expression of $\beta 1$ adrenergic receptor, $\beta_{2} A R, \alpha$-skeletal actin was reduced, indicating reduction of cardiac stress, and expression of FHL-1 and murine Ucn2 were increased (Table 4b).

In conclusion, we have shown that Ucn2 gene transfer in aged mice with diastolic impairment, but normal EF, returns LV diastolic function to normal, 4 months later. The mechanism for these beneficial effects lies, at least in part, on increased LV SERCA2a expression. Furthermore, in parallel separate studies, we have found that Ucn2 gene transfer when performed in young mice, prevents the development of age-related LV dysfunction-hearts of such animals have systolic and diastolic functional parameterseven at 2 years of age-that are indistinguishable from young mice. Finally, we have shown that a single intravenous delivery of AAV8.Ucn2 results in sustained high plasma Ucn2 levels 20 months after delivery. These findings are relevant to the treatment of clinical HFpEF, an entity that has few effective therapies. Our findings support Ucn2 gene transfer as a potential therapy for clinical HFpEF.

\section{DISCLOSURES AND FUNDING SOURCES}

Disclosure. Dr. Hammond is a founder, board member and unpaid consultant for Renova Therapeutics. Renova played no role in the studies. None of the other authors have disclosures.

Funding Sources. This work was supported by National Institute of Health grant (P01 HL66941) and Merit grants from the Department of Veteran's Affairs (1101 BX001515 and 1101 BX003774). 


\section{REFERENCES}

1. Lloyd-Jones D, Adams RJ, Brown TM, Carnethon M, Dai S, De Simone G, et al. Executive summary: heart disease and stroke statistics--2010 update: a report from the American Heart Association. Circulation. 2010;121(7):948-54.

2. Borlaug BA, Paulus WJ. Heart failure with preserved ejection fraction: pathophysiology, diagnosis, and treatment. European heart journal. 2011;32(6):670-9.

3. Ouzounian M, Lee DS, Liu PP. Diastolic heart failure: mechanisms and controversies. Nature clinical practice Cardiovascular medicine. 2008;5(7):375-86.

4. Maeder MT, Kaye DM. Heart failure with normal left ventricular ejection fraction. Journal of the American College of Cardiology. 2009;53(11):905-18.

5. Bale TL, Hoshijima M, Gu Y, Dalton N, Anderson KR, Lee KF, et al. The cardiovascular physiologic actions of urocortin II: acute effects in murine heart failure. Proc Natl Acad Sci U S A. 2004;101(10):3697-702.

6. Rademaker MT, Charles CJ, Ellmers LJ, Lewis LK, Nicholls MG, Richards AM. Prolonged urocortin 2 administration in experimental heart failure: sustained hemodynamic, endocrine, and renal effects. Hypertension. 2011;57(6):1136-44.

7. Chan WY, Frampton CM, Crozier IG, Troughton RW, Richards AM. Urocortin-2 infusion in acute decompensated heart failure: findings from the UNICORN study (urocortin-2 in the treatment of acute heart failure as an adjunct over conventional therapy). JACC Heart failure. 2013;1(5):433-41.

8. Gheorghiade M, Greene SJ, Ponikowski P, Maggioni AP, Korewicki J, Macarie C, et al. Haemodynamic effects, safety, and pharmacokinetics of human stresscopin in heart failure with reduced ejection fraction. European journal of heart failure. 2013;15(6):679-89.

9. Stirrat CG, Venkatasubramanian S, Pawade T, Mitchell AJ, Shah AS, Lang NN, et al. Cardiovascular effects of urocortin 2 and urocortin 3 in patients with chronic heart failure. $\mathrm{Br}$ J Clin Pharmacol. 2016;82(4):974-82.

10. Patel K, Rademaker MT, Kirkpatrick CM, Charles CJ, Fisher S, Yandle TG, et al. Comparative pharmacokinetics and pharmacodynamics of urocortins 1, 2 and 3 in healthy sheep. British journal of pharmacology. 2012;166(6):1916-25.

11. Gao MH, Lai NC, Miyanohara A, Schilling JM, Suarez J, Tang T, et al. Intravenous adenoassociated virus serotype 8 encoding urocortin-2 provides sustained augmentation of left ventricular function in mice. Hum Gene Ther. 2013;24(9):777-85.

12. Lai NC, Gao MH, Giamouridis D, Suarez J, Miyanohara A, Parikh J, et al. Intravenous AAV8 Encoding Urocortin-2 Increases Function of the Failing Heart in Mice. Hum Gene Ther. 2015;26(6):347-56.

13. Giamouridis D, Gao MH, Lai NC, Tan Z, Kim YC, Guo T, et al. Effects of Urocortin 2 Versus Urocortin 3 Gene Transfer on Left Ventricular Function and Glucose Disposal. JACC: Basic to Translational Science. 2018;3(2):249-64.

14. Xiao X, Li J, Samulski RJ. Production of high-titer recombinant adeno-associated virus vectors in the absence of helper adenovirus. Journal of virology. 1998;72(3):2224-32.

15. Gao MH, Lai NC, Roth DM, Zhou J, Zhu J, Anzai T, et al. Adenylylcyclase increases responsiveness to catecholamine stimulation in transgenic mice. Circulation. 1999;99(12):1618-22.

16. Palakodeti $\mathrm{V}, \mathrm{Oh} \mathrm{S}, \mathrm{Oh} \mathrm{BH}$, et al. Force-frequency effect is a powerful determinant of myocardial contractility in the mouse. Am J Physiol. 1997;273:H1283-H1290.

17. Paari Dominic Swaminathan, Anil Purohit, Thomas J Hund, and Mark E Anderson. CaMKII: linking heart failure and arrhythmias. Circ Res. 2012 Jun; 110(12): 1661-1677. 
18. Shyu KG, Chen CC, Wang BW, Kuan P. Angiotensin II receptor antagonist blocks the expression of connexin43 induced by cyclical mechanical stretch in cultured neonatal rat cardiac myocytes. J Mol Cell Cardiol. 2001 Apr;33(4):691-8.

19. Buzello M, Boehm C, Orth S, Fischer B, Ehmke H, Ritz E, Mall G, Amann K. Myocyte loss in early left ventricular hypertrophy of experimental renovascular hypertension. Virchows Arch. 2003 Apr;442(4):364-71. 56.

20. Battistoni A, Rubattu S, Volpe M. Circulating biomarkers with preventive, diagnostic and prognostic implications in cardiovascular diseases. Int J Cardiol. 2012;157:160-168.

21. F M Black, S E Packer, T G Parker, L H Michael, R Roberts, R J Schwartz, and M D Schneider. The vascular smooth muscle alpha-actin gene is reactivated during cardiac hypertrophy provoked by load. J Clin Invest. 1991 Nov; 88(5): 1581-1588.

22. Copeland O, Nowak KJ, Laing NG, et al. Investigation of changes in skeletal muscle alpha-actin expression in normal and pathological human and mouse hearts. J Muscle Res Cell Motil. 2010;31:207-214. 


\section{Chapter}

SUMMARY

\& GENERAL DISCUSSION 


\section{SUMMARY}

Heart failure (HF) incidence is increasing and the current therapeutic options have remained the same over the past years, without resplendent improvements in the disease's outcomes. In addition to this, there are no efficacious treatments for specific subgroups of heart failure patients, such as those with heart failure with preserved ejection fraction (HFpEF). Early disease detection can offer the opportunity of lifestyle changes and pharmacologic interventions that can effectively manage the disease, although the complexity and heterogeneity of HF makes early diagnosis difficult (1). Furthermore, the management of some risk factors of HF, like diabetes, is still challenging with restricted number and efficacy of the available treatments (2-4). Therefore, new therapies for HF and its risk factors are warranted.

Among a plethora of agents that could benefit HF patients are the corticotropin releasing factor (CRF) family peptides. The four know members of this family are CRF, which binds predominantly to CRF receptor 1 (CRFR1), Ucn1, which binds to both CRFR1 and CRFR2, and Ucn2 and Ucn3, which bind exclusively to CRFR2. In the last two decades, promising findings on the beneficial effects of Ucns IV infusions on healthy or failing animal and human hearts, have demonstrated the potency of those peptides to be used as therapeutic agents for heart failure (5-18). Ucns' regulatory role in glucose metabolism also suggests a potential use in diabetes management. However, the exact molecular mechanisms that are activated by Ucns and underlie the therapeutic effects in diabetes and HF are still unclear. The use of Ucn2 and Ucn3 for chronic treatment is restricted by peptides' short half-life (about 10 minutes) (19); therefore, gene transfer of those peptides has been proposed.

The main goal of this thesis was to evaluate the effects Ucn2 and Ucn3 gene transfer on heart function and glucose metabolism, as well as to unravel the molecular mechanisms contributing in these effects. The major findings of this work are:

- Ucn2 and Ucn3 gene transfer increased systolic and diastolic function in healthy young mice. (Chapter 2 )

- Ucn2, but not Ucn3, gene transfer improved glucose clearance in healthy young mice. (Chapter 2)

- Ucn2 and Ucn3 gene transfer resulted in increased $\mathrm{Ca}^{2+}$ transients and decreased time constant of relaxation (Tau) of isolated cardiac myocytes from young healthy mice. (Chapter 2)

- Ucn2 and Ucn3 gene transfer increased the left ventricular (LV) levels of sarco/endoplasmic reticulum $\mathrm{Ca}^{2+}$ ATPase 2a (SERCA2a). (Chapter 2)

- Ucn3 gene transfer increased the function of the failing heart in a murine model of $\mathrm{HF}$ with reduced ejection fraction. (Chapter 3 )

- Ucn3 gene transfer increased $\mathrm{Ca}^{2+}$ transients and decreased Tau of isolated cardiac myocytes from failing murine hearts. (Chapter 3 ) 
- Ucn3 gene transfer in a murine model of HFrEF increased the LV content of SERCA2a and decreased the phosphorylation of $\mathrm{Ca}^{2+} /$ calmodulin mediated kinase II (CaMKII). (Chapter 3)

- Ucn2 gene transfer improved glucose clearance in two murine models of type 2 diabetes mellitus (T2DM). (Chapter 4)

- Ucn2 gene transfer in a T2DM murine model increased adenosine monophosphate-activated protein kinase (AMPK) activation and induced translocation of glucose transporter 4 (Glut4). (Chapter 4)

- Ucn2 gene transfer reversed, and also prevented, age-related diastolic dysfunction in aged mice. (Chapter 5)

- Ucn2 gene transfer increased the levels of SERCA2a and decreased the phosphorylation of CaMKII in the LVs of 2-year-old mice. (Chapter 5)

- There was no observation of adverse effects related to UCn2 and Ucn3 gene transfer. (Chapters 2, 3, 4, 5) 


\section{GENERAL DISCUSSION}

\section{Gene therapy approach and AAV8 selection}

To circumvent the unfavorable pharmacokinetics of Ucn2 and Ucn3 peptides we proposed a paracrine liver targeted gene transfer approach. Early-phase gene transfer clinical trials in patients with HF (20) or hemophilia B (21) proved that use of an adeno-associated viral (AAV) vector is safe for gene delivery. Previous experimental work already suggested the potential of gene therapy for resolving HF or related risk factor diseases, such as diabetes. For example, preclinical studies using S100A1 (22), G-protein coupled receptor kinase-2 (GRK2) (23), and SERCA2a (24) gene transfer demonstrated increased function in normal and failing hearts. In addition, preclinical diabetes models treated with insulin and glucokinase gene transfer (25), or glucagon-like peptide-1 (GLP-1) and the NK1 fragment of hepatocyte growth factor (HGF/NK1) gene transfer (26), had improved glucose homeostasis. Therapeutic benefit in insulin deficiency was the main focus of those latter studies, aiming mainly at type 1 diabetes and late-stage T2DM, contrarily to our Ucn2 gene transfer method which increased insulin sensitivity in early-stage insulin resistance models.

For our study we had to select between two most commonly used vectors for gene delivery; adenoviruses (Advs) and AAVs. Advs have greater cloning capacity than AAVs, however our transgene's encoding sequence was small enough to fit in an AAV vector. The first two generations of Advs have the disadvantage to cause inflammation and immune responses, unlike AAVs that in most cases are not pathogenic. Deletion of all viral genes lead to the creation of the gutted Adv ( $3^{\text {rd }}$ generation), which has lower immunoreactivity and larger cloning capacity, however its genetic manipulation is unwieldy and it is difficult to produce (27).

$A A V$ vector lends itself well for chronic treatment of $\mathrm{HF}$ and/or diabetes, enabling long-term transgene expression. Persistent circulatory elevation of clotting factors encoded by AAV vectors has been documented in rodents, dogs, and primates (28-30). Our studies confirmed this, showing persistent plasma elevation of Ucn2 in mice up to 20 months after gene transfer (Chapter 5). Previously seen low-grade immune response triggered by some AAV serotypes (31) is a problem that seems to be resolved by the newer generation of AAV vectors (32-34). Additionally, selection of a serotype 8 AAV vector was supported by the low pre-existence of serum neutralizing factors in humans (19\%), compared to other AAV serotypes (AAV1, 51\%; AAV2, 59\%; AAV9, 34\%) (35). This will be required for clinical trial initiation, providing a bigger pool of subjects that will unlikely have adverse immune responses to the vector. Also, if approval for commercial use is granted, the use of AAV8 will allow more people to safely benefit from such a treatment.

General concerns regarding gene therapy are mainly related to potential integration of the alien DNA into the hosts, occasional oncogene activation, and the overexpression of a protein, in our case a hormone-like peptide with paracrine actions. It is well known that the elevation or downregulation of a peptide hormone, for example thyroid hormone, can 
result in a plethora of adverse effects $(36,37)$. Although our gene transfer managed to increase peptide levels up to 70 times higher than its normal endogenous levels in mice, no adverse effects were noticed during physiological and histological evaluation. Unpublished data from a biodistribution and toxicology study that we conducted, further supports that Ucn2 gene transfer can increase plasma levels without notable side effects. Furthermore, a lower vector dose which results in a smaller elevation of transgene's plasma levels can also be efficacious as we found in our studies. The safety, and subsequently the efficacy, of this gene transfer approach needs to be confirmed in other species and a small number of humans (phase 1 clinical trial) prior to the initiation of a large clinical trial. To minimize the risk of a continuous transgene expression, we designed and executed studies using regulated viral expression of Ucn2. The expression efficiency of that vector was much lower than the unregulated one, restricting the possibility to reduce viral dose, even though the amount of plasma Ucn2 was still able to alter cardiac and metabolic physiologic parameters. The disadvantage of a regulated vector utilization is the necessary use of an agent(de)activator, usually an antibiotic, which diminishes the convenience of the single-injection gene therapy, while adding undesirable effects of antibiotic administration.

\section{Similarities and Differences of Ucn2 vs Ucn3 Gene Transfer}

Ucn2 and Ucn3 gene transfer were initially tested in healthy young mice. Since both peptides are about $40 \%$ homologous and bind the CRFR2 receptor with similar affinity (38), we were interested to determine whether or not they evoke similar physiological effects. As described in Chapter 2, both Ucn2 and Ucn3 gene transfer were able to increase systolic and diastolic cardiac function 8-10 weeks after vector delivery. However, Ucn2, but not Ucn3, gene transfer managed to improve glucose clearance in those mice. This interesting difference might reflect the slightly different tertiary structure of the peptides; Ucn2 comprised by two interconnected $\alpha$-helixes forming a $90^{\circ}$ angle, while Ucn 3 comprised by a single helical domain/fragment (39). Stimulation of G-protein coupled receptors (GPCRs), such as $\beta$-adrenergic receptors ( $\beta$-AR), by various receptor agonists can lead to differential downstream pathway activation (40). Taking in account all the facts described above in the context of the observed divergent physiological effects, this may point to a biased agonism of CRFR2 by Ucn2 and 3, leading to activation of common/shared as well as distinct downstream signaling pathways. This notion is corroborated by the differential phosphorylation of ryanodine receptor by Ucn2 but not Ucn3 gene transfer. However, further research is needed to clarify whether a biased agonism phenomenon occurs, or even explore the existence of a different isoform through variant splicing of CRFR2 receptor (41), that is activated only by Ucn2. It is also possible that the observed differences in cardiac effects are not solely receptor-mediated and reflect in part protein-protein interactions. Although, as described in Chapter 4, the improvement in glucose clearance in diabetic animals by Ucn2 gene transfer was absent in animals lacking CRFR2, suggesting that the metabolic effects of Ucn2 are CRFR2-dependent.

From a translational perspective, similarities and differences of Ucn2 and Ucn3 gene transfer actions could be used to serve different goals. Since Ucn3 gene transfer has the ability to improve heart function without affecting glucose levels, it could be better utilized as a treatment for heart failure patients with normal glucose homeostasis. On the other 
hand, diabetes is one of the main risk factors for heart failure causing a variety of cardiovascular defects $(42,43)$. The use of Ucn2 gene transfer would be a preferred therapeutic solution in patients with heart failure and impaired glucose clearance. Those patients would benefit double by Ucn2 gene transfer: i) their glucose homeostasis will be improved, which can subsequently diminish further cardiovascular complications, and ii) also their cardiac function will be enhanced. For those reasons, each treatment is novel and equally important, while their existence would offer the option of disease-focused individualized therapy.

\section{Increased systolic and diastolic LV function}

Gene transfer of Ucn2 and Ucn3 resulted in sustained elevation of plasma levels of those peptides and subsequent increase in both systolic and diastolic function in normal young animals (Chapter 2). Studies in a murine HF model with reduced EF (Chapter 3 ), and others in aged animals with diastolic dysfunction and preserved EF (Chapter 5), showed that Ucn3 and Ucn2 gene transfer, respectively, could increase LV contractility and relaxation. Evidence of cardiac function improvements come from echocardiographic assessment, where increases in EF and VCFc were associated with Ucn2 or Ucn3 gene transfer. Increases seen in $\mathrm{LV}$ peak $+\mathrm{dP} / \mathrm{dt}$ and $-\mathrm{dP} / \mathrm{dt}$, heart function measurements less sensitive to loading conditions than EF, are additional proof of the increased systolic and diastolic function in these animals. Furthermore, studies with isolated cardiac myocytes from mice with HF that received Ucn3 gene transfer showed increased sarcomere shortening $(+d L / d t)$ and lengthening $(-\mathrm{dL} / \mathrm{dt}$ ) rate (Chapter 3$)$, supporting that beneficial cardiac effects reside in the myocyte per se, while diminishing a possible vasodilation-related improvement of LV function. It is noteworthy that Ucn2 transgene expression was detectable up to 20 months after gene transfer and prevented the development of adverse age-related cardiac effects. These long-lasting benefits in heart function by our gene transfer approach, favor its use for chronic HF therapy.

\section{Improved insulin sensitivity and increased glucose disposal}

In Chapter 2 it is shown that Ucn2, but not Ucn3, gene transfer enhances glucose disposal and lowers fasting glucose in healthy mice. More importantly, Ucn2 gene transfer improved glucose clearance and increased insulin sensitivity in two murine models of T2DM (Chapter 4). Elevated glucose uptake in skeletal muscle, reduced hepatic fatty infiltration, and reduced weight gain after prolonged high fat diet (HFD), were also results of Ucn2 gene transfer. The difference in the weight gain seen in HFD-fed animals, does not seem to be related to the reduced fatty infiltration in the liver, since livers from $\mathrm{db} / \mathrm{db}$ mice, having no difference in their body weights, had lower fat content after Ucn2 gene transfer as well. These effects seemed to be mediated via Glut4 translocation, which is linked to AMPK activation (44) and can be triggered by CRHR2 stimulation $(45,46)$.

Mice lacking Ucn2 expression had increased skeletal muscle glucose utilization (47), a finding that seems to contradict ours, but may hint to a biphasic mode of action, since overexpression of a gene is not the opposite of gene silencing vis-à-vis physiologic responses. Intravenous infusion of Ucn2 peptide (18), as well as the closely related 
stresscopin (17), in clinical trials did not lead to changes in plasma glucose levels. The difference between Ucn2 infusion and gene transfer might lay in the duration (4h vs sustained) and the achieved elevation of protein expression in plasma (3-fold vs 15 fold) (18). In contrast to our findings that Ucn3 gene transfer does not affect glucose homeostasis in mice, studies using transgenic mice globally overexpressing Ucn3 reported increased glucose clearance after HFD, although insulin sensitivity was unaltered (48). Increased body weight and skeletal muscle mass were two main characteristics of this transgenic line which may play a role in the increased glucose disposal by Ucn3 overexpression. Additionally, a 44-fold elevation of Ucn3 was found in the brains of those animals, while Ucn2 gene transfer did not increase peptide levels in the brain. The high Ucn3 expression in the brain of these transgenic mice complicates the interpretation of the physiologic effects due to potential central nervous system reflexes. Last, Ucn3 is shown to regulate insulin production and secretion in $\beta$-pancreatic cells under excessive caloric conditions (49), even though in our studies Ucn3 gene transfer did not improve glucose homeostasis.

\section{Heart Rate and Blood Pressure Effects}

Infusion of high doses of Ucn2 or Ucn3 peptide increased heart rates and reduced blood pressure in clinical studies $(12,13)$. We used telemetric transducers in conscious untethered animals and also a non-invasive tail-cuff in unsedated restrained animals to monitor heart rate and blood pressure. There were no heart rate differences related to either Ucn2 or Ucn3 gene transfer. Assessment of blood pressure by tail-cuff showed no differences caused by Ucn2 gene transfer, and telemetry devices measuring intra-arterial pressure via a fluid-filled transducer line revealed that both Ucn2 and Ucn3 gene transfer result in normal arterial pressure. Although these pressures were in the normal range, they were lower than the arterial pressure of saline-treated animals that were somewhat elevated. The difference in the observations are probably due to the sensitivity of the techniques used. Supportive measurements from non-anesthetized mice which are able to freely move in their housing indicate that, unlike in IV infusion studies in humans, gene transfer of Ucn2 or Ucn3 neither results in abnormal low blood pressure nor in increased heart rate. A plausible explanation for the different findings of the infusion vs the gene transfer studies, knowing that both peptides can reduce systemic vascular resistance, is that sustained elevation of the plasma levels of these peptides might diminish their vasodilatory and chronotropic effects.

\section{Reduced LV Mass and Dimensions}

In Chapter 2, Ucn2 and Ucn3 gene transfer in normal young mice caused a $14 \%$ reduction in LV mass, and that reduction was correlated with similar reductions in cardiac myocyte volume. This volume reduction was mainly due to decreased cardiac myocyte width, with less reduction in length. The lower blood pressures seen in animals that received Ucn2 and Ucn3 gene transfer, might serve as an explanatory mechanism leading to reduced LV mass, since higher arterial pressure causes hypertrophy. Control mice had a relative systolic hypertension compared to the Ucn2 and Ucn3 groups, especially during nocturnal activity. The reduced phosphorylation of CaMKII caused by Ucn2 and Ucn3 gene transfer (Chapter 2 ) is another possible change that can lead to reduced LV mass, since pharmacological 
inhibition of CaMKII diminishes hypertension-induced LV hypertrophy (50). There was a non-significant $7 \%$ reduction of LV mass in young mice with HF that received Ucn3 gene transfer (Chapter 3) and in aged mice with diastolic dysfunction that received Ucn2 gene transfer (Chapter 5). The reason why we did not see a similar LV reduction in those studies, might lay on the pathophysiological characteristics and heart remodeling occurring in these HFrEF and HFpEF models.

Reductions in LV end-diastolic and end-systolic diameter by Ucn2 and Ucn3 gene transfer were seen using echocardiography (Chapter 2). Also, aged mice that received Ucn2 gene transfer had smaller LV EDD and ESD (Chapter 5). Although those reductions might reflect a smaller LV mass, they cannot be used as an accurate LV mass surrogate due to their dependency on loading conditions. However, these are valuable data vis-à-vis cardiac function. Ucn3 gene transfer in mice (Chapter 3) with HF did not alter LV dimensions, probably due to the existence of myocardial scar and alterations in LV remodeling because of the cardiac stress.

\section{Force-Frequency Effect}

Assessment of LV function using micromanometer catheters showed increased systolic and diastolic function in mice after Ucn2 and Ucn3 gene transfer. In these studies, in which mice were under deep anesthesia, the heart rates of the Ucn2 and Ucn3 groups were increased compared to the controls. Similarly increased heart rates were noticed in HF animals that received Ucn3 gene transfer (Chapter 3 ) and in aged animals with impaired relaxation treated with Ucn2 gene transfer (Chapter 5). It is known that elevation in the HR can contribute to increased LV function via a positive force-frequency effect. However, the increase in heart rate can lead up to a $30 \%$ increase in cardiac contractility (51) which is a much smaller change than the one that we observed due to gene transfer (40-90\%). Furthermore, echocardiographic assessment of cardiac function under light anesthesia and similar heart rates between control and treatment groups, further supports an increased function due to Ucn2 or Ucn3 gene transfer. Differential response to anesthesia due to gene transfer might explain this phenomenon, since telemetric studies in unsedated unrestrained animals showed no difference in the heart rates between control and Ucn2 or Ucn3 gene transfer groups.

\section{Improved $\mathrm{Ca}^{2+}$ Handling and Increased SERCA2a}

Cardiac myocytes isolated from mice that received Ucn2 or Ucn3 gene transfer had increased peak cytosolic $\mathrm{Ca}^{2+}$ and decreased Tau (Chapters 2, 3). This alteration, which likely contributes to the increased LV contractility and relaxation, is associated with increased levels of sarco-endoplasmic reticulum $\mathrm{Ca}^{2+}$ ATPase 2a (SERCA2a). This ATPase is responsible for pumping the cytosolic $\mathrm{Ca}^{2+}$ back to the sarco-endoplasmic reticulum, therefore an increase of its levels would result in a faster relaxation, and also increase $\mathrm{Ca}^{2+}$ availability to the myofilaments for a more forceful following contraction. The molecular pathway through which Ucn2 and Ucn3 gene transfer increase the expression of SERCA2a remains to be unraveled. Data support that activation of CRFR receptor can alter gene expression through NF-KB (52). SERCA2a expression might be upregulated through a similar Ucn2 or Ucn3 
stimulation of the CRFR2-depedent downstream pathway, but this would require more experimentation. Assessment of $\mathrm{Ca}^{2+}$ transients in aged animals was avoided due to low quality, functionality, and survival of cardiac myocytes isolated from 2-year-old mice. However, increased levels of SERCA2a in the LVs of aged animals after Ucn2 gene transfer suggest improved $\mathrm{Ca}^{2+}$ handling.

\section{Effects in LV Signaling}

Ucn2 and Ucn3 gene transfer caused alterations in the expression and the levels of proteins related to cardiac function and cardiac stress. In normal mice (Chapter 2) LV expression of cardiac myosin light chain kinase (MLCK) was increased by Ucn2 and Ucn3 gene transfer, indicating a potential contribution to increased LV contractility, since phosphorylation of the regulatory $\mathrm{MLC}$ increases force and rate of cross-bridge recruitment in murine heart muscle (53). Expression of other proteins, such as atrial natriuretic factor (ANF), brain natriuretic peptide (BNP), $\alpha$-skeletal actin, and $\beta$-myosin heavy chain ( $\beta-\mathrm{MHC}$ ), associated with pathophysiological cardiac remodeling and stress, was reduced in animals that received Ucn2 or Ucn3 gene transfer. More specifically, the two natriuretic peptides ANF and BNP, playing a major role in cardiovascular homeostasis and being increased as a response to cardiac injury (54) were elevated in $\mathrm{HF}$ animals treated with saline and significantly reduced by UCn3 gene transfer (Chapter 3 ). Similar reductions in ANF and BNP were seen in normal Ucn2 and Ucn3 treated young mice (Chapter 2). Although BNP expression was reduced in aged animals 4 months after Ucn2 gene transfer (Chapter 5), assessment of NT-proBNP levels, a more stable precursor molecule than BNP commonly used as its surrogate, showed no significant reduction when compared with the aged controls, underlining potential differences in translation or degradation. Noteworthy and consistent in our studies was the reduced mRNA levels of $\alpha$-skeletal actin following either Ucn2 gene transfer in young or aged mice, or Ucn3 gene transfer in mice with healthy or failing hearts. LV expression of $\alpha$-skeletal actin has been shown to be increased in human and murine $\mathrm{HF}$ (55), thus its reduction can possibly result in beneficial cardiac effects. Mice with $\mathrm{HF}$ had an expression shift from $\alpha-\mathrm{MHC}$ to $\beta-\mathrm{MHC}$, a disadvantageous maladaptive response common in HF setting (56), which was attenuated by Ucn3 gene transfer (Chapter 3). CARP is another protein that is known to be upregulated in HF patients and animals, and this increase is shown to exacerbate pathological cardiac remodeling by upregulation of calcineurin and subsequent hypertrophic response induction, or by up-regulation of p53 and subsequent increase of cardiac myocyte apoptosis $(57,58)$. Increase of CARP expression was limited in HF mice that received Ucn3 gene transfer compared to saline treated ones.

Besides the increase in LV SERCA2a content that Ucn2 and Ucn3 gene transfer result into, there are other changes in protein levels that might have mechanistic importance due to their potential contribution in the observed physiologic effects. Phosphorylation of CaMKII was reduced in LV samples from normal young mice that received Ucn2 or Ucn3 gene transfer (Chapter 2). Similarly, phosphorylation of CaMKII in LVs from aged animals that received Ucn2 gene transfer was lower than their age-matched controls (Chapter 5). Expression and activation of CaMKII plays an important role in cardiac function, and its inhibition benefits LV function (59). Another mainly lusitropy-related change seen in mice with HF after Ucn3 gene transfer (Chapter 3), was the increased phosphorylation of 
troponin I (TnI). Tnl phosphorylation was reduced in saline treated mice with HF, a finding also seen in explanted hearts from end-stage HF patients (60). Ucn3 gene transfer increased phosphorylation of $\mathrm{Tnl}$ at Serine residues 23 and 24, which has shown to be associated with more rapid relaxation (61). This alteration might play a role in the increased diastolic function provided by Ucn3 gene transfer. The molecular pathways through which Ucn2 and Ucn3 change the phosphorylation of these proteins require further investigation. Stimulation of CRFR2, might lead to potential recruitment of GRKs, $\beta$-arrestins, PKA, and Epac (exchange protein directly activated by CAMP) since studies on similar GPCR, $\beta 1 / 2$ adrenergic receptor, have shown the involvement of these proteins in CaMKII activation $(62,63)$. However, phosphorylation of CaMKII via cAMP-dependent activation of PKA or Epac is unlikely to be a key player in our studies, due to the unchanged levels of cAMP seen in the LVs of Ucn2 and Ucn3 groups.

\section{Transgene expression and modification}

Differences in the level of transgene expression were seen between Ucn2 and Ucn3 gene transfer. Absolute plasma levels of Ucn2 transgene were higher than that of Ucn3, in contrast to the relative to endogenous peptide plasma levels which was increased 20 -fold for Ucn2 versus 70-fold for Ucn3 (Chapter 2). Furthermore, the two peptides have comparable affinity to CRFR2 receptor, albeit that that of Ucn2 is slightly higher, and their plasma levels were not adequately increased for CRFR1 stimulation (38). Therefore, we think that CRFR1 receptor activation was unaffected and the majority of CRFR2 receptors were possibly saturated by both Ucn2 and Ucn3 gene transfer. Thus, it is unlikely that any differences we noticed between Ucn2 and Ucn3 gene transfer are due to differences in transgene expression. Interestingly, in Chapter 3, in which male and female mice with HF were treated with Ucn3 gene transfer, we saw significantly lower transgene expression in females versus males. In female mice Ucn3 gene transfer resulted in a greater than 20 -fold increase compared to the female mice that received saline, which had similar endogenous Ucn3 expression to the male saline treated animals. This plasma Ucn3 increase in females, even though was lower than in males, it was sufficient to increase LV contractility and relaxation to a comparable degree, suggesting that a lower AAV8.Ucn3 dose will still be beneficial for the heart function. Hormonal differences may be the major reason of the decreased transgene expression in females and this will be addressed in dose response studies in male and female, intact and neutered mice.

Both Ucn2 and Ucn3 are expressed as pre-pro-peptides, similar to peptide hormones like BNP (64), to be processed intracellularly into pro-peptides by cleavage of their N-terminal signaling sequence. Ucn2 and Ucn3 are released into the circulation in the pro-peptide form, but will further mature into active peptides by cleavage of the "pro-" sequence. It has been shown that, besides Ucn2, pro-Ucn2 peptide can also bind CRFR2 receptor (65). Future studies will define whether the observed physiological effects are due to increased levels of the mature or the uncleaved form of Ucn2 and Ucn3. Also, the degradation mechanisms of those two peptides need to be elucidated, since not only the expression but also the clearance of a protein and the internalization of its receptor could possibly affect its efficacy. Endothelin converting enzyme-1 is known to cleave CRF and Ucn1 at high CRFR1 
agonist concentrations (66), but it is unclear whether it plays any role in the clearance of Ucn2 and Ucn3 peptides.

\section{Implications and future perspectives}

In the experimental chapters of this thesis, we provide evidence that gene transfer of Ucn2 and Ucn3 increases cardiac function by improving $\mathrm{Ca}^{2+}$ handling (Chapters 2, 3, 5). Additionally, Ucn2, but bot Ucn3, gene transfer improves glucose clearance, an effect that is mediated through CRFR2 receptor (Chapter 4). Although, it is quite evident that the observed cardiac effects of Ucn2 and Ucn3 gene transfer are due to beneficial changes in $\mathrm{Ca}^{2+}$ related proteins and subsequently in $\mathrm{Ca}^{2+}$ transients, there are still missing links between the increased transgene plasma levels and the observed physiological and molecular changes. Using CRFR2 knockout mice to evaluate the cardiac effects of UCn2 and Ucn3 gene transfer, we could clarify whether or not this effect is mediated, like the improved glucose homeostasis, via the CRFR2 receptor. Selective CRFR2 antagonists, as astressin $2 b$ and antisauvagine-30, or CRFR2 silencing using siRNA could also be used in cell studies to investigate whether the observed phenotype is dependent on CRFR2 stimulation. Additionally, the downstream targets of CRFR2 need to be identified using western blotting and gene expression arrays. It is important to investigate receptor internalization and also involvement of GRKs and $\beta$-arrestins. Molecular pathway investigation should preferably be done in a simple cell culture setting rather than in a complex intact organism. In the case that the cardiac effects are indeed due to CRFR2 activation, then the speculation of biased agonism of the receptor by Ucn2 and Ucn3 needs to be tested. Structural analysis of the agonist-receptor binding through $\mathrm{X}$-ray crystallography or nuclear magnetic resonance would be particularly informative, providing evidence of the differences in three dimensional structure of the receptor upon different agonist activation. Utilization of mass spectrometry could offer insights in any potential protein-protein interaction between transgene and crucial proteins related to cardiac function or glucose homeostasis. Lastly, the safety and efficacy of Ucn 2 and Ucn3 gene transfer should be verified in a larger animal model, such as swine HF model, prior to clinical trial initiation. 


\section{REFERENCES}

1. King $M$, Kingery J, Casey B. Diagnosis and evaluation of heart failure. Am Fam Physician. 2012;85(12):1161-8.

2. Yang H, Negishi K, Otahal P, Marwick TH. Clinical prediction of incident heart failure risk: a systematic review and meta-analysis. Open Heart. 2015;2(1):e000222.

3. Chawla A, Chawla R, Jaggi S. Microvasular and macrovascular complications in diabetes mellitus: Distinct or continuum? Indian J Endocrinol Metab. 2016;20(4):546-51.

4. Haffner SM, Lehto S, Ronnemaa T, Pyorala K, Laakso M. Mortality from coronary heart disease in subjects with type 2 diabetes and in nondiabetic subjects with and without prior myocardial infarction. N Engl J Med. 1998;339(4):229-34.

5. Rademaker MT, Charles CJ, Espiner EA, Fisher S, Frampton CM, Kirkpatrick CM, et al. Beneficial hemodynamic, endocrine, and renal effects of urocortin in experimental heart failure: comparison with normal sheep. J Am Coll Cardiol. 2002;40(8):1495-505.

6. Rademaker MT, Cameron VA, Charles CJ, Richards AM. Integrated hemodynamic, hormonal, and renal actions of urocortin 2 in normal and paced sheep: beneficial effects in heart failure. Circulation. 2005;112(23):3624-32.

7. Rademaker MT, Cameron VA, Charles CJ, Richards AM. Urocortin 3: haemodynamic, hormonal, and renal effects in experimental heart failure. Eur Heart J. 2006;27(17):2088-98.

8. Gao MH, Lai NC, Miyanohara A, Schilling JM, Suarez J, Tang T, et al. Intravenous adenoassociated virus serotype 8 encoding urocortin-2 provides sustained augmentation of left ventricular function in mice. Hum Gene Ther. 2013;24(9):777-85.

9. Lai NC, Gao MH, Giamouridis D, Suarez J, Miyanohara A, Parikh J, et al. Intravenous AAV8 Encoding Urocortin-2 Increases Function of the Failing Heart in Mice. Hum Gene Ther. 2015;26(6):347-56.

10. Parkes DG, Vaughan J, Rivier J, Vale W, May CN. Cardiac inotropic actions of urocortin in conscious sheep. Am J Physiol. 1997;272(5 Pt 2):H2115-22.

11. Davis ME, Pemberton CJ, Yandle TG, Lainchbury JG, Rademaker MT, Nicholls MG, et al. Urocortin-1 infusion in normal humans. J Clin Endocrinol Metab. 2004;89(3):1402-9.

12. Davis ME, Pemberton CJ, Yandle TG, Fisher SF, Lainchbury JG, Frampton CM, et al. Urocortin 2 infusion in healthy humans: hemodynamic, neurohormonal, and renal responses. J Am Coll Cardiol. 2007;49(4):461-71.

13. Venkatasubramanian S, Griffiths ME, McLean SG, Miller MR, Luo R, Lang NN, et al. Vascular effects of urocortins 2 and 3 in healthy volunteers. J Am Heart Assoc. 2013;2(1):e004267.

14. Stirrat CG, Venkatasubramanian S, Pawade T, Mitchell AJ, Shah AS, Lang NN, et al. Cardiovascular effects of urocortin 2 and urocortin 3 in patients with chronic heart failure. $\mathrm{Br}$ J Clin Pharmacol. 2016;82(4):974-82.

15. Davis ME, Pemberton CJ, Yandle TG, Lainchbury JG, Rademaker MT, Nicholls MG, et al. Effect of urocortin 1 infusion in humans with stable congestive cardiac failure. Clin Sci (Lond). 2005;109(4):381-8.

16. Davis ME, Pemberton CJ, Yandle TG, Fisher SF, Lainchbury JG, Frampton CM, et al. Urocortin 2 infusion in human heart failure. Eur Heart J. 2007;28(21):2589-97.

17. Gheorghiade M, Greene SJ, Ponikowski P, Maggioni AP, Korewicki J, Macarie C, et al. Haemodynamic effects, safety, and pharmacokinetics of human stresscopin in heart failure with reduced ejection fraction. Eur J Heart Fail. 2013;15(6):679-89.

18. Chan WY, Frampton CM, Crozier IG, Troughton RW, Richards AM. Urocortin-2 infusion in acute decompensated heart failure: findings from the UNICORN study (urocortin- 2 in the treatment 
of acute heart failure as an adjunct over conventional therapy). JACC Heart Fail. 2013;1(5):43341.

19. Patel K, Rademaker MT, Kirkpatrick CM, Charles CJ, Fisher S, Yandle TG, et al. Comparative pharmacokinetics and pharmacodynamics of urocortins 1, 2 and 3 in healthy sheep. $\mathrm{Br} \mathrm{J}$ Pharmacol. 2012;166(6):1916-25.

20. Jaski BE, Jessup ML, Mancini DM, Cappola TP, Pauly DF, Greenberg B, et al. Calcium upregulation by percutaneous administration of gene therapy in cardiac disease (CUPID Trial), a first-in-human phase 1/2 clinical trial. J Card Fail. 2009;15(3):171-81.

21. Nathwani AC, Tuddenham EG, Rangarajan S, Rosales C, McIntosh J, Linch DC, et al. Adenovirusassociated virus vector-mediated gene transfer in hemophilia B. N Engl J Med. 2011;365(25):2357-65.

22. Most P, Raake P, Weber C, Katus HA, Pleger ST. S100A1 gene therapy in small and large animals. Methods Mol Biol. 2013;963:407-20.

23. Pleger ST, Brinks H, Ritterhoff J, Raake P, Koch WJ, Katus HA, et al. Heart failure gene therapy: the path to clinical practice. Circ Res. 2013;113(6):792-809.

24. Gwathmey JK, Yerevanian Al, Hajjar RJ. Cardiac gene therapy with SERCA2a: from bench to bedside. J Mol Cell Cardiol. 2011;50(5):803-12.

25. Callejas D, Mann CJ, Ayuso E, Lage R, Grifoll I, Roca C, et al. Treatment of diabetes and longterm survival after insulin and glucokinase gene therapy. Diabetes. 2013;62(5):1718-29.

26. Gaddy DF, Riedel MJ, Pejawar-Gaddy S, Kieffer TJ, Robbins PD. In vivo expression of HGF/NK1 and GLP-1 From dsAAV vectors enhances pancreatic ss-cell proliferation and improves pathology in the $\mathrm{db} / \mathrm{db}$ mouse model of diabetes. Diabetes. 2010;59(12):3108-16.

27. Lai CM, Lai YK, Rakoczy PE. Adenovirus and adeno-associated virus vectors. DNA Cell Biol. 2002;21(12):895-913.

28. Koeberl DD, Alexander IE, Halbert CL, Russell DW, Miller AD. Persistent expression of human clotting factor IX from mouse liver after intravenous injection of adeno-associated virus vectors. Proc Natl Acad Sci U S A. 1997;94(4):1426-31.

29. Marcos-Contreras OA, Smith SM, Bellinger DA, Raymer RA, Merricks E, Faella A, et al. Sustained correction of FVII deficiency in dogs using AAV-mediated expression of zymogen FVII. Blood. 2016;127(5):565-71.

30. Nathwani AC, Gray JT, Ng CY, Zhou J, Spence Y, Waddington SN, et al. Self-complementary adeno-associated virus vectors containing a novel liver-specific human factor IX expression cassette enable highly efficient transduction of murine and nonhuman primate liver. Blood. 2006;107(7):2653-61.

31. Manno CS, Pierce GF, Arruda VR, Glader B, Ragni M, Rasko JJ, et al. Successful transduction of liver in hemophilia by AAV-Factor IX and limitations imposed by the host immune response. Nat Med. 2006;12(3):342-7.

32. Louis Jeune V, Joergensen JA, Hajjar RJ, Weber T. Pre-existing anti-adeno-associated virus antibodies as a challenge in AAV gene therapy. Hum Gene Ther Methods. 2013;24(2):59-67.

33. Mingozzi F, High KA. Immune responses to AAV vectors: overcoming barriers to successful gene therapy. Blood. 2013;122(1):23-36.

34. Lerch TF, O'Donnell JK, Meyer NL, Xie Q, Taylor KA, Stagg SM, et al. Structure of AAV-DJ, a retargeted gene therapy vector: cryo-electron microscopy at $4.5 \mathrm{~A}$ resolution. Structure. 2012;20(8):1310-20.

35. Boutin S, Monteilhet V, Veron P, Leborgne C, Benveniste O, Montus MF, et al. Prevalence of serum IgG and neutralizing factors against adeno-associated virus (AAV) types 1, 2, 5, 6, 8, and 9 in the healthy population: implications for gene therapy using AAV vectors. Hum Gene Ther. 2010;21(6):704-12.

36. De Leo S, Lee SY, Braverman LE. Hyperthyroidism. Lancet. 2016;388(10047):906-18.

37. Diaz A, Lipman Diaz EG. Hypothyroidism. Pediatr Rev. 2014;35(8):336-47; quiz 48-9. 
38. Lewis K, Li C, Perrin MH, Blount A, Kunitake K, Donaldson C, et al. Identification of urocortin III, an additional member of the corticotropin-releasing factor (CRF) family with high affinity for the CRF2 receptor. Proc Natl Acad Sci U S A. 2001;98(13):7570-5.

39. Grace CR, Perrin MH, Cantle JP, Vale WW, Rivier JE, Riek R. Common and divergent structural features of a series of corticotropin releasing factor-related peptides. J Am Chem Soc. 2007;129(51):16102-14.

40. Hodavance SY, Gareri C, Torok RD, Rockman HA. G Protein-coupled Receptor Biased Agonism. J Cardiovasc Pharmacol. 2016;67(3):193-202.

41. Catalano RD, Kyriakou T, Chen J, Easton A, Hillhouse EW. Regulation of corticotropin-releasing hormone type 2 receptors by multiple promoters and alternative splicing: identification of multiple splice variants. Mol Endocrinol. 2003;17(3):395-410.

42. Domingueti CP, Dusse LM, Carvalho M, de Sousa LP, Gomes KB, Fernandes AP. Diabetes mellitus: The linkage between oxidative stress, inflammation, hypercoagulability and vascular complications. J Diabetes Complications. 2016;30(4):738-45.

43. Lehrke M, Marx N. Diabetes Mellitus and Heart Failure. Am J Med. 2017;130(6S):S40-S50.

44. Kurth-Kraczek EJ, Hirshman MF, Goodyear LJ, Winder WW. 5' AMP-activated protein kinase activation causes GLUT4 translocation in skeletal muscle. Diabetes. 1999;48(8):1667-71.

45. Reyes TM, Lewis K, Perrin MH, Kunitake KS, Vaughan J, Arias CA, et al. Urocortin II: a member of the corticotropin-releasing factor (CRF) neuropeptide family that is selectively bound by type 2 CRF receptors. Proc Natl Acad Sci U S A. 2001;98(5):2843-8.

46. Davidson SM, Yellon DM. Urocortin: a protective peptide that targets both the myocardium and vasculature. Pharmacol Rep. 2009;61(1):172-82.

47. Chen A, Brar B, Choi CS, Rousso D, Vaughan J, Kuperman Y, et al. Urocortin 2 modulates glucose utilization and insulin sensitivity in skeletal muscle. Proc Natl Acad Sci U S A. 2006;103(44):16580-5.

48. Jamieson PM, Cleasby ME, Kuperman Y, Morton NM, Kelly PA, Brownstein DG, et al. Urocortin 3 transgenic mice exhibit a metabolically favourable phenotype resisting obesity and hyperglycaemia on a high-fat diet. Diabetologia. 2011;54(9):2392-403.

49. Li C, Chen P, Vaughan J, Lee KF, Vale W. Urocortin 3 regulates glucose-stimulated insulin secretion and energy homeostasis. Proc Natl Acad Sci U S A. 2007;104(10):4206-11.

50. Cipolletta E, Rusciano MR, Maione AS, Santulli G, Sorriento D, Del Giudice C, et al. Targeting the CaMKII/ERK Interaction in the Heart Prevents Cardiac Hypertrophy. PLoS One. 2015;10(6):e0130477.

51. Palakodeti $\mathrm{V}$, Oh S, Oh BH, Mao L, Hongo M, Peterson KL, et al. Force-frequency effect is a powerful determinant of myocardial contractility in the mouse. Am J Physiol. 1997;273(3 Pt 2):H1283-90.

52. Grammatopoulos DK. Insights into mechanisms of corticotropin-releasing hormone receptor signal transduction. Br J Pharmacol. 2012;166(1):85-97.

53. Stelzer JE, Patel JR, Moss RL. Acceleration of stretch activation in murine myocardium due to phosphorylation of myosin regulatory light chain. J Gen Physiol. 2006;128(3):261-72.

54. Battistoni A, Rubattu S, Volpe M. Circulating biomarkers with preventive, diagnostic and prognostic implications in cardiovascular diseases. Int J Cardiol. 2012;157(2):160-8.

55. Copeland O, Nowak KJ, Laing NG, Ravenscroft G, Messer AE, Bayliss CR, et al. Investigation of changes in skeletal muscle alpha-actin expression in normal and pathological human and mouse hearts. J Muscle Res Cell Motil. 2010;31(3):207-14.

56. Krenz M, Robbins J. Impact of beta-myosin heavy chain expression on cardiac function during stress. J Am Coll Cardiol. 2004;44(12):2390-7.

57. Chen C, Shen L, Cao S, Li X, Xuan W, Zhang J, et al. Cytosolic CARP promotes angiotensin II- or pressure overload-induced cardiomyocyte hypertrophy through calcineurin accumulation. PLoS One. 2014;9(8):e104040. 
58. Shen L, Chen C, Wei X, Li X, Luo G, Zhang J, et al. Overexpression of ankyrin repeat domain 1 enhances cardiomyocyte apoptosis by promoting p53 activation and mitochondrial dysfunction in rodents. Clin Sci (Lond). 2015;128(10):665-78.

59. Swaminathan PD, Purohit A, Hund TJ, Anderson ME. Calmodulin-dependent protein kinase II: linking heart failure and arrhythmias. Circ Res. 2012;110(12):1661-77.

60. Messer AE, Jacques AM, Marston SB. Troponin phosphorylation and regulatory function in human heart muscle: dephosphorylation of Ser23/24 on troponin I could account for the contractile defect in end-stage heart failure. J Mol Cell Cardiol. 2007;42(1):247-59.

61. Salhi HE, Hassel NC, Siddiqui JK, Brundage EA, Ziolo MT, Janssen PM, et al. Myofilament Calcium Sensitivity: Mechanistic Insight into Tnl Ser-23/24 and Ser-150 Phosphorylation Integration. Front Physiol. 2016;7:567.

62. Mangmool S, Shukla AK, Rockman HA. beta-Arrestin-dependent activation of $\mathrm{Ca}(2+) /$ calmodulin kinase II after beta(1)-adrenergic receptor stimulation. J Cell Biol. 2010;189(3):573-87.

63. Pereira L, Metrich M, Fernandez-Velasco M, Lucas A, Leroy J, Perrier R, et al. The cAMP binding protein Epac modulates $\mathrm{Ca}^{2+}$ sparks by a $\mathrm{Ca}^{2+} /$ calmodulin kinase signalling pathway in rat cardiac myocytes. J Physiol. 2007;583(Pt 2):685-94.

64. Ichiki T, Huntley BK, Burnett JC, Jr. BNP molecular forms and processing by the cardiac serine protease corin. Adv Clin Chem. 2013;61:1-31.

65. Vaughan JM, Donaldson CJ, Fischer WH, Perrin MH, Rivier JE, Sawchenko PE, et al. Posttranslational processing of human and mouse urocortin 2: characterization and bioactivity of gene products. Endocrinology. 2013;154(4):1553-64.

66. Hasdemir B, Mahajan S, Bunnett NW, Liao M, Bhargava A. Endothelin-converting enzyme-1 actions determine differential trafficking and signaling of corticotropin-releasing factor receptor 1 at high agonist concentrations. Mol Endocrinol. 2012;26(4):681-95. 



\section{Appendices}

Valorization Addendum

Acknowledgements

Curriculum Vitae

List of Publications

and Presented Work 


\section{VALORIZATION ADDENDUM}

Patients with congestive heart failure (CHF) who have symptoms with mild activity or at rest (Class III and Class IV) have a poor long-term outcome, with up to $50 \%$ of patients dying within four years of symptom onset despite optimal pharmacological and device therapy. Heart transplantation has an 80\% 5-year survival rate, but fewer than 2500 cardiac transplants are performed in the US each year, where the prevalence for CHF is estimated at 5.1 million patients, and 900,000 new cases are diagnosed annually. Angiotensin converting enzyme inhibitors, angiotensin receptor antagonists, $\beta$-adrenergic receptor $(\beta A R)$ antagonists, aldosterone inhibitors, implanted defibrillators, and biventricular pacing devices have improved survival - the $50 \%$ survival time in 1980 was 18 months while nowadays is 5 years. However, even with optimal medical and device management, heart failure is an inexorable disease associated with unacceptably high morbidity and mortality. Because the prevalence of CHF is increasing, and outlook remains dismal, we need new advances in heart failure treatment.

Although heart failure traditionally is defined as reduced contractile function, left ventricle (LV) dilation, and reduced ejection fraction, there is a growing epidemic of heart failure accompanied by preserved ejection fraction (HFpEF) and aging has been defined as one factor in the HFpEF epidemic. Echocardiographic studies often reveal normal or nearnormal ejection fraction in elderly patients with heart failure, with abnormal diastolic relaxation and LV filling and cardiovascular stiffness.

Gene transfer for the treatment of cardiovascular diseases is justified because there is an unmet medical need for treating diastolic dysfunction, and, at least in theory, gene transfer has much to offer to reduce morbidity and mortality in patients with HFpEF. Cardiovascular gene transfer is conceptually attractive, but difficulty in obtaining high yield transgene expression in the heart in a manner that can be easily and safely applied has been a chief impediment to progress. Current methods of gene transfer for heart disease include intramuscular injection into heart muscle or intracoronary delivery, approaches that provide limited expression, and are cumbersome to apply. In previous studies and also in those presented in this thesis, we have discovered the usefulness of intravenous injection of a vector encoding a paracrine transgene. In this approach, the transgene encoding urocortin 2 or urocortin 3 peptide that act as hormones, having cardiac effects after being released to the circulation from a distant site. This approach would circumvent the problem of attaining high yield cardiac gene transfer and enable patients to be treated by a simple intravenous injection during an office visit.

Findings presented in this thesis are important and promising steps towards Ucn2 and Ucn3 gene transfer translation to clinical applications. It is verified that gene transfer of Ucn2 increased systolic and diastolic function in normal mice and in mice with age-related diastolic dysfunction. Additionally, Ucn2 gene transfer was able to decrease fasting glucose and improve glucose disposal in normal and diabetic mice, unlike Ucn3 gene transfer. Therefore, gene transfer of Ucn2 could be a viable treatment for elderly patients with either 
systolic or diastolic dysfunction and also for patients with HF and diabetes. Ucn3 gene transfer was able to increase both systolic and diastolic function in normal young mice and also in a murine model of HFrEF, however it did not affect glucose homeostasis. According to these observations, Ucn3 gene transfer may be a viable treatment for HFrEF patients without diabetes. Verification of diastolic function improvement by Ucn3 gene transfer in undergoing studies using aged animals could further suggest its potential to be used as HFpEF treatment.

There are specific issues and requirements that will have to be addressed prior to the initiation of a clinical trial. Initially, the safety of our gene transfer approach has to be verified. It is necessary to meticulously investigate potential adverse effects caused by the sustained increases in plasma Ucn 2 and Ucn3. We have recently accomplished this step via a biodistribution and toxicology study in which we tested the long term and dose related effects of Ucn2 gene transfer. A similar study testing Ucn3 gene transfer will be launched in the near future. Another important milestone that needs to be achieved is to prove that intravenous administration of an AAV8 encoding Ucn2 or Ucn3 gene transfer in different, preferably larger, species will still result in sustained elevation of plasma levels of Ucn2 or Ucn3. Additionally, we need to verify that elevation of plasma Ucn2 and Ucn3 can cause increases in systolic and diastolic heart function in normal animals, but most importantly in $\mathrm{HF}$ animal models different than mice. In the case that Ucn2 gene transfer is intended to be used as diabetes treatment, similar efficacy studies in different species with diabetes will also be required. If there is no observation of adverse effects in the biodistribution and toxicology study and the beneficial effects of Ucn2 and Ucn3 gene transfer are verified in a second animal model, there are great chances to get approval for the investigational new drug (IND) application. That will allow us to begin clinical studies and test the safety and efficacy of our gene therapy in human subjects. 

Appendices

Valorization Addendum

Acknowledgements

Curriculum Vitae

List of Publications

and Presented Work 


\section{ACKNOWLEDGEMENTS}

This dissertation is dedicated to the memory of my grandfather Dimosthenis I. Giamouridis and my uncle loannis D. Giamouridis. They served as great examples of determination and diligence and they supported me emotionally and financially whenever I needed help. This is for them.

I would like to express my sincere gratitude to my mentor Prof. Dr. H. Kirk Hammond for the continuous support of my Ph.D. research, for his priceless advices, motivation, patience, and immense knowledge. I would also like to thank my Maastricht University affiliated mentors, Prof. Dr. Erik A. L. Biessen and Dr. W. Mathjis Blankesteijn, for their valuable help with my enrollment and progress throughout my Ph.D. studies in the CARIM Ph.D. program.

Besides my advisors, I would also like to thank the members of my thesis committee, professors Dr. F. Prinzen, Dr. A. Baker, Dr. D. Duncker, Dr. S.R.B. Heymans, and Dr. C.G. Schalkwijk, for their time and effort to review my academic work.

My sincere gratitude also goes to Dr. Mei Hua Gao and Dr. N. Chin Lai who were next to me in every difficulty I faced in the scientific, as well as personal, life. Their guidance and educational comments throughout the design and execution of my research were decisive. I would also like to thank our amazing technician Tracy Guo for her valuable help whenever I was busy with other experiments, as well as past members of our lab as Drs. Tong Tang, Young Chul Kim, Zhen Tan, and Zhenxing Fu.

Throughout the past 5 years I also had a lot of support, mainly psychological, by family and friends. I thank all of the people that stood by me and believed in me, not only during my Ph.D. but throughout my whole life. I would like to specifically thank my mother and father, as well as my brother (who I have not seen for four years since he is in commercial shipping, sailing around the world), my grandmothers and my uncles and aunts for their emotional support and their advices. Many thanks also to my beloved friends here in San Diego as well as back in Greece and all around the world for answering my phone calls at any time and cheering me up in my difficult moments or sharing the happiness of my good moments. 


\section{Appendices}

Valorization Addendum

Acknowledgements

Curriculum Vitae

List of Publications

and Presented Work 


\section{CURRICULUM VITAE}

Dimosthenis Giamouridis was born on $15^{\text {th }}$ of August, 1987 in Drama, Greece, and lived in a village, called Krinides, in the region of Kavala. He graduated from Krinides high school in 2005 with educational focus on natural sciences. Next, he enrolled in the bachelor's program of the department of Molecular Biology \& Genetics at the Democritus University of Thrace, from which he graduated in 2010. During his bachelor studies he conducted research as an Erasmus exchange student, for the completion of his undergraduate thesis in Dr. Peter Verrijzer's laboratory at Erasmus Medical Center in Rotterdam, the Netherlands. After obtaining his BSc degree, he enrolled in the Biomedical Sciences master's program at the University of Maastricht, in Maastricht, the Netherlands. In 2013 he obtained his MSc degree after completing his junior internship in Dr. Aalt Bast's laboratory at Maastricht University, and his senior internship in Dr. H. Kirk Hammond's laboratory at the University of California San Diego, in the U.S.A..

After working for a year in Dr. H. Kirk Hammond's and Wilbur Lew's labs he officially enrolled in the CARIM PhD program under the supervision of Drs Erik A.L. Biessen and W. Mathjis Blankestein. He conducted all of his work in Dr. Hammond's lab by continuing and expanding some of the projects that he was working on during his master's internship. His work was presented in prestigious conferences in the U.S.A. and also yielded a plethora of publications. He was also involved in the supervision and guidance of undergraduate and graduate student's that worked occasionally in Dr. Hammond's lab. 


\section{Appendices}

Valorization Addendum

Acknowledgements

Curriculum Vitae

List of Publications and Presented Work 


\section{List of Publications and Presented Work}

\section{Publications:}

- Kim YC, Giamouridis D, Lai NC, Guo T, Xia B, Fu Z, Gao MH, Hammond HK. "Urocortin 2 Gene Transfer Reduces the Adverse Effects of Western Diet on Cardiac Function in Mice." Hum Gene Ther. 2019 Jan.

- $\quad$ Tan Z, Giamouridis D, Lai NC, Kim YC, Guo T, Xia B, Gao MH, Hammond HK. "Cardiac-directed Expression of Adenylyl Cyclase Catalytic Domain (C1C2) Attenuates Deleterious Effects of Pressure Overload." Hum Gene Ther. 2019 Jan.

- $\quad$ Giamouridis D, Gao MH, Lai NC, Tan Z, Kim YC, Guo T, Miyanohara A, Blankesteijn MW, Biessen EAL, Hammond HK, "Urocortin 3 Gene Transfer Increases Function of the Failing Murine Heart." Hum Gene Ther., 2018 Jul.

- $\quad$ Giamouridis D, Gao MH, Lai NC, Tan Z, Kim YC, Guo T, Miyanohara A, Blankesteijn WM, Biessen E, Hammond HK, "Effects of Urocortin 2 Versus Urocortin 3 Gene Transfer on Left Ventricular Function and Glucose Disposal.", JACC Basic Transl Sci., 2018 Apr.

- $\quad$ Parikh J, Zemljic-Harpf A, Fu J, Giamouridis D, Hsieh TC, Kassan A, Murthy KS, Bhargava V, Patel HH, Rajasekaran MR., "Altered Penile Caveolin Expression in Diabetes: Potential Role in Erectile Dysfunction.”, J Sex Med., 2017 Oct.

- Gao MH, Lai NC, Giamouridis D, Kim YC, Guo T, Hammond HK., "Cardiac-directed expression of a catalytically inactive adenylyl cyclase 6 protects the heart from sustained $\beta$-adrenergic stimulation.", PLoS One, 2017 Aug.

- $\quad$ Gao MH, Lai NC, Giamouridis D, Kim YC, Tan Z, Guo T, Dillmann WH, Suarez J, Hammond HK., "Cardiac-Directed Expression of Adenylyl Cyclase Catalytic Domain Reverses Cardiac Dysfunction Caused by Sustained Beta-Adrenergic Receptor Stimulation.", JACC Basic Transl Sci., 2016 Dec.

- Gao MH, Giamouridis D, Lai NC, Walenta E, Paschoal VA, Kim YC, Miyanohara A, Guo T, Liao M, Liu L, Tan Z, Ciaraldi TP, Schenk S, Bhargava A, Oh DY, Hammond HK., "One-time injection of AAV8 encoding urocortin 2 provides long-term resolution of insulin resistance.", JCI Insight, 2016 Sep. 
- $\quad$ Lai NC, Gao MH, Giamouridis D, Suarez J, Miyanohara A, Parikh J, Hightower S, Guo T, Dillmann W, Kim YC, Diaz-Juarez J, Hammond HK., "Intravenous AAV8 Encoding Urocortin-2 Increases Function of the Failing Heart in Mice.", Hum Gene Ther., 2015 Jun.

- Gao MH, Lai NC, Miyanohara A, Schilling JM, Suarez J, Tang T, Guo T, Tang R, Parikh J, Giamouridis D, Dillmann WH, Patel HH, Roth DM, Dalton ND, Hammond HK., "Intravenous adeno-associated virus serotype 8 encoding urocortin-2 provides sustained augmentation of left ventricular function in mice.", Hum Gene Ther., 2013 Sep.

- $\quad$ van de Wier B, Balk JM, Haenen GR, Giamouridis D, Bakker JA, Bast BC, den Hartog GJ, Koek GH, Bast A., "Elevated citrate levels in non-alcoholic fatty liver disease: the potential of citrate to promote radical production.", FEBS Lett., 2013 Aug.

\section{Attendance in Conferences:}

American Heart Association, Scientific Sessions Conference, November 2018, Chicago IL, USA

Presented work:

- Oral presentation, Dimosthenis Giamouridis, Meihua Gao, Ngai Chin Lai, Atsushi Miyanohara, Erik Biessen, Matthijs Blankesteijn, and H Kirk Hammond, "Age-Related Left Ventricular Dysfunction: Effects of Urocortin 2 Gene Transfer."

- Poster 1, Kim YC, Giamouridis D, Lai NC, Guo T, Xia B, Gao MH, Hammond HK. "Urocortin 2 Gene Transfer Reduces the Adverse Effects of Western Diet on Cardiac Function in Mice."

\section{Experimental Biology Conference, April 2017, Chicago IL, USA}

Presented work:

- Poster 1, Dimosthenis Giamouridis, Ngai Chin Lai, Meihua Gao, Atsushi Miyanohara, Erik Biessen, Matthijs Blankesteijn, and H Kirk Hammond, "Urocortin-3 Gene Transfer Increases Function of the Failing Heart in C57BI/6 Mice"

- Poster 2, May Ling Tay, Ngai Chin Lai, Dimosthenis Giamouridis, Eric Tang, Tong Tang, and Wilbur Lew, "Intracoronary Gene Therapy with AdvCRTC2 Improves LV Dysfunction after Pressure Load Hypertrophy" 


\section{Experimental Biology Conference, April 2016, San Diego CA, USA}

Presented work:

- Poster, Dimosthenis Giamouridis, Ngai Chin Lai, Meihua Gao, Erik Biessen, Matthijs Blankesteijn, and H Kirk Hammond, "Urocortin 3 Gene Transfer Increases LV Peak dP/dt in Normal Mice"

\section{Experimental Biology Conference, April 2014, San Diego CA, USA}

Presented work:

- Poster 1, N. Chin Lai, Mei Hua Gao, Atsushi Miyanohara, Dimosthenis Giamouridis, Jay Parikh, Stephen Hightower, and H. Kirk Hammond, "Intravenous AAV8 Encoding Urocortin-2 Provides Sustained Augmentation of Left Ventricular Function in Heart Failure Mice"

- Poster 2, Mei Hua Gao, Ngai Lai, Atsushi Miyanohara, Dimosthenis Giamouridis, Theodore Ciaraldi, Simon Schenk, and H. Kirk Hammond "Urocortin-2 gene transfer for type-2 diabetes mellitus" 